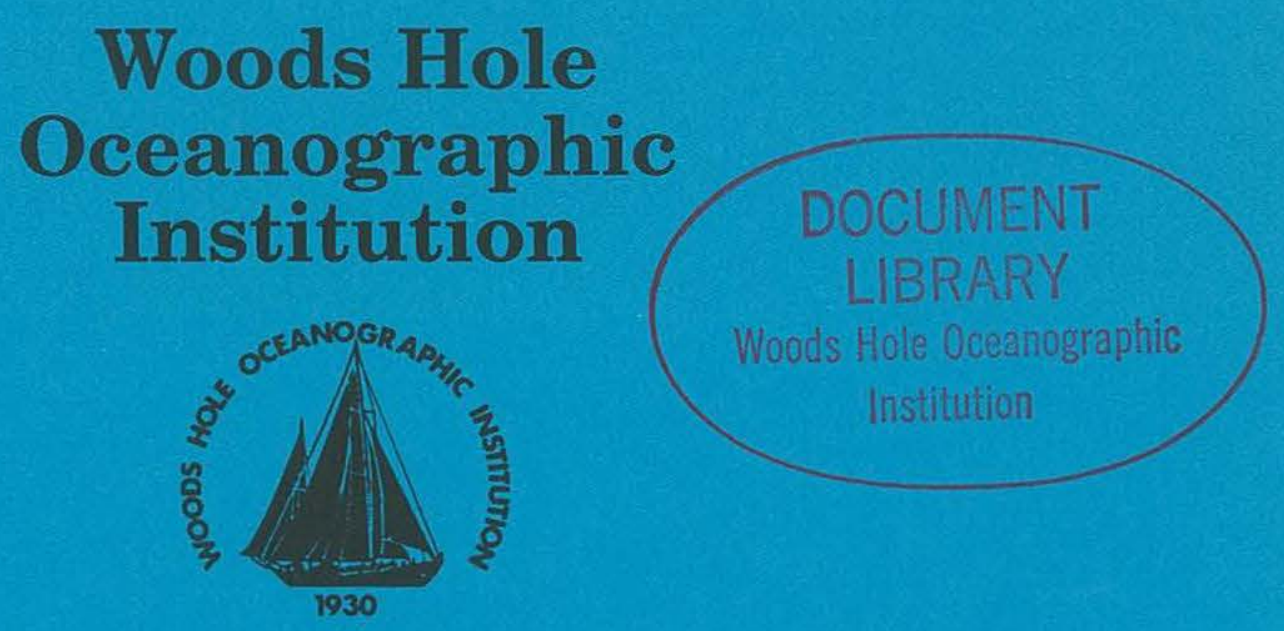

\title{
Determining the Structure of the United States Marine Instrumentation Industry and Its Position in the World Industry
}

\author{
by \\ James M. Broadus \\ Porter Hoagland III \\ Hauke L. Kite-Powell \\ November 1988 \\ Technical Report
}

Funding was provided by the Department of Commerce, NOAA, National Ocean Service,

Office of Marine Operations through a grant to the Massachusetts Centers

of Excellence Corporation, grant Number NA87-AA-D-M0037.

Approved for public release; distribution unlimited. 


\title{
Determining the Structure of the United States Marine Instrumentation Industry and Its Position in the World Industry
}

\author{
by
}

James M. Broadus, Porter Hoagland III, Hauke L. Kite-Powell

\author{
Marine Policy Center \\ Woods Hole Oceanographic Institution \\ Woods Hole, Massachusetts 02543
}

November 1988

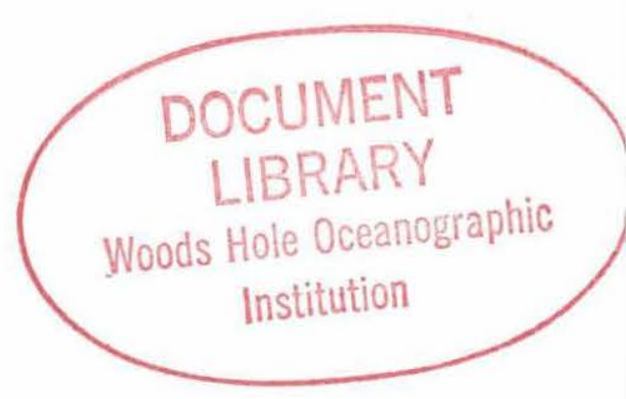

\section{Technical Report}

Funding was provided by the Department of Commerce, NOAA, National Ocean Service, Office of Marine Operations

through a grant to the Massachusetts Centers of Excellence Corporation, grant Number NA87-AA-D-M0037.

Reproduction in whole or in part is permitted for any purpose of the

United States Government. This report should be cited as:

Woods Hole Oceanog. Inst. Tech. Rept., WHOI-88-55.

Approved for publication; distribution unlimited.

Approved for Distribution:

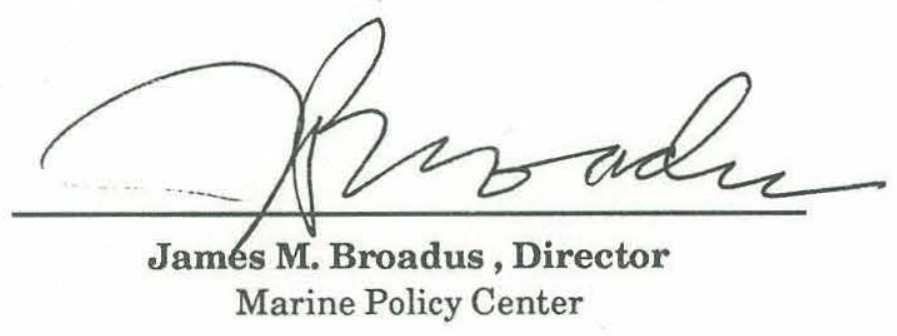



Abstract:

\section{Determining the Structure of the U.S. Marine Instrumentation Industry and Its Position in the World Industry}

This report is a general, but comprehensive, description and analysis of industrial organization in the field of marine electronic instrumentation (MEI), a broadly defined "industry," which until now has received little systematic, scholarly attention. The report reviews the current literature on international trade and competitiveness, as well as trade and scientific journals relevant to the industry. The results of a series of interviews with representatives of the industry and responsible govermment agencies are presented and industry and government data on R\&D and output have been collected and analyzed together with other indicators of industrial performance. On the basis of these sources, the structure of the industry and its markets is characterized and the importance of marine electronic instrumentation in international high technology trade is established. Over 350 firms in the U.S. industry are identified, which annually earn total estimated gross revenues of approximately $\$ 5$ billion. These firms fall into three largely distinct industry groups: (1) defense systems contractors; (2) commercial marine electronics; and (3) scientific instrumentation. The first group is by far the largest in sales volume and is oligopolistic in structure, consisting of a few large rivals for infrequent and complex defense systems contracts. The other groups are more purely competitive. Four major customer groups are distinguished: (1) military; (2) commercial and recreational shipping and boating; (3) offshore oil and gas; and (4) oceanographic/environmental. Most of the firms in the industry face international competition. The importance of marine electronic instrumentation to technological advance and economic activity in the world's oceans is strongly apparent. Parameters affecting the international competitiveness of firms in this industry, including those relating to industry structure and behavior and governmental practices and institutions such as sponsored research, procurement, intellectual property rights, tax allowances, antitrust enforcement, small business encouragements, export controls, import restrictions, exchange rates, and technology transfer are summarized. A number of issues relating to international competition, economic analysis, and govermment policy that are fruitful areas for further research also are identified. 

PREFACE

This document reports the results of a first year of research on the structure of the U.S. marine instrumentation industry and its position in the world industry. The goal of this first year of study was to provide a broad description of industrial organization in the field of marine electronic instrumentation. During the course of the study it has become clear that no previous overview of industrial organization and competitive dynamics in this field is available.

This research project is one of three comprising a multi-institutional program, "Developing a National Marine Electronics Agenda," sponsored by the Massachusetts Centers of Excellence Corporation (MCEC) with funds from the National Oceanic and Atmospheric Administration (NOAA). The two other research projects in the MCEC program are being conducted at the oceanic Institute of Hawaii ("Projecting Demand for United States Manufactured Instrumentation in Aquaculture and Selected Fisheries Sectors") and at Florida State University ("Survey of Marine Instrumentation User Communities in Selected Marine Sectors").

The three research projects have been assisted and reviewed by a "Marine Instrumentation Panel" consisting of participants in and experts on the marine instrumentation industries. Drawing on results of the research projects and its own expertise, the Marine Instrumentation Panel is seeking to devise and articulate a national marine electronics agenda to enhance the health of the nation's marine electronic instrumentation sector.

The research results reported herein will be supplemented by those of a second year of work concentrating on: (1) a sharper resolution and quantification of the broad industry profile presented here; (2) detailed examination of the sources of incentive activity and pathways of technology transfer in the field; and (3) a comparative study of govermmental involvement and support for firms in this field in those nations with which U.S. firms compete most heavily. Therefore, this report should be treated as a working draft of research in progress and still subject to substantial revision, correction, and modification. All comments and suggestions are most heartily welcomed.

A large number of individuals contributed in various ways to the completion of this report, and they are listed with great appreciation in Appendix E. Special thanks are due to Director Megan Jones and Project Director Gary Glenn of the Massachusetts Centers of Excellence Corporation, to Program Monitors Charles Kearse and Bernard Polanin of National Ocean Service in NOAA, and to Program Coordinator Arthur Gaines of the Woods Hole Oceanographic Institution. All have supported this work through active involvement and enthusiastic encouragement. This report was prepared by James Broadus, Porter Hoagland, and Hauke Kite-Powell at the Marine Policy Center of the Woods Hole Oceanographic Institution. 



\section{EXECUTIVE SUMNARY}

The purpose of this study has been to generate a broad description of the industrial field of marine electronic instrumentation. The report seeks to provide a fairly comprehensive, qualitative overview of industrial organization in this field and to identify those features that merit more detailed examination.

\section{Marine Electronic Instrumentation in the Context of World High Technology Competition}

High technology products are important to the economic strength of the United States, as R\&D-intensive products continue to show the best performance of any U.S. foreign trade sector (Figure $1 ;$ p. 1 ). It is a matter of national concern, therefore, that the U.S. share of world high technology manufactures exports has been declining since 1982, potentially indicating that the competitiveness of U.S. high technology firms has faltered. U.S. civilian R\&D expenditures (as a percentage of GNP) have lagged substantially behind those of competitors like Japan and West Germany (Figures $3 \mathrm{a}$ and $3 \mathrm{~b} ; \mathrm{pp} .3-4$ ). Although general causes are superficially appealing, issues associated with international competitiveness are likely to be idiosyncratic to individual industries, requiring careful examination of those industries to understand and analyze appropriate policy responses.

At the intersection of the world electronics market of $\$ 400$ to $\$ 500$ billion sales per year (spy), the world marine market on the order of $\$ 400$ billion spy, and the world instrumentation market of about $\$ 250$ billion spy, there exists a significant area of high technology products that can be described as "marine electronic instrumentation." Broadly defined as the group of firms producing electronic tools and devices for use in marine environments (including oceans, lakes, and streams) the marine electronic instrumentation sector includes an annual U.S. production of some $\$ 5$ billion in a world market of about $\$ 10$ billion (Figures 16, 19; pp. 24, 26).

Early marine electronic instrumentation includes radio, first employed on ships in the early 1900s, sonar devices in the 1910s, and radar in the 1930s. The history of these instruments highlights several features of importance in today's industrial dynamics: (1) the prevalence and vigor of international competition; (2) the limited usefulness of patent protection; (3) the manner in which the technology may span several important end use sectors; (4) the crucial importance 
of the Navy as a dominant customer and influence on industry evolution; and (5) the effects of nationalistic interests in governmental intervention. Modern developments have been driven largely by government interest in the ocean activities and by the offshore energy boom in the 1960s and 1970s. The importance of advanced marine technologies and instrumentation was emphasized by the Stratton Commission in its 1969 report and has also been noted in other government studies.

Due to its "high tech" aspects and the underlying similarities of the world's oceans, trade and competition in this field are international in nature. U.S. producers face foreign competition in virtually all product lines. Four principal end-use sectors can be distinguished, and they are listed here with estimates of U.S. annual sales volumes (Figure 15; p. 23): (1) the military (\$2 billion), (2) offshore energy (\$200 million), (3) recreational and commercial shipping and boating (\$500 million), and (4) scientific (\$100 million) .

Structural Overview of the U.S. Marine Electronic Instrumentation "Industry"

Serving the four user groups above are four major groups of firms (see Figure 21; p. 23): (1) oceanographic/environmental instrumentation shops, clustered around academic institutions (see Figure 22; p. 36), which generally mature at annual sales below \$10 million and specialize in custom instruments for the scientific and offshore communities; (2) commercial "marine electronics" firms, which produce retail navigation and communication equipment for the commercial and recreational "mass markets" and generally have annual sales in the tens of millions; (3) military contractors, which specialize in large systems work for the U.S. and foreign navies and are usually $\$ 100$ million-plus divisions of defense contracting giants (Figure 23; p. 39); and (4) service companies, which provide product design and support for all end-user groups and are particularly important in the offshore business.

The "industry" as a whole is competitive and characterized by niche-seeking and specialization. Barriers to entry and exit, and to mobility across product lines, tend to be relatively low. A small number of large suppliers dominate the military markets, where high-stakes, multi-year systems contracts are the rule. Anti-submarine warfare (ASW) and integrated navigation/communication/battle management systems are the major military uses (Figure 24; p. 41). Mass production is found only in some retail marine electronics and in expendable probes. Key aspects of the "industry" include the involvement of govermments 
(R\&D subsidies, procurement policies, import restrictions and export controls, among others), the international nature of competition and trade, and the importance of R\&D and inventiveness to sustained success (Figure 25; p. 44).

Institutional Parameters Affecting Competition in Marine Electronic Instrumentation

Some of the most important factors that affect the performance and competitive position of U.S. marine electronic instrumentation firms are institutional ones, namely incentives or restrictions on R\&D, production, and domestic and international trade. Broad national and international policies govern research, production, and markets for most manufactured goods, and specific policies govern individual goods and services in this industry. These policies include domestic "industrial" policy, such as the protection of intellectual property, business and income taxation, and antitrust policy, and policies affecting international trade, such as export controls and import restrictions.

Other policies specific to marine electronic instruments include government investments in R\&D, "buy-national" procurement rules, validated export license determinations for controlled items, and nontariff trade barriers (such as government funding of development costs of technologies competing in world markets), among others. The U.S. government annually provides on the order of \$500 million for R\&D in marine electronic instrumentation. Nearly all of these expenditures originate from the U.S. Navy, are directed predominantly toward advanced research and development stages of technologies (called RDT\&E), and now emphasize ASW as a research priority (Figures 26 and 27; pp. 48-49). Basic research efforts, while small in comparison, originate in the Navy, NOAA, and NSF, and are important to the oceanographic/environmental instrumentation sector of the industry. Similarly, the Navy accounts for the lion's share of government procurement (Figures 32 and 33; pp. 56-57). As a consequence, military research priorities and procurement policies have a major effect on the state and development of the industry.

Government programs that encourage investment across all industries are seen to have only a limited impact on the industry. For example, patent protection rarely is sought by members of this industry, and research tax allowances are employed by only a subset of firms in the industry. Joint ventures in R\&D and small business innovation research awards to date (Figure 37; p. 73) have been of 
minor importance in this industry. Venture capital investments are inconsequential, indicating that industry growth may be perceived as long-term, although discrete opportunities for investment in technologies with rapid, shortterm growth potential may exist.

The variable imposition of export controls has caused problems in terms of regulatory uncertainty and foreclosed sales for some members of the industry, particularly for smaller firms in the scientific/environmental instrumentation sector (Figure 40; p. 78). Recent technology diversions around international export control mechanisms may have had an important influence on the allocation of government defense funds toward ASW, stimulating activity in the military contractor sector. Tariffs are less significant barriers to trade than "buynational" policies and government subsidies of R\&D programs. The introduction of new policies in the United States (the 1988 Trade Bill and the U.S. Canada Free Trade Agreement) will have as yet unseen effects on international trade in marine electronic instrumentation. These issues require further attention.

The flows of technology between industry sectors (e.g., offshore to military) and across institutional and international boundaries (e.g., from govermment labs to industry [Figure 43; p. 90] and from the North sea to the Gulf of Mexico) potentially are significant factors that affect industry growth and international competition. Technology transfer and the sources of inventiveness and innovation are likely to hold the key to the future competitiveness of the industry. The influence of national laboratories, engineering centers of excellence, and university curricula and the mechanisms by which consumer needs are communicated to firms in the industry are also areas requiring additional investigation.

\section{Conclusions}

Marine electronic instrumentation encompasses most of the high technology tools that are vital to the efficient exploration, understanding, and use of the oceans. Technological advance and economic activity in the world's oceans depend strongly on this class of technology. Producers of these instruments sell into a world market, and their consumers span all ocean sectors from undersea defense to offshore oil and gas, oceanographic research, environmental monitoring, commercial shipping, fishing, and recreational boating.

Annual production of marine electronic instrmentation in the U.S. is on the 
order of $\$ 3$ to $\$ 5$ billion, with perhaps 20 to 30 percent of this being exported, and a smaller amount being imported. The world market for these products is estimated at about $\$ 10$ billion annually. U.S. firms face foreign competition on nearly all of their marine electronic instrumentation products.

Governments affect international competitiveness in the marine electronic instrumentation industry. The Navy has always been of central importance in driving technology development in this field. R\&D intensity and the rate of inventiveness and innovation are particularly important to the success of firms in this industry. The sources and pathways of technology transfer, as well as inventiveness and innovation, in this U.S. industry are of great importance to its continued competitiveness. 



\section{Table of contents}

Page

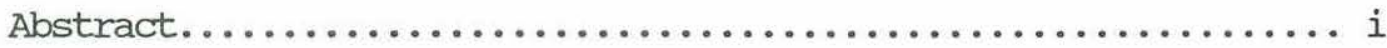

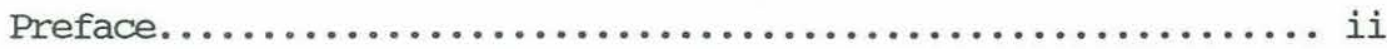

Executive Summary.$\ldots \ldots \ldots \ldots \ldots \ldots \ldots \ldots \ldots \ldots \ldots \ldots \ldots \ldots \ldots \ldots$

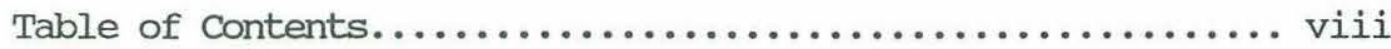

Table of Figures..................................

1. Introduction: Marine Electronic Instrumentation in the Context of World High Technology Competition.......... 1

1.1. The Importance of High Technology Competitiveness....... 1

1.2. The Marine Electronic Instrumentation Industry........ 5

1.3. An Industry Definition...................... 8

1.4. Historical Review........................ 10

1.4.1. Origins and Industry Development........... 10

1.4.2. The Stratton Commission Report............. 17

1.5. International Nature of the Marine Electronic Instrumentation Markets.................. 21

1.6. Size of the Marine Electronic Instrumentation Sector Within the Marine Industry................ 21

1.7. Methodology and Scope of this study............. 27

2. A Structural Overview of the U.S. Marine Electronic Instrumentation "Industry"................. 29

2.1. Industrial Organization Analysis................ 29

2.1.1. Introduction and Basic Concepts............ 29

2.1.2. Applications to Marine Electronic

Instrumentation..................... 30 

2.2. Overview: Firms Serving the Marine Electronic Instrumentation Markets.................. 31

2.2.1. The Product and End-Use Sectors............ 31

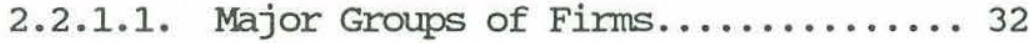

2.2.2. The Oceanographic/Envirommental Instrumentation

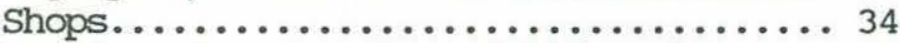
2.2.2.1. Spawning Grounds and Lifecycles.... 36

2.2.3. The Commercial "Marine Electronics" Firms...... 37

2.2.4. The Large Military Contractors............. 39

2.2.5. The Service Companies................. 42

2.2.6. Overlaps and Interrelationships............. 42

2.3. Key Aspects of the Marine Electronic Instrumentation

"Industry"........................... 42

2.3.1. Importance of Govermment Involvement.........442

2.3.2. Importance of the International Nature of Trade

in Marine Electronic Instrumentation........443

2.3.3. Importance of R\&D and Inventiveness.........44

3. Institutional Parameters Affecting competition in Marine

Electronic Instrumentation...................46

3.1. Domestic Industrial Policy.................. 47

3.1.1. Govermment-Sponsored Research.............47

3.1.2. Navy Research...................... 47

3.1.3. Research by other Agencies............... 52

3.1.4. IR\&D and B\&P Trends..................... 54

3.1.5. Govermment Procurement................. 55

3.1.6. Intellectual Property Rights..............60

3.1.7. Tax Allowances for R\&D and Other MEI

Investments......................64 64

3.1.8. Antitrust Policy for R\&D...............66

3.1.9. Small Business Encouragements............ 71

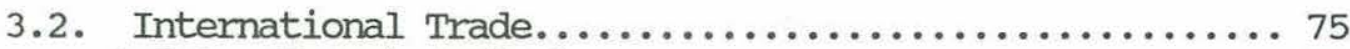

3.2.1. Export Controls...................... 75

3.2.2. Import Restrictions and Barriers to Trade......80

3.2.3. Exchange Rates........................ 86 



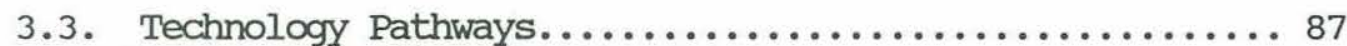

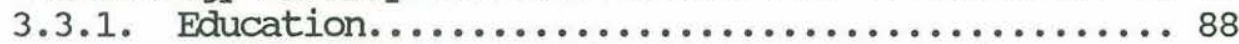

3.3.2. Universities and Independent Laboratories....... 89

3.3.3. National Laboratories................... 90

3.3.4. Intersectoral Transfers..................91

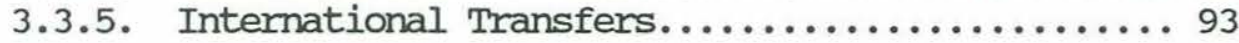

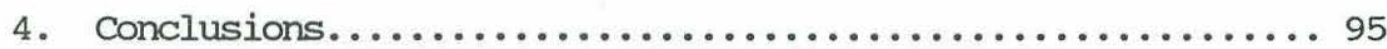

5. Appendices

Appendix A: Products List....................... A-1

Appendix B: U.S. Companies List.................... B-1

Appendix C: Foreign Companies List.................. C-1

Appendix D: MEI Export Conmodity Control List............ D-1

Appendix E: Acknowledgements...................... E-1

Appendix F: References.......................... F-1 

1. R\&D Expenditures, High Technology and Other Industries,

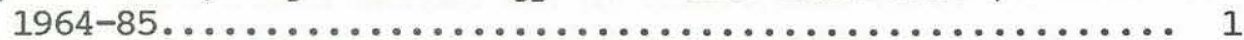

2. Trade Balances of Manufacturing Industries, 1970-84......... 2

3. R\&D Expenditures as a Percentage of Gross National Product,

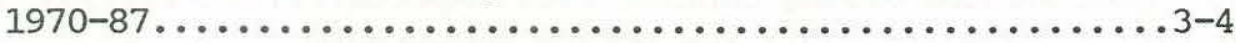

4. U.S. High Technology Trade Balance, $1980-86 \ldots . . . \ldots \ldots \ldots \ldots .66$

5. World Expenditures on Geophysics for Oceanography, 1963-86.... 7

6. SIC Codes Relevant to Marine Electronic Instrumentation

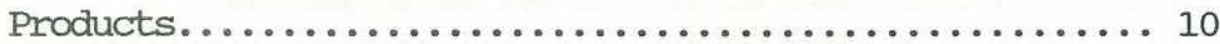

7. Federal Support for Marine Science and Technology, 1950-67.... 13

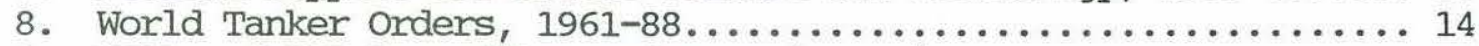

9. NOAA and NSF Expenditures for Marine Science, 1960-88........ 15

10. World Expenditures on Geophysics for Offshore Oil and Gas,

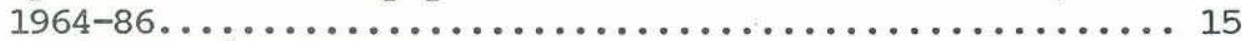

11. U.S. Navy RDT\&E Expenditures, $1961-88 \ldots \ldots \ldots \ldots \ldots \ldots \ldots \ldots \ldots \ldots$

12. U.S. Retail Boating Expenditures, $1964-87 \ldots \ldots \ldots \ldots \ldots \ldots \ldots \ldots 17$

13. Major Studies of Marine Science and Technology............. 20

14. Size of World and U.S. Marine Market Sectors.............. 22

15. Size of U.S. Marine Electronic Instrumentation Market Sectors.. 23

16. 1985 U.S. Shipments of Marine Electronic Instrumentation...... 24

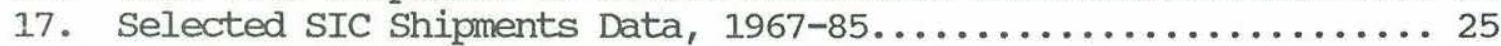

18. Selected Import/Export Data on Marine Electronic

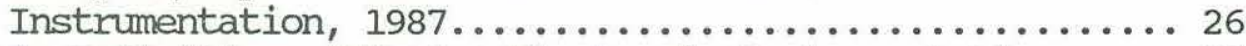

19. A Graphic Definition of Marine Electronic Instrumentation...... 26

20. Overlapping End-Use Sectors in Marine Electronic

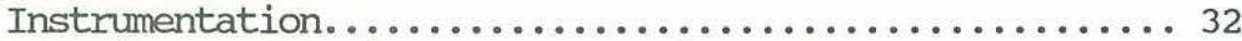

21. The Four Marine Electronic Instrumentation Industry Subgroups.. 33

22. Geographic Distribution of Marine Scientific Instrumentation

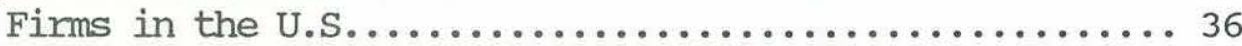

23. Major Defense Contractors Supplying Marine Electronic

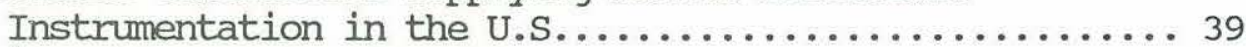

24. U.S. Shipments of Sonar Products, $1967-85 \ldots \ldots \ldots \ldots \ldots \ldots \ldots \ldots 1$

25. R\&D Expenditures as a Function of Sales Volume for Marine Electronic Instrumentation Firms.............. 44

26. Agency R\&D Budgets for Marine Electronic Instrumentation.......48

27. Department of Defense RDT\&E Breakdown by Performer...........49

28. U.S. Navy RDT\&E Categories and Expenditures............... 49

29. U.S. Navy ASW Procurement and R\&D Expenditures, 1965-88....... 50

30. U.S. Navy Anti-Submarine Warfare (A.SW) Programs.............. 51

31. Global Ocean Science Program (GOSP) Level of Effort Analysis... 53

32. Other Procurement Navy (OPN) of Marine Electronic

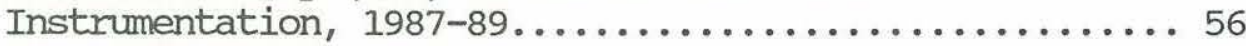

33. Agency Procurement Budgets for Marine Electronic

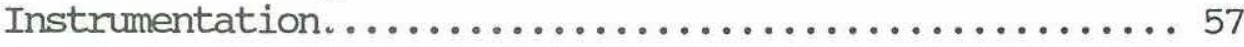


34. Patent for a Bathythermograph, $1945 \ldots \ldots \ldots \ldots \ldots \ldots \ldots \ldots \ldots . \ldots \ldots 2$

35. Qualified R\&E Expenditures and Tax Credits, $1981-83 \ldots \ldots \ldots .66$

36. Microelectronics and Camputer Technology Corporation

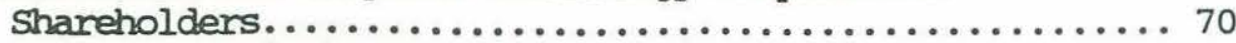

37. SBIR Awards for Projects Related to Marine Electronic

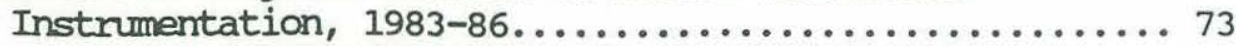

38. Problems Faced by Small Businesses in the Marine Electronic Instrumentation Field...................... 74

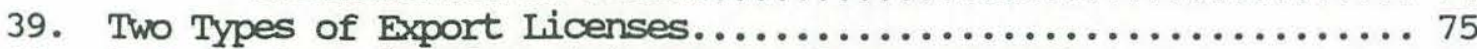

40. Federal Agencies Exercising Control over Exports........... 78

41. Sample Tariff Schedule Entry for Marine Electronic

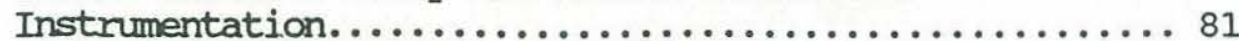

42. Foreign Exchange Rates, $1978-87 \ldots \ldots \ldots \ldots \ldots \ldots \ldots \ldots \ldots \ldots . \ldots \ldots$

43. U.S. National Labs and R\&D Centers Involved in Marine Electronic Instrumentation..................... 90 
1. Introduction: Marine Electronic Instrumentation in the Context of World High Technology Competition

\subsection{Importance of High Technology Competitiveness.}

High technology products (and associated industries and services) are important to the economic strength of the United States, both domestically and internationally (Spence and Hazard, 1988). High technology products are defined generally to include those products for which research and development (R\&D) expenditures are a significant (perhaps as high as 5 to 15 percent) proportion of sales. Figure 1 compares R\&D expenditures for high technology manufacturers with other manufacturing industries over the twenty year period from 1964 through 1985 (NSB, 1987). High technology's share of domestic U.S. production and exports has grown rapidly during the past decade and is generally considered to be one of the mainstays, present and future, of American economic wellbeing.

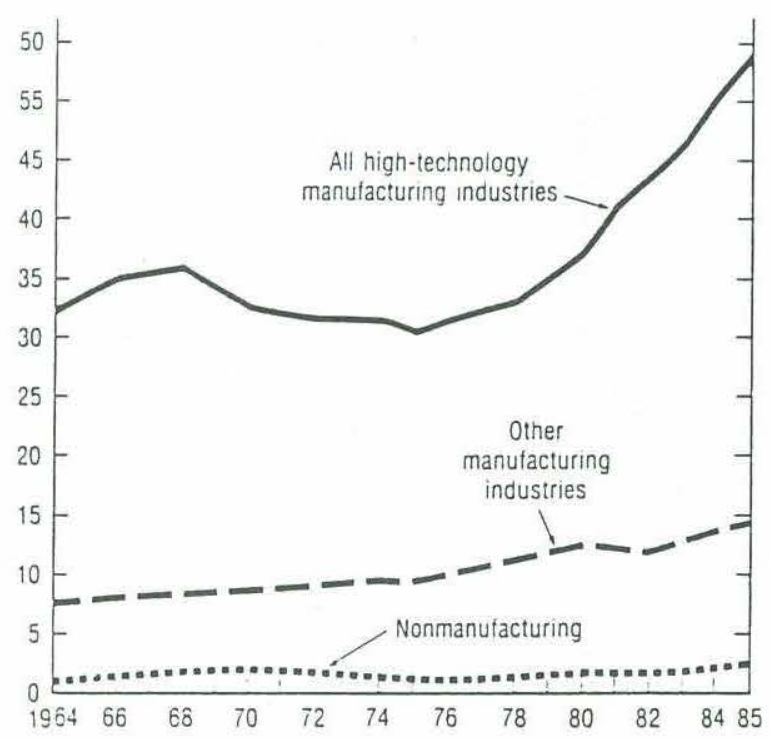

Figure 1: U.S. R\&D Expenditures for High Technology and Other Industries, 1964-85. Constant 1982 dollars, in billions. Source: NSB (1987).

It is a matter of national concern, therefore, that the U.S. share of world high technology manufactures exports has been declining since 1982 (ITA, 1985). The U.S. share of all major industrial countries' high technology exports fell from 28.4 percent in 1965 to 23.1 percent in 1978 (ITA; 1985). As shown in Figure 2, although the U.S. share has recovered somewhat in the past decade, it did not regain its 1965 mark and has been slipping again in recent years (OECD, 1986). 


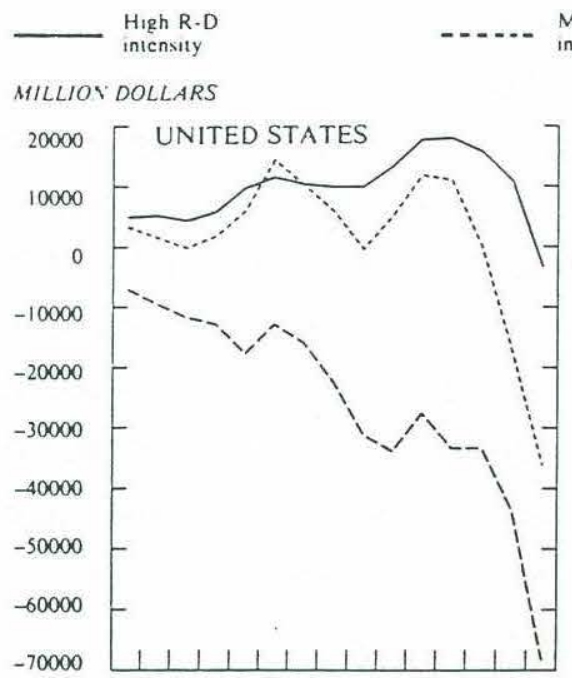

Mcdium R-D intensity
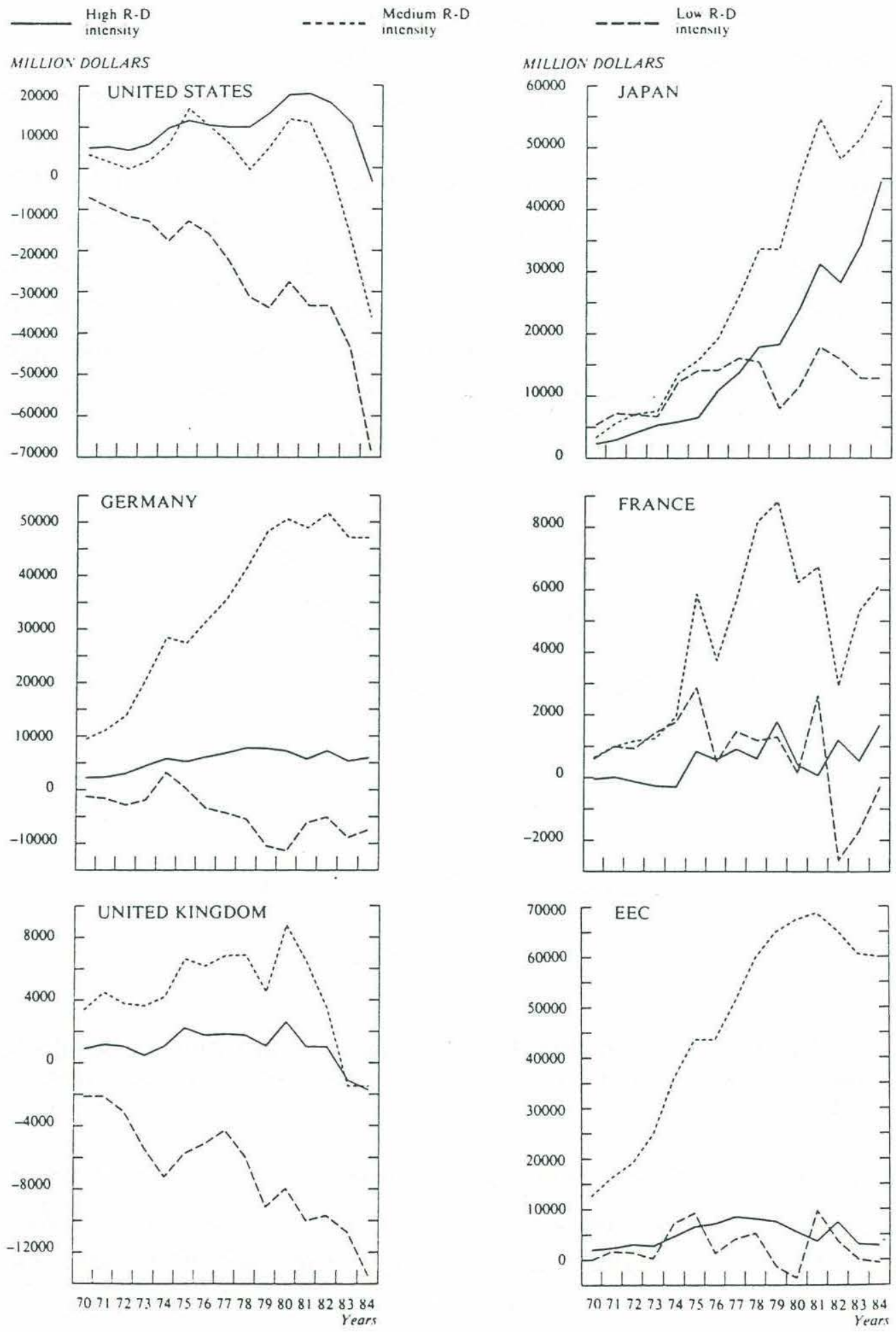

Figure 2: Trade Balances of Manufacturing Industries for Selected Nations, 1970-84. Source: OECD (1986). 
Some of the immediate causes of the eroding U.S. high technology competitiveness are becoming apparent. Inadequate investment in both tangible (plant and equipment) and intangible (R\&D and learning) capital may be an important factor, resulting primarily from the high costs of capital associated with a low overall national savings rate (Hatsopoulos, Krugman and Summers, 1988). For the advanced technology industries, intangible capital investments may be the most important, and inadequate investment in this field seems almost paradoxical in light of upward trends in R\&D expenditures. For example, industrial R\&D in electrical equipment (SIC code 36), which includes radio and television receivers, communications equipment, and electronic components, has followed the trend for high technology manufacturers generally, increasing from \$8 billion in 1960 to \$10 billion in 1970, and \$15 billion in 1985 (NSB, 1987). The electrical equipment class has a relatively high rate of R\&D funding as a percent of net sales, averaging just under seven percent during this period, almost double the average for all manufacturing industries. Even with this growth, however, the rate of R\&D spending has barely kept pace with the efforts of other high technology competitors (Figures $3 \mathrm{a}$ and $3 \mathrm{~b}$ ).

\begin{tabular}{|c|c|c|c|c|c|}
\hline Year & France & West Germany & Japan & United Kingdom & United States \\
\hline & \multicolumn{5}{|c|}{ National expenditures on R\&D as a percent of GNP } \\
\hline $1970 \ldots \ldots \ldots \ldots$ & 1.91 & 2.06 & 1.85 & 2.07 & 2.57 \\
\hline $1971 \ldots \ldots \ldots \ldots$ & 1.90 & 2.19 & 1.85 & NA & 2.42 \\
\hline $1972 \ldots \ldots \ldots \ldots$ & 1.90 & 2.20 & 1.86 & 2.11 & 2.35 \\
\hline $1973 \ldots \ldots \ldots \ldots$ & 1.76 & 2.09 & 1.90 & NA & 2.26 \\
\hline $1974 \ldots \ldots \ldots \ldots$ & 1.79 & 2.13 & 1.97 & NA & 2.23 \\
\hline $1975 \ldots \ldots \ldots \ldots$ & 1.80 & 2.22 & 1.96 & 2.19 & 2.20 \\
\hline $1976 \ldots \ldots \ldots \ldots$ & 1.77 & 2.15 & 1.95 & NA & 2.19 \\
\hline $1977 \ldots \ldots \ldots \ldots$ & 1.76 & 2.14 & 1.93 & NA & 2.15 \\
\hline $1978 \ldots \ldots \ldots \ldots$ & 1.76 & 2.24 & 2.00 & 2.24 & 2.14 \\
\hline $1979 \ldots \ldots \ldots \ldots$ & 1.81 & 2.40 & 2.09 & NA & 2.19 \\
\hline $1980 \ldots \ldots \ldots \ldots$ & 1.84 & 2.42 & 2.22 & NA & 2.29 \\
\hline $1981 \ldots \ldots \ldots \ldots$ & 2.01 & 2.44 & 2.38 & 2.41 & 2.35 \\
\hline $1982 \ldots \ldots \ldots \ldots$ & 2.10 & 2.59 & 2.47 & NA & 2.51 \\
\hline $1983 \ldots \ldots \ldots \ldots$ & 2.15 & 2.54 & 2.61 & 2.25 & 2.56 \\
\hline $1984 \ldots \ldots \ldots \ldots$ & 2.25 & 2.52 & 2.61 & NA & 2.59 \\
\hline $1985 \ldots \ldots \ldots \ldots$ & 2.31 & 2.67 & 2.77 & 2.42 & 2.69 \\
\hline $1986 \ldots \ldots \ldots \ldots$ & 2.41 & 2.74 & NA & NA & 2.72 \\
\hline $1987 \ldots \ldots \ldots \ldots$ & NA & NA & NA & NA & 2.77 \\
\hline
\end{tabular}

Figure 3a: National Expenditures for Performance of R\&D as a Percent of Gross National Product, by Country, 1970-87. Source: NSB (1987) . 


\begin{tabular}{|c|c|c|c|c|c|}
\hline Year & France & West Germany & Japan & United Kingdom & United States \\
\hline & & Estimated non-de & \&D expen & s as a percent of $G$ & 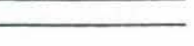 \\
\hline $1971 \ldots \ldots \ldots \ldots$ & NA & 2.03 & 1.84 & NA & 1.65 \\
\hline $1972 \ldots \ldots \ldots \ldots$ & 1.58 & 2.08 & 1.84 & 1.56 & 1.60 \\
\hline $1973 \ldots \ldots \ldots \ldots$ & 1.38 & 1.94 & 1.89 & NA & 1.58 \\
\hline $1974 \ldots \ldots \ldots \ldots$ & 1.43 & 1.98 & 1.96 & NA & 1.63 \\
\hline $1975 \ldots \ldots \ldots \ldots$ & 1.46 & 2.08 & 1.95 & 1.55 & 1.63 \\
\hline $1976 \ldots \ldots \ldots \ldots$ & 1.44 & 2.01 & 1.94 & NA & 1.62 \\
\hline $1977 \ldots \ldots \ldots \ldots$ & 1.44 & 2.01 & 1.92 & NA & 1.61 \\
\hline $1978 \ldots \ldots \ldots \ldots$ & 1.41 & 2.10 & 1.98 & 1.61 & 1.63 \\
\hline $1979 \ldots \ldots \ldots$ & 1.42 & 2.27 & 2.08 & NA & 1.69 \\
\hline $1980 \ldots \ldots \ldots \ldots$ & 1.43 & 2.30 & 2.21 & NA & 1.79 \\
\hline $1981 \ldots \ldots \ldots \ldots$ & 1.50 & 2.34 & 2.37 & 1.72 & 1.81 \\
\hline $1982 \ldots \ldots \ldots \ldots$ & 1.63 & 2.48 & 2.46 & NA & 1.88 \\
\hline $1983 \ldots \ldots \ldots \ldots$ & 1.69 & 2.43 & 2.60 & 1.60 & 1.87 \\
\hline $1984 \ldots \ldots \ldots \ldots$ & 1.76 & 2.41 & 2.59 & NA & 1.86 \\
\hline $1985 \ldots \ldots \ldots \ldots$ & 1.85 & 2.53 & 2.75 & 1.71 & 1.86 \\
\hline $1986 \ldots \ldots \ldots \ldots$ & 1.94 & 2.60 & NA & NA & 1.85 \\
\hline $1987 \quad \ldots \ldots \ldots$ & NA & NA & NA & NA & 1.88 \\
\hline
\end{tabular}

Figure 3b: Estimated Non-Defense R\&D Expenditures as a Percent of Gross National Product, by Country, 1971-87. Source: NSB (1987).

Compared to Japan and West Germany, there has been a distinct erosion in relative non-defense R\&D effort by the United States. Although the U.S. total national R\&D-to-GNP ratio for 1988 is estimated at 2.7 percent (comparable to that of Japan and West Germany), the U.S. spends a substantial proportion of its national R\&D funds on military projects. Since World War II, military R\&D has accounted for roughly half of all U.S. R\&D spending; this figure has risen today to 68 percent. Japan and West Germany, prohibited since World War II from following this example, have instead invested their R\&D efforts into commercial products and processes. The U.S. civilian R\&D-to-GNP ratio for 1983-88 has hovered just below 1.9 percent, while the comparable figures for Japan and West Germany are 2.6 and 2.7 percent, respectively (NSF, 1988).

It is likely, however, that there are idiosyncratic factors that affect the competitive position of firms in discrete markets, and broadscale analysis may result in only a generalization of problems and solutions, inadequate or sometimes inappropriate to the individual industry. From a industry-level perspective, several theories have emerged in attempts to to explain the dwindling competitive position of U.S. firms. Some commentators believe that business in the United States has entered a period of "financial caution and interest in short-term profits," relying less on investment in risky high 
technology R\&D and more on technology import (Roman and Puett, 1983). Others believe that the innovation process in the United States gives too much emphasis to "significant new technical breakthroughs" (Young, 1988) and that incremental innovation focusing on manufacturing, design, and the product development cycle may be of greater importance to the commercialization of a breakthrough and ultimately to competitiveness (Gomory and Schmitt, 1988).

This report is part of a study designed to determine the nature of the U.S. marine electronic instrumentation "industry," to identify the competitive position of U.S. firms with respect to foreign manufacturers in international markets, and to suggest ways in which its future viability and competitiveness might be assured.

\subsection{The Marine Electronic Instrumentation Industry.}

Bridging a world electronics market of $\$ 400$ to $\$ 500$ billion, and a world marine market on the order of $\$ 400$ billion, there is a small but recognizable and critically important area of high technology that can be described as "marine electronic instrumentation." Annual production of marine electronic instrumentation in the United States is on the order of \$5 billion, with perhaps 20 to $30 \%$ of this being exported, and a smaller amount being imported (the world market is estimated here at about \$10 billion) (see section 1.6. below).

Marine electronic instrumentation encompasses most of the high technology tools that are vital to the efficient exploration, understanding, and use of the oceans. The producers of these technologies sell into a world market, and their consumers span all ocean sectors from undersea defense to offshore oil and gas, oceanographic research, enviromental monitoring, commercial shipping, fishing, and recreational boating.

In the three general industrial classes most closely related to marine electronic instruments (communications equipment, electronic components, and scientific instruments), the U.S. has faced strong competition in the international marketplace from Japan and, to a lesser extent, West Germany. As shown in Figure 4, for trade in this decade, these are the only high technology industrial classes that have moved from trade surpluses to trade deficits (CBO, 1987). The marine electronic instrumentation field is part of the electronics products business, for which U.S. exports in 1987 totalled some \$40 billion, well below the U.S. imports of nearly $\$ 58$ billion (EIA, 1988). Among all manufactured products, U.S. firms are exposed to foreign competition on 70 percent of their 


\begin{tabular}{|c|c|c|c|c|c|c|c|c|c|}
\hline \multirow{2}{*}{$\begin{array}{l}\text { Industry (Standard } \\
\text { Industrial Classification) }\end{array}$} & \multicolumn{3}{|c|}{1980} & \multicolumn{3}{|c|}{1983} & \multicolumn{3}{|c|}{1986} \\
\hline & Exports & Imports & $\overline{\text { Balance }}$ & Exports & Imports & $\overline{\text { Balance }}$ & Exports & Imports & Balance \\
\hline Drugs (283) & 2.0 & 1.0 & 1.0 & 2.6 & 1.3 & 1.3 & 3.1 & 2.3 & 0.8 \\
\hline Industrial Organic Chemicals (286) & 6.4 & 2.2 & 4.2 & 6.0 & 2.9 & 3.1 & 6.9 & 4.1 & 2.8 \\
\hline Computers and Office Equipment (357) & 8.7 & 2.5 & 6.2 & 11.7 & 6.2 & 5.5 & 16.1 & 13.5 & 2.6 \\
\hline Communications Equipment (366) & 2.7 & 2.5 & 0.2 & 3.7 & 4.5 & -0.8 & 4.3 & 6.3 & -2.0 \\
\hline Electronic Components ( 367 ) & 6.2 & 5.3 & 0.9 & 7.7 & 8.0 & -0.3 & 9.2 & 13.4 & -4.2 \\
\hline Aircraft and Parts (372) & 14.6 & 2.7 & 11.9 & 14.6 & 2.6 & 12.0 & 18.4 & 5.7 & 12.7 \\
\hline Scientific Instruments (380) & 7.8 & 4.8 & 3.0 & 8.5 & 6.1 & 2.4 & 9.7 & 10.7 & -1.0 \\
\hline Total & 48.4 & 21.0 & 27.4 & 54.8 & 31.6 & 23.2 & 67.8 & 56.1 & 11.7 \\
\hline
\end{tabular}

Figure 4: U.S. High Technology Trade Balance for Selected Years. In billions of current dollars. Note: MoGuckin and Pascoe (1988) explain problems associated with the representation of broad-scale SIC categories in high-technology areas. Source: CBO (1987).

products (Young, 1986). In contrast, U.S firms in the marine electronic instrumentation industry are exposed to foreign competition on nearly 100 percent of their products.

Prior to the study we have undertaken, the industry serving the marine electronic instrumentation field had received virtually no systematic attention, despite the fact that marine instrumentation is a market in which the U.S. traditionally has been a leader. Historically, the United States has been aware of the importance of marine instruments as technologies fundamental to all ocean sectors. In 1966, the Marine Resources and Engineering Development Act [P.L. 89$688]^{1}$ identified as a U.S. policy objective:

The development and improvement of the capabilities, performance, use, and efficiency of vehicles, equipment, and instruments for use in exploration, research, surveys, the recovery of resources, and the transmission of energy in the marine environment (emphasis added).

The "Stratton Commission Report," called for by this Act and published almost 20 years ago, noted the importance of marine instrumentation to the exploration and

133 U.S.C.A. 1101 (b) (3). 
development of marine resources, but did not include an industry study (CMSER, 1969). Subsequent reports also have recognized the indispensable nature of marine instruments but have stopped short of an examination of the overall organization and performance of the industrial effort that invents and produces them (see section 1.4.2. below).

There can be no doubt of the value of progress in marine electronic instrumentation, since it is closely linked to progress in our ability to understand and use the oceans effectively. However, in addition to facing problems common to all high technology industries today, U.S. marine electronic instrumentation firms are further affected by other circumstances specific to the marine industries. Prominent among these are the cyclical fortunes of the offshore oil industry, which in its exploration and development activities has been a major market for marine electronic instrumentation.

As expressed by experts in govermment and academia, the recent downturn in offshore oil and gas activity may cause concern for future progress in marine electronic instruments, particularly because of present reductions in basic research (e.g., Figure 5) and education. This point is made by Wells

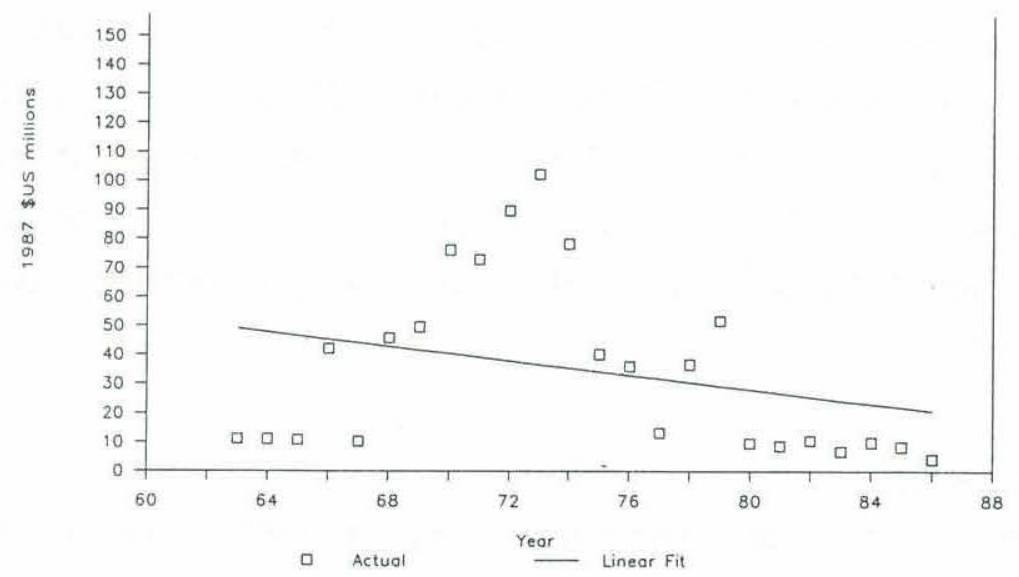

Figure 5: World Expenditures on Geophysics for Oceanography, 1963-86. Source: Geophysics (1961-80) and Ieading Fdge (1981-86).

(1988) of the Naval Civil Engineering Laboratory:

Today, the offshore oil industry has limited dollars available for ocean engineering and research. Most research is now sponsored or conducted by military research activities, and this is having an unintended but inevitable impact on oceanic research conducted at universities. Loss of research income is hampering university efforts to retain staff and 
acquire modern equipment leading in turn to fewer students seeking careers in ocean engineering. . . Downstream effects of the decline in ocean research are troubling. Engineers and scientists who have already left the industry probably will not return; the influx of new engineers and scientists will continue to decline and our national ability to compete in the marketplace will be seriously impaired.

At the same time, Lou (1988) points out an apparent disparity in the international distribution of research support that has favored the conduct of ocean engineering research in foreign countries over the United States.

Historically, industrial support for ocean engineering education and research in this country [has] been minimal. Many factors have contributed to this lack of support, including: the strong in-house research capabilities of major oil companies, the millions of dollars spent by these companies on research at European universities and laboratories as part of their North Sea lease obligations, and the more advanced experimental research and testing performed in foreign countries due to the higher level of sophistication of their research facilities. Moreover, the level of industrial support at American universities is even further reduced by the depressed offshore industry.

Declining advanced technology export market shares, a proportionally small civilian R\&D effort, and reduced international competitiveness are serious issues for the U.S. economy as a whole. However, solutions to these problems come only through careful analysis of factors that influence individual industries and markets. This study is a first attempt at the examination of the present and future competitiveness of U.S. firms in the marine electronic instrumentation field. In particular we consider problems and policies relevant to the establishment of a National Agenda designed to improve the competitive position of U.S. firms in this field.

\subsection{An Industry Definition.}

An important first step in any industry study is definition of the subject industry and explicit determination of the boundaries (firms, markets) that delimit the activities to be examined. This is always a nontrivial undertaking, and in any case depends a great deal on the analyst's judgment. It has proven to be particularly complicated for "marine electronic instrumentation." The difficulty in discerning a single, well-delineated industry producing marine electronic instrumentation, in fact, may be an important reason for the absence of previous systematic industry studies of this field. Discussing marine observational tools (a subset of marine instrumentation), Rear Admiral J. R. 
Wilson Jr. (1988), U.S. Chief of Naval Research, recently noted "the absence of a specific industry concerned with the entire ocean enviroment." He stated that:

[t]herefore, the observational tools are, in most instances, developed by the oceanographer asking the questions. This is different from physics, electronics, chemistry, life sciences, etc., where there is a significant industrial component that generally supplies the observational tools.

For the purposes of our study, the basis for industry definition is derived from identification of the relevant products: marine electronic instrumentation. "Marine" is interpreted broadly to include all products designed and marketed specifically for use in or on the oceans, and can include aquatic uses such as in lakes and streams. "Electronics" refers to devices that utilize electrical currents (electrons) for the purpose of transmitting signals or information (as distinguished from "electrical" equipment, which involves the use of electrical currents as a means of supplying power). Finally, "instrumentation" is interpreted as tools and other devices, including those used for observation, control, recording, regulating, and computing.

On the basis of these definitions, it is possible to construct a fairly exhaustive product list of those items qualifying as "marine electronic instrumentation" (see Appendix A). From this product list, in turn, one can assemble a list of firms that supply these marine electronic instrumentation products (see Appendices B and C). At a rough level, this constitutes a definition of the industry or group of industries supplying marine electronic instrumentation. With a definition of this kind, some statistical information on the "industry" can then be obtained by identifying the U.S. Bureau of Census Standard Industrial Classification (SIC) codes corresponding to the product list (see Figure 6).2

An examination of the products and markets served by these firms has resulted in the delineation of four major market categories, or end use sectors, which subdivide the marine electronic instrumentation industry group

2 Any analysis based on Bureau of Census SIC data must take into consideration the selection and editing biases of the Bureau data collection process. Under current procedures, "many small establishments of multiestablishment companies [are] excluded," and establishments with fewer than 250 employees "are selected with a probability which is proportional to their size" (MoGuckin and Pascoe, 1988). 


$\begin{array}{lll}\text { SIC Code } & \text { Products } \\ 3601000 & \text { Electronics } \\ 366 & 0000 & \text { Communications Equipment } \\ 366 & 2000 & \text { Communications Equipment except Telecom. } \\ 366 & 2070 & \text { Marine Electronics } \\ 366 & 2153 & \text { Marine Mobile Radio } \\ 366 & 2158 & \text { Air-to-Submarine Communciations Equipment } \\ 366 & 2431 & \text { Air Navigation Equipment, LoRAN } \\ 366 & 2460 & \text { Marine Navigation Equipment } \\ 366 & 2470 & \text { Underwater Navigation Equipment } \\ 366 & 2540 & \text { Radar Systems and Equipment } \\ 366 & 2544 & \text { Ship-Based Search and Detect Radar } \\ 366 & 2552 & \text { Airborne and Space Tracking Radar } \\ 366 & 2557 & \text { Airborne and Marine Instrument Radar } \\ 366 & 2570 & \text { Sonar Systems } \\ 366 & 2571 & \text { Sonobuoys } \\ 366 & 2573 & \text { Submarine Sonar } \\ 366 & 2574 & \text { Anti-Mine Sonar } \\ 366 & 2576 & \text { Oceanographic Sonar } \\ 366 & 2578 & \text { Sonar Checkout and Support Equipment } \\ 366 & 2600 & \text { Signal Processing Equipment } \\ 366 & 2730 & \text { Electronic Geophysical Equipment } \\ 366 & 2740 & \text { Electronic Oceanographic Equipment } \\ 367 & 9917 & \text { Acoustic Transducers } \\ 381 & 1100 & \text { Aeronautical and Nautical Instruments }\end{array}$

Figure 6: Standard Industrial Classification (SIC) Codes Relevant to Marine Electronic Instrumentation Products.

(and the marine industry in general). These are (1) the military, (2) offshore oil and gas, (3) recreational and commercial boating and shipping, and (4) scientific and oceanographic activities (including environmental monitoring). Although there is some overlap between these sectors, both in terms of products and in terms of companies, the distinctions have proven useful in describing this industrial field. The end use sectors are discussed in greater detail in Chapter 2.

As marine instruments span end-use sectors and are employed internationally, so too they are used in related marine applications by several U.S. agencies (including the Navy, NOAA, National Science Foundation [NSF], Coast Guard [USCG], Army Corps of Engineers [ACOE], Department of Energy [DOE], Environmental Protection Agency [EPA]). Some initial steps toward understanding the extent to which govermment agencies influence the performance of firms in this field are taken in chapter 3.

\subsection{Historical Review.}

1.4.1. Origins and Industry Development. Identification of the first use of a marine electronic instrument is clouded in time and, in any event, is bound to be somewhat arbitrary. Electrical lights were introduced on some 
ships in the latter part of the nineteenth century, and, to the extent these were used for signalling purposes, they might qualify as electronic instrumentation (Hezlet, 1975). It is not clear, however, that these were specially designed for marine applications. Apparently Steadmore and German colleagues developed a resistance thermometer for oceanographic applications, also late in the last century, and this might be viewed as a primitive marine electronic instrument (Vine, 1988). The first major introduction of clearly electronic instrumentation explicitly for marine use, however, appears to have been radio.

Guglielmo Marconi publicly demonstrated wireless telegraphy in England in 1896, and the company he established the following year to market the new technology was oriented primarily toward shipping firms and marine communications. In an effort to cultivate demand in the United States, Marconi used his wireless in 1899 to report on the America Cup Races from the yacht MACKAY-BENNETT for The New York Herald. Days later, the U.S. Navy made its first test of the technology on the ships MASSACHUSETTS and NEW YORK in New York Harbor. Although the Navy was relatively slow to adopt radio, primarily because it embarked on an extended period of supplier competitions and because of internal organizational indifference, both the cunard and White Star Lines began placing the devices on their ships in 1900. In response to the TITANIC disaster in 1912, Congress enacted the Radio Act ${ }^{3}$, which greatly increased the Navy role in radio communications (Douglas, 1985).

By intensifying demand for better hazard-warning devices, the TITANIC disaster also hastened development of two other fundamental marine electronic technologies, radar and sonar. In 1914, U.S. Navy wireless operators were able to demonstrate that radio could be used to locate enemy ships (Douglas, 1985). As early as 1904, the German engineer Christian Hulsmeyer had obtained patents in several countries for a radio echo device to prevent ship collisions, but it was not until the 1930s that radar as we now know it began to emerge. The French had devised an iceberg detector in the mid-1930s for the liner NORMANDIE, and the Submarine Signal Company in the United States had disclosed a complete radio-based detection and ranging system by 1930 . The

3 The early "Radio and Communications Acts" are found at Ch. 379, 36 Stat. 629 (24 June 1910) and Ch. 287, 37 Stat. 302 (13 August 1912). 
British devised a practical microwave system in 1940, and the U.S. Navy coined the term 'radar' in 1942. Application and refinement of the technology took off during World War II, and several manufacturers in England and America were marketing simple commercial systems for coastwise navigation immediately after the war.

The development of sonar followed a similar pattern. A 1889 report by the U.S. Lighthouse Board noted the promising studies of underwater bells and microphones by Professor Blake at Kansas, but no action followed. In 1901 the Submarine Signal Company was established to promote underwater bells as hazard signals, and by 1912 hundreds of transatlantic ships were equipped with receivers for a worldwide network of bells (Fay, 1963). In England, L.F. Richardson filed a patent for airborne echo ranging five days after the TITANIC sinking, and a month later he applied for a patent on its underwater analog (Urick, 1983). The TITANIC tragedy also convinced R.A. Fessenden at the Submarine Signal Company that his oscillator echo sounder could be used for detection and ranging. This was proved in a 1914 test on the coast Guard Cutter MIAMI, detecting an iceberg at 2 miles and establishing the ability to generate and read echoes from objects in the water and from the bottom (Fay, 1963). The French physicist Paul Langevin used a vacuum-tube amplifier in an experimental sonar system in 1917 and so is credited with the first application of modern electronics in underwater sound equipment (Urick, 1983) . Meanwhile, the Submarine Signal Company had been joined by GE and Western Electric to develop antisubmarine warfare sonar applications for coastal defense, but practical results were not obtained until after WWI. The first practical echo sounders were introduced in 1919 with the Hayes sonic depth finder. And widespread availability of the Submarine Signal Company Fathometer followed its first commercial installation on the BERKSHIRE in 1924. Thermal distortions of sonar signals led Athelstan Spilhaus to develop the first bathythermograph in Woods Hole in 1937, just in time for useful deployment and refinement in World War II (Spilhaus, 1987).

The history of the introduction of radio, radar, and sonar as marine electronic instruments is especially instructive for our purposes because it highlights several features of importance in today's industrial dynamics: the prevalence and vigor of international competition; (2) the limited usefulness of patent protection; (3) the manner in which the technology may 
span several important end use sectors; (4) the crucial importance of the Navy as a dominant customer and influence on industry evolution; and (5) the effects of nationalistic interests in governmental intervention.

Although marine electronic instrumentation in its broadest sense can be traced back to the turn of the century, the modern era of marine electronic instrumentation in the United States may be dated as beginning in the late 1950s and early 1960s. Rapid developments in electronics, coupled with a strong interest in the marine frontier and potential uses of the oceans for food, living space, and energy, helped to bring forth a number of small firms of the "instrumentation shop" variety that specialized in oceanographic sensors and systems. At that time, the dominant customer and driving force behind marine electronic instrumentation technology was the government (Figure 7), both in its military and in its civilian operations (PSAC, 1966).

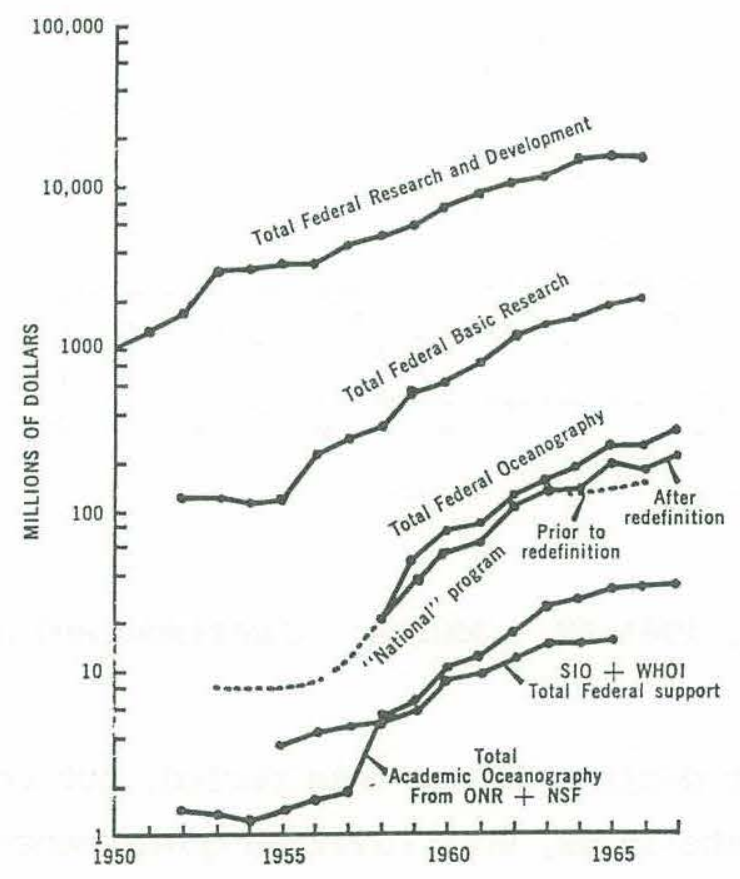

Figure 7: Federal Support for Marine Science and Technology, 1950-67. Source: PSAC (1966).

Especially in its civilian research functions, the government was willing to buy "at least one of almost anything" in its effort to further the understanding of the oceans. This first heyday of marine electronic instrumentation firms culminated in the publication of the stratton Report and the establishment of NOAA, illustrating well the ambitious marine objectives 
of that decade.

Following closely on the heels of the awakening public interest in the oceans, a boom in offshore energy activity occurred, starting earlier in the Gulf of Mexico and moving quickly to the North Sea and elsewhere (Holcott and Purser, 1983). Many of the firms that had gotten off the ground by selling to the government and research institutes quickly switched their focus to the offshore oil and gas sector, and applied their technologies to the problems and demands of this new major customer. Yearend orders for tankers increased substantially during this period (Figure 8), as it became increasingly profitable to move large volumes of crude oil from producers to refineries.

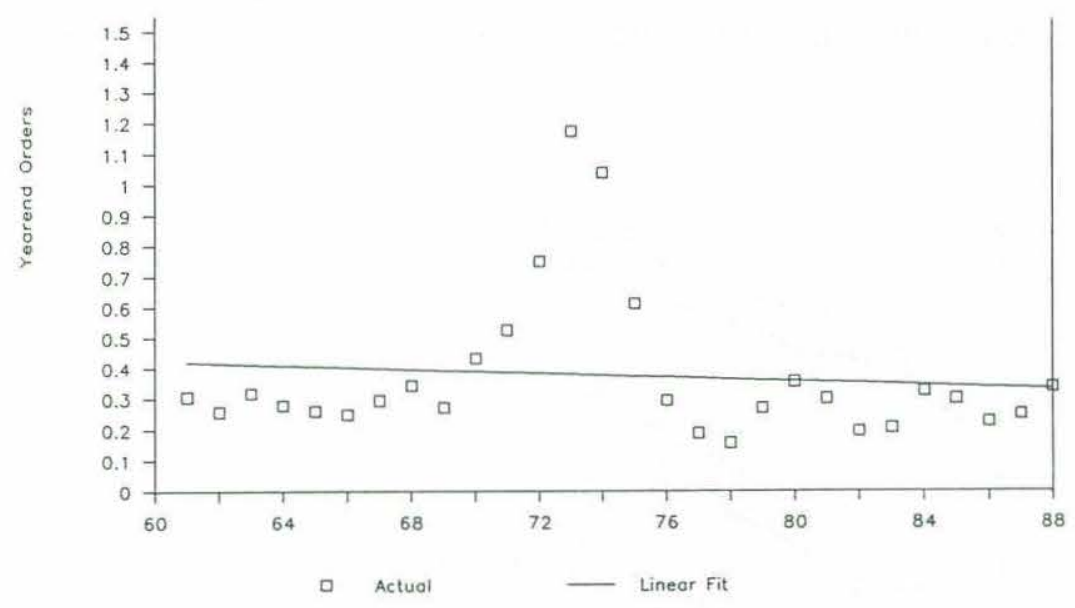

Figure 8: World Tanker Orders, 1961-88. Source: Champness and Jenkins (1985).

The govermment business did not decline during this period, but continued to increase, at least until the late 1970s, when civilian government-sponsored research began to tail-off (Figure 9).

The offshore business was lucrative for marine electronic instrumentation firms until the price of oil dropped precipitously in the early 1980s, and energy companies' budgets for marine exploration and development of electronic products and services declined similarly (Figure 10). This time, the marine electronic instrumentation business experienced a severe shakeout, the effects of which are continuing to be felt today. In a limited sense, the field is back to where it started in the 1960s, dependent 

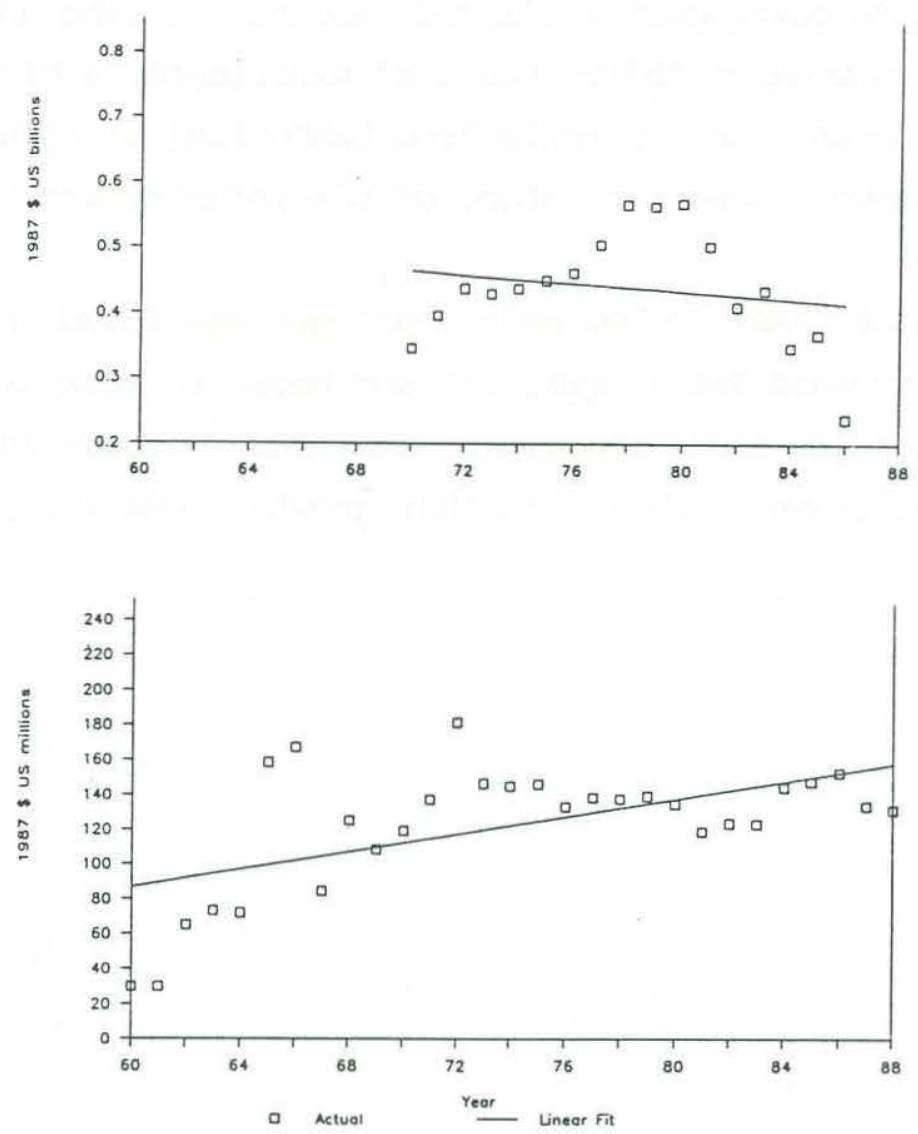

Figure 9: NOAA Expenditures for Marine Science, 1970-86 (top), and NSF Expenditures for Marine Science, 1960-88 (bottom). Source: CAO (1986), Marine Science Affairs (1967-71), and Federal Ocean Program (1972-75).

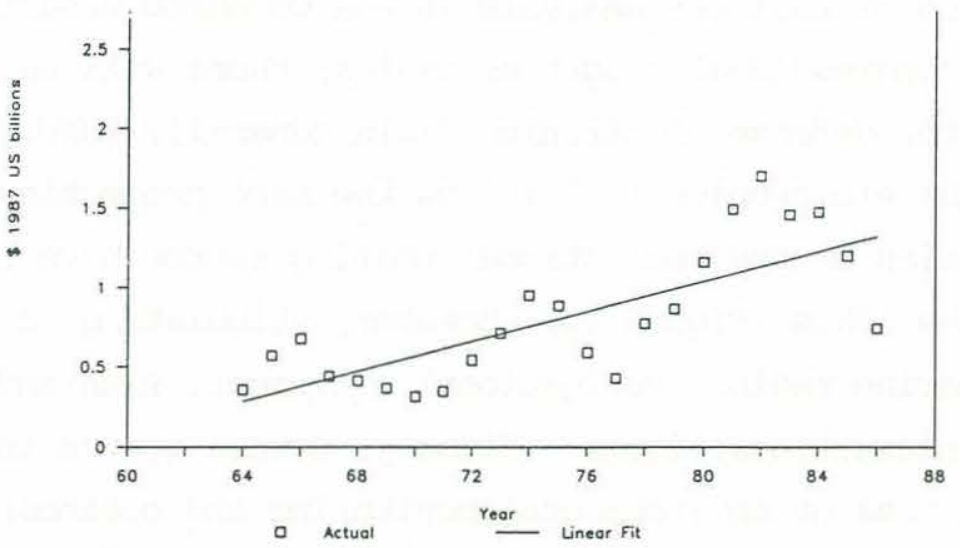

Figure 10: World Expenditures on Geophysics for Offshore Oil and Gas, 196486. Source: Geophysics (1961-80) and Leading Edge (1981-86). 
to a large extent upon government-initiated research funding and procurement budgets. Yet there now exist thirty years of experience, a history of technological development, and spinoffs from technological advances in other fields. All these have changed the shape of the industry and have affected its future potential.

For some firms at least, a new major customer was found in the military, as the U.S. Navy increased R\&D (Figure 11) and began to look harder at proven civilian technologies for their changing needs, particularly in the field of antisubmarine warfare (ASW). Even with this growth, however, a forthcoming

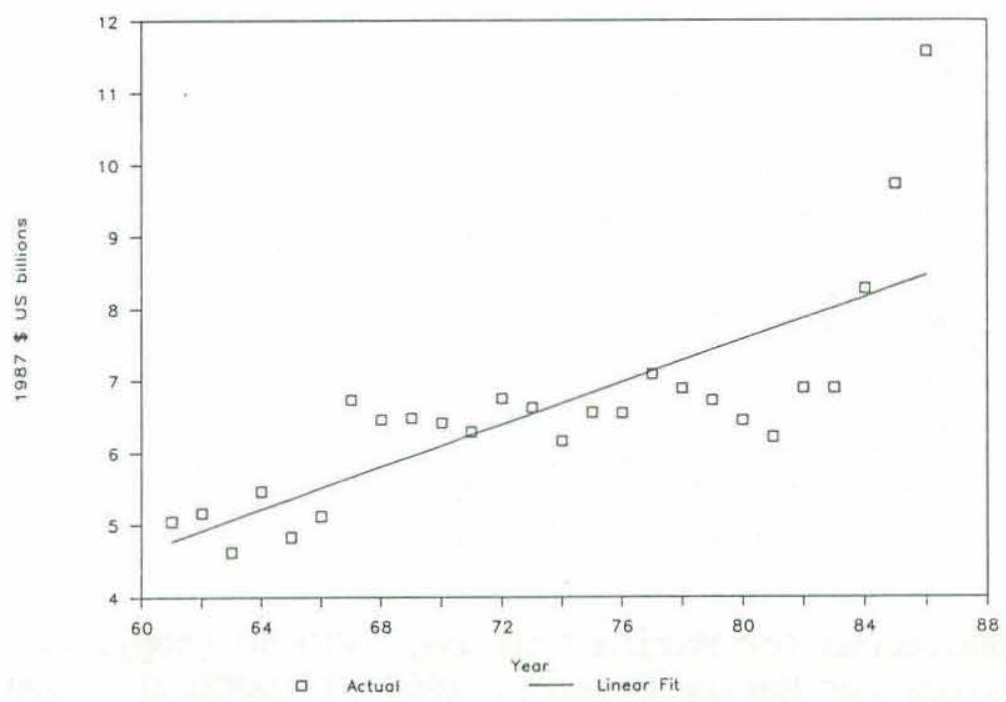

Figure 11: U.S. Navy RDT\&E Expenditures, 1961-88. Source: OMB (1961-87).

study by the Office of Business Analysis in the Commerce Department expects that, based upon congressional budget estimates, there will be little or no future growth in the defense electronics field generally (NNUT, 19 Sept. 1988). Whether ASW electronics will follow the same projection is problematic at this point. Sales in the recreational boating sector have risen dramatically in the 1980s (Figure 12), however, stimulating to a significant extent sales of marine radios, navigational equipment, fishfinding sonars, and other commercial/recreational items. Finally, future growth is expected especially in the area of environmental monitoring and oceanographic research, where increases in consumption of chemical analyzers, water quality instruments, computers, and ocean data collection buoys are anticipated (Woodsum, 1988). 


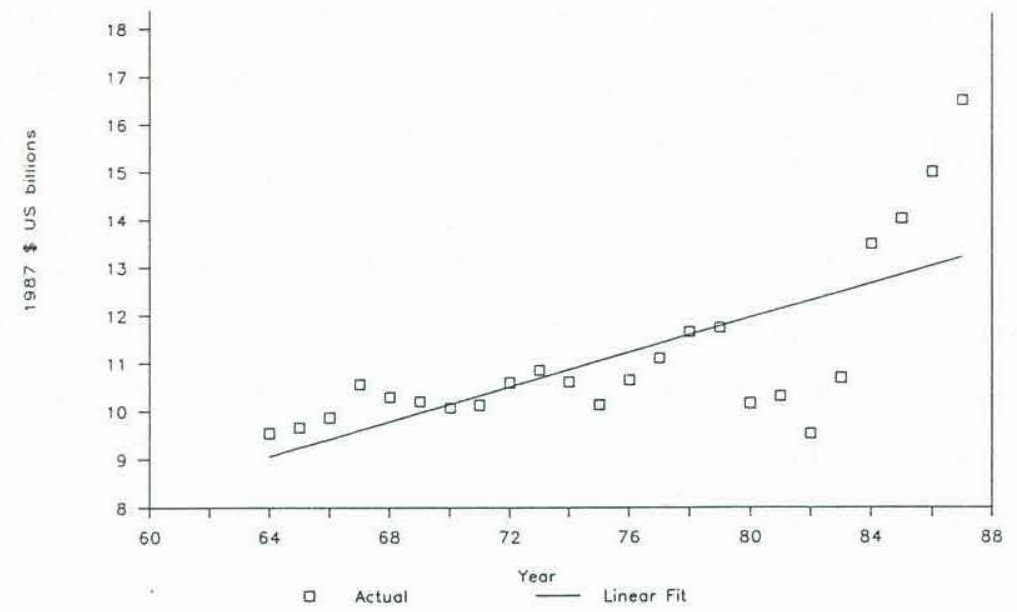

Figure 12: U.S. Retail Boating Expenditures, 1964-87. Source: NMMA (1987).

1.4.2. The Stratton Commission Report. Twenty years ago, the commission on Marine Science, Engineering and Resources (CMSER or "Stratton Commission") was in the process of preparing a comprehensive review of the U.S. ocean industry and ocean policy. Published in 1969, the commission's report (CMSER, 1969) included recommendations that led, among other things, to the establishment of the National Oceanic and Atmospheric Administration (NOAA). In several instances, the report, and its accompanying panel reports (CMSER/PR, 1969), address issues faced by the marine instrumentation field. As its twentieth anniversary approaches, the Stratton Commission's Report provides an interesting starting point for this study of the marine electronic instrumentation industry.

At the time of the Stratton commission's efforts, advances in marine technologies were driven largely by the Navy. The commission realized that extraordinary breakthroughs had been made by military research and that important technologies had been spunoff to benefit civilian applications in such areas as naval architecture and marine propulsion. The commission concluded, however, that other areas of civilian technology and fundamental (non-mission oriented) technology had not received enough attention.

The commission noted that remote sensing platforms and instruments, including expendable free-fall and self-propelled/remotely-guided instruments, provided inexpensive techniques for exploring the oceans. As of 
1968, however, it found that progress in oceanographic sensors had been largely a pioneer effort and had not yet eliminated a "high failure rate." The Commission called on NOAA to "take the lead in fostering a wide variety of instrumentation development programs required for ocean exploration" (CMSER, 1969, pp. 180-181).

The Conmission's Panel on Industry and Private Investment found that "much of the National investment in ocean programs now and in the foreseeable future will be devoted to measuring the characteristics of the marine enviromment" and that reliable, accurate instruments were necessary for this objective. This Panel expressed concern about the performance characteristics of marine instruments:

Most ocean programs have been limited in both staff and budget. As a result, specific program objectives are often compromised and only limited instrumentation is procured. Unlike conditions in many other non-oceanographic programs, such as the space program, ocean instrument specifications are often minimized, meaningful quality assurance programs are largely nonexistent, and service and maintenance manuals and other documentation are often inadequate to meet basic user needs. . . .

Past experience shows that user demand for a particular type of ocean instrument is generally for a limited quantity of highly complex instruments, often requiring custom design. In such cases, manufacturing does not lend itself to mass production, one factor that has allowed the small, technically oriented firm to compete favorably with large corporations. Although large capital facilities are not always essential to produce marine instruments, expensive facilities are often necessary for development and qualification testing (emphasis in the original) (CMSER/PR, 1969, pp. V-46-47).

The Panel suggested that the federal govermment change its procurement policy for oceanographic instruments, so as to pay less attention to initial costs, and place greater emphasis on total costs associated with of the collection, processing and use of data. The Panel report states that:

[u]nder present conditions, instrument manufacturers frequently do not have adequate incentive to develop equipment or systems that will be more cost-effective to the user. This need not be, since industry can produce reliable equipment at costs commensurate with high quality. Until procurement policies are changed, many instruments of inherently poor quality will continue to be procured on a low-bid basis (CMSER/PR, 1969, pp. V-47-48).

The Panel recommended that these changes be initiated as soon as possible by the Navy but that the testing and standardization function should ultimately be taken on by a civilian marine agency. 
International competition in marine instrumentation was not a major concern of the Commission. Its Panel on Marine Engineering and Technology touched briefly on the subject in its discussion of the interrelationships among economic sectors in the marine field:

U.S. marine technology developments should consider both international competition and cooperation. Where consistent with the national interest, programs should encourage increased cooperation and data exchange among ocean scientists and engineers of all nations. The U.S. should consider advanced marine technology as a prime export product and as a foreign aid tool to assist developing countries to strengthen their capabilities for using the ocean and its resources as a means to economic progress (emphasis added) (CMSER/PR, 1969, pp. VI-20) .

Although the commission did not undertake a systematic industry study of the marine instrumentation sector, it did note some of the relevant features of the associated products and firms. Several of the Commission's observations continue to hold true today. For example, the presence of large aerospace firms in the marine sector has increased and the role of small, specialized companies in the development and manufacture of instrumentation has continued to be important. Since the Stratton Report was published, however, other aspects of the industry clearly have changed. Both the importance of the offshore oil and gas sector during the 1970s and stronger international competition in the marine electronic instrumentation field as a whole have helped to improve the quality of marine instrumentation at home and abroad.

other national studies (Figure 13) have made similar observations, but none has examined or even attempted to characterize the supplying industry. The majority of federal govermment studies have expressed concern primarily about the capabilities and quality of instruments for basic research purposes. For example, in 1981, the congressional office of Technology Assessment (OTA) analyzed technologies for govermment-sponsored oceanography. One of OTA's most interesting findings was that high quality instrumentation was available when its development and use had been supported over long periods of time (OTA, 1981). Another OTA report, concerned primarily with the exploration of marine minerals, devoted extensive attention to the description of several kinds of marine electronic instrumentation technologies but drew no conclusions about the industry that supplies them (OTA, 1987). 


\begin{tabular}{|c|c|c|}
\hline YEAR & ORGANIZATION & STUDY \\
\hline 1959 & NAS/NRC: & Oceanography: \\
\hline & Comm. on Oceanography & 1960 to 1970 \\
\hline 1966 & $\begin{array}{l}\text { President's Science } \\
\text { Advisory Committee: } \\
\text { Panel on Oceanography }\end{array}$ & Effective Use of the Sea \\
\hline 1967 & $\begin{array}{l}\text { NAS/NRC: } \\
\text { Comm. on Oceanography }\end{array}$ & Oceanography 1966 \\
\hline 1968 & $\begin{array}{l}\text { American Society for } \\
\text { Oceanograpy, Pacific } \\
\text { Western Division/Dean } \\
\text { Witter \& Co. }\end{array}$ & $\begin{array}{l}\text { The Ocean and the } \\
\text { Investor }\end{array}$ \\
\hline 1969 & $\begin{array}{l}\text { Commission on Marine } \\
\text { Science, Engineering, } \\
\text { and Resources }\end{array}$ & Our Nation and the sea \\
\hline 1972 & NAE: Marine Board & $\begin{array}{l}\text { Toward Fulfillment of a } \\
\text { National ocean Commitment }\end{array}$ \\
\hline 1972 & $\begin{array}{l}\text { NAS: } \\
\text { Comm. on Oceanography }\end{array}$ & $\begin{array}{l}\text { International Marine } \\
\text { Science Affairs }\end{array}$ \\
\hline 1974 & CRS/Robert Nathan Assoc. & $\begin{array}{l}\text { The Economic Value of } \\
\text { Ocean Resources to the } \\
\text { United States }\end{array}$ \\
\hline 1978 & Dept. of Commerce & $\begin{array}{l}\text { U.S. Ocean Policy in the } \\
1970 \text { 's: Status and Issues }\end{array}$ \\
\hline 1979 & NRC: Ocean Science Board & The continuing Quest \\
\hline 1981 & OTA & $\begin{array}{l}\text { Technology and } \\
\text { oceanography }\end{array}$ \\
\hline 1981 & $\begin{array}{l}\text { NAS: Joint Committee of } \\
\text { Polar Research Board and } \\
\text { Ocean Science Board }\end{array}$ & $\begin{array}{l}\text { An Evaluation of } \\
\text { Antarctic Marine } \\
\text { Ecosystem Research }\end{array}$ \\
\hline 1987 & OTA & $\begin{array}{l}\text { Marine Minerals: } \\
\text { Exploring Our New Ocean } \\
\text { Frontier }\end{array}$ \\
\hline
\end{tabular}

Figure 13: Major Studies of Marine Science and Technology. 


\subsection{International Nature of the Marine Electronic Instrumentation Markets} Competition and trade in the marine electronic instrumentation business is largely international in nature. This is due in part to the global similarities of the marine enviromment and in part to the high technology quality of the products. In the most relevant ways, the marine enviromment is the same the world over (especially beneath the surface), so that an instrument developed for use in one location may be equally useful on the other side of the globe. The offshore oil and gas and the ocean shipping industries are truly international users of marine electronic instrumentation, literally carrying and utilizing the same equipment all over the world. Like other high technology products, furthermore, marine electronic instrumentation is used throughout the world but manufactured only in certain nations. A high ratio of product value to transportation costs further contributes to the international character of trade in marine electronic instrumentation. This international market seems to apply to all four end-use sectors identified above; and international competition in this field appears to be on the increase, particularly in the military sector.

The sea presents the same challenges to all who use or study it; and because the community directly engaged in such use or study is small relative to other occupations, it generates a fairly concentrated, homogeneous set of attribute demands for marine instrumentation products that do not vary a great deal from one country to the next. Companies producing marine electronic instrumentation are found throughout the developed nations of the world. Because their products are sought by nomproducing nations as well (for example, by virtue of the jurisdictional rearrangements established by the United Nations Convention on the Law of the Sea and domestic laws), international trade in these products is a natural consequence.

\subsection{Size of the Marine Electronic Instrumentation Sector Within the Marine Industry.}

The world marine industry, broadly defined, presently contributes on an annual basis about $\$ 400$ billion to world production. This includes military, shipping, boating, fishing, mineral resource, and scientific sectors and uses. The U.S. share of this world market is on the order of $\$ 130$ to 140 billion. By far the greatest part of this, especially in the United States, is accounted for by the military uses of the oceans. Figure 14 depicts the world and U.S. markets, 
divided into the four major end use sectors. The U.S. "military" figure of $\$ 100$ billion reflects the approximate size of current annual Navy budgets; the

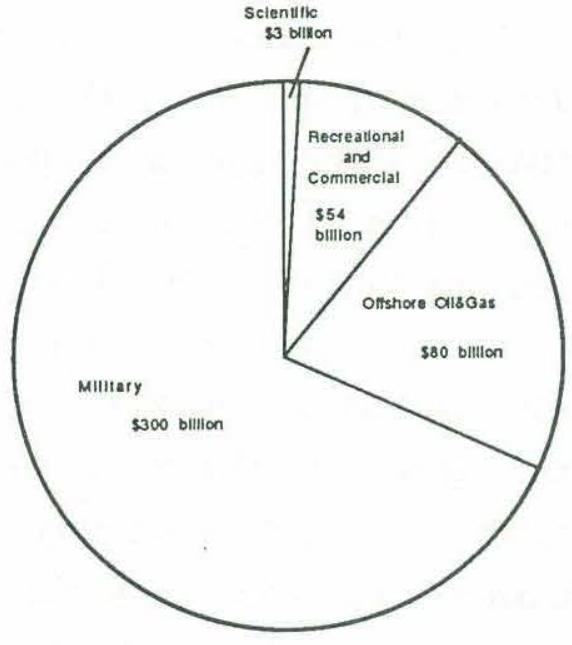

World Marine Market Sectors

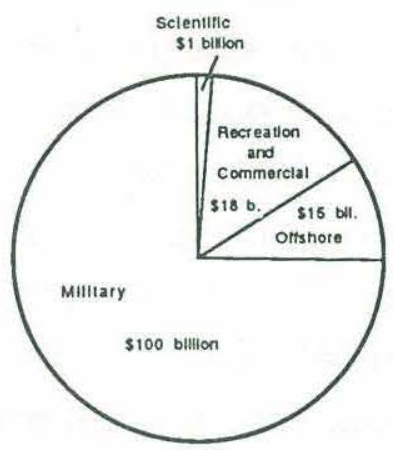

U.S. Marine Market Sectore

Figure 14: Size of World and U.S. Marine Market Sectors. Source: see text. corresponding world figure of $\$ 300$ billion is an approximation based on the relative sizes of U.S. and world naval forces. The "offshore" figures for the United States and the world represent annual marine oil and gas revenues. U.S. "recreational and commercial" expenditures are based on data from the National Marine Manufacturers Association and estimates of commercial shipbuilding activity; the world figure is an approximation based on the U.S. expenditures. Finally, the U.S. "scientific" figure is based on NOAA's annual budget; the world figure is, again, an approximation based on U.S. scientific budgets.

out of the total U.S. marine market, electronic instrumentation appears to account for between 2 to 4 percent, or roughly $\$ 2$ to 5 billion. The lower value is based on an analysis of expenditures on marine electronic instrumentation by the four end-use sectors within the U.S. (Figure 15). The higher value has been derived from a tabulation of U.S. production (shipments) of marine electronic instrumentation (from U.S. Census Bureau [BOC] SIC data) and a preliminary analysis of import/export figures (U.S. International Trade Commission [ITC] data) (see discussion below). No similar analyses have as yet been performed for the world markets. Extrapolation from U.S. data suggest, however, that an upper bound for the size of the world marine electronic instrumentation market might be on the order of $\$ 10$ billion.

The U.S. market sector size estimations in Figure 15 are based on 
procurement budgets, or estimates thereof. The $\$ 2$ billion "military" estimate is derived from actual Navy budgets, as shown in Figure 32 in Section 3 below. The

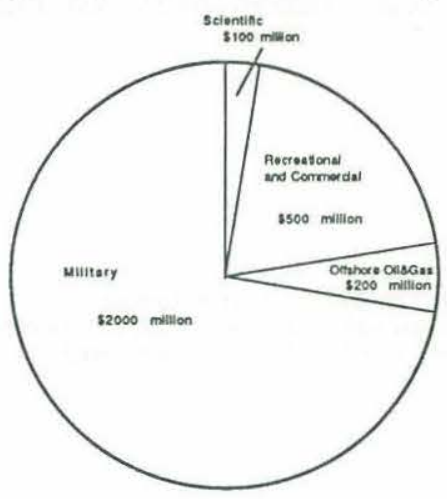

Figure 15: Size of U.S. Marine Electronic Instrumentation Market Sectors. Source: see text.

"offshore" estimate is based on reported U.S. marine geophysical shipments (SIC tabulations) of about $\$ 160$ million, and world offshore oceanographic expenditures(\$10 million) and geophysical expenditures (\$500 million). It should be noted that these estimates are made for a period of relatively low oil prices and, consequently, relatively little offshore exploration activity. The potential contribution of the offshore sector is much greater, as indicated by historical data from the last major oil boom. The "recreational and commercial" estimate of $\$ 0.5$ billion has been calculated based upon discussions with industry representatives, and the "scientific" estimate figure is an approximation based upon NOAA budgets. Taken together, the "demand side" estimates in Figure 15 indicate a U.S. marine electronic instrumentation market of approximately $\$ 3$ billion. As we discuss below, this may understate the true national market size. Figure 16 shows an estimate of the corresponding "supply side." Here, we list and sum the estimated U.S. shipments of marine electronic instrumentation, based on raw SIC data shown (along with some historical time-series) in Figure 17. Before comparing the "shipments" total (a measure of U.S. production) to the U.S. market (consumption), net exports must be subtracted from the former. Figure 18 shows some of the U.S. trade balance information for marine electronic instrumentation. Although incomplete, these import/export data seem to indicate a balance, implying negligible net exports. Thus, the "supply side" total from Figures 16 and 18 appears to exceed substantially the "demand side" total of Figure 15. 
This discrepancy may be due to several factors. The procurement estimates used for Figure 15 are probably low, especially in the military

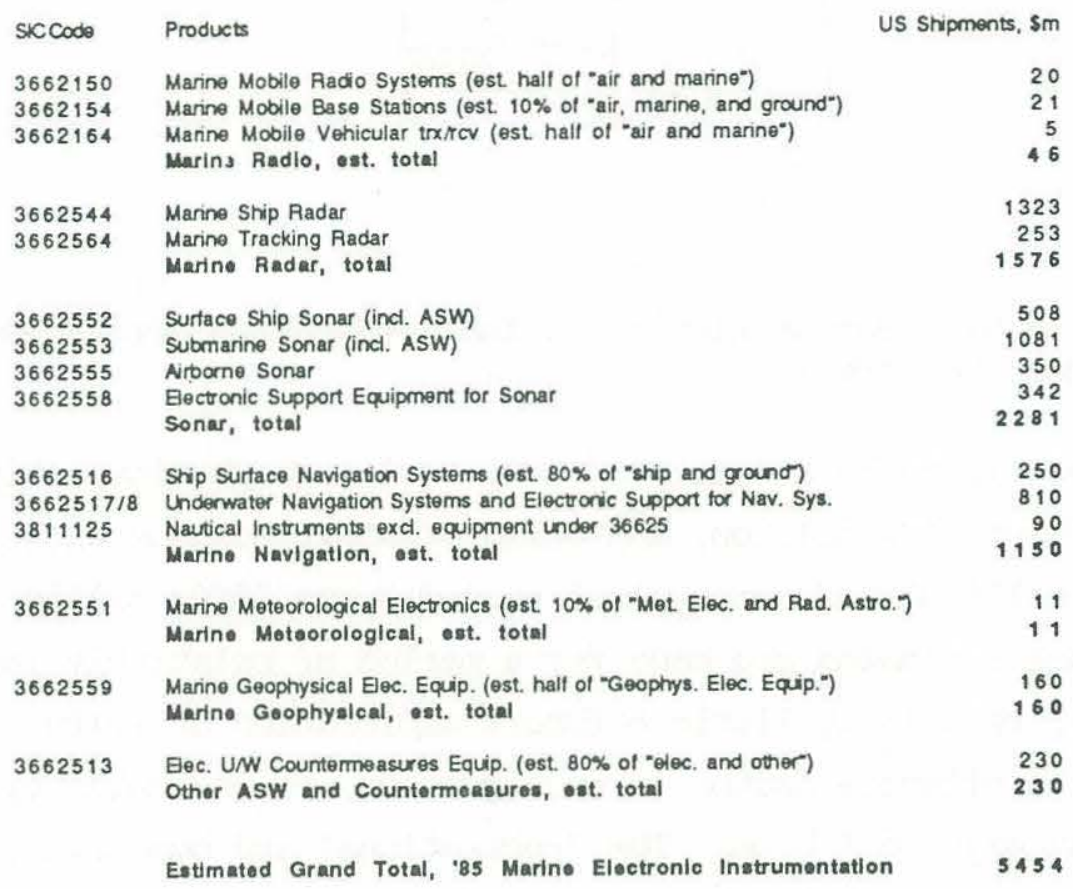

Figure 16: 1985 U.S. Shipments (Production) of Marine Electronic Instrumentation. Estimates adapted from Bureau of the Census (Aug. 1986).

category: purchases under classified programs may not be included in the published procurement budget categories. Also, the shipments in Figure 16 may be slightly inflated in an absolute sense (as a result of estimation procedures, see parenthetical notes in Figure 16), and may be high relative to the numbers in Figure 15 because "support equipment" is included in the SIC data. Finally, the net exports determination from Figure 18 is probably understated, because ITC reports only the import and export of those products on which tariffs are levied, which may not include significant amounts of government sales of military equipment to foreign nations. It is likely, therefore, that the true U.S. market size of the marine electronic instrumentation sectors lies somewhere between the values suggested by these two analyses. 


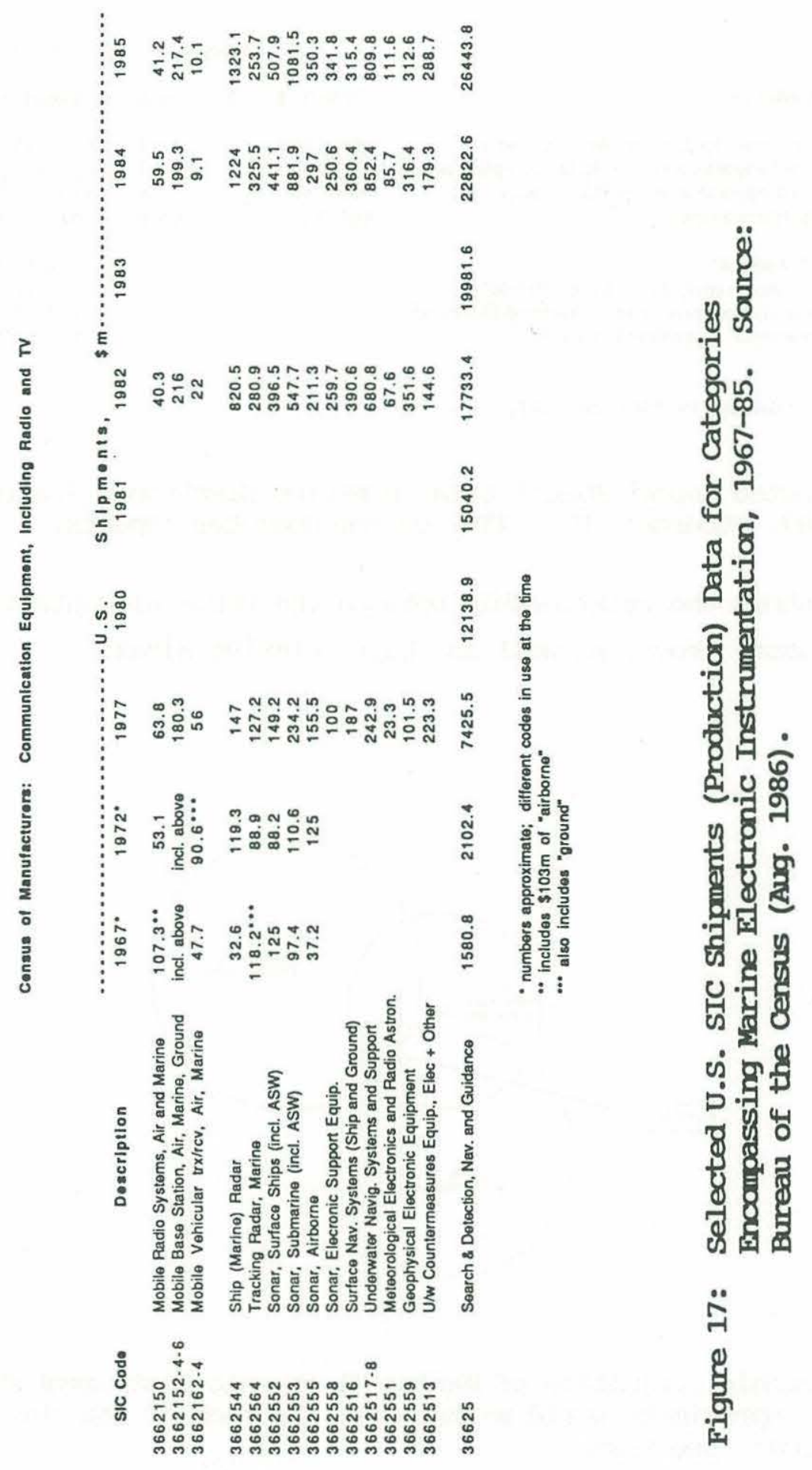




\section{Products}

Radar Apparatus designed for Boat or Ship Installation Radio Navigation. Aid Apparatus except Radar, reception only Radio Navigation. Aid Apparatus except Radar, other Marine VHF Radio Transceivers

Depth-Sounding Apparatus*

Other Navigational Apparatus, Electricai/Electronic ${ }^{\circ}$ Meteorological and Hydrological Instr., Electrical/Electronic ${ }^{\circ}$ Geophysical Instruments, Electrical/Electronic*
U.S. Importe

\begin{tabular}{|c|c|c|}
\hline Import & '87, & smm \\
\hline 685.6021 & & 29.9 \\
\hline 685.6041 & & 17.4 \\
\hline 685.605 & & 26 \\
\hline 685.2441 & & 26.5 \\
\hline
\end{tabular}

U.S. Exports (................... Export * $87,8 \mathrm{~mm}$ $685.6021 \quad 36.6$ $685.6045 \quad 12.3$ $\begin{array}{ll}685.6052 & 25.7\end{array}$ not listed $\quad$.

$710.102 \quad 68.4$ $710.105 \quad 363$

$710.182 \quad 25.3$

$710.282 \quad 295$

- values are for 1986 (not 1987)

Figure 18: Selected Import/Export Data on Marine Electronic Instrumentation, 1987. Source: U.S. ITC, custom computer reports.

Figure 19 shows the relationship between the three elements of the industry definition discussed above, as well as their relative sizes.

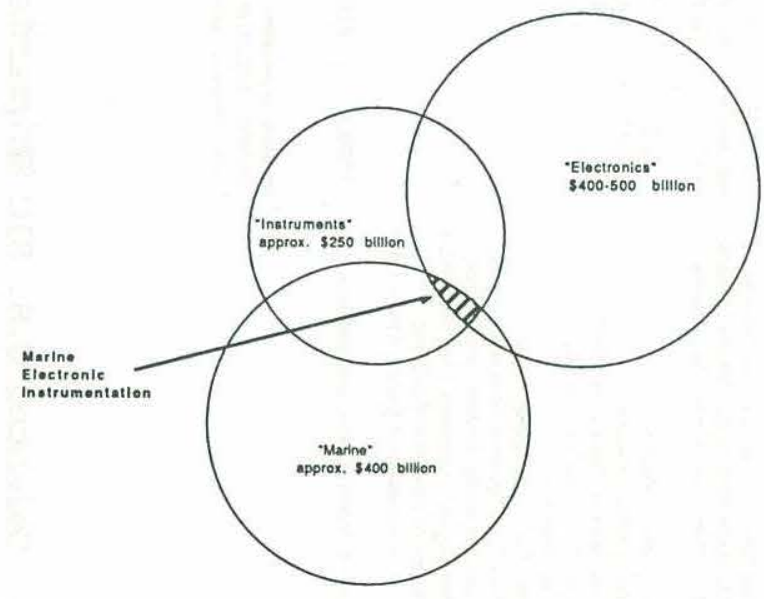

Figure 19: A Graphic Definition of Marine Electronic Instrumentation, showing the approximate world market size for each of the three sectors. Source: see text.

Worldwide instruments production is on the order of $\$ 250$ billion annually, based on SIC code 38 reports of U.S. instruments shipments of \$61 billion in 1986. 
World electronics production now lies somewhere between $\$ 400$ and 500 billion per year, and the world marine market, as mentioned previously, is on the order of $\$ 400$ billion. The overlapping areas indicate the intersections between these markets: electronic instruments, marine electronics, "manual" marine instruments, and, in the center, marine electronic instrumentation.

Under the definition adopted for this report, it appears that "marine electronics" and "marine electronic instrumentation" are almost synonymous; it is difficult to identify "marine electronics" that cannot also be qualified as "instrumentation," whereas it is relatively easy to find examples of nonelectronic marine instruments. For many market participants, however, the term "marine electronics" refers to a more restricted line of products (generally including electronic support equipment for navigation and communication) primarily consumed by the commercial and recreational end-use sector, so we adhere to the more cumbersome and broader terminology of marine electronic instrumentation.

\subsection{Methodology and scope of this study.}

The purpose of this study has been to generate a broad description of the industrial field of marine electronic instrumentation. To this end, we reviewed the relevant literature (including marine trade and scientific journals and works on international trade and competitiveness) and conducted a number of interviews and discussions with industry and government representatives. These contacts included site visits to marine electronics firms on the west and east coasts of the United States, discussions with international industry representatives at the Oceanology 88 Conference in Brighton, England, and interviews with U.S. Commerce Department and Navy Department officials, as well as the meetings of the Marine Instrumentation Panel at Woods Hole.

The goal of this approach is to produce a fairly comprehensive, qualitative overview of industrial organization in this field and to identify those features that merit more detailed examination.

The remainder of the report consists of three chapters, followed by a set of appendices. Chapter 2 presents a structural overview of the U.S. marine electronic instrumentation "industry," focusing on broad descriptions of the firms that populate the broadly defined industry groups in MEI. It describes product and end-use sectors, the "spawning ground" phenomenon in locations near national research centers, and the nature of firms predominantly active in each 
product market. Chapter 3 focuses on the institutional parameters affecting competition in the international marine electronic instrumentation business, describing the components of U.S. domestic "industrial policy" (especially those that influence R\&D in the high technology marine electronic instrumentation field) and the conditions of international trade (including export controls and nontariff barriers to trade). Among the most important factors affecting high technology industries are the characteristics of the pathways by which technology is transferred from its source and the extent to which governments accelerate or slow this flow of technology in the interest of "competitiveness" (Guile and Brooks, 1987). Accordingly, Chapter 3 presents a preliminary discussion of the pathways by which MEI technology is transferred among industrial sectors and nations. Chapter 4 briefly presents the principal conclusions of this study. The appendices list the products, U.S. companies, and foreign companies used in the analysis, as well as categories of items subject to U.S. export controls, acknowledgements, and references. 


\section{A Structural Overview of the U.S. Marine Electronic Instrumentation "Industry"}

\subsection{Industrial Organization Analysis.}

Before we present our findings on the structure of the U.S. marine electronic instrumentation "industry," it is useful to review briefly the basic concepts of the structural analysis of industries in general, and point out some of the difficulties and caveats associated with the application of such an analysis to marine electronic instrumentation.

\subsubsection{Introduction and Basic Concepts. Traditionally, industrial} organization economists have employed a "structure-conduct-performance" framework to analyze the way an industry is organized and how its organization is likely to affect competition among its members and its ultimate efficiency and service to customers. The motivating idea for this approach is that structure--consisting of the number and size distribution of producers and customers, the extent of product differentiation, conditions of entry, and the degree of vertical and conglomerate integration--shapes industry conduct, which, in turn, determines the industry's performance. Conduct refers to the behavior of firms in the industry in such areas as pricing, overt or tacit cooperation among producers, capacity formation, product and technology selection, research and development (R\&D) commitments and direction, legal and regulatory tactics, etc. The principal elements in an industry's performance are the extent to which price reflects the cost of production (and particularly the last unit that consumers are willing to buy "at cost") and the degree to which the industry is technically progressive in developing and implementing more efficient modes of production.

The expected influence of industry structure on conduct and performance is fairly straightforward and well-understood in the limiting cases of monopoly and pure competition in mature industries. But in the more often encountered smallnumbers case or one of its variants, the theoretical expectations become more muddled and likely behavior more complex. The situation is complicated further when the industry is newly-emergent or in a dynamic state of development and when national governments intervene in pursuit of extra-commercial goals.

Problems encountered in attempting a conventional static structural approach to such complicated cases have led to increased emphasis on the dynamics of industry behavior and the evolution of industry structure over time. In this more recent work, firms engage in strategic behavior that is explicitly intended to anticipate and/or influence the behavior of other firms. Industries are often 
treated as composed clusters of firms or "strategic groups," occupying similar niches in the industry or engaged in similar competitive strategies. Thus, the somewhat static view of industrial organization afforded by conventional studies of industry structure has been enriched by the emergence of a new theoretical and analytical literature addressing exactly such questions as:

- what factors determine the emergence of new industries and shape the evolution of their structures

- what are the contexts in which strategic motivations and behavior are most likely

- how strategic motivations and behavior can affect the competitive play in a market and dynamic characteristics of the market's performance

- what are the effects of various forms of govermmental involvement on competition over time and on the development of industry structure

- and what are the factors determining the intensity and distribution of research and development (R\&D) effort and subsequent innovation.

2.1.2. Applications to Marine Electronic Instrumentation. The marine electronic instrumentation industry lacks clear boundaries and does not lend itself easily to distinct identification and definition. Strictly speaking, the field of marine electronic instrumentation manufacturing is best viewed as a group of related and overlapping industries rather than as a distinct industry defined by a high cross-price elasticity of demand for its members' various outputs. Because of a common operating environment, shared technical problems, mutual entry capabilities, overlapping customer pools, and professional linkages, however, it makes sense for our purposes to treat these industry groups as a loosely-defined single industry.

Much of the data we have gathered on these firms are preliminary or approximate. Existing sources of data, such as those collected and published by the Bureau of census and the International Trade commission, are of limited use because, in most cases, they are not organized to generate data specifically on marine electronic instruments. The lack of previous systematic studies of marine electronics firms probably is due at least in part to the lack of a cohesive, well-defined "industry" that encompasses all marine electronics. For whatever reasons, it has become clear that our study is the first concentrated effort at a comprehensive economic analysis of this field. 


\subsection{Overview: Firms Serving the Marine Electronic Instrumentation Markets.}

As discussed in Chapter 1, the market for marine electronic instrumentation can be divided for heuristic purposes into four end-use sectors: (1) the military, (2) offshore oil and gas, (3) recreational and commercial shipping and boating, and (4) scientific and oceanographic activities (including "environmental monitoring"). To some extent, marine electronic instrumentation firms can be distinguished or grouped by the end-use sectors that they serve. As we will show below, these firms can further be distinguished by the product types they produce for or within their end-use sectors. By examining the companies' activities in both dimensions simultaneously, we are able to distinguish several rather distinct groups of firms serving the marine electronic instrumentation markets. The discussion in the following sections is organized by these groups of firms.

2.2.1. The Product and End-Use Sectors. The various products which marine electronic instrumentation firms produce can be grouped into five major categories:
(1) sensors,
(2) data management products,
(3) "support" products, (4) services, and (5) large military systems. "Sensors" are the tools which work in and around the marine environment to extend the human senses and generate observations and raw data. "Data management products" include items that transmit, store, and manipulate the data generated by the sensors. "Support products" are navigational and communication tools that are not so much an end in themselves, but are used in support of other marine activities, such as carrying cargo from one place to another, or maneuvering an ROV toward an oil pipeline. "Services" encompass the activities of firms that do not necessarily generate physical products, but instead help in the design or evaluation of products, or use such products to conduct marine surveys, to precisely position an offshore platform, etc. "Large military systems" merit a category of their own; although they usually consist of sensors, data processing, and/or support components, they differ from other marine electronic instrumentation in their size, scope, and mission, as well as in the nature of the firms that produce them. (See Appendix A for a listing of marine electronic instrumentation products under each of these categories.)

Many of the products comprising marine electronic instrumentation are used in two or more of the four end-use sectors. This situation is illustrated by Figure 20, which depicts the four end-use sectors (while not exactly to scale, the circles do illustrate the relative sizes of the end-use sectors) and gives a 
qualitative idea of their overlapping product coverage. For instance, simple

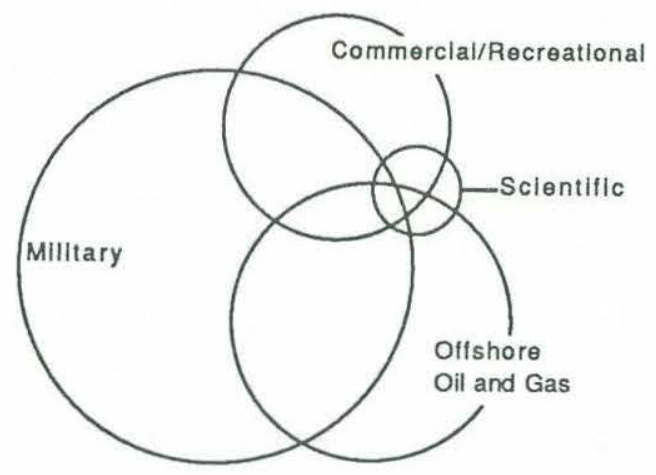

Figure 20: Overlapping End-Use Sectors in Marine Electronic Instrumentation.

acoustic transducers are likely to be found at the intersection of all four circles, since they are part of many marine instruments. Specialized marinegeophysical instruments might be found in the intersection of the Scientific and offshore oil and Gas sectors, while fishfinders would probably exist only within the Commercial/Recreational field. Taken individually, the end-use sectors and the product types do not point to any clear-cut or convenient break-down of the firms serving the marine electronic instrumentation markets.

2.2.1.1. Major Groups of Firms. The inter-meshing of end-uses and product types is better resolved by the illustration in Figure 21 . In this figure, the end-use sectors and product types (minus "military systems") form a grid. Any firm serving the marine electronic instrumentation markets can be characterized by its coverage of certain parts of this grid, depending on its line of products and its range of customers.

We have found that the great majority of firms active in marine electronic instrumentation fall into one of four kinds, as indicated in Figure 21 . One group of firms are those that traditionally consider themselves to be in the "oceanographic," "environmental monitoring," or "offshore energy" business. These are characterized in Figure 21 as "shops" because of their characteristic "garage shop" origins and their relatively small typical size. A second group are large military systems contractors; these are frequently divisions of even larger, diversified companies, and focus narrowly on military and/or large energy-related systems. A third group are those traditionally referred to as "marine electronics" firms: companies serving the commercial and recreational markets 


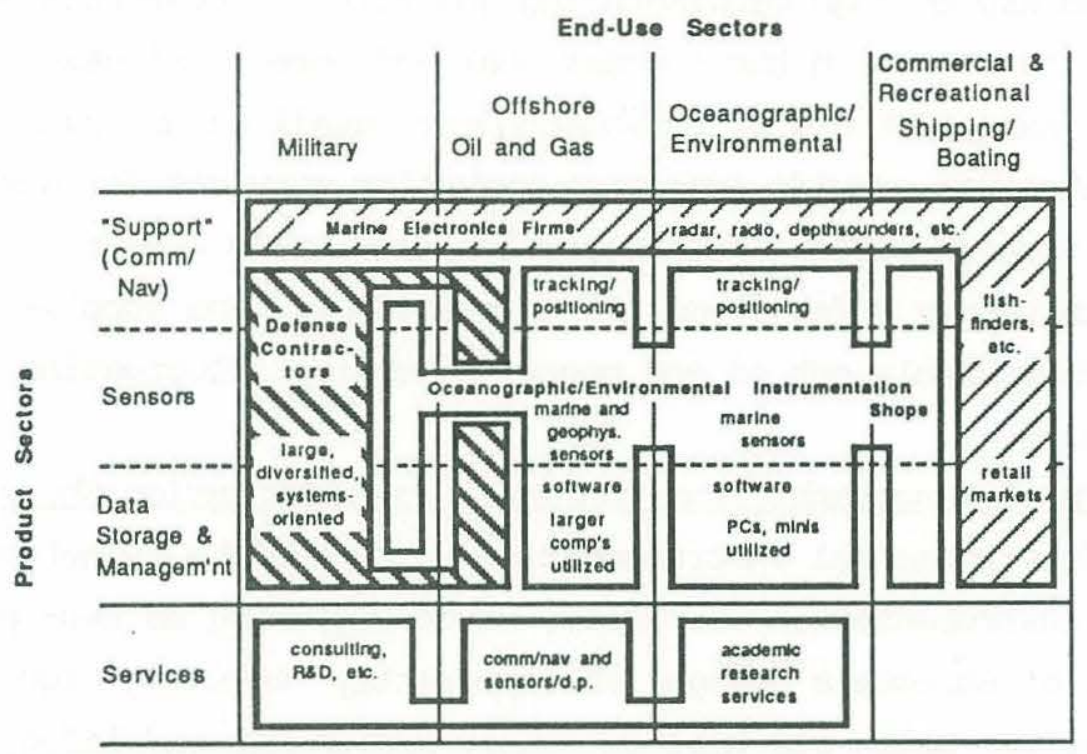

Figure 21: The Four Marine Electronic Instrumentation Industry Subgroups. The "Military," "Marine Electronics," "Instrumentation," and "Service" subgroups are shows as geometric blocks, indicating by their shape and extent the combination of products manufactured and end-use sectors served.

for marine navigation and communications products. Finally, there are the service firms, shown in Figure 21 as three semi-distinct sub-groups: those specializing in military consulting and R\&D, those focused on the offshore oil and gas business, and those specializing in academic research. Each of these groups is discussed in more detail in the sections that follow.

Some general remarks can be made about the "industry" as a whole. With some variations by the sectors served, the marine electronic instrumentation industry is generally very competitive both in its structure and its behavior. Among the broad array of product lines represented, firms do tend to seek out differentiated niches or specialties, but there are only modest barriers to mobility across product lines. A relatively few firms dominate supply of largescale systems development for military applications, but sales to most end use sectors are fairly broadly-distributed across a number of small and medium-sized firms. Minimum efficient scale of operations in the industry appears to be low (though there may be unrealized economies of scale in both R\&D and manufacture) and barriers to entry and exit are, for most product lines, de minimis. Most firms in the industry offer a range of products and tend to be vertically- 
integrated from R\&D through manufacturing and sales; over-the-counter retail sales are important only in the recreational and conmercial shipping and boating sector and are handled there by an independent retail sales industry. Independent sales representatives provide important marketing services for most firms, especially in foreign sales. Demand for the industry's output is relatively thin, in the sense that only a few items are mass-produced, and suppliers tend to deal with a relatively stable set of end users who exhibit fluctuating levels of product demand.

2.2.2. The Oceanographic/Environmental Instrumentation Shops. The oceanographic/envirommental instrumentation shops are the archetypical oceanographic instrumentation companies, often beginning as two- and three-man operations out of someone's garage, and apparently "maturing" (on average) at an annual sales volume below $\$ 10$ million (their beginnings and lifecycles are described further below). These firms serve most significantly the scientific/academic communities (research institutions, environmental monitoring, etc.) and the offshore energy exploration business. (A market study performed by the Florida State University as part of the marine electronic instrumentation project (Woodsum, 1988) indicates that marine pollution monitoring is by itself a significant end-use sector). Their expertise is in the design and construction of sensors (hydrographic, biological, geophysical, etc.) which they often combine with data transmission and storage devices to assemble complete "data acquisition" systems. An increasingly important element of this business is the development of data analysis software, which is usually run on standard (occasionally "ruggedized") PCs or minicomputers.

Firms in this category may sell predominantly to one or more of the end-use sectors. As indicated in Figure 21, their major business is in the offshore and scientific fields, with less significant sales volumes in the military and commercial/recreational sectors. The element that "ties them across" the different end-use sectors is sensor technology -- perhaps the central and primary element of oceanographic/envirommental monitoring instrumentation. Few shops produce only the sensors (this is more frequently done by divisions of larger manufacturing firms, which make sensors or parts thereof); most combine them with some data management scheme, and a few extend their line of products into the "support" area with (usually acoustic) tracking and positioning systems, or electronic charting systems. On the other hand, a few firms specialize in the 
data processing aspects of oceanographic systems, and do not produce any sensors. This is also usually done by larger, information-systems firms for which the marine applications are only one of many lines of business.

The recent sales of ROVs, and the associated tracking/positioning technologies, to both the military and the commercial fishing sectors illustrates the adaptability of these firms in following changing market conditions. For further discussion of the inter-sectoral transfer of technology in ROVs, see Chapter 3.

U.S. firms in this group obtain substantial shares of their revenues from foreign sales (on the order of 50 percent). Independent sales representatives play a significant role within the U.S., and an even more significant role overseas. A strict, tacit respect for each others' market areas and client relationships exists among the relatively small number of U.S. reps in this business. The North American market can be divided into seven distinct sales areas, listed here with the approximate number of reps in each area: California and Hawaii (5 reps), Pacific Northwest (3), Gulf of Mexico (6), Washington DC (3), New York (1), New England (3 to 4), and eastern Canada (1). Foreign representatives tend to be more numerous and are usually specific to the country in which they do business.

Trade associations play a role mostly in the dissemination of technical information. The Marine Technology Society (MIS) is the predominant U.S. trade association for this line of business; many engineers within these firms are also members of IFEE. The Society for Underwater Technology (SUT), based in England, is the European counterpart to MTS, with a more international scope.

The industrial organization of the oceanographic/environmental instrumentation group may be summarized qualitatively using the structure-conductperformance convention. The product market consists largely of sensors, data storage/processing and tracking and positioning instruments. Geographically, the market is international, with some national and even regional segmentation. On the demand side, the market is thin and consists almost entirely of users who are professionals in scientific, environmental monitoring, offshore exploration, and military applications. Structurally, this group consists almost entirely of a moderate number of small firms which specialize in various niches. This may be described as a competitive, or more aptly (because of niches) monopolistically competitive, structure. Entry is easy, there is only limited vertical integration 
and very little conglomerate integration. In terms of conduct, pricing is competitively constrained, there is extensive niche-seeking, patents are rarely employed, joint ventures have been rare, and independent sales representatives play an important role in marketing. Customers can expect this industry structure and conduct to keep price at competitive levels, but technological progressiveness in this group appears to be surprisingly modest. The last observation, however, requires further study.

2.2.2.1. Spawning Grounds and Lifecycles. In the United States and in several European countries, the instrumentation shops are geographically clustered around academic institutions that are active in marine research. Figure 22 shows a map of the United States with circles representing the number and concentration of oceanographic/envirommental monitoring firms. The

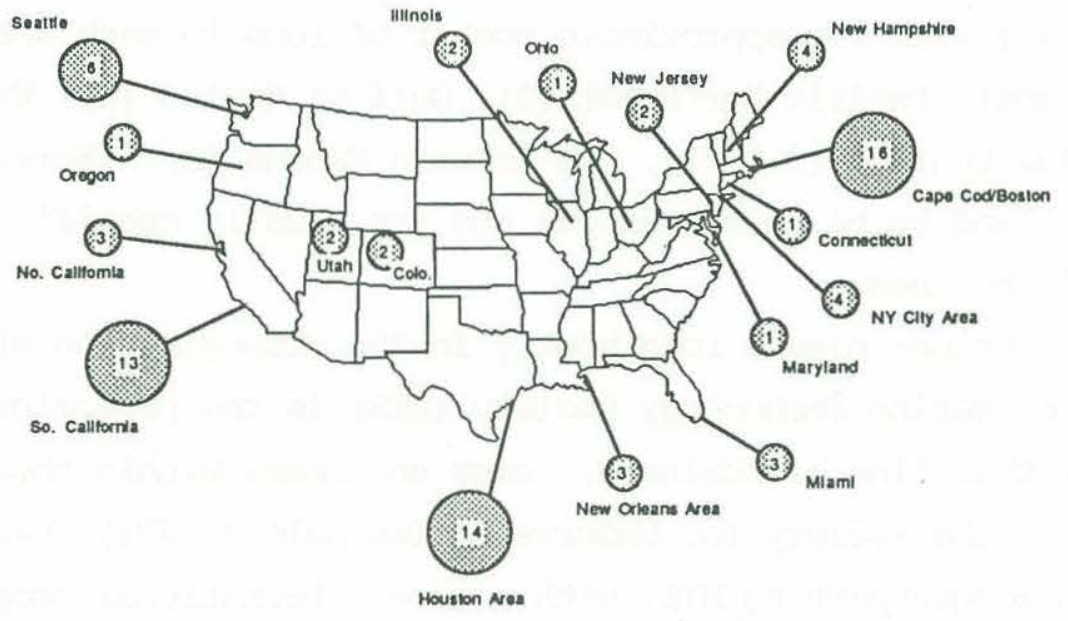

Figure 22: Geographic Distribution of Marine Scientific Instrumentation Firms in the U.S., showing the "spawning ground" phenomenon near Boston, Houston, San Diego, and Seattle.

clustering effect around major centers of marine research is clearly evident: large concentrations of firms are found in eastern Massachusetts (Woods Hole Oceanographic Institution, Boston-area universities), in the Houston area (Gulf of Mexico offshore, plus several universities active in offshore research), around the Scripps Institution of oceanography in southern California, and around the University of Washington in the Seattle area. These firms are commonly founded by engineers working at such institutions (or at another "garage" shop), who detect the need for a non-available instrument or find a new design or production 
technique that shows economic promise. Start-up costs typically are low, perhaps as little as $\$ 25,000$. Research and development work may be supported by research project funding through the academic institution, an SBIR grant, or other sources. The proximity of an academic institution can also aid in initial marketing of the product and in gaining its acceptance by the wider user community.

After one or two "original" products, these firms will often begin to diversify into "standard" product lines already being manufactured by others, in an attempt to gain market share and boost revenues. Because of the limited markets for oceanographic products, total growth potential is limited, and firms tend to find niches in particular product lines on which they concentrate their efforts. Growth may also be limited by the managerial and marketing expertise of the founding engineers. If one of these firms does become large and successful, it begins to attract attention and is generally sold to/bought by a larger electronics or defense firm, of which it then becomes a division or subsidiary (examples: Neil Brown, Sippican).

2.2.3. The Conmercial "Marine Electronics" Firms. This sector is the only one in marine electronic instrumentation that can claim some sort of "mass markets" and true high-volume production runs. Not surprisingly, it is also the only one in which Japanese competition appears to be a somewhat serious factor for U.S. firms.

Recreational and industrial/commercial marine radios, radar systems, radio direction finders, Loran receivers, GPS receivers, weather fax machines, depth sounders, speed indicators, and similar products represent a strong market, especially in the U.S. where total recreational boating expenditures continue to climb (see Figure 12). The U.S. firms involved in this business are, as a rule, larger than the oceanographic/envirommental instrumentation shops, selling in the tens of millions annually; occasionally, they are divisions or subsidiaries of electronics giants. In recent years, several large electronics firms attempted to enter this market with marine electronics divisions (examples include King, Motorola, Mars, and Texas Instruments), but most of these attempts have been unsuccessful.

The area where the products of these "support" oriented firms most closely resemble those of the oceanographic shops (and where their sales may occasionally overlap) is in fishfinders and related, acoustic-based instruments. However, the differences in customers, marketing, packaging, and production volumes between the 
consumer marine electronics sector and the scientific/offshore field is so large that no firms appear to "straddle" the boundary in any significant way. As in the oceanographic/environmental instrumentation business, the most successful marine electronics firms appear to specialize in particular niches of the market.

Japan's Furuno and the United States' Raytheon are leaders in the recreational and commercial radar business; Raytheon supplies most of the larger vessel radars. Stephens Engineering Associates (now owned by Datamarine) is a leader in side-band radio, while Japan's ICOM is a strong force in the VHF radio sector. Loran navigation equipment is supplied by both U.S. and Japanese firms.

Digital depth and speed instrumentation is largely the province of U.S. manufacturers. Fish-finders, a more sophisticated variation on the depth sounder, represent a major part of the U.S. market in marine electronics: inland bass-boat sales alone account for as much as one quarter to one third of the U.S. market in retail marine electronics. Largely because of the preferences of these inland bass-boat customers, who are concentrated in the American heartland and in the South, Japanese firms have not been able to make any inroads into this lucrative market sector. Two well-positioned U.S. companies, Lowrance and Huminbird, completely dominate this niche.

Marine electronics firms use in-house sales staff and independent reps, who deal with as many as 300 distributors nationwide. These distributors in turn pass the products along to thousands of marine shops, boatyards, and waterfront marinas. Foreign sales are usually handled through appointed importers and distributors in the client nations. Foreign sales percentages are not as high here as they are in the oceanographic sectors, on the order of 10 percent; the principal customers are Europe, Australia/New Zealand, and South and Central America (including the Caribbean nations).

The National Marine Electronics Association (NMEA) serves as a trade association for both manufacturers and dealers in this business, and is active in the gathering and dissemination of both technical and marketing information.

Here, we qualitatively sumarize industrial organization in the marine electronics group. The product market includes certain sensors, data storage/processing, and communication/navigation support instruments. The market is international but dominated by sales in developed economies and strongly segmented by nationality in some product lines. The demand side is a broad and dispersed market based largely on over-the-counter retail sales. Structurally, 
there are a smaller number of somewhat larger firms offering moderately differentiated products. Overall, this structure is purely competitive, though some firms do dominate certain product lines. Barriers to entry are low, there is limited vertical integration and a moderate degree of conglomerate integration. Pricing conduct appears to be competitive, patenting strategy is rarely employed, there is distinct niche seeking, little effort at joint venturing in R\&D and manufacture, and marketing is mainly through well-established retail networks. Subject to some sporadic or local strategic retailing behavior, prices can be expected to approximate costs, and there appears to be moderate technological progress.

2.2.4. The Large Military Contractors. As a rule, the producers of large military systems for the Navy are $\$ 100$ million-plus divisions of multi-billion dollar high-technology defense contractors, which are often also involved in aerospace work. These divisions tend to deal exclusively with the military, and the size and complexity of their products makes it virtually impossible for smaller firms to enter into direct competition with them. Their significance for the small instrumentation shops lies in subcontracting, not in direct or indirect competition.

Figure 23 shows the wide geographic distribution of U.S. military contractors in the marine electronic instrumentation (systems) business. Some clustering occurs in the Northeast and in southern California; and many of the names are familiar members of the general defense, aerospace, and electronics communities.

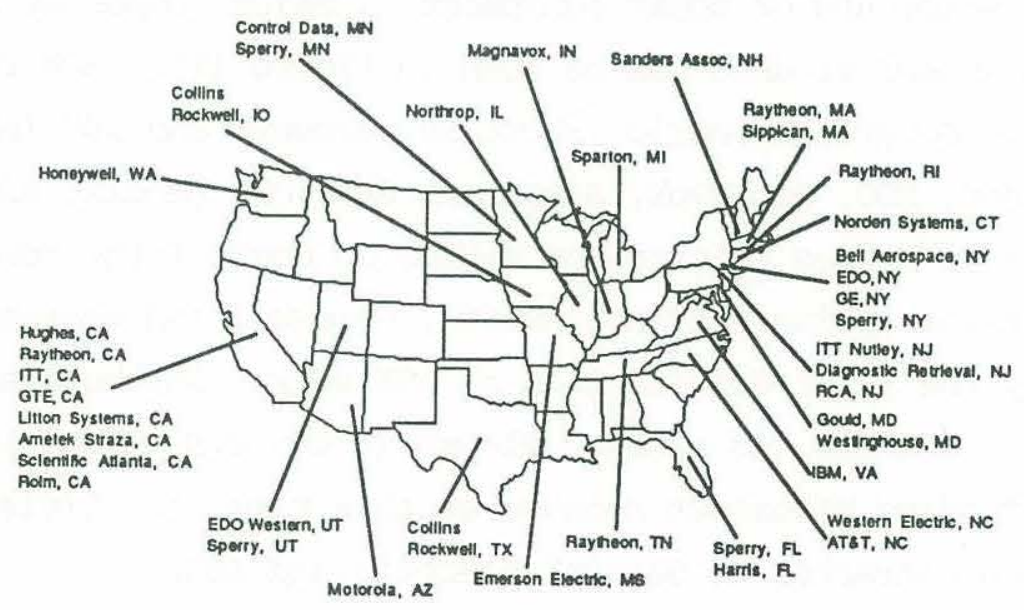

Figure 23: Major Defense Contractors Supplying Marine Electronic Instrumentation in the U.S. Adapted from Rowden (1987). 
Contracts for major systems are awarded by competitive bidding procedures; this process is complicated by the relatively small number of capable military systems contractors that can be sustained by defense business. Because the Department of Defense appears to be moving away from a policy of contracting parts of a large system to various firms, and instead is seeking single prime contractors to manage the entire project, with overall integration responsibility for a particular system, the "competitors" in the defense market increasingly are teaming-up to bid on large contracts. The stakes in this game are gigantic; major system contracts come up in cycles of only ten to twenty years. Those firms that do not win a prime contract must therefore attempt to work as subcontractors to the winning teams (see: section 3.1.5. below). This "teaming" is expected to becomeeven more significant in the future, and soon may extend past national boundaries. An ongoing Commerce Department study is predicting little or no growth in the defense electronics field through the end of this decade, and an anticipated shakeout in the world military electronics business has industry representatives from many nations pursuing the idea of increased international "collaboration" (NNUT, 19 Sept. 1988).

One class of defense electronics that is expected to remain well-funded in the future is also the biggest class of sales in the marine electronic instrumentation field: anti-submarine warfare (ASW) systems, which make extensive use of marine electronic instrumentation, and integrated navigation/communication/battle management systems. Figure 24 shows graphically the trends in U.S. shipments of sonar equipment, a major component of ASW systems (the corresponding numerical data can be seen in Figure 17). ASW funding in the U.S. is dominated by General Electric (about 50 percent) and IBM (about 25 percent), with Hughes, EDO, Magnavox, Sippican, Sparton, Bendix, and the Canadian Commercial Division of Hermes Electronics making up most of the remainder. These percentages only reflect prime contract awards, however, and consequently do not indicate accurately the final distribution of ASW work. Raytheon's Submarine Signal Division, for example, is a major player in the U.S. ASW market, but does not appear in the funding breakdown because at this time, the Division does much of its work as a subcontractor to General Electric and IBM.

ASW, and military marine electronic instrumentation generally, is also an international business; some U.S. defense contractors export as much as 25 percent of their products to foreign navies. England, France, and West Germany 


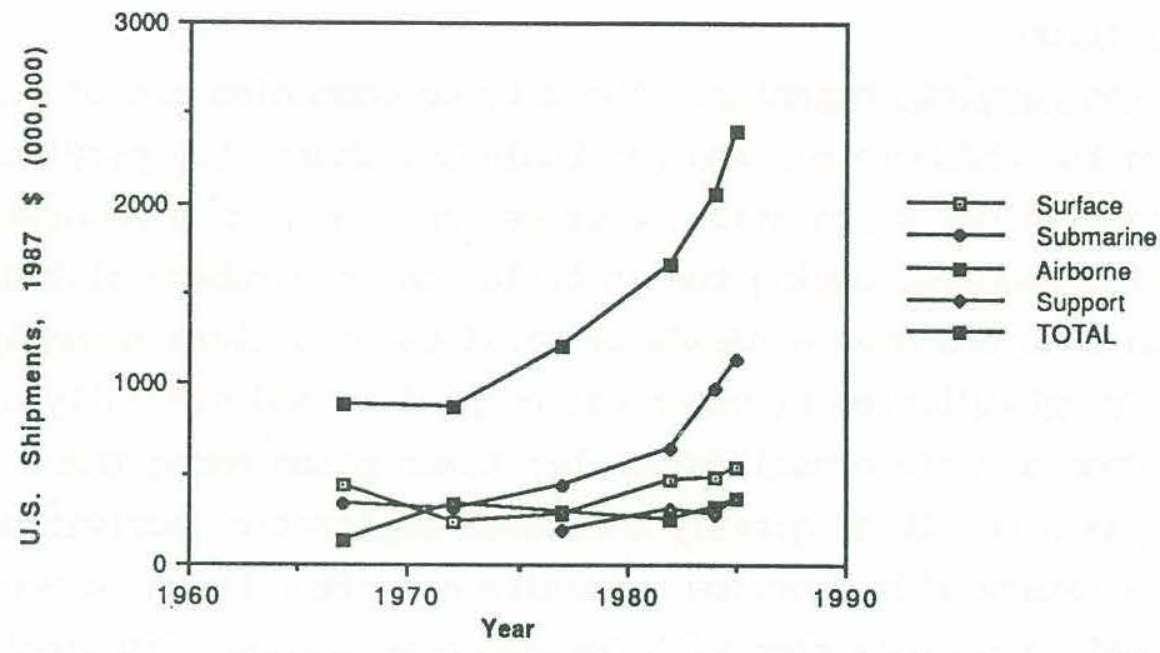

Figure 24: U.S. Shipments of Sonar Products, 1967-85, in millions of 1987 dollars. Source: Bureau of the Census (Aug. 1986).

are among the top international competitors in the ASW business; the leading players include Thomson (France), Plessey and Ferranti (England), and Krupp (Germany). Sales of military electronics instrumentation to foreign customers often proceed under Foreign Military Sales (FMS) procedures (see: section 3.1.5. below).

The industrial organization of the large military contractor group thus is distinctly different from the previous two. Here the products are highly complex and sophisticated, typically unique, electronic systems purchased in huge lumps (requiring multi-year development and production time) on an intermittent and infrequent basis by a single (DOD) or small number (foreign navies) of dominant customers. Not surprisingly, the structure of this group is quite concentrated, with a small number of giant organizations sharing the market as rivals, subcontractors, and sometimes partners. Structurally, this is an oligopoly. The product is highly differentiated, typically customized. Barriers to entry are moderate to high, vertical integration is moderate, and conglomerate integration, while not always pure, is moderate to extensive. In terms of conduct, pricing is complex and expressed through complicated small-numbers bidding on large contract offerings. Patents do not play a major role in this group's conduct. Joint ventures of various kinds are relatively common and increasing through teaming on contract bids. Price may be expected to include a premium over marginal cost. 
Technological progress is quite rapid in product evolution but more modest in process innovation.

2.2.5. The Service companies. The service companies are of particular importance in the offshore oil and gas business, where they provide hydrographic and marine-geophysical exploration services, and the highly accurate navigation and positioning required during the installation of offshore platforms. Sales volumes reach tens and even hundreds of millions of dollars annually. These firms are frequently subsidiaries of major oil companies, and generally operate all over the world. Considerable consolidation has taken place among these firms in the recent past, as a result of greatly decreased exploration activities.

On the military side, service companies are often known as "contract R\&D shops," and maintain close ties with defense contractors. "Academic" service firms include environmental consulting companies and instrument or data acquisition system design consultants.

2.2.6. Overlaps and Interrelationships. While the four industry groups described above capture most of the marine electronic instrumentation market, there are undoubtedly some exceptions that do not fit into this classification scheme. Determination of the approximate extent of overlap between these groups, and further elaboration of the market interrelationships between them, require more investigation.

\subsection{Key Aspects of the Marine Electronic Instrumentation "Industry".}

Three key elements that shape the nature of competition and competitive/comparative advantage in this field warrant separate attention. These areas are briefly described in the sections below, and motivate the more detailed discussion of institutional parameters that follows in Chapter 3.

2.3.1. Importance of Govermment Involvement. One of the most important factors affecting the competitiveness of firms in the marine electronic instrumentation field is the involvement of governments. An outstanding example is the development of the GLORIA sidescan sonar system, which was funded by the U.K. Department of Trade and Industry. Described as a "worldbeater" in part because no comparable technology was available from private firms (including those in the United States), GLORIA has been leased by the U.S. Geological Survey to conduct a comprehensive survey of the U.S. Exclusive Economic Zone (Senior, 1987). Through their procurement ("buy-national") policies, variable interpretations of 
international export controls, different levels of enforcement of intellectual property rights, import licensing delays, and other actions, governments do, in fact, have a substantial influence over international trade and the flow of technology in marine electronic instruments. This influence clearly has an effect on the competitive position of MEI firms in an international marketplace, and we focus on such govermment policies in chapter 3.

An important area of government influence concerns investment in R\&D. In the United States, a major portion of R\&D support for MEI originates from the Navy. Private firms conduct their own R\&D as well, and a preliminary survey has indicated that this investment is comparable to other high technology firms (KitePowell, 1988). Some current issues for public policy concern include an apparent trend for shifting risks for defense-oriented independent R\&D from the govermment onto private defense contractors; determining the effectiveness of transfer of technology developed with government support from national laboratories, universities, and nonprofit research institutions into the commercial sector; and understanding the impact of relaxations in antitrust policy, the institution of tax preferences for research, and other changes in domestic "industrial" policy. Furthermore, several foreign govermments encourage R\&D in marine electronic instrumentation, and this encouragement has the potential for affecting the competition in both foreign and domestic markets. of particular interest are the activities of the following: Japan's Ministry of International Trade and Industry (MITI) and Marine Science and Technology Center (JAMSTEC); the French Institute for Research and Development of the Sea (IFREMER); the Norwegian Council for Scientific and Industrial Research (NTNF); EUROMAR--a EUREKA project proposed by the West German Ministry for Research and Technology; and the United Kingdom's new Coordinating council for Marine Science and Technology.

\subsubsection{Importance of the International Nature of Trade in Marine Electronic} Instrumentation. Competition and trade in marine electronic instrumentation are largely international in nature. Two key aspects of the business explain why this must be the case. The world-wide homogeneity (in very general terms) of the marine enviromment means that an instrument designed for ocean use can be deployed in any number of locations throughout the world. At the same time, the high technology nature of these instruments implies limited geographic distribution of manufacturers, and high ratios of product value to transportation costs. Government data and discussions with members of the industry confirm the 
significance of international trade in this business, which can account for more than half of some U.S. firms' sales and which appears to be on the increase, especially in the military sector.

2.3.3. Importance of R\&D and Inventiveness. Because most of the products comprising marine electronic instrumentation can be characterized as "advanced technology," the R\&D intensity and the rate of inventiveness and innovation are particularly important to the success of firms in this industry. The levels of R\&D spending among U.S. marine electronics firms tends to vary with sales (Figure 25) and range from about 7 to 9 percent of sales. This has been found to be comparable to equivalent measures in other high technology industries, such as communication equipment and professional and scientific equipment (Kite-Powell, 1988). While competition and user demands push for rapid innovation and adoption of new technologies, the "frontier" nature of the marine environment and the

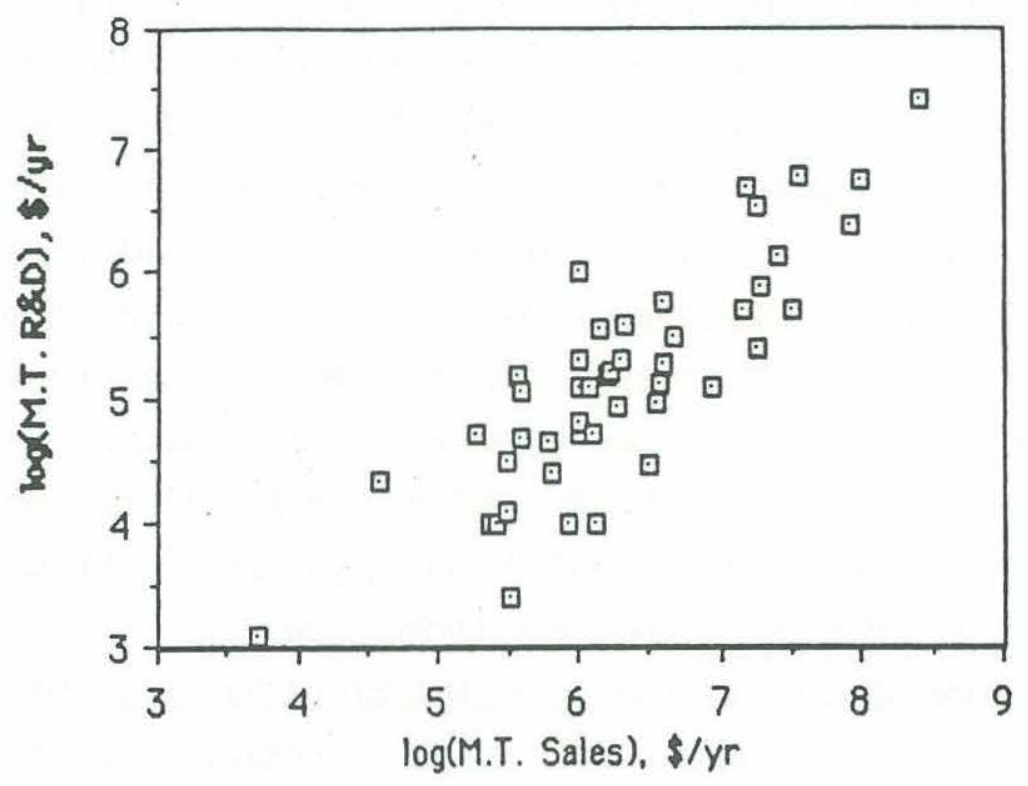

Figure 25: R\&D Expenditures as a Function of Sales Volume for Marine Electronic Instrumentation Firms. Note that both axes show log values. "M. T. refers to the "marine technology" share of sales and R\&D, respectively, for those firms that also engage in other lines of business. Source: Kite-Powell (1988).

premium on reliability at the same time seem to call for a relatively cautious, incremental kind of product evolution. The result appears to be a more gradual 
pace of product evolution and new technology adoption than is evident in most "land-based" high technology industries. Confimation of this observation, however, requires further study as do its implications for the pace of advance in ocean science and resources development. 



\section{Institutional Parameters Affecting Competition in Marine Electronic Instrumentation}

Among those factors that affect the performance and competitive position of MEI firms, some of the most important are institutional ones, namely incentives or restrictions on R\&D, production, and domestic and international trade. Broad national and international policies govern research, production, and markets for most manufactured goods, and specific policies govern either MEI or individual goods and services in the MEI industry (PCIC, 1985). These policies include domestic "industrial" policy, such as the protection of intellectual property, business and income taxation, and antitrust policy, and policies affecting international trade, such as export controls and import restrictions.

Other policies specific to marine electronic instruments include government investments in R\&D, "buy-national" procurement rules, validated export license determinations for controlled items, and nontariff trade barriers (such as govermment funding of development costs of technologies competing in world markets), among others. For example, two U.S. federal statutes include statements of policy that specifically encourage the development of marine electronic instruments. (However, neither statute has been used in the recent past for the purpose of subsidizing or even promoting the U.S. marine electronic instrumentation field.) The Marine Resources and Engineering Development Act of 1966 [P.L. 89-454], which authorized the Stratton Commission study of 1969, was enacted to "encourage and maintain a coordinated, comprehensive, and long-range national program in marine science."1 one of eight specific objectives set out in the Act for marine science (defined to include engineering and technology in the marine enviroment) calls for the development and improvement of marine instruments, particularly for oceanographic research and resource exploration and recovery. 2

A second statute, enacted eight years later in the wake of the oil price hikes, the Solar Energy Research, Development, and Demonstration Act of 1974 [P.L. 93-473], was enacted primarily to promote the development of solar power technologies. One part of the Act required the Chairman of a "Solar Energy coordination and Management Project" to assess solar energy "resources," including the collection of data on insolation, wind, ocean thermal gradients, and

133 U.S.C.A. 1101 (a) (1982).

233 U.S.C.A. 1101 (b) (3) (1982). 
photosynthetic conversion. The specific goals of the resource assessment program were to include:

- . the development of advanced meteorological, oceanographic, and other instruments, methodology, and procedures necessary to measure the quality and quantity of all solar resources on periodic bases. 3

Although the policy goals set forth in these legislative enactments have been largely ignored in recent years, the importance of marine electronic instrumentation to the advance of knowledge and to progress in all ocean sectors remains clear. Furthermore, the competitive position of U.S. firms in the MEI field can be affected significantly by a wide array of government policies and actions. Here, we present summaries of such national and international policies. We conclude with a preliminary analysis of the pathways through which MEI technology is transferred from its origins to U.S. and international markets and across marine sectors.

\subsection{Domestic Industrial Policy}

3.1.1. Govermment-sponsored research. In the United States, R\&D for marine electronic instruments is conducted by both the public and private sectors. Some of the private sector R\&D is performed under contract to public agencies. It is difficult to break out funding specific for marine electronics from either sector. For federal agencies, we have conducted a limited telephone survey to identify federal agencies that conduct programs involving either R\&D or the use of marine electronic instruments. To the extent feasible, we have been able to obtain rough estimates of R\&D spending for the current fiscal year (1988) on marine electronic instrumentation (Figure 26). our extremely rough estimates place total federal R\&D spending on MEI at approximately $\$ 500$ million annually.

3.1.2. Navy Research. Historically, the Navy has been the primary government source of funds for R\&D in marine electronics, beginning with the investments in radio and radar at the turn of the century, sonar during World War II, and other technologies. Until 1950, when the National Science Foundation was created, the Navy funded the majority of govermment marine electronics research (including MEI)

342 U.S.C.A. 5554 (a) (2) (1982). 


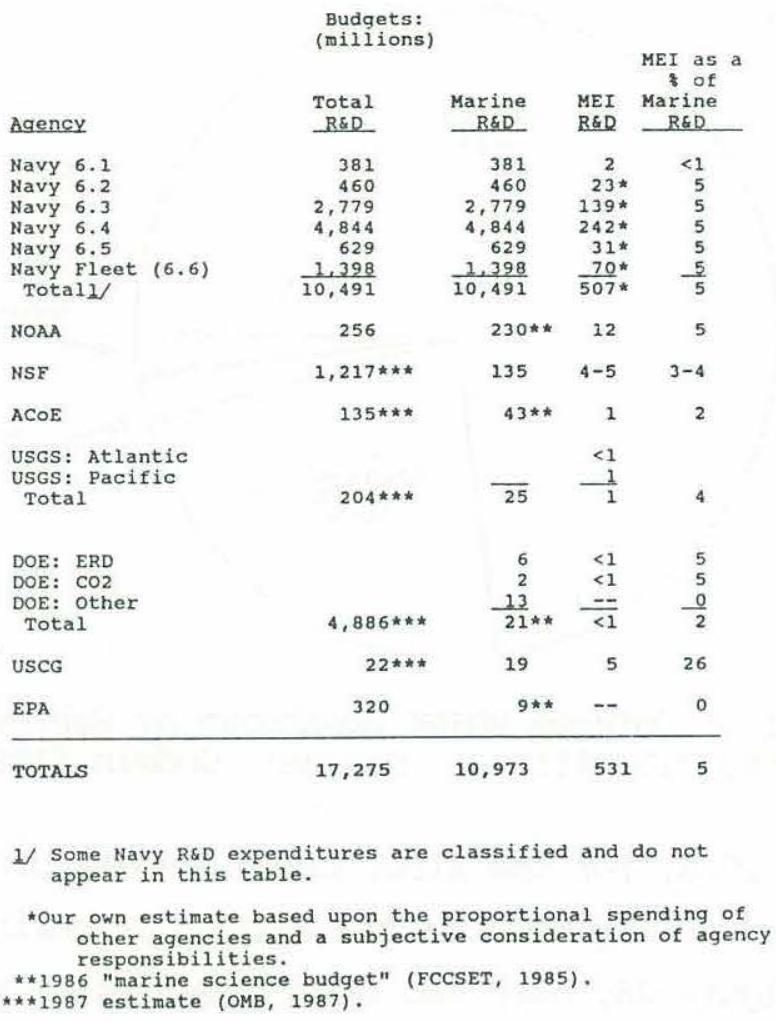

Figure 26: Agency R\&D Budgets for Marine Electronic Instrumentation, 1988 estimated. Source: telephone interviews with goverrment officials.

and other marine technologies at private firms, national laboratories, universities, and independent research institutions (Allison, 1985). As a rough approximation for the Navy, Figure 27 shows the current distribution of total DoD research budget among these research performers. In general, independent oceanographic institutions and universities tend to conduct basic scientific research, while the Navy labs and private firms are involved to a greater extent in the exploratory development, prototyping, and advanced testing stages. 4 Although the Navy still funds a substantial portion of basic research under 6.1 and 6.2 monies, NSF and NOAA have now also assumed major funding roles in this

4 There are many exceptions to this general rule. For example, the development of a "forward deployed sensor system" for Navy submarines at WHOI might be considered "exploratory" (6.2) to "advanced" (6.3) development work (NNUT, 5 Sept. 1988). Conversely, there are many projects sponsored by the Navy laboratories that are purely theoretical, and thus arguably categorized as "development of the knowledge base" (cf., NORDA, 1986). 


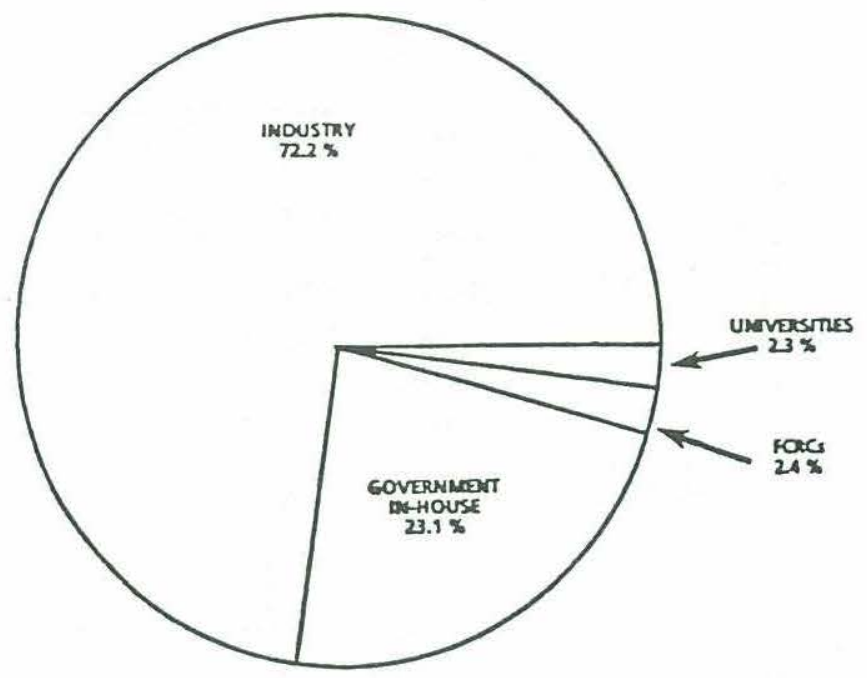

Figure 27: Department of Defense RDT\&E Breakdown by Performer, FY 1988. 1988 total is $\$ 43,719$ million. Source: Godwin (1987).

area. In fiscal year 1988, for the first time, a small program (\$400K) using 6.1 monies, was established solely for the development of marine instrumentation.

As depicted in Figure 28, Navy R\&D is divided into six categories (McCarthy, 1987; USN, 1985). Navy research is more properly referred to as research, development, testing, and evaluation (RDT\&E), because approximately 90 percent of defense research cannot be characterized as basic science (NSF, 1988). Figure 11

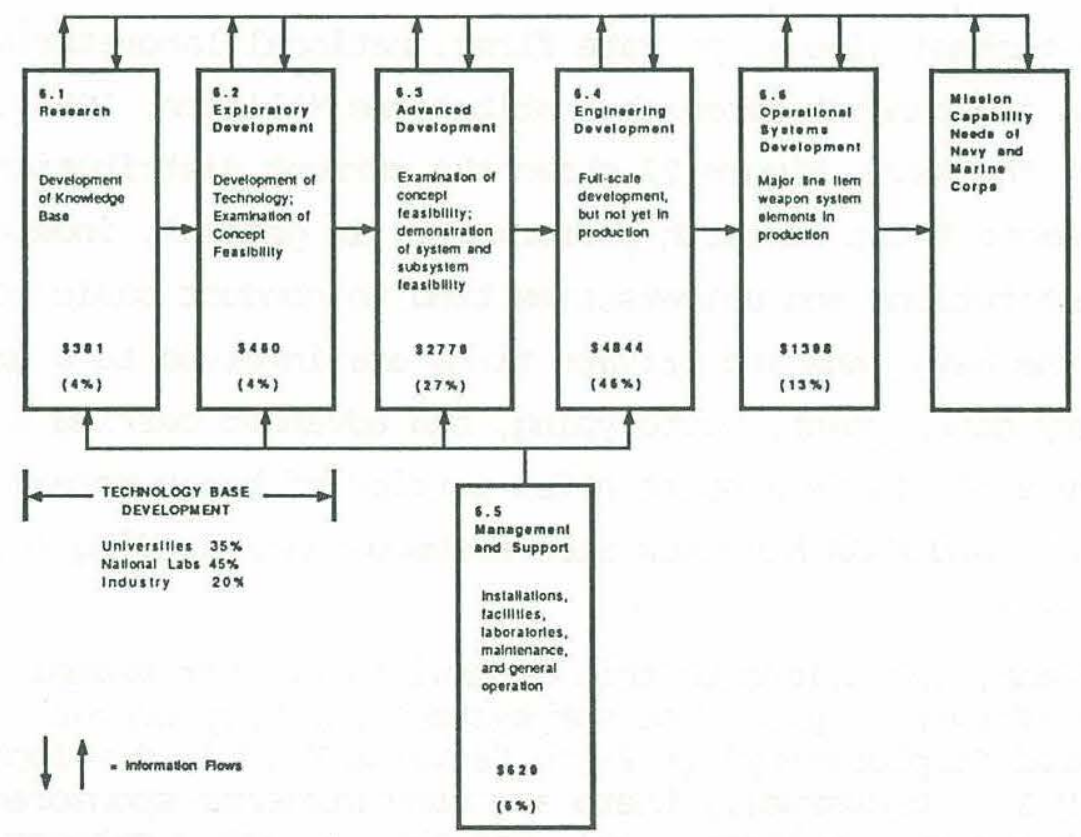

Figure 28: U.S. Navy RDT\&E Categories and Expenditures. Source: MoCarthy (1987) and USN (1985). 
(see: section 1.4.1. above) demonstrates that total Navy research funding has increased significantly since 1982 (OMB, 1961-1986). Projections for Navy research call for significant cutbacks in the rate of increase, perhaps even a decrease in funding levels. Already, the Navy has cut back the number of individual R\&D "programs" by nearly 40 percent, although this has occurred as total R\&D funding has increased (Lehman, 1987).

One major focus of Navy instrumentation R\&D is in the area of antisubmarine warfare (ASW), and this has been the "leading priority" for Naval R\&D funding requests since 1985 (Paisley, 1987). Figure 29 gives an impression of U.S. Navy

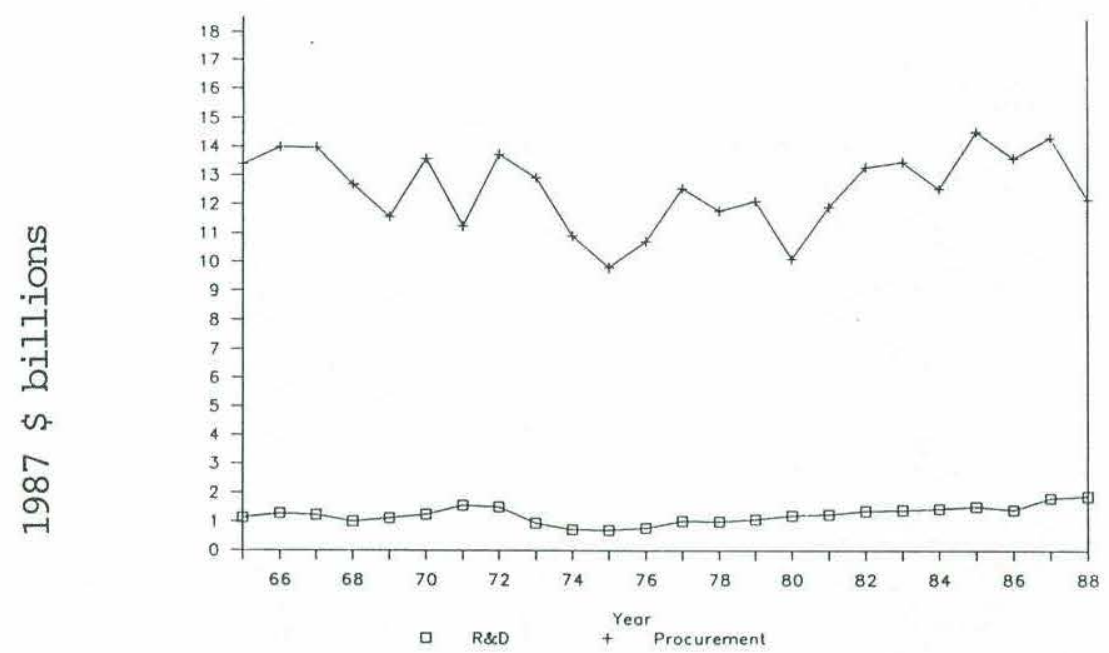

Figure 29: U.S. Navy ASW Procurrement and R\&D Expenditures, 1965-88, in billions of 1987 dollars. Source: Sea Technology (11 Nov. 1987). expenditures on ASW procurement and R\&D over time. Figure 30 shows a current listing of ASW programs funded by the Navy, including existing and proposed funding levels. One important research area, known as the Surface Antisubmarine Warfare Improvement Program (AN/SQQ 89), is directed at improving the capability of surface warships to detect, identify, locate, and track enemy submarines. This program has received a major impetus as a result of the diversion of technology useful for submarine propeller noise reduction to the Soviet Union (see section 3.2.1.). The Navy already has awarded two fixed contracts for the system "design definition" to competing contractors and expects to spend a total of approximately $\$ 1$ billion on R\&D for this program. The initial stages of the program will encompass an updating of software and the repackaging of existing technologies. 


\begin{tabular}{|c|c|c|c|}
\hline \multicolumn{4}{|c|}{$\begin{array}{l}\text { ASW PROGRAMS } \\
\text { [n meses a d cevil }\end{array}$} \\
\hline \multirow{2}{*}{ RLo ines } & \multicolumn{3}{|c|}{. losen rea- } \\
\hline & 1981 & 1984 & 1989 \\
\hline \multicolumn{4}{|c|}{ Submane ASW Progaams } \\
\hline SSN CMET CHI SYS IMP 6456250236 & 40398 & 43300 & 45165 \\
\hline SSN-21 ZMBI SYS 64524 S1941 & 81754 & 211333 & 303592 \\
\hline SSK-21 DEV 6455151946 & 240556 & 213242 & 195080 \\
\hline SUD ACEK W/F OEV 63562 S1739. & 9759 & 9035 & 9410 \\
\hline MK-48 ALCAP (ENG) 64675 50366 & 58008 & 32238 & 30300 \\
\hline Sea Lance 6430950863 & 109701 & 114341 & 11358 \\
\hline SSN-688 VIS 64370 S1500 & 11586 & 21395 & 14.388 \\
\hline Sub hull attay DeV $63560 \$ 0222$ & 3764 & 0 & 0 \\
\hline ADV CURFORM SUA ACOUS 63560 RI305 & 4851 & 0 & 0 \\
\hline Sub sonar inpoventient 6350450223 & 8710 & 8298 & 14775 \\
\hline Suo senat inprovement 6450350219 . & 46368 & 34518 & 37084 \\
\hline Nov Sub lech 63569 S1974 & 0 & 12.899 & 24028 \\
\hline EMSP/ECOS $64507 \times 1440$ & 9172 & 65.936 & 26415 \\
\hline AOV SIC PRCC 61507 S1990 ... & 0 & 3531 & 2952 \\
\hline$A N / B S Y-16452451347$ & 203195 & 131199 & 88592 \\
\hline Operational teactox der 25675 S1303 & 18.310 & 35.497 & 39.587 \\
\hline \multicolumn{4}{|c|}{ NR NSW PROGRUMS } \\
\hline S-3 WSIP 64217 W0489 & 9.747 & 0 & 0 \\
\hline CV NSW mookle 63228 SOS17. & 3.106 & 5.115 & 5175 \\
\hline 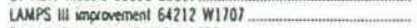 & 1.935 & 3.964 & 1.986 \\
\hline Penguin integration 64212 W1902 & 16947 & 12.956 & 1185 \\
\hline CV HELO AVIONICS IMP 61219 W0185 REN IMPROV & 1.228. & 0 & 0 \\
\hline CV 12 NSW HELO 64229 W1810 & 3.975 & 0.581 & $0^{\circ}$ \\
\hline P-3 Update iv anonics 64221 W1588 & 48.077 & 108.04 & 108.11 \\
\hline ESM system inporvements 64221 w1149.... & 1.034 & 0 & 0 \\
\hline SPP SYS integration 64221 W1152. & 5.330 & 5.054 & 5.209 \\
\hline P+36 $64221 \mathrm{~W} 1926$ & 0 & 13.811 & 38521 \\
\hline 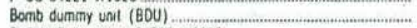 & 0 & 1.457 & 1318 \\
\hline 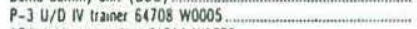 & 0 & 16.585 & 16.184 \\
\hline 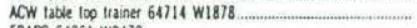 & 0 & 1.921 & 1.919 \\
\hline ERAPS 64261 W0478 & 0 & 4,45 & 1463 \\
\hline NWW sensors \& PROC 64261 WO480: & 23.790 & 3753 & 1243 \\
\hline Houtu line atray (HLA) 64261 W2000. & 0 & 11.250 & 20300 \\
\hline IRC SURV bwar (ISS) 64261 W2001 & 0 & 13053 & 11300 \\
\hline NOV NSW sensors 63251 W1292 & 5333 & 8523 & 9117 \\
\hline Propect Beattrap 63254 w1292 & 8868 & 11074 & 5.022 \\
\hline Project Bearthap 63708 w0490 & 8868 & 11014 & 5022 \\
\hline Brosoband Ncoustic Spstem 64261 W1624 & 10.765 & 15.336 & 12.079 \\
\hline \multicolumn{4}{|c|}{ SURFACE NSW PROGRAMS } \\
\hline$N /$ SOS-53C $6157551451 \ldots$ & 24311 & 11.421 & 8418 \\
\hline NWW concat sys integrin 25620 S0896. & 16638 & 16399 & 14931 \\
\hline AOV watheas DEV DEV $63610 \mathrm{~S} 1873$ & 0 & 0 & 1686 \\
\hline NK-SO TORP (NWT) 64610 SO199. & 172.994 & 85.172 & 12622 \\
\hline US NROC 54355 SISO4 & 39836 & 18.675 & 5.670 \\
\hline SOQ 89 inprovemeni 64713 S1916 & 15606 & 21.279 & 48674 \\
\hline Surlace shy TORP Off 63506 SO225 & 17585 & 27.339 & 36.518 \\
\hline Surlace ship siencing 6355350229 & 4283 & 5.105 & $\$ 976$ \\
\hline NW ADV DEV 63553 S1704 & 15.053 & 15.968 & 25.124 \\
\hline SURF TNCT TH Traner 64715 S1427 & 9.548 & 5.619 & 11.288 \\
\hline \multicolumn{4}{|c|}{ UNDERSEA SENSORS PROCRIMS } \\
\hline NSS devebonments $24311 \times 0766 \ldots \ldots \ldots$ & 22549 & 30.576 & $13<1 ?$ \\
\hline ASW ATD $63147 \times 1933$ & 22868 & 22759 & 2428 \\
\hline FIXED OIST SYS $63784 \times 1312$ & 33301 & 75991 & $1: 204$ \\
\hline SURIASS $24313 \times 0758$ & 5552 & 6226 & (44) \\
\hline ARILONE $63743 \times 1883$ & 8965 & 11062 & 11844 \\
\hline TACKUC DEV 63634 S0342 & 7.676 & 11.499 & 19315 \\
\hline \multicolumn{4}{|c|}{ OTHER ASW PROGRAMS } \\
\hline NWW 6.1 programs 61153 xoxox.... & 81000 & 87.000 & 10000 \\
\hline NSW 6262314 X000X & 10900 & 10900 & 11500 \\
\hline AT SEA ASW GRII EXPER 63792 RI959 & 2000 & 28431 & 25570 \\
\hline NCOUS/ROH-ACOUS AKt SP 65853 T1038. & 0645 & 1316 & 2543 \\
\hline KWC STRAT SlWoes SUPT 65853 R1767.... & 1581 & i.794 & i 581 \\
\hline MUV W/F TNC ARUL 65853 ROSOS & 3326 & 1561 & 5633 \\
\hline NWW SYS SUPT $65853 \times 0231$ & 3822 & 1598 & 1400 \\
\hline SHCLANT ASW Resaaten CIR 65857 R0115: & 0.925 & 1309 & 1334 \\
\hline NSW AOV TECH $63311 \times 2012$ & 0 & 12200 & $61+60$ \\
\hline NSW SYS ANA: $63311 \times 2013$ & 0 & 5000 & $60 \mathrm{~ns}$ \\
\hline AEAS OCN MSSN 2nd MOdel PROG 63785 R0120 & 10708 & 13435 & $135: 0$ \\
\hline ADV. NSW TARG 6352950968 & 6.705 & 3861 & 095) \\
\hline EMATT 6352951011 & 1058 & 0 & 0 \\
\hline FSI DEEP IGI 63529 S1955 & 12500 & 9809 & 10562 \\
\hline AUIEC 65864 W0541 & 19692 & 19024 & 51 315 \\
\hline AOV ACOUS PROC $63708 \times 0821$. & 1579 & 1388 & 1526 \\
\hline Non NCOUSIC NSW $63528 \times 0967$ & 20255 & 20391 & 20818 \\
\hline
\end{tabular}

Figure 30: U.S. Navy Anti-Submarine Warfare (ASW) Programs. Funding in millions of dollars. Source: Rumpf (1987). 
Later stages will involve the development of new technology (GAO, 1988a). Two other areas of Navy research may have an influence on marine electronics. Joint research efforts are conducted by the Navy with other U.S. government agencies and with some of the NATO governments. In particular, the Defense Advanced Research Projects Agency (DARPA), an agency that does not perform any research itself but instead coordinates research projects of use to more than one defense department, spends roughly 6 percent of its budget on ASW research. Because of the heightened importance of ASW activity to the Navy, DARPA has recently (1986) created a Navy Technology Office to elevate the status of ASW as a research priority (Duncan, 1987). The Navy is involved under provisions of the "Nunn Amendment" in the conduct of joint research projects with NATO governments, including the development of an "advanced sea mine" with the United Kingdom. Under both the Foreign Weapons Evaluation (FWE) and the NATO Comparative Test programs, the Navy is investigating foreign-made equipment such as the "Barra Sonobuoy" manufactured in Australia and a naval depth sounder manufactured in Greece (McCarthy, 1987).

3.1.3. Research by other Agencies. For several reasons, it may be difficult to disaggregate funding specifically for R\&D in marine electronic instruments out of the federal marine science budgets. Agency budgets usually do not include a lineitem identifying funding for instrumentation. Research contracts may include either the development or the purchase of instruments as a necessary charge for studying a scientific question. (In fact, Navy sources have indicated that instruments are always developed as part of a scientific program or to achieve a specified military mission. There is no funding solely for the purpose of developing instruments.) Nevertheless, it is reasonable to assume that govermment funding for MEI follows the same trends as overall govermment marine science funding, even if the actual level is unknown. And it is clear from an examination of Figure 26 that the Navy is by far the largest, most influential source of expenditures for R\&D on marine electronic instrumentation.

With some exceptions, funding for R\&D on marine electronic instruments generally is under 5 percent of total agency $R \& D$ for those agencies with marine responsibilities. The future for govermment funding of R\&D on marine electronic instruments is optimistic. It is expected that Navy funding will continue at roughly the present level in real dollars. (Although Navy R\&D funding 
skyrocketed during the last eight years, industry experts expect that Navy budgets will have to be reoriented toward the design, manufacture, and procurement of downstream products of research. This will effectively put a ceiling on future increases in R\&D.) Several large-scale scientific "global change" studies involve substantial ocean components, and these are expected to require the development of instruments, particularly current meters, telemetering systems, and data management systems. Although not providing specific expenditure information, Figure 31 characterizes the projected "level of effort" for the U.S. Global Ocean Science Program, showing the total effort and the proportion that is expected to be devoted to "sensors and sampling" (GOSP, 1987). NSF will be the
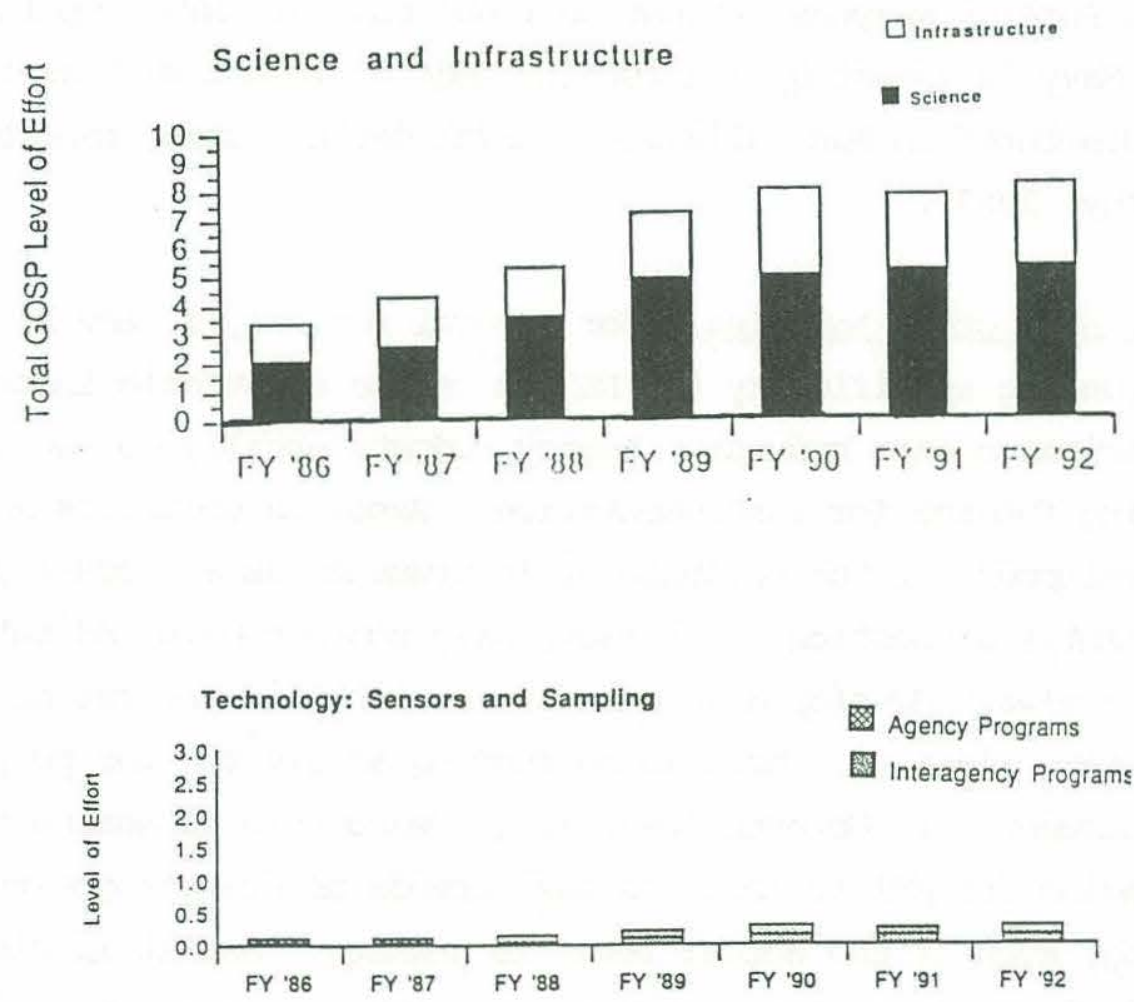

Figure 31: Global Ocean Science Program (GOSP) Level of Effort Analysis. Source: U.S. GOSP/IWG (1987).

major funding source, and NSF officials are forecasting a 5-10\% increase in funding over the next decade. In addition, increased emphasis by the Department of Energy, $\mathrm{ACOE}$, and the EPA in monitoring pollution of estuaries and marine 
environments may involve stepped-up levels of R\&D on marine electronic instrumentation. In particular, $\mathrm{ACOE}$ has begun a multiyear, $\$ 7.6$ million project to develop onboard dredge monitoring systems as one component of their "Dredging Research Program."

3.1.4. IR\&D and B\&P Trends. Funding of "independent research and development" (IR\&D) or "bid and proposal" (B\&P) costs incurred by private defense contracting firms may have an important stimulating effect on research activity in marine electronics. As part of the procurement process, U.S. defense contracting procedures 5 allow a portion of "negotiated, allowable" costs for the development of new technology and products by private firms to be allocated to either IR\&D or $B \& P$.

IR\&D is firm-initiated and -funded and is not contracted for specifically by defense agencies. Firms allocate IR\&D costs over all contracts (and thus into the price of their products), regardless of whether the customer is military or civilian. Defense customers, however, have access by law to all results of IR\&D efforts, although contracting firms may retain proprietary rights to IR\&D results. The defense agencies may reimburse firms for up to $40 \%$ of their defense-related IR\&D costs, but this amount may not exceed the dollar amount of projects having a "potential military relationship."

Although defense agencies have no direct influence over the selection or elimination of IR\&D projects, or over their scope or research direction, one congressional study has found that "guaranteed funding by DoD to negotiated or accepted ceilings stimulates the expenditures of corporate resources and, in fact, lessens the elements of risk" (House Approp. Cm., 1982). Thus research efforts on marine electronics, for example, that result in either immediate commercial benefits or future spinoff potentials could be enhanced by defense agency IR\&D reimbursements.

The amount of allowable IR\&D is determined either on the basis of a statutory formula in the case of small defense contractors or through an annual negotiation process in the case of large defense contractors. For negotiated IR\&D cases, the amount of allowable IR\&D is dependent upon a determination of the potential

5 The Federal Acquisition Regulations (FAR) are found generally at 31 C.F.R. 205-218 (1988). 
military relationship (PMR) of individual projects in the firm's research portfolio. PMR determinations are to a large extent discretionary, based upon the examination of project description reviews and on-site evaluations performed by officials from DoD laboratories. Recently, large defense contractors have perceived a trend of decreasing amounts of negotiated, allowable IR\&D measured as a percent of sales over the recent five year period from 1982 through 1987--from 5.25 to 4.23 percent (ADPA, 1987).

This trend has been of particular concern to high technology defense contractors, whose principal customer is the military and whose advanced technology R\&D to sales ratio may average from 7 to 9 percent. In effect, the govermment may be shifting an increasing share of the risk of R\&D effort onto defense contractors, who must pay for the costs associated with increased risk out of profits.

Although all of the reasons for this perceived trend are not immediately apparent, govermment defense budget concerns may be a significant influence. For example, concurrent with the decreasing trend in allowable IR\&D, there may be an increasing trend in negotiated, allowable B\&P costs. The presumed effect of this shift (decreasing IR\&D, increasing $B \& P$ ) is to encourage more firms to submit bids and write proposals on specific govermment contracts, thereby increasing competition early in the procurement process and potentially reducing overall costs to defense agencies. The primary concern of the large defense contractors, other than facing increased competition up front, is that reductions in allowable IR\&D costs will hamper their ability to maintain research momentum and, as a result, reduce their ability to compete on a technological basis. This issue may be particularly important to the military sector of the marine electronics instrumentation industry, but its effects are not immediately measurable. This issue (along with others related to government contracting and procurement practices) is a potentially useful area for further research.

3.1.5. Govermment Procurement. Federal govermment agencies are an important factor in the markets for marine electronic instruments, and, measured in terms of sales revenues, they are indeed the most significant customers. Of all federal agencies, the Navy is, of course, the largest customer. Figure 32 presents a breakdown of planned other Procurement Navy (OPN) expenditures specifically for general classes of marine electronics (Smith, 1987). When all classes of Navy 


$\begin{array}{lrrr} & \text { FY1987 } & \text { FY1988 } & \text { FY1989 } \\ \text { Communications/Electronics } & & & \\ \text { Ship Radars } & 135 & 148 & 165 \\ \text { Ship Sonars } & 226 & 243 & 178 \\ \text { ASW Electronics Equipment } & 378 & 201 & 250 \\ \text { Reconnaissance/Elec. Warfare } & 251 & 230 & 327 \\ \text { Other Electronic Equipment } & 325 & 213 & 303 \\ \text { Communications Equipment } & 463 & 655 & 913 \\ \text { Strategic Platform Support } & 159 & 78 & 143 \\ \text { Aviation Support Equipment } & & & \\ \text { Sonobuoys } & 187 & 118 & 138 \\ \text { TOTAIS } & & & \\ & 2124 & 1886 & 2417\end{array}$

Figure 32: Other Procurement Navy (OPN) of Marine Electronic Instrumentation, 1987-89. Numbers in millions of dollars. Source: Smith (1987).

procurement are considered, expenditures specifically for marine electronics are roughly five percent of the total. Although this figure appears small, Navy annual procurement for marine electronics may represent between 50 and 75 percent of the U.S. domestic market--a very significant proportion. Figure 33 gives a perspective on procurement for other govermment agencies for marine electronics. Generally, procurement budgets for MEI in federal agencies with marine responsibilities are 5 percent or less of their total procurement. Together, all federal agencies outside of the Navy spend only about 2 percent of what the Navy spends to procure marine electronics. These figures are at best only coarse estimates, because agency budgets usually do not break out specific marine electronic procurements as a line item. For example, the U.S. Coast Guard Bear class medium-endurance cutters are fitted out with new "Comdac" command, control, and communications equipment. The costs of these advanced radar/navigation/ communication systems are buried within one contract for eleven cutters. Agencies may seek innovative methods for marine electronics procurements, including the sharing of expenditures with other agencies. For example, the coast Guard is now procuring Forward Looking Airborne Radars (FLAR) for its HC-130 aircraft. The radars can be used for search and rescue missions, law enforcement, and ASW (they are capable of spotting a periscope at $28 \mathrm{mmi}$ in moderate sea conditions). Since 1982, funding for these radars totalling $\$ 88$ million has been obtained from such diverse sources as coast Guard acquisition, construction and improvement (AC\&I) accounts, supplemental Defense Department appropriations, and Navy Aircraft 


\begin{tabular}{|c|c|c|c|}
\hline \multirow{2}{*}{ AGENCY } & \multirow{2}{*}{\multicolumn{2}{|c|}{ Procurement }} & \multirow{2}{*}{$\begin{array}{l}\text { MEI as } \\
\text { a o of } \\
\text { Total }\end{array}$} \\
\hline & & & \\
\hline \multicolumn{4}{|l|}{ NAVY } \\
\hline Aircraft & 9,925 & -- & -- \\
\hline Weapons & 6,502 & -- & -- \\
\hline Shipbuilding/Conversion & 11,605 & -- & -- \\
\hline Other Procurement & 4,984 & 1,830 & 37 \\
\hline Procurement Marines & 1,402 & -- & -- \\
\hline Military Construction & 1,451 & -- & . \\
\hline Total & 35,869 & 1,830 & 5 \\
\hline USCG & 550 & $28 *$ & $5 *$ \\
\hline NOAA & 80 & 4 * & $5 *$ \\
\hline$A C O E$ & 995 & $10 *$ & $1 *$ \\
\hline USGS & 36 & 1 & 3 \\
\hline $\mathrm{DOE}$ & 1,657 & -- & 0 \\
\hline EPA & 47 & $<1$ & $<1$ \\
\hline TOTALS & 39,234 & 1,873 & 5 \\
\hline
\end{tabular}

Figure 33: Agency Procurement Budgets for Marine Electronic Instrumentation, 1988 estimated in millions of dollars. Source: telephone interviews with government officials.

procurement funds. 6 There are many facets to the broad issue of government procurement which may have substantial influence on investments made by marine electronics firms. ${ }^{7}$ Because the government is such an important customer in this field, virtually any shift in procurement policy or obligation authority will have a tangible effect. Three policy aspects seem to stand out as having the greatest

6 In 1986, a special Defense Department appropriation [P.L. 99-190] allocated $\$ 235$ million for augmentation of USCG inventories of equipment and other procurement items for national defense purposes. These monies are to remain available until fully expended.

7 Procurement can be broadly defined as any public expenditure made to obtain goods or services (R\&D, consulting, manufacturing, off-the-shelf items or parts, systems, maintenance, etc.) from the commercial sector. However, we focus narrowly here on the purchase of manufactured goods. 
potential for affecting competitiveness in marine electronic instrumentation markets: multiyear defense contracting, buy-national provisions, and foreign military sales. We concentrate here on these issues, but note that there are several other aspects of procurement which may deserve closer attention in future research efforts.

In 1981, due largely to a perceived problem with underinvestment in facilities, advanced technology, and manufacturing equipment by firms in the defense industry, the Defense Department's authority to contract for weapons systems for more than one year was broadened. A recent congressional study has found that some prime contractors have been influenced by multiyear contracting, but, perhaps more importantly, subcontractor investments have been encouraged by this contracting method (GAO, 1988b). In effect, multiyear contracting may provide a lower risk, stable investment enviromment for both prime contractors and subcontractors. However, although Federal Acquisition Regulations (FAR) encourage prime contractors to negotiate multiyear subcontracts, this is not a mandatory requirement.

Stuart Platt (1984), the Navy's first Competition Advocate General, has explained that "the biggest most noticeable advantages of competition come early in the life cycle [of the acquisition process], and we are acting accordingly." In line with this statement, industry sources in the defense contracting business have indicated that there is an increasing trend toward contracting with one prime contractor for the production of an entire weapon system or system element. This has resulted in contracts going to one large defense contractor or, in some cases, to joint ventures. For example, in March of 1988, General Electric won a $\$ 1.8$ billion contract to engineer and produce on a limited basis a submarine advanced combat system (AN/BSY-2), which includes both acoustic sensors and combat control, for the Navy's new Seawolf (SSN-21) class attack submarine. IBM will subcontract for roughly 15 percent of the work and GE must "qualify" IBM as a second production source. The two companies will then compete for future production contracts (GAO, 1988a).

Where large multiyear defense contracts are won by one firm, the opportunity exists for other defense-oriented firms to subcontract with the prime. However, the negotiating position of the prime contractor is significantly enhanced by the stability of the multiyear contract, even in cases where there may be only one firm available for a specific subcontracting job (GAO, 1988b). Opportunities for 
encouraging investment in the defense sector of the marine electronics field might be enhanced through the increased employment of multiyear subcontracts. This issue may not be as important for those subcontractors who conduct a significant portion of their business in non-defense-related areas.

Buy-national provisions are another form of encouragement for the U.S.-based marine electronic instrumentation industries. Industry sources have indicated that the Navy may be looking at foreign-based sources for some marine electronic technologies, but this still represents a very small proportion of Navy procurement. In many cases, foreign firms may be ineligible for security clearances (even firms from NATO countries) and this may either exclude these firms from the U.S. market or force them to set-up or buyout U.S.-based subsidiaries. Military-strategic concerns thus remain an important stimulus to firms incorporated in the United States.

On another front, a bill recently was introduced in the U.S. House (H.R. 4704 ) to modernize and expand NOAA's oceanographic fleet. The bill contains a provision requiring that "at least 50 percent of the cost of all machinery and equipment must be purchased in the United States" (OSN, 1988). Certain kinds of scientific equipment may be exempt, if it cannot be "reasonably" acquired in the United States. Although this kind of buy-national rule would apply to marine electronic instruments, we expect that its benefits, if enacted, may be limited to only a few U.S. firms for only a short period of time. Furthermore, the potential exists for the procurement of relatively costly equipment, thereby raising the total costs of establishing and maintaining the national oceanographic fleet without necessarily facilitating the international competitiveness of U.S. manufacturers.

The foreign military sale (FMS), as authorized by the arms export control laws of the United States ${ }^{8}$, is a method by which sales to qualified foreign govermments of defense-related marine electronic instruments may be encouraged. The President is authorized to sell defense articles or services to "friendly" foreign countries and international organizations, to contract with private firms for the procurement of defense articles or services for sale to these foreign countries, to finance foreign procurements of defense articles (known as "credit sales"), and, for a fee, to guarantee U.S. firms against political and credit

8 Foreign military sales authorizations: 22 U.S.C.S. 2761 et seq. (1982). 
risks of nompayment when U.S. firms finance sales to foreign countries. It is clear that a significant part of defense marine electronics are traded as foreign military sales. For example, in 1981, the Naval Sea Systems Command awarded Gould's Defense Electronics Division a \$71 million increase on a contract to produce towed array sonars (AN/SQR-19) for the U.S. Navy and for Spain through a foreign military sale program (ST, Oct. 1984). The proportion of foreign military sales in all defense sales for marine electronics and the extent to which FMS programs stimulate the production of marine electronics are questions deserving of future research.

\subsubsection{Intellectual Property Rights.}

In the United States, a patent is a grant from the federal government that allows an inventor to exclude others from the manufacture, use, or sale of an invention (PIO, 1982). Patents are defined by "specifications" that "claim" the technology that is new and useful. Patent claims are supported by the description, which may include pictures, drawings, or even a scale model, but the claims are the most important part of the patent in terms of property rights. In the case of an infringement, where issues of the scope of patent protection frequently arise, reviewing courts examine the patent claims. Persons found to be infringing on existing patent rights may be enjoined from continued infringements or required to pay damages (sometimes up to treble the estimated damages, and including attorney's fees).

Patent protection granted in the United States extends to every state, territory, and possession. Patent protection outside of the United States is possible only through application to individual govermments. Under provisions of the Paris Convention for the Protection of Industrial Property, several countries have agreed to standardize patent rights and to treat the date of first application in one of the signatory countries as controlling. A separate international agreement, the Patent cooperation Treaty, established a standard application and centralized filing procedure that allows one patent application to be filed concurrently in any of the signatory countries. Upon issuance, fees and other requirements may differ substantially by country, even for those that are signatories to the above agreements. In general, patent protection is stronger in the industrialized countries and is weaker (or sometimes nonexistent) in developing countries. The issue of the protection of intellectual property 
rights, especially in high technology fields, currently is receiving attention at the "Uruguay Round" of international trade discussions on the General Agreement on Tariffs and Trade (GATT).

Once a patent has been granted, as a kind of property right, it can be mortgaged, assigned, or the rights to make, use, or sell the invention can be transferred under license. However, not every patent is valuable, and obtaining a patent can be costly. ${ }^{9}$ coles (1983) has suggested that many academic patents are "pioneering" patents at the forefront of technology (and therefore perhaps not immediately useful for commercial purposes) in comparison to industrial patents that tend to be more "defensive" (perhaps to maintain a monopoly position). Patents resulting from basic research may have significant payoffs, but the payoffs may be so far into the future that, when discounted, they appear small.

Members of the Marine Electronics Instrumentation Panel have indicated that firms in the MEI industry usually do not employ a strategy of patent protection for their technologies. There may be several reasons for this. First, given a low expected discounted return on basic research, it may be commercially infeasible to seek patent protection. Second, the rapid pace of technological advance exhibited by marine electronic instrumentation firms, implying a relatively short lifetime for individual products, may militate as well against a strategy of protecting intellectual property through obtaining a patent and may be an indication of the use of trade secrets instead. ${ }^{10}$ Third, if the issuance of a patent is determined to be detrimental to the national defense, the Commissioner of Patents and Trademarks has the authority to withhold the patent grant and order that the patent be kept secret. Because much marine electronics R\&D is conducted for the military sector, a substantial proportion may fall under this national

9 The average cost of obtaining a commercially marketable academic patent has been estimated at $\$ 30,000$ per patent, up to one-third of which may be attributed to search costs (Coles, 1983). Members of the Marine Instrumentation Panel have indicated that this may be an overestimate. We have received no revised estimate from the Panel, but Driscoll and Kransdorf (1987) have stated that the average cost may be as little as one-tenth of the above estimate.

10 In some of our interviews, a few industry officials felt that their R\&D efforts were not directed so much toward patentable technological breakthroughs as toward the "ruggedization" of existing technologies. It is not completely clear that this kind of innovation is unpatentable. We have found no evidence that the patent applications of firms have been denied, but it appears that (for whatever reason) firms may not bother to file applications. 
defense clause. Fourth, there appears to be a significant movement of engineers and other researchers among the firms and research institutes in the field, thus permitting a technology transfer pathway that may help break-down the patent barrier. Fifth, in 1982, the Patent and Trademark Appropriation and Authorization Act [P.L. 97-247] instituted "maintenance fees" for issued patents, a performance requirement intended to curb the practice of patenting solely in order to preclude the entry of competitors into a patented area. Patents do exist in the industry, however, and it is still possible that developments which are perceived as major technological breakthroughs may be patented. For example, patents exist on the bathythermograph and its variants (Figure 34), on side-scan sonar, and on LORAN navigation systems. Whether or not there has been a shift away from a historical strategy to patent in this industry is a question for further research.

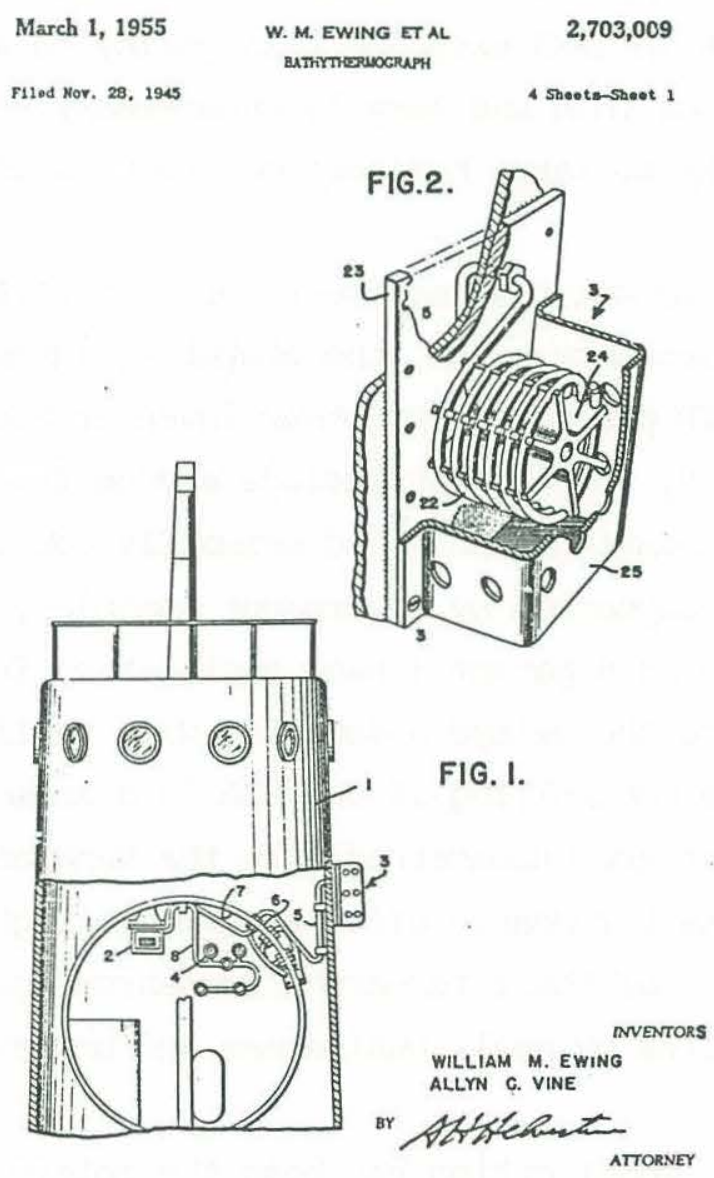

Figure 34: Excerpt from a Patent Application for a Bathythermograph, 1945. Source: U.S. Patent Office. 
Within the last decade, several modifications of the U.S. patent laws have been made, some of which have important implications for research in marine electronic instrumentation. 11 These modifications were instituted primarily as a result of the realization that large numbers of patents were held by government agencies but were being commercialized only to a limited extent (Daddario, 1985). A significant change was the Patent and Trademarks Act of 1980 [P.L. 96-517], which gave universities, nomprofit research institutions, and small businesses the option to retain title to patents granted as a result of research conducted with U.S. govermment funds. Although some funding agencies (NSF in particular) had begun this practice in the 1970s, it was expected that this might encourage research leading to patents under some of the larger funding agencies (Defense, Energy, NASA). One of the most profound results of this Act was an increase in business funding of university research efforts (GAO, 1987a). An memorandum issued by President Reagan in 1983 extended this policy to all businesses receiving federal funds, but this was largely unnecessary, because most federal agencies gave patent rights to large business contractors as a matter of course in negotiating contracts.

Another statute, the Patent Law Amendments of 1984 [P.L. 98-622], created a new form of intellectual property right, the statutory invention registration (SIR). The grant of an SIR precludes any other inventor from obtaining a patent on an invention. ${ }^{12}$ However, it does not exclude anyone from manufacturing, using, or selling a registered invention. Intended primarily for use by government agencies and for research supported by govermment agencies, obtaining an SIR is less expensive than obtaining a patent (lower application fees and no maintenance charges) and not subject to the delays associated with publishing in journals (the date of SIR application is controlling if the SIR is granted). SIRs might be attractive to entities that are unconcerned with the manufacture, use, or sale of products resulting from their research efforts, and who might gain through the publication (advertisement) of their research breakthroughs. Thus far, there has been only limited use of SIRs by small businesses and universities. Federal

11 One nonlegislative modification has been the relaxed enforcement of antitrust laws in patent cases (see section 3.1.8. below).

12 By law, the grant of an SIR establishes "prior art" and is a "constructive reduction to practice." 
agencies see them primarily as a means to preclude costly patent infringement suits levied against the govermment by private firms (GAO, 1987a). Other similar methods, such as NASA's "Tech Briefs," which establish prior art, may be just as effective as the SIR process. The "Tech Briefs" method was suggested by the Marine Instrumentation Panel as a method for improving technology transfer in the field of marine electronic instrumentation.

\subsubsection{Tax Allowances for R\&D and other MEI Investments.}

Here we briefly discuss some of the provisions of the U.S. tax code relating to R\&D efforts. Interviews with industry officials in the marine electronic instrumentation field have resulted in a general impression of the importance of these provisions to the field. Many provisions are relatively new, instituted in the wave of tax reform that took place during the tenure of the Reagan Administration. Because of their novelty, it is difficult to make authoritative conclusions about their effect on the industry. Most industry sources lament the removal of the investment tax credit, which for almost twenty years was, in effect, an added allowable depreciation over and above the total depreciable cost of many types of corporation assets. At the same time, however, the general corporation tax rate has been lowered considerably, and differences in effective tax rates among asset types and industries have been reduced. The net intended effect is the removal of distortions among investments, but, in order to achieve this, a redistribution of tax rates affecting some industries more than others was necessary. Thus the effective tax rate for some industries was increased (e.g. , from 1981 to 1986, the effective tax rate for communications industries increased from 24 to 36 percent), while that for others decreased (Pechman, 1987).

To a limited extent, tax allowances specifically for R\&D investments have substituted for the removal of other kinds of capital consumption allowances, such as the investment tax credit. In the marine electronic instrumentation field, many firms devote a significant portion of their activity to R\&D (Kite-Powell, 1988). "Research and experimental" (R\&E) expenses may qualify for varying tax treatments including deductions as a current expense, deferrals, or credits, and 
accelerated depreciation of physical capital. 13 The use of one or more of these tax allowances is dependent upon the individual firm's financial situation and investment strategy.

There are now two credits available for research expenses, and both credits may be taken together. These credits are combined with other business credits into a "general" business credit used to offset tax liability. ${ }^{14}$ First, 20 percent of certain "basic research" payments made after 1986 to qualified organizations (e.g., universities, tax-exempt scientific research institutions) can be taken as a credit. 15 Second, 20 percent of "qualified research expenses" in excess of the greater of either the average of research expenses over a three year base period or 50 percent of the current year's expenditures can be taken as a credit. 16 Research qualifying for the credit must:

- discover information that is technological in nature;

- involve experimentation relating to a new or improved function, performance, or reliability or quality; and

- be useful in the development of a new or improved business component. 17

13 Although there is no fine line separating the activities of "research" and "development," U.S. tax policy favoring development potentially may contravene international accords as a form of export subsidy (see section 3.2.2. below).

14 IRC sec. 41.

15 The credit is based on the amount of research expenses that exceed a "special floor," which is calculated roughly as average contract research costs plus average university contributions incurred during a three year base period. See IRC sec. 4l(e) for specific details on the calculation of the special floor. Basic research that qualifies for this credit is defined as an "original investigation for the advancement of scientific knowledge not having a specific commercial objective."

16 This credit has replaced the previous 25 percent credit for qualified research expenses incurred between 1981 and 1985. However, the rules explaining what types of research expenses qualify have been modified.

17 In determining the level of qualifying research, final products are considered first, to see whether or not they meet the above standards. If not, individual components of the product are considered to determine the proportion of total research qualifying for the credit. These are abstracts of a three-part 
Tax policy analysts disagree about whether or not the R\&E tax credit actually does encourage industrial research (Eisner, 1987; Baily, 1987). These analysts generally agree, however, on some of the "perverse" effects that result from the way in which the credit is structured. For example, if R\&E expenditures for any particular year exceed the average of three previous year expenditures, the real tax credit is only $10 \%$ or half of the nominal rate on the excess (GAO, 1988C). Further, there may be an inducement for firms to decrease R\&D expenditures in some years if there are reasons to expect that this might increase the probability of tax benefits available at a later date. Finally, firms with little or no tax liability (especially firms that are just starting-up) may be unable to use the tax credit, although the credit may be carried forward for up to fifteen years.

This does not mean that tax credits are of no use to firms conducting R\&D, although it is difficult to make conclusions about their usefulness for marine electronic instrumentation firms without access to individual tax returns. Figure 35 shows the growth in qualified R\&E expenditures from 1981 to 1983 over base period amounts and the total credit available for corporations in the broad industrial categories of electrical/electronics and instruments, which include marine electronic instruments as a subset. It is interesting to note that large

\begin{tabular}{|c|c|c|c|c|c|}
\hline Industry & Year & $\begin{array}{c}\text { Qualified } \\
\text { R\&E }\end{array}$ & $\begin{array}{c}\text { Base } \\
\text { Amount }\end{array}$ & $\begin{array}{l}\text { Growth Rate } \\
\text { Over Base }\end{array}$ & $\begin{array}{l}\text { Total* } \\
\text { Credit }\end{array}$ \\
\hline Electrical/ & 81 & 1953 & 1385 & $41 \%$ & 130 \\
\hline \multirow{2}{*}{ Electronics } & 82 & 3463 & 2402 & 44 & 273 \\
\hline & 83 & 4598 & 3059 & 50 & 451 \\
\hline \multirow{3}{*}{ Instruments } & 81 & 756 & 518 & $46 \%$ & 51 \\
\hline & 82 & 1624 & 1202 & 35 & 106 \\
\hline & 83 & 1858 & 1339 & 39 & 137 \\
\hline \multirow[t]{3}{*}{ Total U.S. } & 81 & 13,492 & 9612 & $40 \%$ & 878 \\
\hline & 82 & 26,172 & 19,606 & 34 & 1653 \\
\hline & 83 & 28,199 & 20,512 & 38 & 2189 \\
\hline
\end{tabular}

*Includes carryover from previous years in 1982 and 1983. Some of this may be used in years subsequent to the year in which it is calculated here.

Figure 35: Qualified R\&E Expenditures and Tax Credits, 1981-83, in current millions of dollars. Source: after Mentz (1987), using data from the Office of Tax Analysis, U.S. Department of the Treasury.

test specified in the Internal Revenue Code. See IRC sec. 41 for details and for ineligible expenses. 
companies tend to reap the most benefits from the tax credit (this might be expected because on average they may spend more on R\&D). For example, from 1981 through 1984, a congressional study using a sample of 927 corporations found that corporations with assets greater than $\$ 250$ million earned from 75-80 percent of the total tax credit (GAO, 1988c). Based upon our discussions with industry officials in the marine electronic instrumentation field, we have found that some firms take advantage of the R\&D credits, while others do not. Evidence of the use of research credits, however, is evidence of increases in an industry's research effort (assuming that the increases are not solely a reclassification of other types of investment as R\&E). Increases in research effort are important indicators of behavior in an industry, and so we plan to investigate the use of research credits more closely in our future investigations.

There are several other provisions of the U.S. tax laws that may influence economic activity in the marine electronic instrumentation field, including depreciation rules, deductible and deferred expenses, among others. A complete understanding of the net effect of federal tax rules on the behavior of firms in this field should include an examination of these types of provisions, and we plan to include a closer examination of the net effect in the second year. Here we focus on two types of institutions that potentially could have a profound effect on international competitiveness in this field: foreign sales corporations and venture capital firms.

The foreign sales corporation (FSC) ${ }^{18}$ is a type of firm established in a foreign country organized under the laws of that country for the import of U.S. manufactured goods. 19 Even though the U.S. tax laws encourage the establishment of FSCS for the facilitation of U.S. exports, based upon our discussions with industry officials, we have found that there may be only limited use of FSCs in the MEI field. Apparently, many firms (particularly the smaller size firms) prefer instead to employ foreign sales representatives, to engage in foreign marketing themselves, or to invest in joint ventures with foreign firms.

Venture capital companies, certified by the Securities and Exchange

18 Similar to "domestic international sales corporations" or DISCs. Because DISCs were found to be a form of illegal export subsidy under the terms of GATT, the 1984 Tax Reform Act created FSCs. IRC sec. 921-927.

19 FSCs often are subsidiary corporations usually set up by large U.S. firms trading high volumes of goods. 
Commission, invest in other corporations that are "principally engaged in developing or exploiting inventions, technological improvements, new processes, or products not previously generally available."20 As a form of "regulated investment company," venture capital firms are permitted to deduct dividends paid to shareholders and are taxed only on income that remains undistributed. 21 Because venture capital institutions tend to "forge linkages" among a diverse array of organizations with variable skills to reduce the risks of innovation (Florida and Kenney, 1988), their activity level in a particular field may be an important indicator of industrial behavior.

Although there were at least two mutual funds (similar in concept to venture capital firms) and one venture capital firm, Ocean Science Capital Corporation (Paine, 1968), established in the 1960s that focused on marine instrumentation, little interest has been expressed recently by venture capitalists in MEI firms. It is interesting to note that venture capital investments in the broad class of electronic components and other electronics, were more than $\$ 300$ million in 1986, the third largest group for these kinds of investments. Nevertheless, relative to other fields, such as computers, medical research, or biotechnology, the MEI field may be perceived by venture capitalists as having only a small potential for rapid, short-term growth. Moreover, the removal of the capital gains differential by the Tax Reform Act of 1986 reduced the incentive for venture capitalists to invest in emerging fields with long-term potential (Schrage, 1988). To the extent that marine electronic instrumentation technologies are perceived as early-stage, long-term investments, we expect that venture capital activity may be minor at best.

\subsubsection{Antitrust Policy for R\&D}

In the late 1970s and early 1980s, American industry faced burgeoning competition from foreign firms in many domestic markets, and international trade increasingly became an important factor in these markets and for the U.S. economy

20 IRC sec. 851 (e) (1); Treas Reg. 1.851-6.

21 Regulated investment companies must meet certain standards in terms of registration, nature and distribution of income, and diversification of assets. Venture capital companies are permitted to meet a looser diversification of assets standard than other regulated investment companies. 
as a whole. During the tenure of the Reagan Administration, the effects of govermment policies on international competitiveness were examined and several proposals were made to free the private sector from what were seen as unnecessary "restrictions." Among the national policies receiving close scrutiny were the antitrust laws. In many instances, these laws were perceived as anachronistic, applying to a bygone era when the U.S. economy was less international (NAE, 1988). One of the priorities of the executive branch was the removal of antitrust barriers to the conduct of R\&D (Baxter, 1985), an issue of significant importance to the high technology industries. One immediate result of this policy shift has been the promotion by the Department of Justice (DOJ) of increased intellectual property protection and the relaxed enforcement of certain patent licensing practices that were considered "per se" antitrust violations in the recent past (McMahon, 1986).

In 1984, Congress passed the National Cooperative Research Act (NCRA) (P.L. 98-462) 22 , which in the main was a legislative affirmation of existing Department of Justice (DOJ) enforcement policy regarding joint ventures in R\&D. 23 Its most important provision states that, in legal actions taken under the U.S. or similar state antitrust laws, joint R\&D ventures are not considered to be illegal per se but instead are judged according to their "reasonableness."24 The latter standard requires a higher level of proof that a particular joint venture is anticompetitive. Joint ventures may take advantage of the Act's limitation on relief provisions (removing traditional antitrust treble damages) by registering the venture with DOJ.

A cursory review of R\&D joint ventures registered with DOU has revealed that no ventures have been formed since the enactment of NCRA specifically for the purpose of conducting R\&D on marine electronic instrumentation. Based upon our initial set of discussions with industry officials, we have found only a limited

\section{U.S.C.A. 4301 et seq. (1982).}

23 Concerns about this issue were examined first by President Carter's "White House Domestic Policy Review of Industrial Innovation" in 1979. See: Antitrust Division, Antitrust Guide Concerning Research Joint Ventures, Washington: U.S. Department of Justice, 1980.

2415 U.S.C.A. 4302 (1982). In addition, the Act removes the traditional treble damage relief and awards attorneys fees to the substantially prevailing claimant. 15 U.S.C.A. 4303, 4304. 
number of cases where R\&D is conducted jointly among firms in the industry. One registered joint venture, the Microelectronics and computer Technology Corporation (MCC), includes as shareholders (Figure 36) several large companies (11 out of 22 shareholders) that also are producers of marine electronic instruments. MCC focuses on the following areas of research: advanced computer architectures; high density packaging of semiconductors; software technology; and very large scale integration/computer-aided design. 25

Although it is unknown whether any marine instruments have benefited specifically from the results of the MCC effort, we expect that, given the interests and involvement of the shareholders, the possibility exists that future benefits will flow from this research into marine instruments.

Under the provisions of the Export Trading Company Act of 1982, trading companies may be established in the United States to facilitate export trade.

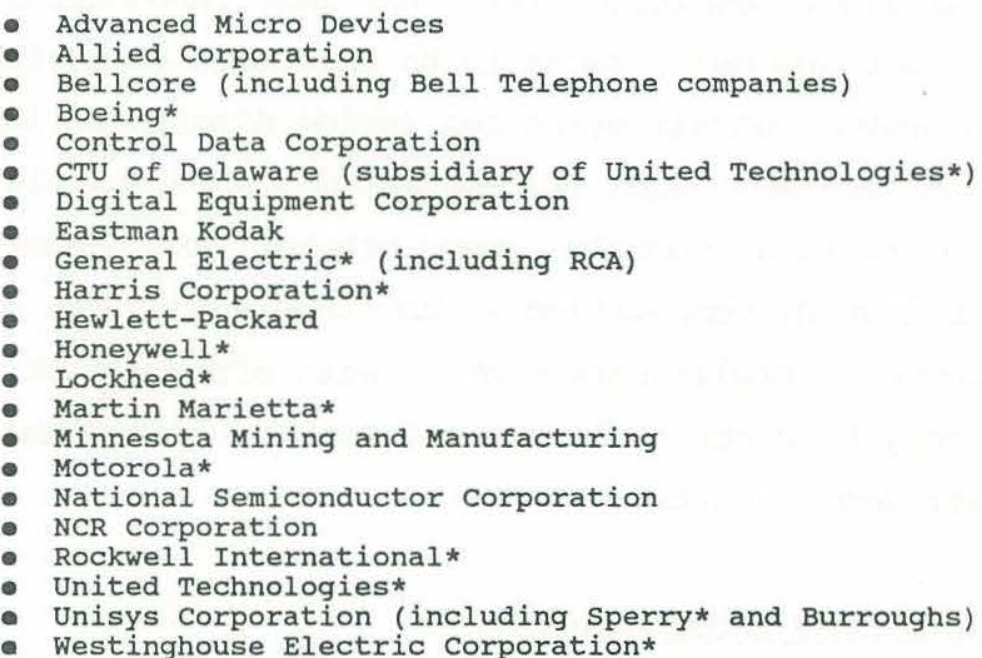

Figure 36: Microelectronics and Computer Technology Corporation Shareholders. "*" indicates a firm involved in marine electronic instrumentation.

Among some of the encouragements found in the Act is a preliminary antitrust clearance review conducted by the Departments of Commerce and Justice. Although the companies are not exempt from suit by private parties after review, there is a "presumption of validity" for the export conduct of trading companies that receive certification. Several companies already have been organized to export electronics, envirommental, and scientific equipment, although we know of none

25 Federal Register 50(78): 15989-90 (23 April 1985). 
71

that are organized specifically for the export of marine electronic instrumentation. Because several factors influence the volume and rate of exports, especially foreign economic growth, relative exchange rates, and others, it may be too early to determine whether or not this Act has had any positive effect (GAO, 1986a).

Companies, joint ventures, trade associations, and other business entities may request DOJ's Antitrust Division to conduct a "business review." This review allows DOT to examine and conment upon the potential competitive effect of "proposed business conduct." A business review states DOJ's enforcement intention at the time of the review but does not limit its enforcement power subsequent to the review. We have examined the Antitrust Division's Digest of Business Reviews and have found no reviews of business conduct related to the marine electronic instrumentation industry. 26

The Federal Trade Commission (FTC) has many responsibilities under the U.S. antitrust laws, but one major focus is to encourage competitive forces in the U.S. economy and to prevent unfair practices (price discrimination, exclusive dealing arrangements, mergers and acquisitions that may substantially lessen competition or that tend to create a monopoly, among others) that hinder competition. One role of FTC's Bureau of competition is to study conditions affecting competition in the U.S. economy. Preliminary contact with officials at the Bureau has revealed that they have not collected information specifically on the marine electronic instrument industry.

\subsubsection{Small Business Encouragements.}

Several programs providing financial or other incentives for small businesses are sponsored by the U.S. Small Business Administration (SBA), an independent agency with an annual budget of roughly $\$ 500$ million. SBA rules set out specific requirements for firms that qualify as small businesses, generally in terms of

26 Antitrust Division, Digest of Business Reviews: 1968-1982, Washington: U.S. Dept. of Justice, 1983 [includes annual supplements through 1987]. Two distantly related reviews concerned a proposal by the Electronics Industry Association for access for American firms into a worldwide certification system for electronic components (1978) and NSF's Ocean Margin Drilling Program, which included U.S. oil companies engaged in joint research and scientific exploration of the outer continental shelf and deep ocean (1980). 
numbers of employees or value of sales volume. 27 Because many firms in the marine electronic instrumentation field qualify as small businesses under these rules, SBA programs, including business development, govermment contract assistance, financial assistance, and advocacy, are important to this industry. Here we discuss three programs which are of special interest.

A small business investment company (SBIC) is a privately capitalized, profit-making firm which is assisted financially by the SBA. SBICs make "venture or risk" investments (unsecured or partially secured loans or equity loans) in small businesses. They are licensed and regulated by the SBA. We have not found any SBICs that are specifically devoted to marine electronic instrumentation. However, because of govermment assistance, this kind of a venture capital institution potentially may be less affected by the trends toward later-stage, short-term investments (see section 3.1.4.), and, as a result, could benefit firms in the marine electronics field.

Regular business loans made by commercial lending institutions may be guaranteed between 85 to $90 \%$ by SBA. An average SBA-guaranteed loan is approximately $\$ 175,000$ with a maturity of eight years (the maximu loan size is limited to $\$ 500,000)$. Loans can be guaranteed by SBA for working capital, plant and equipment, or other needs. In the event that a small business is unable to obtain a loan guaranteed by SBA, SBA is authorized to make loans (up to $\$ 175,000$ ) directly to small businesses. SBA also has other kinds of loan programs and makes bond guarantees (SBA, 1987). We have uncovered no information about the extent to which SBA guaranteed loans have been used by MEI firms, but this appears to be a program with much promise for discrete market opportunities requiring improved economies of scale for efficient production.

Under provisions of the 1982 Small Business Innovation Development Act, 28 SBA coordinates a program of competitive Small Business Innovation Research (SBIR) awards for govermment-sponsored research to small businesses. The Act requires

27 Small businesses are defined generally as businesses that are independently owned and operated and not dominant in their fields. SBA regulations set limits on the number of employees or sales volume for specific 4digit SIC industry groups. The limit for SIC 3662, which encompasses most of the marine electronic instrumentation sector, is set at 750 employees. 13 CFR 121.2, Tables 1 and 2 (1987).

2815 U.S.C.S. 638 (1982). 
federal agencies with large R\&D budgets (usually larger than $\$ 100$ million) to allocate a certain portion (1.25\%) of their annual budget toward this program. 29 Figure 37 shows the SBIR awards specifically for marine electronic instruments over the period 1983-1986 (OIRT/SBA, 1984-87). Phase 1 and phase 2 awards are broken-out by funding agency. Over \$16 million has been awarded over this period, with the Defense Department (primarily the Navy) contributing 73 percent. Expenditures in this area have grown steadily each year; in 1986, they topped $\$ 1.5$ million to 31 firms for phase 1 research and $\$ 5$ million to 17 firms for phase 2 research. In 1986, the average SBIR award for MEI research projects was $\$ 132,000$.

\begin{tabular}{|c|c|c|c|c|c|c|c|c|c|c|c|}
\hline & & & & & Exponditur & (eurremt & 5 thouear & & & & \\
\hline & Phaso & 1883 & & 1984 & & 1085 & & 1986 & & Total 83-26 & 1083.86 \\
\hline DOD & 1 & $\$ 874$ & $(16 / 12)$ & $\$ 824$ & $(16 / 14)$ & $\$ 1,020$ & (21/19) & $\$ 1,168$ & $(23 / 22)$ & & \\
\hline & 2 & & & $\$ 1,409$ & (9/8) & $\$ 2,027$ & $(9 / 8)$ & $\$ 4,314$ & $(15 / 14)$ & $511^{636}$ & 73 \\
\hline NASA & 1 & $\$ 145$ & $(3 / 3)$ & $\$ 100$ & (2/2) & $\$ 148$ & $(3 / 3)$ & & & & \\
\hline & 2 & & & $\$ 974$ & $(2 / 2)$ & $\$ 959$ & $(2 / 2)$ & $\$ 485$ & (11/1) & $\$ 2,811$ & 18 \\
\hline DOT & 1 & $\$ 49$ & (1/1) & & & $\$ 100$ & $(2 / 2)$ & $\$ 100$ & (2/2) & & \\
\hline & 2 & & & $\$ 300$ & $(1 / 1)$ & & & & & $\$ 549$ & \\
\hline NSF & $\frac{1}{2}$ & $\$ 101$ & $(3 / 3)$ & $\$ 305$ & (111) & $\$ 120$ & $(3 / 3)$ & $\begin{array}{r}565 \\
510\end{array}$ & (2/2) & & \\
\hline & & & & & & & & & & SH42 & 3 \\
\hline Doc & $\begin{array}{l}1 \\
2\end{array}$ & & & & & $\$ 30$ & (1/1) & $\begin{array}{r}\$ 90 \\
\$ 170\end{array}$ & $\begin{array}{l}(3 / 3) \\
(1 / 1)\end{array}$ & & \\
\hline DOE & 1 & & & SA7 & (1/11) & & & 599 & (2/2) & $\mathbf{\$ 2 9 0}$ & 2 \\
\hline & 2 & & & & & & & & & & \\
\hline Dol & 1 & $\mathbf{S 3 5}$ & (1/1) & $\$ 35$ & (1/1) & & & & & $\$ 146$ & 1 \\
\hline & 2 & & & & & & & & & $\$ 70$ & $<1$ \\
\hline HHS & 1 & & & & & $\$ 50$ & $(1 / 1)$ & & & & \\
\hline & & & & & & & & & & $\$ 50$ & $<1$ \\
\hline EPA & 1 & & & & & SAg & (1/1) & & & & \\
\hline & & & & & & & & & & $\$ 49$ & $<1$ \\
\hline All Agencies & 1 & 51,204 & $(24 / 20)$ & $\begin{array}{l}51,041 \\
52,683\end{array}$ & $(21 / 18)$ & 51,517 & $(32 / 30)$ & 51,522 & $\begin{array}{l}(32 / 31) \\
(18 / 17)\end{array}$ & $\begin{array}{r}\$ 5,284 \\
\$ 10,758\end{array}$ & \\
\hline & TOTAL & $\mathbf{3 1 , 2 0 4}$ & $(24 / 20)$ & $\begin{array}{l}\mathbf{\$ 2 , 6 8 3} \\
\mathbf{\$ 3}, 724\end{array}$ & $\begin{array}{l}\left(\begin{array}{l}12 / 11) \\
(33 / 28)\end{array}\right. \\
\text { (3) }\end{array}$ & $\begin{array}{l}\$ 2,, 987 \\
34,503\end{array}$ & $\begin{array}{l}(11 / 110) \\
(43 / 38)\end{array}$ & $\begin{array}{r}\$ 5,089 \\
\$ 6,611\end{array}$ & $\begin{array}{l}(18 / 17) \\
(80 / 45)\end{array}$ & $\begin{array}{l}\$ 10,75 \theta \\
\$ 16,042\end{array}$ & 100 \\
\hline
\end{tabular}

Figure 37: Small Business Innovation Research (SBIR) Awards for Projects Related to Marine Electronic Instrumentation, 1983-86. Source: OIRT/SBA (1984-87).

29 The program is divided into three "phases." Under Phase I, up to $\$ 50,000$ is available to support up to one-half of a year of effort. Phase 2 projects are directed at successful Phase 1 efforts, and up to $\$ 500,000$ is available for two year development projects. Phase 3 projects with a specific federal government application may be funded to help support a project to commercialization. 
Annual SBIR awards probably represent ony 2-5 percent of the marine electronic instrumentation industry's total R\&D efforts. The Marine Instrumentation Panel identified small business policy in the United States as an area of special concern. Their deliberations resulted in a list of several problems faced by small businesses in the marine instrumentation field (Figure 38 is an edited form of the list). One of the main conclusions reached by the panel was that the SBIR program was insufficient (Comerford, 1988). In particular, the members of the panel felt that SBIR awards "don't go far enough, either in numbers or dollars" (Williams, 1988).

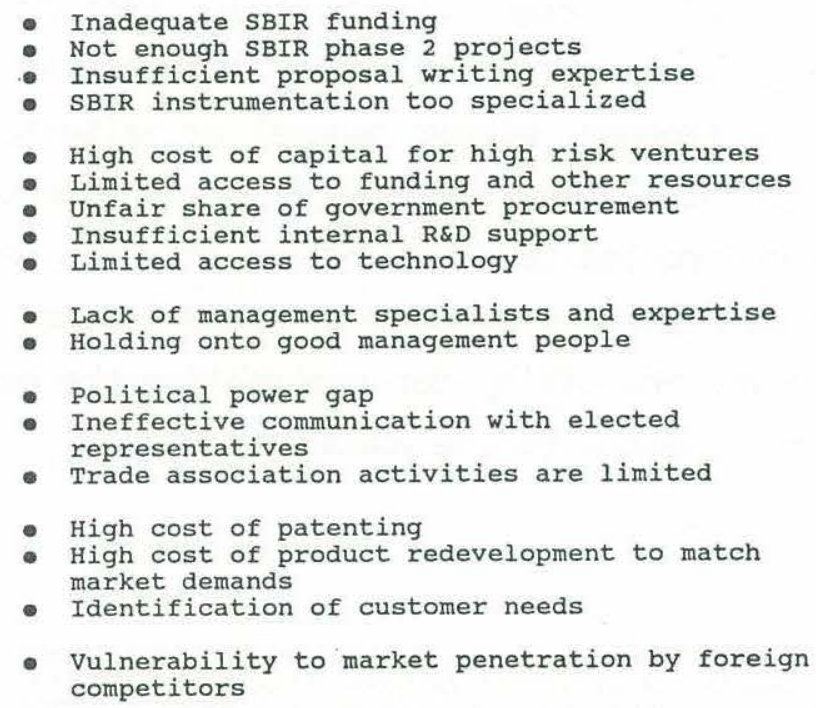

Figure 38: Problems Faced by Small Businesses in the Marine Electronic Instrumentation Field, as identified by the Marine Instrumentation Panel.

An examination of Figure 37 reveals the high concentration of SBIR awards (nearly three-quarters of both the number and the dollar value) issued by the Defense Department (Navy), presumably for predominantly defense-related research. Navy awards have increased in numbers from 45 in 1983 to 286 in 1987 (DoD, 1987). The number of proposals received by the Navy has increased as well, from 944 in 1983 to 2004 in 1987. Yet some agencies with specific marine electronics research needs, such as the U.S. Coast Guard and the Army Corps of Engineers, may find their research needs (and their potential for making SBIR awards) buried among the priorities of their parent agencies. It might be worthwile for the National Marine Electronics Agenda to promote the potential for benefits from SBIR-type 
research for agencies with smaller research budgets but with more specific marine responsibilities. At the same time, small marine electronic instrumentation businesses might be encouraged to take advantage of some of the other SBA programs that have the potential for improving their productive output.

\subsection{International Trade}

\subsubsection{Export Controls.}

In the United States, the congress has a constitutional authority to control international commerce, and the right to export any item from the United States is a grant from the federal government. As shown in Figure 39, a grant to export appears in the form of a license, either general or validated (requiring written authorization). In particular, the exports of certain commodities, technical data, or services are controlled for one or more of three general reasons: national security, foreign policy, or domestic output constraints ("shortages of supply"). Much of the responsibility for controlling the export trade from the United States has been delegated to the executive branch.

\footnotetext{
GENERAL LICENSES: There are 21 types of general licenses. General licenses are available without application, and no documentation is issued to authorize exports under a general license. General licenses are available for commodities which do not appear on the control list and which are not subject to a "denial order." For commodities not subject to the Department of Commerce rules (munitions, controlled substances, nuclear equipment and material), general licenses are unavailable. The categories of general licenses are found in the code of Federal Regulations, Title 15, Part 371.

VALIDATED LICENSES: For commodities, technical data, or services found on the commodity list above a minimum value, application must be made by an exporter for a validated license. Generally, a validated license is for a specified shipment. It is possible to obtain a validated license for a project, for distribution of products by a foreign distributor, or for the supply of replacement parts and repair services. An application for a validated license must include the identification of all parties to a transaction and "substantiate" an actual order for the product. BXA reviews all applications to determine consistency with U.S. export policy. In addition, DoD reviews all applications for export licenses to communist countries. DoD uses its unofficial "Militarily Critical Technologies List" as a reference for export control determinations. The application review period is variable, depending on the nature of the product and its destination, and may run from five days to four months. This review period is now being shortened through the use of computerized validation.
} 
The U.S. Export Administration (BXA), a bureau located within the Department of commerce, maintains a "control list" of commodities subject to export controls, the nature and scope of control, and other pertinent information. Generally speaking, commodities found on the "control list" in excess of specified minimum values must receive a "validated" license prior to export. All applications for export licenses are directed initially to BXA. In some cases, license applications are sent to the Defense Technology Security Agency (DTSA) in the Defense Department or the Office of Munitions Control (OMC) in the State Department for review.

Appendix D is an abstract of the Commodity Control List identifying several marine electronic instruments subject to export control rules of varying stringency. Commodities for export are reviewed on a continuing basis to determine whether or not they should be placed on or removed from the control list. 30 Review is conducted by interagency Technical Task Groups (TTGs) with advice from the Commerce Department's Technical Advisory Committees (TACs). The TACs may receive comments from any interested party concerning the disposition of a commodity.

The control list also identifies countries for which validated licenses are required. These countries are segregated into eight "country groups." (In some instances, certain commodities may be prevented from exportation, especially to countries such as Libya, South Africa, Vietnam, or countries of the Soviet bloc.)

In addition, the United States is a member of the coordinating committee for Multilateral Export Controls (COCOM), an international body established in 1949. COCOM consists of 15 countries that maintain similar export control standards based on the "technical performance" (not the stated end-use) of specific commodities. 31 A general license is available for the export to Cocom

30 For example, if a non-U.S. origin commodity is found to be "available-infact" in a proscribed country, U.S. producers may be able to claim "foreign availability" and to seek decontrol of the export of a commodity (or technical data) controlled for reasons of national security to that country. 15 CFR 391 (1987).

31 The member countries are: Belgium, Canada, Denmark, France, West Germany, Greece, Italy, Japan, Luxembourg, the Netherlands, Norway, Portugal, Spain, Turkey, the United Kingdom, and the United States. 15 C.F.R. 370.2 (1987). A recent ruling by the U.S. Export Administration permits exports to Finland to be treated as if Finland were a COCOM member. 52 Fed. Reg. 32121 (26 August 1987). 
destinations of "low-tech" commodities that otherwise would require a validated license. For example, a recent COCOM review resulted in a revision to validated license controls on item 1501A (navigation, direction-finding radar and airborne communication equipment). 32

COCOM maintains three "lists" of commodities, the export of which the member countries agree should be controlled to the Soviet Union and other communist countries: the International Atomic Energy List, the International Munitions List, and the International List ("dual-use" items that might be used for either civilian or military purposes). However, individual member countries are not necessarily constrained by agreements concluded at COCOM; domestic export law and policy may supersede Cocom agreements. In addition, there may be variable interpretations of license restrictions by individual COCOM member countries, resulting in a variable export control system.

Perhaps the most salient recent example of this variability is the 1986 Toshiba-Kongsberg Technology Diversion case. In this case, three Japanese companies and one Norwegian company were found to have sold "sophisticated" marine propeller milling machines and related computer technology to the Soviet Union. This sale is referred to as a "diversion" because the technology was considered important for national security reasons and export licenses should have been denied under the COCOM system (Senate Banking Cm., 1987). This case is of particular importance to some sectors of the marine electronic instrumentation field, because the technology can be used to make Soviet submarines run quieter, thus creating a need for the U.S. to research, develop, and produce more effective ways to detect these submarines. The discovery of the diversion resulted in the tightening of the Japanese and Norwegian export control systems and heightened the sensitivity of U.S. agencies with export control authority, even though none of the equipment in question was manufactured in the United States.

As can be seen in Figure 40, several other federal agencies share significant responsibility over the control of exports with BXA, resulting in a complicated export control process driven in sometimes variable directions by different agency viewpoints (Lindstrom, 1985). Two of these agencies are important for MEI products, the Department of State, which manages the U.S. "munitions list," and the Department of Defense, which manages its list of

32 Federal Register 50(176) : 37136 (11 September 1985). 


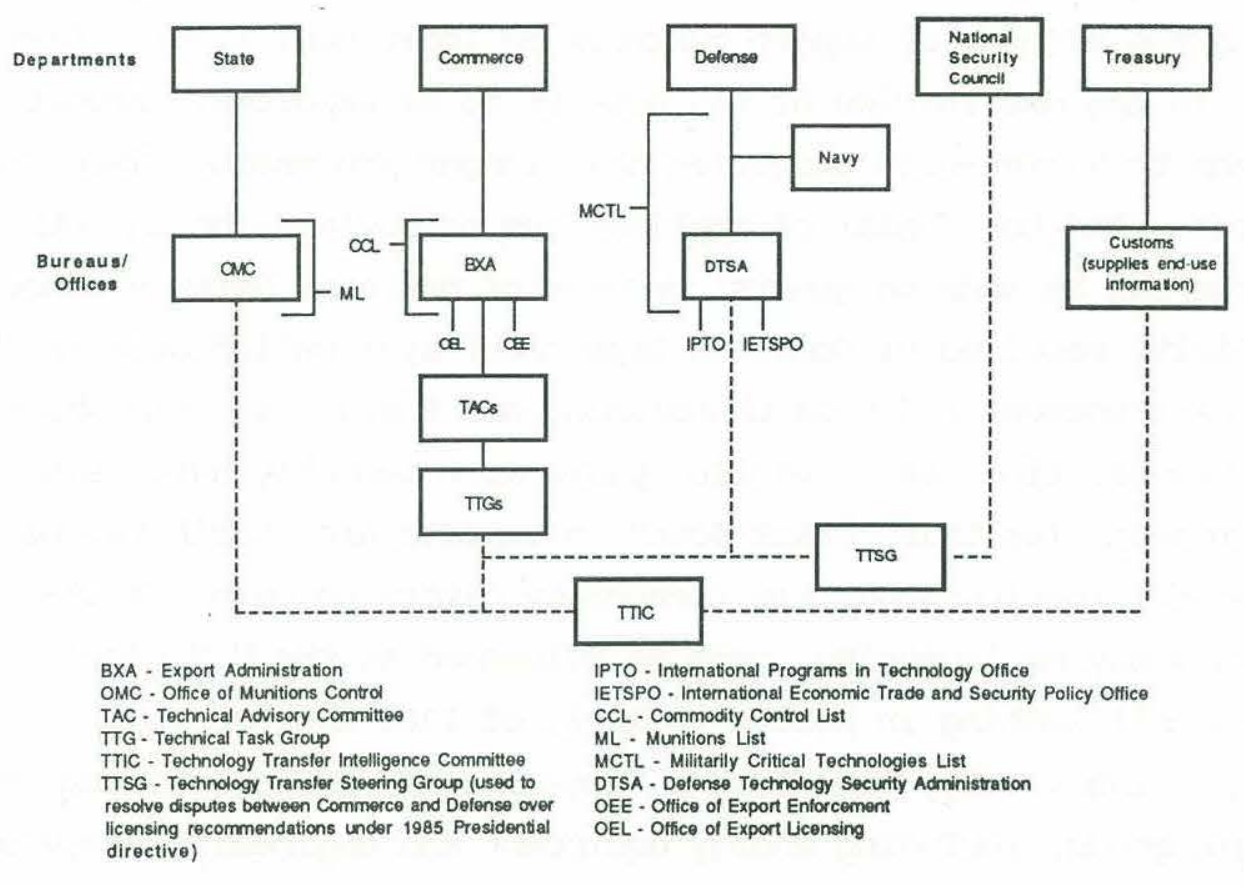

Figure 40: Federal Agencies Exercising Control over Exports.

"militarily critical technologies." All license applications made by firms located in COCOM member countries are received initially for review by OMC in the State Department, which seeks additional review from Commerce or Defense, if necessary. Under a presidential directive issued in 1985, the Defense Department's license application review authority was broadened to include eight product categories (including one that covers "electronics and semiconductor manufacturing") for destination to 15 specified free world countries (all outside of COCOM), the Soviet Union and China. 33 Recently (May 1988), the list of free world destinations was shortened to eight countries, and this has cut DoD's review load by roughly 43 percent (GAO, 1988d).

Based upon interviews with industry officials, we have obtained a mixture of impressions of the effects of U.S. export control policy on international trade in marine electronic instrumentation markets. These impressions range from no effect

33 However, since 1981 DoD has reviewed "high technology, computer-related" applications to most free world destinations under the provisions of a commerceDefense interagency understanding (GAO, 1986). 
at all to a significant effect, but there are at least four important factors influencing the effects of export controls on individual firms. First, and most important, is the destination of the product to be exported. Export license applications to Soviet-bloc countries have longer processing times and higher denial rates. And DoD denial of applications to Soviet-bloc and other free world destinations can be made on general grounds of national defense concerns, without the specificity required of Commerce Department application denials (GAO, 1986b). MEI firms have encountered this phenomenon, and there are cases where products that were granted licenses in earlier years more recently have been denied. Most often the reasons for this "crack-down" on exports are attributed to the Walker spy case or the Toshiba-Kongsberg technology diversion case. There are signs that controls may be loosening, such as evidenced at the U.S.-Soviet Trade and Economic Council meeting in Moscow in April of 1988 where the U.S. Secretary of Commerce, William Verity, announced a loosening of controls on some types of nonstrategic goods, including energy equipment and engineering services, but progress is expected to be slow (Starrels, 1988).

Second, the nature of the products are important. Not all marine electronics are considered to be "militarily critical," most notably the commercial/recreational marine radios, fishfinders, etc., and many of these products are exportable under general licenses. At the other extreme, some defense technologies may be traded in foreign military sales programs (see: section 3.1.2. above) and thus are, in effect, sanctioned for export by the federal govermment. Technologies that fall outside of these two cases, and especially products that are elements to be combined with other technologies into a marine electronic system or assembled in a foreign jurisdiction for resale elsewhere (computer hardware and software are good examples), seem particularly vulnerable to U.S. license application denials. In part, this is due to the (not wholly unfounded) perception that export controls are less stringent in foreign jurisdictions, even within COCOM countries. Researching foreign license validations is fraught with difficulty, especially since most foreign export control systems are not computerized or otherwise difficult to access. Lost sales of some kinds marine electronic instrumentation products to foreign producers due to the inability of U.S. firms to assure foreign customers of the ability to obtain a U.S. export license are not uncommon.

Both the size of the exporting firm and the proportion of its sales into 
foreign markets influence the effect of export controls on international trade. Larger firms tend to have the resources to devote one or more employees solely to the task of obtaining export clearances. In some circumstances, sales representatives or dedicated agents located in foreign jurisdictions can speed the process of obtaining documentation to assure federal govermment officials that technology will not be diverted. Firms that sell only a small proportion of their products into foreign jurisdictions would be expected to face a smaller number of export control problems, although this is highly dependent upon the nature of the product being exported. Small firms may still face significant problems in obtaining export clearances, even if only one product line is involved.

There are additional issues associated with the effect of export controls on international trade in marine electronic instruments. 34 Some industry officials have doubts concerning the level of technical expertise shown by federal license reviewers, and this may be understandable given a wide range of technologies that must be examined and the limited number of examiners. In cases where technologies are available in foreign jurisdictions, but U.S. export licenses are denied, it can be costly, with no guarantee of success, for U.S. firms to demonstrate "foreign availability" as an appeal to the licensing decision. But perhaps the most important issue concerns the fluctuating imposition and relaxation of controls that has been experienced during this decade. The regulatory uncertainty associated with variable levels of control (seemingly driven by foreign policy directives or national security breaches) raises the costs faced by U.S. firms involved in exporting marine electronic instrumentation. This is a problem of direct relevance to the international competitiveness of the field as a whole and would seem to impact to a larger proportional extent on small, newly-emerging firms in these markets.

\subsubsection{Import Restrictions and Barriers to Trade}

The majority of barriers to trade concern import restrictions instead of export controls. The erection of trade barriers raises two general issues: the restriction of imports of U.S. items into foreign jurisdictions and the restriction of imports of foreign items into the United States. While these

34 Two additional areas of potentially productive research include controls on technical data or information useful for the design or manufacture of marine electronic instrumentation, and export insurance policy. 
issues seem simple at a general level, because of the variety of methods by which imports can be restricted and the different reasons for restriction, import policy can become quite complex. It is not our intention here to give an indepth description of import restrictions and import policy (cf. OTA, 1983). Instead, we will present an overview of the issues faced by U.S. manufacturers of marine electronic instrumentation as they export into foreign jurisdictions, and the remedies available to those manufacturers as they face trade barriers, both at home and abroad.

Most countries impose duties, known as tariffs, upon the entry of a foreign product into their home jurisdiction. The exorbitant tariffs erected by the United States under the Smoot-Hawley measure in 1930 (and the resulting international countervailing reactions) are believed to have been a major factor leading to a breakdown in international trade and to worldwide economic depression. Generally, most countries have realized the detrimental effects of large tariffs upon international trade in goods and have agreed in multilateral trade negotiations to control tariffs to nominal rates on most products. This does not mean that all countries are given identical tariff treatment. As an example, in the Tariff Schedule of the United States (ITC, 1986a), which is maintained by the U.S. International Trade Commission, a typical entry for marine electronic instrumentation is found (Figure 41). The three columns underneath

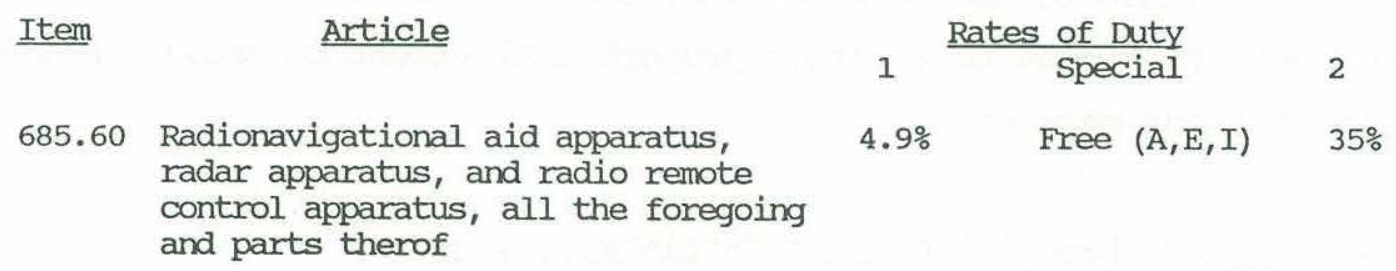

Figure 41: Sample Tariff Schedule Entry for Marine Electronic Instrumentation. Source: ITC (1986a).

"rates of duty" are variable tariff levels for one item entering the U.S. customs territory. Column one represents the tariff imposed on products from canada; this 
column is known as the U.S. most favored nation (MFN) tariff rate. 35 The "Special" column represents the special tariff faced by selected developing countries under a "generalized system of preferences" 36 and by others such as selected Caribbean Basin countries and Israel, which have free trade agreements with the United States. Column 2 represents the tariff faced by countries of the Soviet Bloc and other selected communist countries (in 1980, the People's Republic of China was removed from the list).

Tariffs imposed by other countries are not identical to those of the United States, even under the MFN system. However, the "Tokyo Round" of multilateral trade negotiations (part of the General Agreement on Tariffs and Trade [GATT]) resulted in substantial cuts in average tariffs. For example, because of the Tokyo Round negotiations, the average nominal tariff on electrical machinery (SIC 383) was reduced from 6.6 to 4.4 percent in the United States, from 9.9 to 7.9 percent in the European Community, and from 7.4 to 4.3 percent in Japan. 37 Because of the nominal tariff rates imposed on most marine electronic instruments (averaging perhaps less than five percent), we expect that tariffs are not perceived as a major barrier to trade in this industry. Items originating in communist-bloc countries still face substantial tariff rates.

An interesting, but small, program established in the United States allows the duty-free entry of scientific instruments. This program is available for public or private nonprofit institutions established for educational or scientific purposes. Eligible institutions make an application for duty-free entry to the International Trade Administration (ITA), which then sends that applications out

35 "Most favored nation" tariffs are nondiscriminatory tariffs applied to imports from nations agreeing to provisions of the General Agreement on Trade and Tariffs (GATT). For Canada, this tariff rate may be affected by the ratification of the recent United States-Canada Free Trade Agreement.

36 The generalized system of preferences (GSP) is a system of reduced tariffs for imports from qualifying developing countries. The concept of GSP originally was formulated at meetings of the United Nations Conference on Trade and Development (UNCTAD). For a good description of GSP, see: Sapir and Lundberg (1984).

37 These reductions were initiated in 1980 and phased in over the next seven years (Deardorff and Stern, 1984). 
for review to agencies with relevant expertise. 38 A brief review of recent Federal Register notices of applications has shown that marine electronic instrumentation is imported from foreign jurisdictions under this program. Among recent imports listed: the Huntec (Canada) "deep towed pressure compensated boomer seismic system" to WHOI (1987); the I.S.E. Gulf (Canada) "remotely operated vehicle system, HYSUB-40 to Harbor Branch Foundation (1987); and the Sea-I Research Canada "towed underwater submersible system, Model MANTA" to NOAA/NMFS (1987). We have requested a computer search from the Statutory Import Programs staff at ITA of duty-free applications during the past five years to get a better understanding of the extent to which this program is used.

There are several areas in which government policies might have an effect on the competitive position of U.S. firms in the international marketplace (NAE, 1984). In the future, we plan to look more closely at the policies exercised by other govermments, especially govermment-sponsored R\&D efforts, and characterize their effect on the competitiveness of U.S. firms in this international market. In a related context, we will consider the extent to which foreign firms and governments perceive U.S. defense R\&D spending to be a form of domestic industry support, particularly for technologies that are commercialized and traded internationally. The following are examples of the kinds of foreign programs that we will be examining closely:

- EUROMAR. Established in 1986 as a EUREKA project, EUROMAR's specific goal is the "development, application and successful exploitation of Europe's advanced marine technology having worldwide market potential." One specific objective has been to "promote cooperation between industry and science in developing marine instrumentation and methods." Participants in the EUROMAR program (firms, research institutions, govermments) seek private as well as public funding for their efforts. Participating European governments include France, the Netherlands, West Germany, Finland, and Norway, all of which have firms that sell into marine electronic instrument markets and which compete substantially with U.S. firms (Euromar Sect., 1988).

38 This program was established as section $6(c)$ of the Educational, Scientific, and Cultural Materials Importation Act of 1966 [P.L. 89-651], 89 Stat. 897. Applicants must show that for the instrument's intended use, no instrument is being manufactured in the United States of "equivalent scientific value" to the foreign instrument. 
- Japan. The Japan Ministry of International Trade and Industry (through the Agency for Industrial Science and Technology and Japan Ocean Industries Association) and the Agency of Science and Technology (through the Japan Marine Science and Technology Agency) target R\&D opportunities in the ocean sector and have subsidized marine electronic instrumentation R\&D projects, such as the development of ROVs, XBTs, optical fiber communication links, and automatic offshore oil and gas drilling (Kitamura, p.c., 1988; Saeki, 1984).

- United Kingdom. The U.K. Department of Trade and Industry (DTI) provides support for the development of radars, sonars, simulators, automated control, and satellite navigation systems (SCST, 1985). In 1984, approximately 193 million pounds (\$259 million) was spent by the United Kingdom govermment on "marine science and technology." Iess than 7 percent (about \$18 million) was devoted specifically for "improvement of technology" (GBCO, 1984). Further research will be necessary to identify expenditures specifically for marine electronics. The U.K. govermment recently has organized a coordinating committee on Marine Science and Technology to coordinate govermment funded activities in marine science and technology and to "develop a national strategic framework" involving government departments, research councils, and industry (NERC, 1988). The British Electrical Engineering Association has testified before the Select Committee on Science and Technology in the House of Lords regarding the large export potential for marine electronic equipment (SCST, 1985).

There are many other forms of nontariff trade barriers (NTBS), including import licenses, "buy-national" govermment procurement policies, performance requirements, technical standards, quotas (including orderly marketing agreements and voluntary export restraints), intellectual property right infringements (see section 3.1.6 above), and outright production subsidies (CBO, 1987). Our discussions with industry officials revealed that many of these kinds of NTBs are not prevalent in international trade of marine electronic instrumentation. There is a strong impression, however, that in some countries (United Kingdom, Canada) buy-national provisions do in fact restrict the markets for U.S. manufactured products. Although the tendency for U.S. govermment agencies (especially the Navy) to favor purchases of marine instruments from U.S. manufacturers is recognized by firms in the industry, generally this is not seen as a counterbalance to similar actions of foreign govermments.

There are several methods by which U.S. manufacturers might seek relief from 
the effects of NTBS, particularly in U.S. markets. Among these are the import relief ("escape clause"), countervailing duty, and antidumping laws, as well as other provisions that direct federal agencies (particularly the ITC) to investigate "serious injury" to U.S. firms due to increased imports or "unfair trade practices" (ITC, 1986b). Section 301 of the Trade Act of 1974 allows the President to enforce U.S. trade rights on his own initiative or in response to the filing of a petition. This section's applicability is broad, applying to "acts, policies, or practices of a foreign govermment that are unjustifiable, discriminatory, or unreasonable and that restrict U.S. trade or violate international agreements" (GAO, 1987b). Although this section has had limited use in the past, more recently (since 1985) it has become the Administration's primary method for countering unfair foreign trade practices (the Japan semiconductor agreement was the result of a 301 case). The 301 process invokes dispute settlement procedures either bilaterally or under GATT, depending upon whether or not an international agreement may have been violated. Some 301 cases have taken extraordinarily long to reach resolution, especially under the GATT rules. The President may act prior to the end of the formal settlement, by enacting trade sanctions, for example, even on commodities which are not in dispute. However, the President traditionally has waited until the GATT process or bilateral negotiations have been successful. Often the threat of action under 301 may be more useful than the action itself (GAO, 1987b, 1985). The recent trade bill passed by Congress this year has transferred much authority from the President to the Office of the U.S. Trade Representative, increasing administrative discretion and potentially speeding the initiation of 301 cases as well as retaliatory actions (Langley and Mossberg, 1988). Although we know of no marine electronic instrumentation cases or investigations pending under 301 or other U.S. trade law provisions, it appears that section 301 may have a higher probability of use should a case arise in the future.

In 1986, the U.S. Senate Finance Committee requested the ITC to conduct "competitiveness studies" in several industries. Although none of the industries were related to marine electronic instrumentation, we expect that the methods employed by the ITC, including the development of automated data bases providing measures of competitiveness and generic questionnaire formats, are transferable. We plan to examine this avenue as we begin the second year. 


\subsubsection{Exchange Rates}

The fluctuations of exchange rates can have a profound effect on international trade in commodities like marine electronic instruments. Figure 42 depicts over the decade from 1978 to 1988 the movement of U.S. dollar and real effective exchange rates for several of the major industrial countries in which trade in marine electronic instrumentation is important. Since 1984, the U.S. dollar has depreciated substantially, resulting in a general improvement in the international competitiveness of manufacturers in the United States (IMF, 1988). Interviews with industry officials in MEI markets have formed an impression that exports of U.S. manufactured MEI commodities have improved as well with the decline in the U.S. dollar. 39
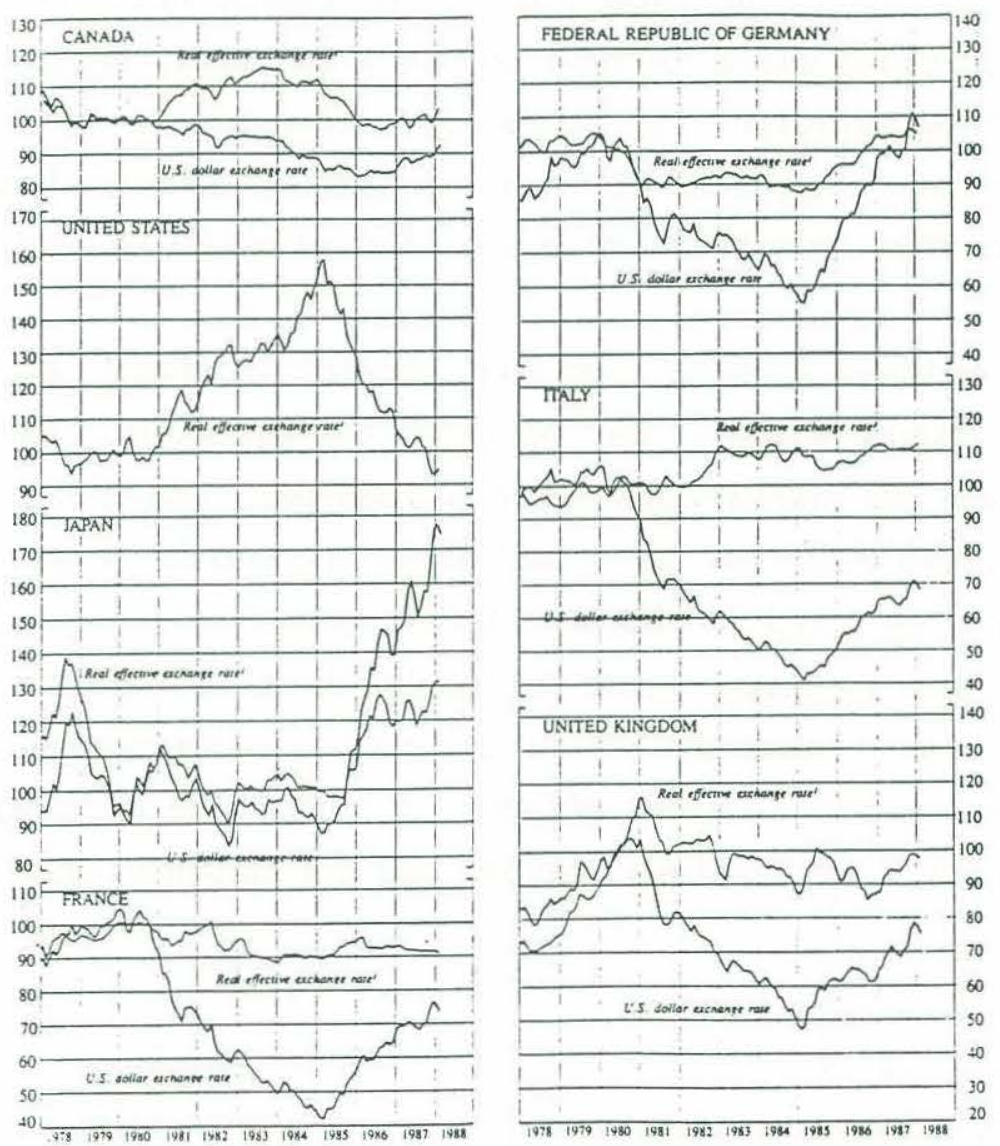

Figure 42: Foreign Exchange Rates, 1978-87. Monthly average U.S. dollar and real effective rates. Source: IMF (1988).

39 We would also expect imports to slacken at the same time, but we have no evidence to this effect. 
We expect that the magnitude of the influence of exchange rate fluctuations will depend upon idiosyncratic characteristics of individual markets. For example, the effect of exchange rate variation may be more pronounced for large volume, low profit-margin commodities that are produced in more than one country. Thus the commercial/recreational sector is likely to be the most sensitive to exchange rate effects. At the other extreme, international trade in unique instruments, which may be produced by only a few firms in the world and which are not easily substitutable, may be virtually unaffected by any but the largest exchange rate variations. Further, the extent to which traders engage in longterm contracts for both manufactures and support or maintenance services with fixed price arrangements will influence the sensitivity of international trade to exchange rate fluctuations. We expect that long-term contractual relationships are relatively rare among firms in this industry and more common among countries, although further investigation will be required to substantiate this hypothesis. Foreign military sales, supported at least in part by international economic aid programs, may be of the type that are not easily effected by exchange rate movements.

Recent international negotiations that attempt to stabilize exchange rates, such as the 1987 "Louvre Accord," may minimize the effect of fluctuating exchange rates on the markets for marine instruments. However, the value of the U.S. dollar and the related exchange rates may be influenced by numerous factors, some of which are beyond the reach of international accords. Among these factors are trade disputes between nations, which may shake the foundations of international agreements, and domestic monetary and fiscal policy adjustments (IMF, 1988). In the future, we plan to focus on the effects of short-term exchange rate movements on trade in some of the high-volume commodities for which credible trade data are available.

\subsection{Technology Pathways.}

The sources and pathways of inventiveness and innovation in the marine electronic instrumentation industry are of great importance to continued competitiveness. We have begun to examine the parameters governing technological development in this industry, both between the sectors of the business in the United States and internationally. However, much work remains to be done on this topic, which will become a major focus of our continuing study of the marine 
electronic instrumentation industry.

\subsubsection{Education.}

The effect of advanced educational programs in marine electronic instrumentation on the transfer of technology is a subject of further research, as is the involvement of the National Sea Grant College Program. Professional conferences and seminars provide additional settings for the transfer of knowledge and technology, and also require further investigation.

Foreign students studying in the United States - and in particular, in advanced degree programs of study -- are likely to be a source of technology transfer from the United States to Europe, Scandinavia, Japan, and other nations.

In the area of scientific oceanographic instrumentation, research universities play a major role in the development of new designs, techniques, and instruments. This role is exemplified by the "spawning ground" effect previously discussed in Chapter 2 of this report. Like the spawning ground effect, which appears to be strongest for oceanographic instrumentation firms and which manifests itself most obviously in the United States, the technology transfer from U.S. research universities to other nations is also likely to be larger in the oceanographic/scientific area than any such transfer into the United States. American research institutions are, and consistently have been, at the forefront of oceanographic research and instrumentation design, and are therefore attractive places of study for European and Scandinavian engineers in this field. Conversely, U.S. oceanographic engineers have correspondingly less incentive to attend European research institutions for advanced degrees. Discussions with representatives of European and Scandinavian firms in the oceanographic instrumentation business often include references to staff members being "sent to the States" for additional education.

This is probably not true in the offshore oil and gas field. In this area, European research institutions historically have been at the forefront due to their proximity to the pioneering North Sea offshore developments. In offshore technology, European and Scandinavian institutions continue to set the pace, and U.S. institutions have been catching up since the beginnings of offshore work in the Gulf of Mexico. Still, the oil companies working the North Sea fields spend large sums on research at European institutions as part of their lease obligations; and the flow of technology due to foreign students in the offshore 
field is likely to be much less one-sided than in the oceanographic field.

\subsubsection{Universities and Independent Laboratories.}

Although universities and independent laboratories are known more for basic than for applied research, even basic research (particularly in the marine environment) often implies "applied" work on and with sensor technology. This leads directly to the "spawning ground" effect discussed in Chapter 2, which has direct implications for the transfer of personnel--and therefore of information and technology--from universities and government laboratories to the private sector. Indeed, this is inherent to the very nature of the "spawning" of new oceanographic instrumentation firms: a scientist or engineer working at a research university, laboratory, or other institution decides to form a commercial enterprise in order to produce and market a new instrument that was conceived and initially developed within the research institution. The common occurrence of this sort of spawning points to the pervasive importance of such technology transfer, at least in the United States and (perhaps to lesser extent) Great Britain.

As described in Chapter 2, American oceanographic instrumentation firms tend to be established in the vicinity of the institutions from which they spring. This geographic proximity has implications for additional transfers of information and technological developments long after the founding of the firms. The founding engineer(s) or scientist(s) are likely to maintain contacts with their colleagues at the institution (especially since they will be hoping to sell their instruments to them); they may even continue to work at the institution while they start their commercial operations. Because they are right next door, they can easily attend seminars and conferences on oceanographic techniques held at the institution. These contacts with the research community provide valuable market information to the firm. In many instances, oceanographic firms maintain strong relations with their "parent" institution for many years after the initial spinoff.

The extent to which similar mechanisms are at work around other institutions, such as cooperative research centers (NSF centers), remains a topic for further research. 


\subsubsection{National Laboratories}

The role of national (govermment owned and/or operated) laboratories in the transfer of technology to private firms, and their effect on the domestic and international competitiveness of these firms, is a subject of growing national interest. It is possible that technology transfer of this kind could help the industry in overcoming natural barriers to investment in basic research.

The national laboratories and R\&D centers involved in the development of marine electronic instrumentation are shown in Figure 43. Many of these labs and centers are "Navy labs," directly under the control, and funded by, the U.S. Navy. According to current Navy. Secretary William Ball, "Navy technical activities have had technology transfer offices for almost twenty years, and we are expanding and strengthening this network of field command offices." Some of these technology transfer offices "specifically [provide] access to technology available for licensing and commercializing, and opportunities for participating in cooperative Research and Development Agreements" (Navy Factsheet, August 1988). The effectiveness of these Navy programs remains a topic for further investigation.

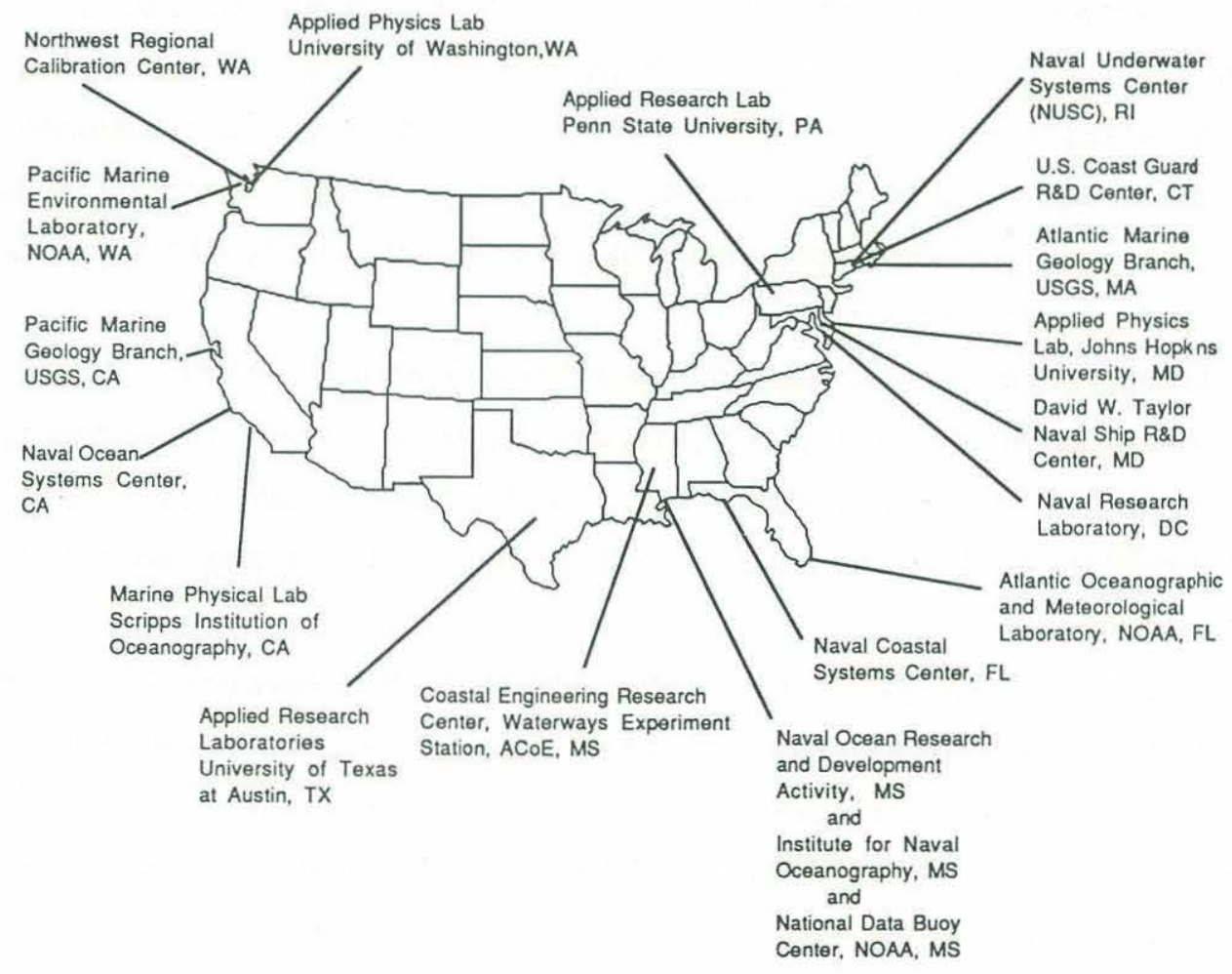

Figure 43: U.S. National Labs and R\&D Centers Involved in Marine Electronic Instrumentation. Adapted from Paisley (1987) . 
91

Other programs and initiatives which we will examine include those established under the Federal Technology Transfer Act of 1986 [P.L. 99-502], such as the Research and Technology Applications Offices and the Federal Laboratory Consortium for Technology Transfer; the Department of Commerce's Center for the Utilization of Federal Technology (CUFT) and personnel exchange programs established under the Stevenson-Wydler Technology Transfer Act of 1980 [P.L. 96480], and other programs run by the National Technical Information Service.40 In addition, we will further examine the role of special considerations given to small businesses in dealing with national laboratories and preferences to U.S. businesses agreeing to manufacture in the United States.

\subsubsection{Intersectoral Transfers.}

Other dimensions of inventiveness and technology transfer involve the relationships between the end-use sectors. In particular, the flow of technology between the naval and civilian offshore sectors, the two largest customers of marine electronic instrumentation firms, bears further investigation. It is likely that products and techniques developed in one sector could find markets in another sector; a recent example of this, the military mine-sweeping use of civilian ROVs refined for use by the offshore industry, is discussed below. This corresponds to what may be the easiest sort of transfer, because developments in the commercial and offshore sectors are publicized widely through advertising in the trade and popular journals.

The development of the expendable bathythermograph (XBT) serves as a possibly anomalous example of a development, funded by private R\&D investment, which has spread through the military, scientific, and offshore sectors. There is, however, a general problem of the products of R\&D not crossing inter-sectoral boundaries (Williams, 1988) .

Scientific facilities, such as the Woods Hole Oceanographic Institution (WHOI) and its Navy-funded research submarine ALVIN, serve as "safe places" for the Navy to try out new devices. "Halo" labs, less subject to criticism than commercial ventures, can be more easily used for certain kinds of development

40 For a brief description of these programs, see: National Technical Information Service, "Productivity, Technology, and Innovation; Study of Alternatives for Privatizing the National Technical Information Service," Federal Register 51(81): 15868-15870 (28 April 1986). 
efforts. The research qualifications of scientists at those labs further enhance the capabilities for risky developments. The result is in effect a transfer of technology across the military/scientific barrier, in both directions. Twenty to thirty percent of the money the Navy put into ALVIN in the first 15 years of its operation was intended for the testing of concepts and procedures in an enviromment where a failure would be less embarrassing than in a military program (Williams, 1988).

A number of failures of R\&D efforts, successful in themselves, to cross inter-sectoral boundaries, can be cited. Benthos developed emergency acoustic beacons to be used to mark lost equipment; these have never caught on in either the scientific or the commercial user group. Raytheon developed piezoelectric polymer material for a wide-aperture acoustic array, but this has not been used, even within the Wide Array project. Passing a particular technology to another user group may be inhibited by the small demand for a particular device. For example, a limited number of special flex-tensional acoustic transducers were built, but they were "swapped around" within and between the military and scientific user groups, and satisfied the research needs without generating a larger market (Williams, 1988).

There are clearly successes as well as failures in the crossing of intersectoral boundaries. Radar and sonar have diffused through all user groups. Sonobuoys--in one form or another--have crossed the boundaries between offshore, scientific, and military sectors. The common characteristics of these successes seem to be the vast quantities used, military needs, or offshore energy companies' demands (Williams, 1988).

In this time of budgetary constraints, the U.S. Congress has asked the Navy to examine the possibilities of using more off-the-shelf, commercially developed systems, thereby saving the considerable expense associated with the development of similar systems to Navy specifications by military contractors. In the case of marine electronic instrumentation, this would mean the Navy procurement of instrumentation systems originally developed for the scientific, offshore, or commercial/retail sectors. While this has happened in isolated instances (see discussion of mine-hunting ROVs below), it appears that several substantial barriers preclude this from becoming a nonmal occurrence.

One problem is bureaucratic momentum. The Navy procurement system is highly complex, and staffed with officials who are used to buying systems from military 
contractors. It will most likely take more than an occasional "suggestion" from Congress to make a difference in the Navy's standard procurement procedures. A related issue is the stringent "military spec" to which all Navy systems are designed, and which the commercial systems would presumably also have to meet. Unless special provisions are made, it is not likely that off-the-shelf commercial equipment will pass the test of these Navy specifications. Finally, the Navy's overall trend away from item-by-item procurement and towards the purchase of large, complete systems from major military contractors would also appear to decrease the chances of direct transfers of civilian systems into the military sector.

A recent example of a transfer from the offshore sector to the military is seen in the adoption by the U.S. Navy of slightly customized off-the-shelf ROV systems for mine hunting operations. ROVs were developed largely at the instigation of the offshore business, for which they are a less expensive alternative to divers or manned submersibles in the installation and maintenance of offshore structures. When the U.S. Navy needed additional mine-sweeping capabilities on short notice in the Persian Gulf crisis during the spring of 1988, they turned to Benthos, a Massachusetts oceanographic firm and ROV manufacturer, for eight SeaROVER ROV systems. Under a \$3 million contract from the Naval Sea Systems Command, Benthos "militarized" its standard SeaROVER design, and quickly installed the units on U.S. Navy mine-sweepers in the Gulf, where they soon proved valuable in the detection and identification of underwater mines.

Although Benthos easily could have added manipulators to the ROVs to cut mines from their moorings or to carry explosive charges to the mines, this step was not taken because established Navy procedures for handling ordnance did not permit such activities at the time and had to go through lengthy review before any such steps could be taken. The ROVs were therefore used only as roving sensors, using both sonar and video systems. This restriction of the full capabilities of the ROVs points to the difficulty of introducing and using conmercial systems in naval operations, as discussed in the section above.

\subsubsection{International Transfers.}

Industry characteristics such as the ready movement of personnel between firms, internationally as well as domestically, and restrictions on domestic trade or export of products, are likely to have significant impacts on innovation and 
the transfer of technology in this industry. These issues are of clear significance to the competitiveness of U.S. marine electronic instrumentation firms, and will be pursued during future research in the form of case studies of technological transfer across national boundaries as well as across end-use sectors.

One group clearly in a position to influence international technology transfer are the sales representatives. Sales representatives tend to be specific to one country, since they must know the intricacies of doing business, and maintain close contact with the buyers of technology within that nation. While they serve as mediators of the sale of marine instrumentation, sales representatives are not always cognizant of the technical details of the equipment they are selling, and probably do not serve as personal conduits of technological information. They do play a large role in the distribution of the instruments themselves, however, and this international transfer of instruments can constitute technological transfer on a large scale.

Other topics of further investigation in the area of international technology transfer include the role of trade shows, foreign sales corporations, international joint ventures, the International Development cooperation Act of 1979 [P.L. 96-53], and other policies such as the Japanese Technical Literature Act. These considerations also tie in with further investigations of the policies governing the enforcement of intellectual property rights in foreign jurisdictions. 



\section{Conclusions}

Marine electronic instrumentation encompasses most of the high technology tools that are vital to the efficient exploration, understanding, and use of the oceans. Technological advance and economic activity in the world's oceans depend strongly on this class of technology. Producers of these instruments sell into a world market, and their consumers span all ocean sectors from undersea defense to offshore oil and gas, oceanographic research, environmental monitoring, commercial shipping, fishing, and recreational boating. U.S. firms face foreign competition on nearly 100 percent of their marine electronic instrumentation products.

Marine electronic instrumentation is a small but critically important area of high technology, bridging a world electronics market of $\$ 400$ to $\$ 500$ billion and a world marine market on the order of $\$ 400$ billion. High technology products are defined generally to include those products for which research and development (R\&D) expenditures are a significant (perhaps as high as 5 to 15 percent) proportion of sales. Annual production of marine electronic instrumentation in the U.S. is on the order of $\$ 3$ to $\$ 5$ billion, with perhaps 20 to 30 percent of this being exported, and a smaller amount being imported. The world market for these products is estimated at about \$10 billion annually.

Four major end-user groups of marine electronic instrumentation products have been identified. These are, with their approximate annual U.S. sales volumes: (1) the military, \$2 billion; (2) offshore oil and gas, \$200 million; recreational and commercial boating and shipping, \$500 million; and (4) scientific and oceanographic activities (including environmental monitoring), \$100 million. Throughout the industrial evolution of marine electronic instrumentation manufacturing, a shifting balance of support from these user groups has provided the funds and the impetus for the development and introduction of new products. Within this balance, the Navy has always been of central importance in driving technology development.

Three largely distinct industry groups supply the products of marine electronic instrumentation. These are (1) the oceanographic/environmental instrumentation shops, producing customized research equipment; (2) the commercial "marine electronics" firms producing retail navigation and communications products; and (3) the large defense contractors, specializing in complex military systems. An additional, smaller group encompasses the service/consulting firms 
that serve the military, offshore, and academic/research user sectors. In the U.S., the oceanographic/enviromental instrumentation shops are typically established by scientists working at academic institutions or at other small firms, who detect the need for an instrument or find a new design or production technique that shows economic promise. As a consequence, these firms tend to "cluster" around U.S. academic institutions engaged in marine research.

The industrial field of marine electronic instrumentation can be described broadly as an "industry," on the basis of a common operating environment, product line overlaps, shared technical problems, mutual entry capabilities, overlapping customer pools, and professional linkages. Some general observations apply to the "industry" as a whole. With some variations across industry groups and sectors served, it is generally very competitive both in its structure and its behavior. Firms tend to seek out differentiated niches or specialties in product lines, but there are only modest barriers to mobility across product lines. A relatively few firms dominate the supply of large-scale systems development for military applications, but sales to most end-use sectors are fairly broadlydistributed across a number of small and medium-sized firms. Minimum efficient scale of operations in the industry appears to be low (though there may be unrealized economies of scale in both R\&D and manufacture), and barriers to entry and exit are minimal for most product lines. Over-the-counter retail sales are important only in the recreational and commercial shipping and boating sector and are handled there by an independent retail sales industry. Independent sales representatives provide important marketing services for most firms, especially in foreign sales. Demand for the industry's output is relatively thin, in the sense that only a few items are mass-produced, and suppliers tend to deal with a relatively stable set of end users who exhibit fluctuating levels of product demand.

R\&D intensity and the rate of inventiveness and innovation are particularly important to the success of firms in the marine electronic instrumentation industry. At the same time, the pace of product evolution and new technology adoption appears to be more gradual here than in most "land-based" high technology industries. Confirmation of this observation, however, requires further study as do its implications for the pace of advance in ocean science and resource development.

Another important factor affecting the competitiveness of firms in the marine 
electronic instrumentation field is the involvement of governments. In addition to providing funds to support R\&D, govermments affect international competitiveness in this industry through policies governing procurement, intellectual property rights, tax allowances, antitrust enforcement, small business encouragements, export controls, import restrictions, exchange rates, and technology transfer.

In the United States, existing law specifically encourages the development of marine electronic instruments, but little has been done to implement these laws through either subsidy or other incentives. Instead broader policies have been employed which directly or indirectly have an effect on the industry. Government R\&D and procurement policies have the most direct effect. A rough, conservative estimate places federal R\&D spending in this field at \$500 million annually. Although it is difficult in many cases to break-out R\&D and procurement funding specifically for marine electronic instruments, we estimate (based primarily upon Navy figures) that federal R\&D in this field is 5 percent or less of federal marine R\&D spending and federal procurement is 5 percent or less of total agency procurement budgets for those agencies with marine responsibilities.

The Navy is the most important factor in both R\&D funding and procurement. Only about 10 percent of all Navy R\&D can be classified as "basic" research, with the other 90 percent directed at "development, testing and evaluation." Nonprofit research institutions and universities generally are involved in basic scientific research, and funding for this activity with respect to marine electronic instrumentation is split among the Navy, NOAA, and NSF. Private firms and Navy laboratories are more likely to be involved in the development and prototyping stages. Anti-submarine warfare has been the leading priority for Navy R\&D since 1985 and is believed to have received this emphasis in part because of technology diversion overseas. Navy funding projections call for cuts in the rate of increase in R\&D (and perhaps even a levelling-off) as outputs from R\&D efforts move downstream.

Navy procurement of marine electronics products (estimated at 98 percent of federal total) is substantial, representing between 50 and 75 percent of U.S. domestic sales. Increasingly, there has been a trend toward selecting one prime contractor for large weapon system contracts and toward the employment of multiyear contracts. The effects of this trend on the defense sector of the industry are only beginning to be felt, and it is still unclear how the structure 
of the defense sector of the industry may be altered as a result. A significant portion of defense marine electronic instrumentation products are sold to foreign defense agencies through the govermment-brokered foreign military sales (FMS) programs.

Intellectual property right protection in the form of patents rarely is sought in this industry, where technological advances often occur merely as the "ruggedization" of existing technology. Research and experimentation tax credits are seen as incentives for research by some firms, although this kind of allowance may sometimes have perverse effects. Many firms in the industry lament the removal of the general investment tax credit.

The relaxation of U.S. antitrust policies relating to joint ventures in R\&D and patent licensing practices has not had a discernable effect on the industry. There are only a limited number of cases where joint R\&D efforts are undertaken between firms in the industry. Small business innovation research (SBIR) awards are measurable, but minor, representing only an estimated 2-5 percent of the industry's total R\&D expenditures.

Some firms have problems with export controls. The extent to which export control policy affects firms in this industry is dependent upon product type, destination, and the size and capabilities of the exporting firm as well as the proportion of its sales into foreign markets. Tariffs are not a major trade barrier in this industry (averaging under 5 percent), although products originating in communist-bloc countries still face substantial tariffs. Depending upon their intent and substance, government-sponsored R\&D programs might be considered a form of nontariff barrier to trade. The nature and extent of the foreign programs and the importance of both domestic and foreign R\&D sponsorship in international trade will be examined more closely in further research.

Several other conclusions can be drawn from this study relating to international trade. There appears to be a strong impression in the U.S. industry that "buy-national" requirements in some countries restrict markets for U.S.manufactured products. The enactment of new legislation governing trade policy in the United States and the recent U.S.-Canada free trade agreement are expected to have an (as yet unseen) impact on trade in marine electronic instrumentation. Export sales seem to have improved with the depreciation in the U.S. dollar relative to the currencies of consuming nations (an expected concomitant slackening in imports has not yet been noticed). Trade in commercial/recreational 
marine electronic instrumentation may be more sensitive to exchange rate variations than are products in the other industry groups.

The sources and pathways of technology transfer, as well as inventiveness and innovation, in this U.S. industry are of great importance to its continued competitiveness. In particular, the flow of technology between the naval and civilian offshore sectors (recently seen in the adoption by the U.S. Navy of slightly customized, off-the-shelf ROV systems for mine-hunting operations) bears further investigation. In the scientific instrumentation sector, further, the mechanisms for demand feedback about customer needs are unclear, and a "market intelligence" problem may exist for firms in this sector. 

Appendix A:

Marine Electronic Instrumentation

Product List with Definitions 



\section{Marine Electronic Instrumentation Product List with Definitions}

\section{Oceanographic/Environmental Instrumentation ("Sensors")}

- acoustic instruments: instruments dealing with sound waves

echo sounder: acoustic sounding device to measure water depth

hydrophone: instrument for listening to sound transmitted through water, usually then transformed into an electrical signal

sonar ( $s$ ound na vigation and $r$ anging): devices that use sonic or supersonic waves to determine the presence and location of an object, or the distance to an object (seafloor)

diver sonar: hand-held sonar device used by divers

side scan sonar: usually mounted on a towed "fish," this sonar determines distance to bottom by measuring the phase shift between two sound signals transmitted downward at an angle; used for (relatively) shallow water surveys

Swath (multi-beam) sonar: usually mounted on the bottom of the survey vessel's hull in a longitudinal trx and a transverse rcv array, this sonar sends separate signals to distinct angles; used for deeper water surveys (lower frequency that side scan)

sonobuoy: a buoy that emits a sound signal, usually for positioning/ranging sound sources:

pingers, boomers, sparkers, air guns: underwater sound sources (turn electrical signal into sound)

sub-bottom profilers: low-frequency sound systems (transducers and receivers) that produce acoustic "images" of subbottom formations

transceiver: a transducer that can also receive signals transducer: a device that transmits a signal (such as a sound source), usually into the water from a vessel, "fish," or buoy

transponder: a device that, upon receiving a designated signal, emits a signal of its own, used for detection, identification, and location of objects

- attitude indicator: instrument that senses the inclination(s) of a platform

- bathythermograph: instrument that records water temp as a function of depth

- CDT (conductivity/density/temperature) measurement: a single probe that measures all of these, often as a function of depth; resulting data permit calculation

- current meters: of salinity and density

surface current measurement:

- dissolved oxygen: probe that measures oxygen content of water 
- fluorometer:

- geophysical instruments:

geothermal heat (flow) probe: device for measuring temp (and temp gradient)

in the earth or seafloor

gradiometer: instrument for measuring the gradient of a physical quantity, such as the earth's magnetic field

gravimeter: measures the strength of earth's gravitational pull

magnetometer: measures strength of earth's magnetic field

spectrometer: an instrument used in determining the index of refraction

spectroradiometer: (?)

- inclinometer: measures the inclination of a platform

- metal detectors:

- meteorological instruments (marine):

- radiation sensors:

- salinometer: measures the salt content of water

salt refractometer: determines salt content by measuring the refraction of a

- satellite sensors: beam of light through a water sample

- underwater inspection/ROV systems:

- velocimeter: measures the velocity of water passing the sensor

- video imaging systems: TV, still photography, etc

- "water quality instruments":

dissolved oxygen measurement:

electronic thermometer:

salinometer:

transmissometer:

turbidity measurement:

- wave/water level instruments (hydrological):

tide gauge:

wave height spectra measurement: often mounted on a buoy; measures waves by measuring acceleration of the buoy, then uses data processing techniques to determine height, direction, and energy spectra

\section{Data Management Instruments ("Storage and Analysis")}

- amps and preamps: devices that condition an electrical signal

- analyzers: devices that process a signal or substance

acoustic analyzers: devices that process an acoustic signal (usually after it is converted to an electrical signal)

acoustic navigation processing: processing of acoutic data (depth info, sonobuoy signals, etc) for navigation sonobuoy receiver systems: receive and analyze data from a number of sonobuoys, usually for positioning chemical analyzers: devices that analyze a physical substance for content or composition

electronic analyzers: devices that process an electronic signal 
- computers: processing devices

- data converters: devices that convert a signal from one medium to another (such as acoustic to electronic, etc)

- data indicators, recorders, and storage: video screens, light-emitting diodes, liquid crystal displays, printers, plotters, tape and disk

digital:

drives, etc. (includes depth indicators, etc.)

graphic:

solid-state: as opposed to on removable or flexible media

submersible: data recorders that can be incorporated into $\mathrm{u} / \mathrm{w}$ probes or buoys

- software:

(self-contained)

hydrographic survey software: helps with the storage, interpretation, and presentation of survey data

navigation software: helps with course plotting, analysis of navigation signals

tracking software: helps with navigation in surveying, tracking streamers, etc

\section{Communication/Navigation Instruments ("Support")}

- antennas:

- autopilots: (electronic) devices that keep boats/vessels on course by monitoring compass heading and adjusting the rudder angle

- communications equipment:

diver communications:

satellite communications: radio communications relayed via a satellite single-side-band (SSB) radios: marine equivalent of Citizens' Band (CB) radio

very-high-frequency (VHF) radios: FM-range two-way communications, very common among recreational and commercial boaters

- electronic chart systems: often part of integrated navigation systems; the chart is stored digitally and displayed on a video screen (or plotter)

- fax machines, receivers/printers (weather charts): radio transmission of weather charts and other documents

- "fishfinder" echo sounders: used by sport and commercial fishermen, acousic systems that display acoustic images of objects between the surface and the bottom (including the latter)

- fuel management systems (consumption tracking. etc): system that measures fuel consumption, aids in improving fuel economy

- navigation. position fixing, and tracking equipment:

depth. speed, and other indicators:

gyrocompass: inertial compass based on gyroscopic principles inertial navigation systems: based on inertial guidance principles

(measurement of accelerations)

Loran-C receivers: Loran-C is a US navigation/positioning system based on shore-based radio transmitters; commonly used in coastal areas by pleasure craft and others

magnetic digital compasses: 
Pulse/8 receivers: Pulse/8 is the UK equivalent of Loran-C

radar systems: a device that determines distance and location of objects on

the basis of reflections of ultra-high frequency radio waves

radio direction finders: radio receivers that home in on radio beacons

radiopositioning systems: usually local sets of radio transmitters specifically placed for precise positioning in a particular project (offshore installations, etc)

recreational boat instrumentation (speedometers, etc):

satellite locating systems: navigation/positioning using satellites

GPS (Global Positioning System): satellite-based positioning system;

on-board receiver gets accurate time and

position info from satellites, calculates speed

and course

SAT/NAV (Satellite Navigation): satellite-based navigation system

- satellite timing receivers: on-board receivers that obtain accurate timing signals

from satellites

- telemetry instrumentation: data transmission devices (usually via radio waves)

digital telemetry systems: transmit data in digital form (1s and 0s)

fiber-optic telemetry: transmit data via fiber-optic cables (for example, from

a tethered probe to the vessel)

photogrammetry: transmission of video images

video/sonar multiplexing: allows transmission of video and sonar signals via a

- telex systems:

single line

- transponders: (see Oceanographic Instrumentation above)

\section{Advanced Military Technology}

- acoustic processor (ASW): device that processes acoustic signals, both "active" and "passive" sonar) to detect, identify, and locate subs

- acoustic simulators (ASW training): training device that simulates acoustic signals for interpretation by operators in training

- countermeasures: measures taken to confound opponent's ASW and other detection schemes

acoustic: means of hiding/distorting a vessel's acoustic "signature"

electronic: means of hiding/distorting a vessel's electronic/magnetic

"signature"

- digital magnetic anomaly detection system: (?)

- infrared detection systems: devices that detect differences in temperature (heat radiation)

- radar detection (ASW): device that detects radar being used by a submarine (a means of locating subs from the air)

- radar systems: (see Communication/Navigation above)

inverse synthetic aperature radar (ASW): (?)

long range maritime surveillance radar: used on surface ships to detect vessels, aircraft, etc 
- sonar (ASW): (see Oceanographic Instrumentation above) helicopter dipping sonar: a sonar system that is deployed on a tether by a hovering helicopter, to look for subs

- underwater sound surveillance systems: on-board or stationary "passive" sonar systems for the detection of subs/ships

\section{SERVICES}

- oceanographic instrumentation lease and rental:

- oceanographic survey and exploration:

- (design) engineering:

- underwater photography/inspection:

- data processing:

- calibration, testing. and evaluation:

- positioning and navigation: 

Appendix B:

Marine Electronic Instrumentation

U.S. Firms

Source of Sales and Employment Data:

Dun's Marketing Services, Million Dollar Directory, 1987. 



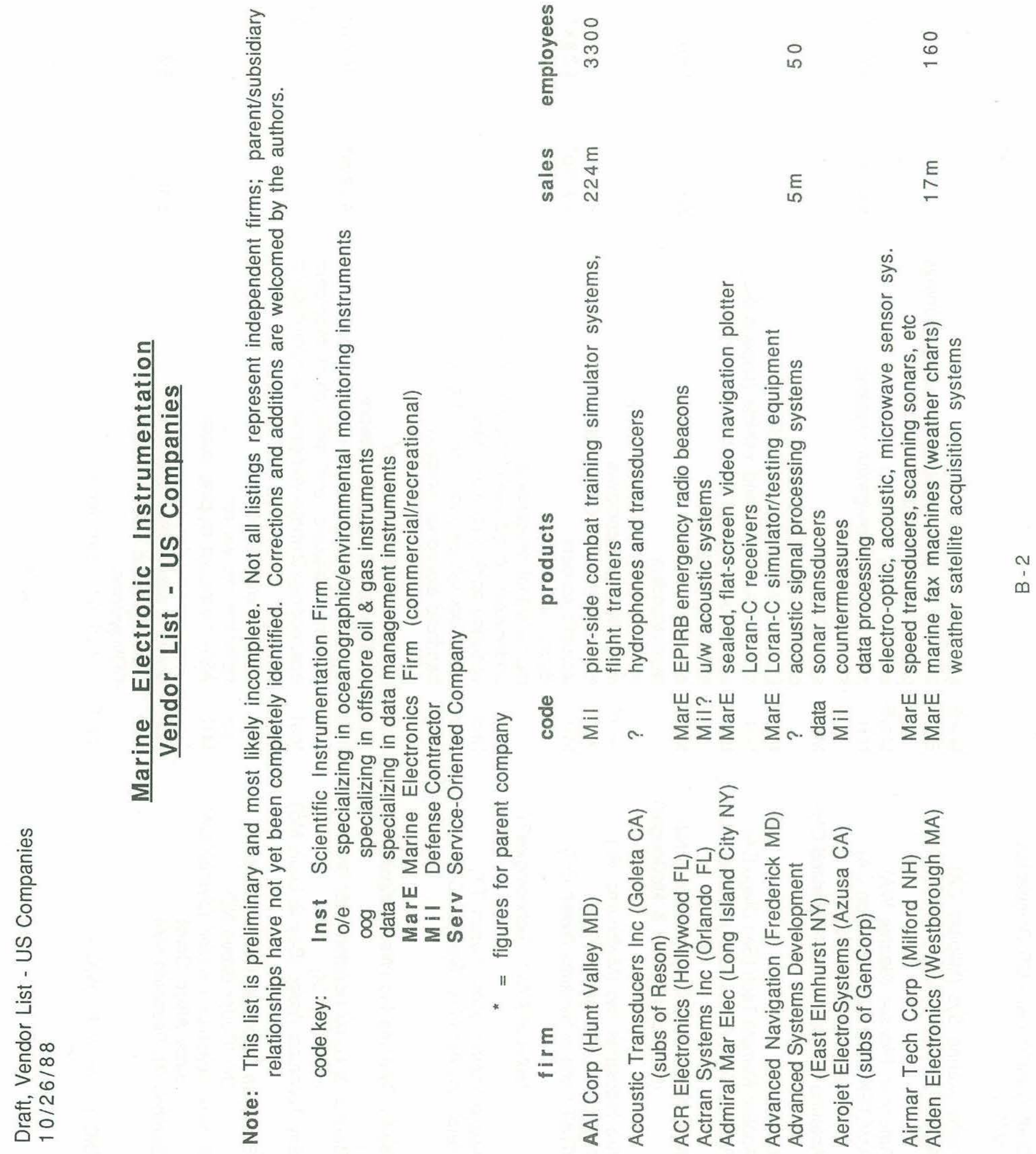


$\vdots$

产
$*$
0
0
1
1

$m$

$\omega$

$\frac{E}{10}$

$E$
0
0
0

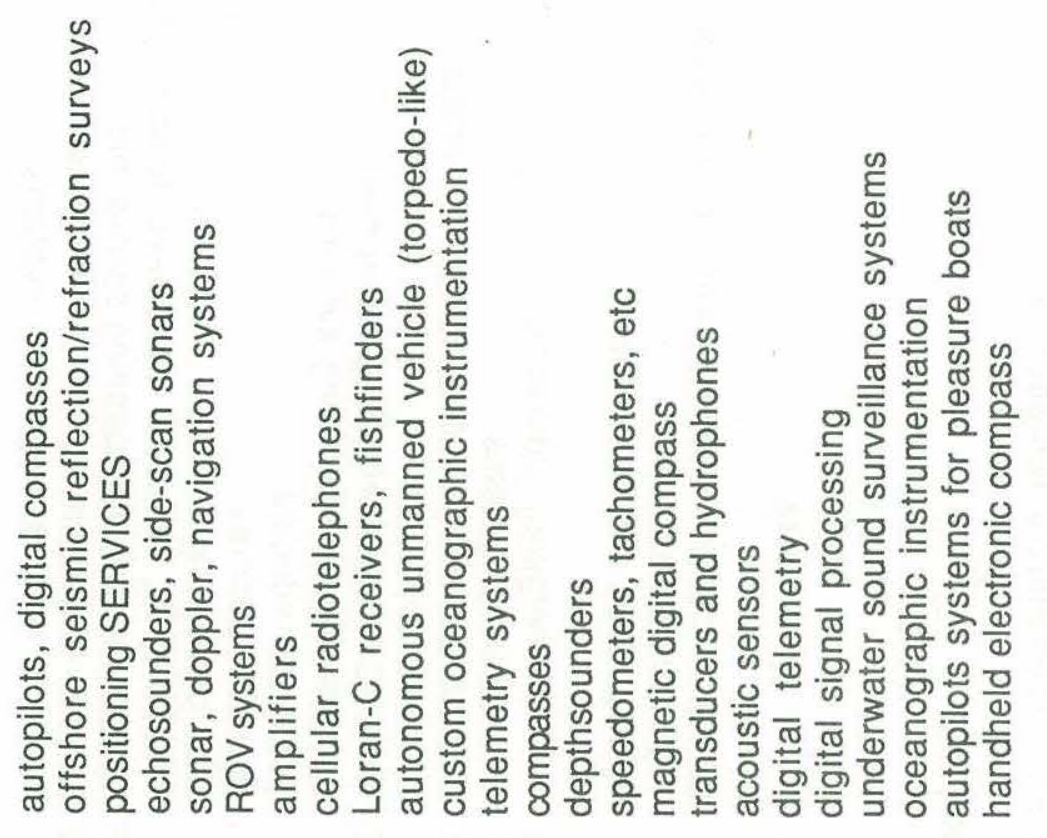

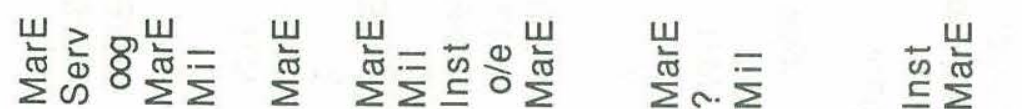

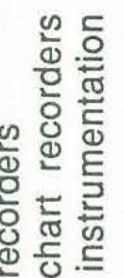

닌

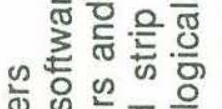

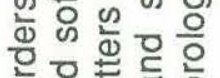

흥등ㅎㅇ 뜽

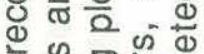

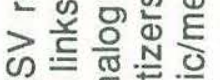

๘

点

$\times$ 的 के

플 뜡

흐ㅇㅝㅠ. 잉

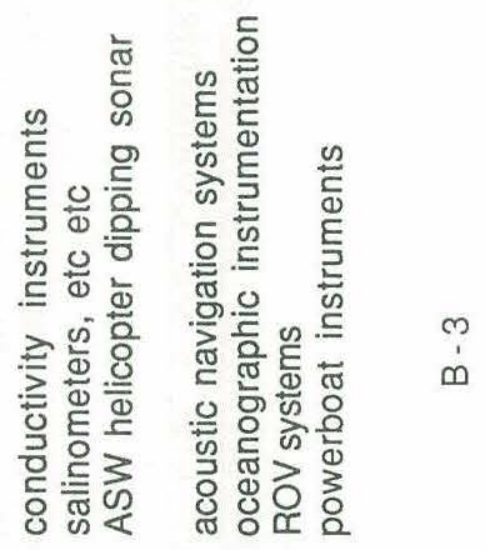

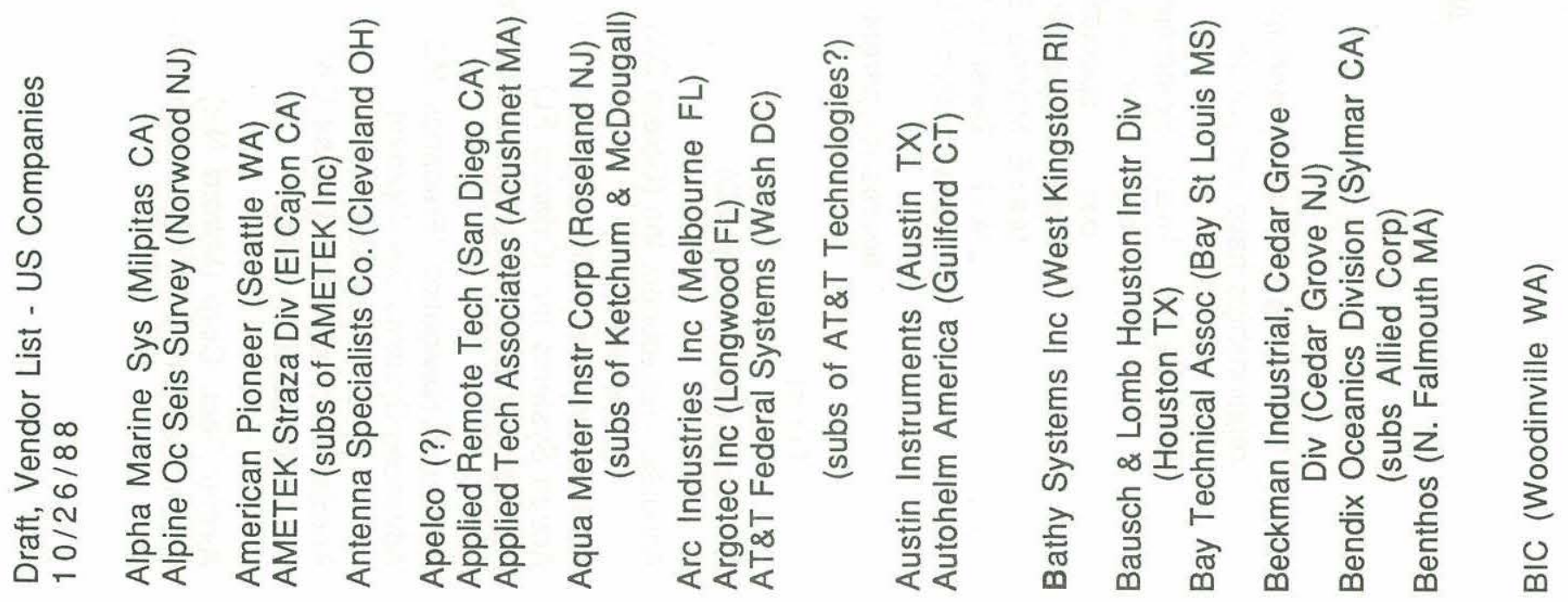




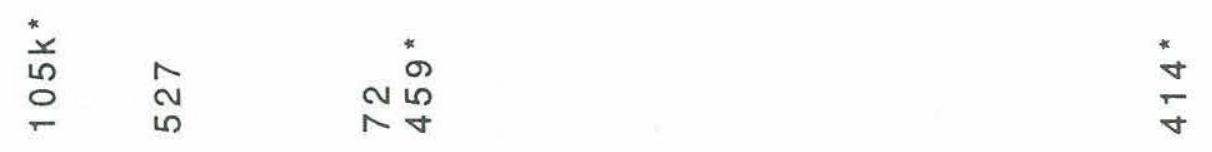

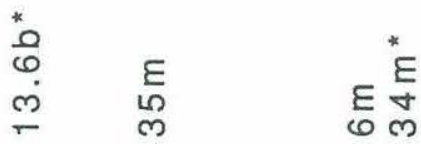

$\stackrel{*}{*}$

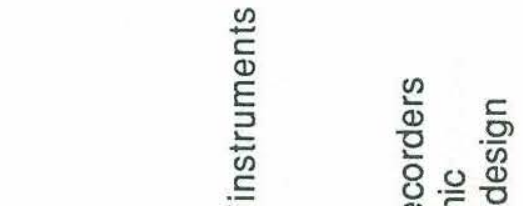

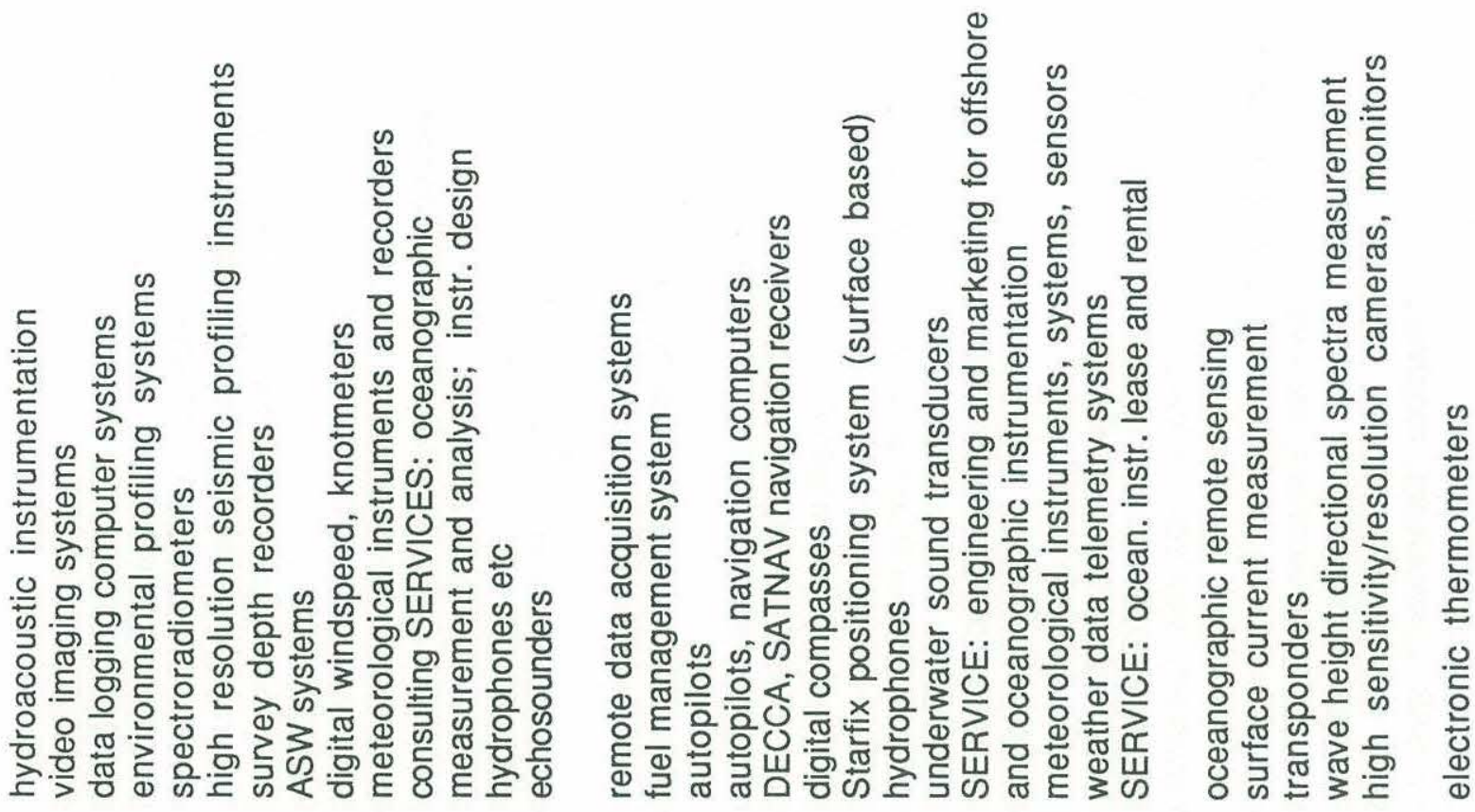

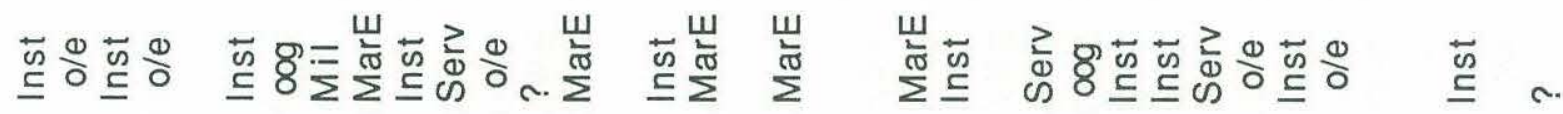

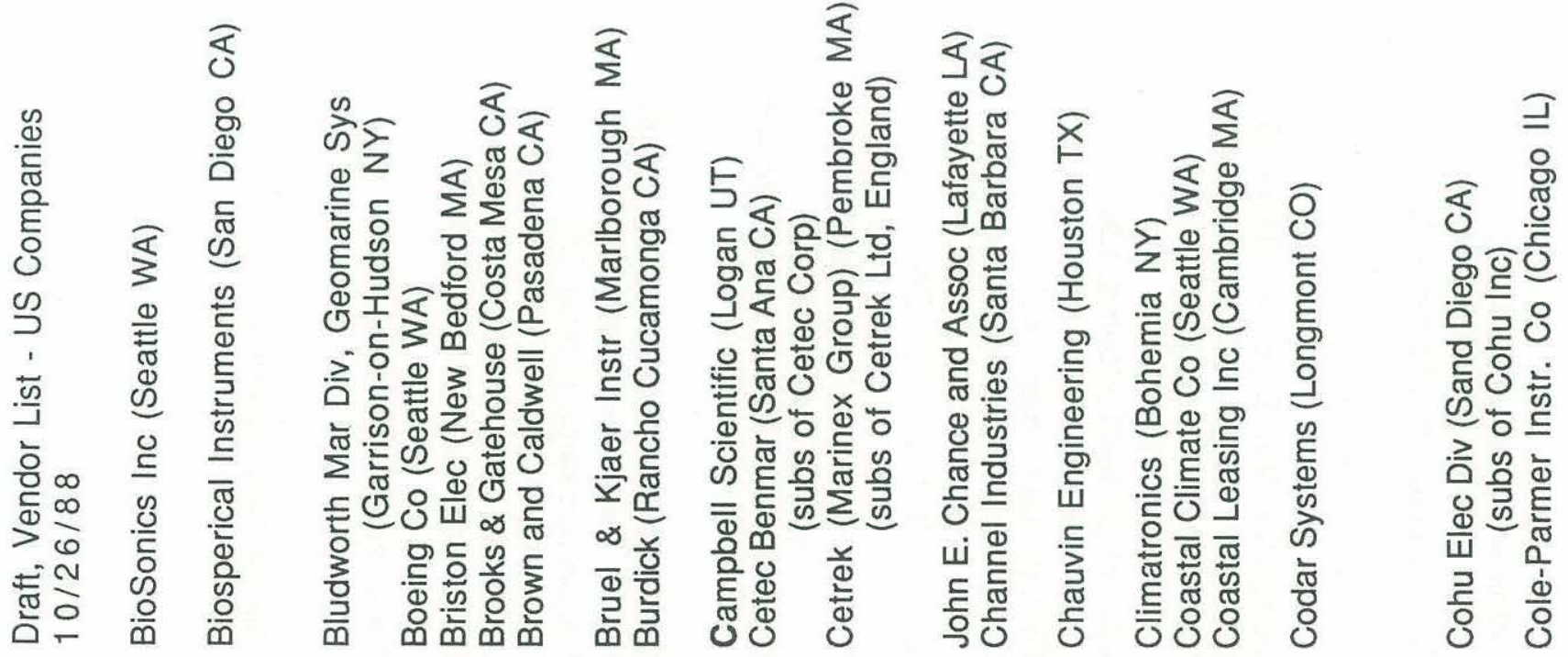




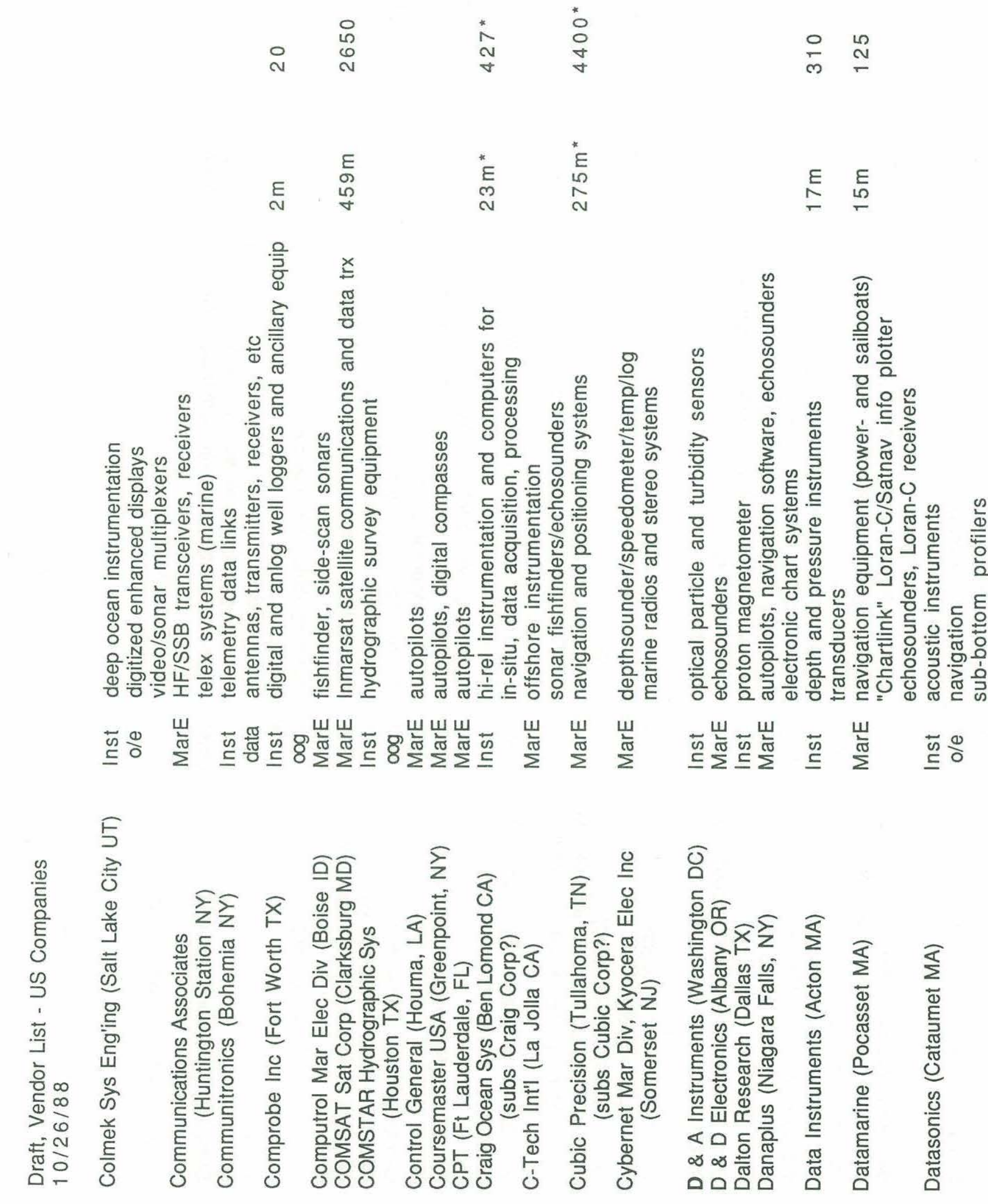



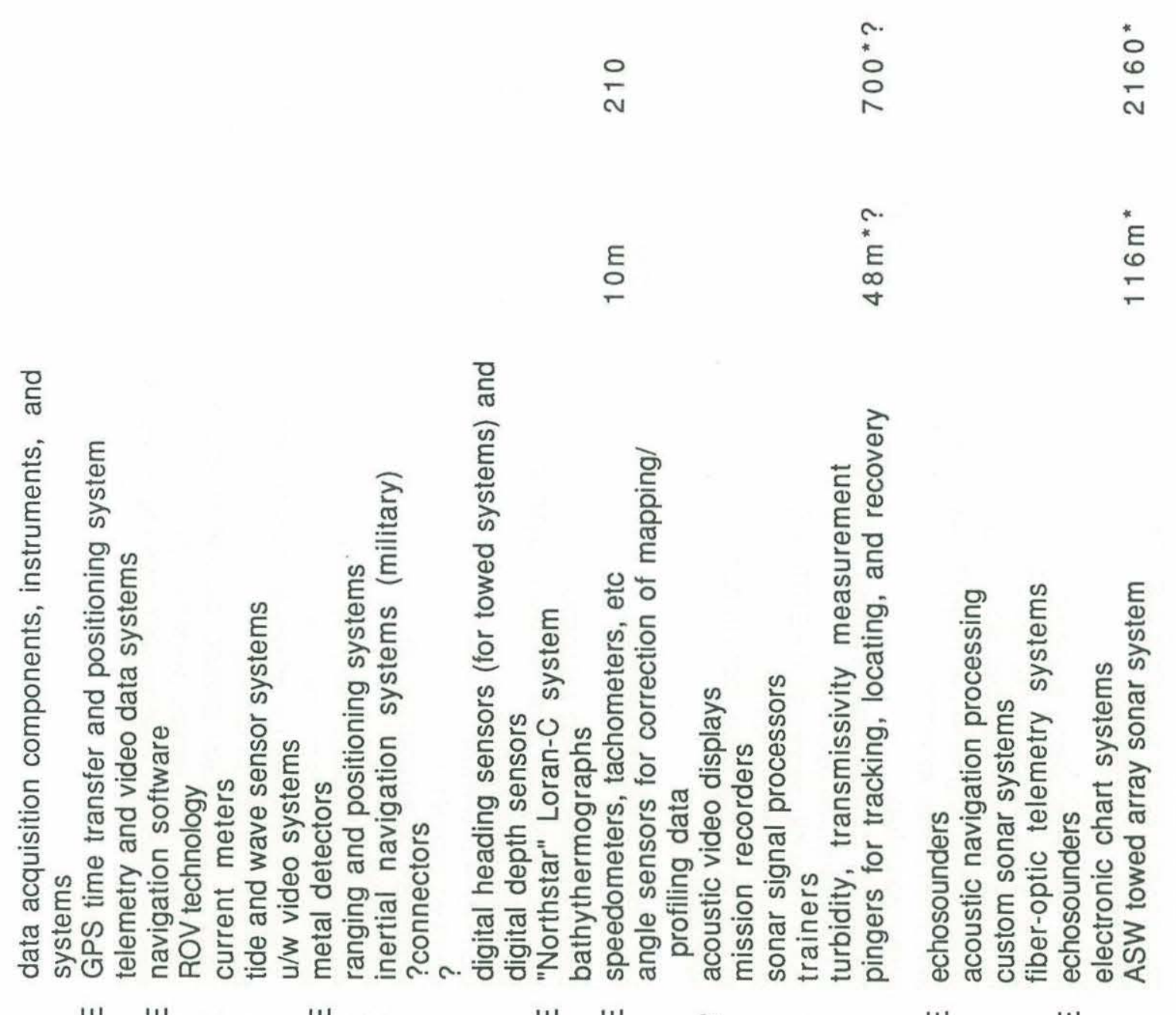

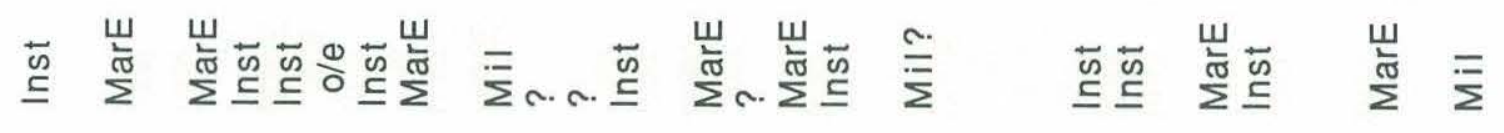

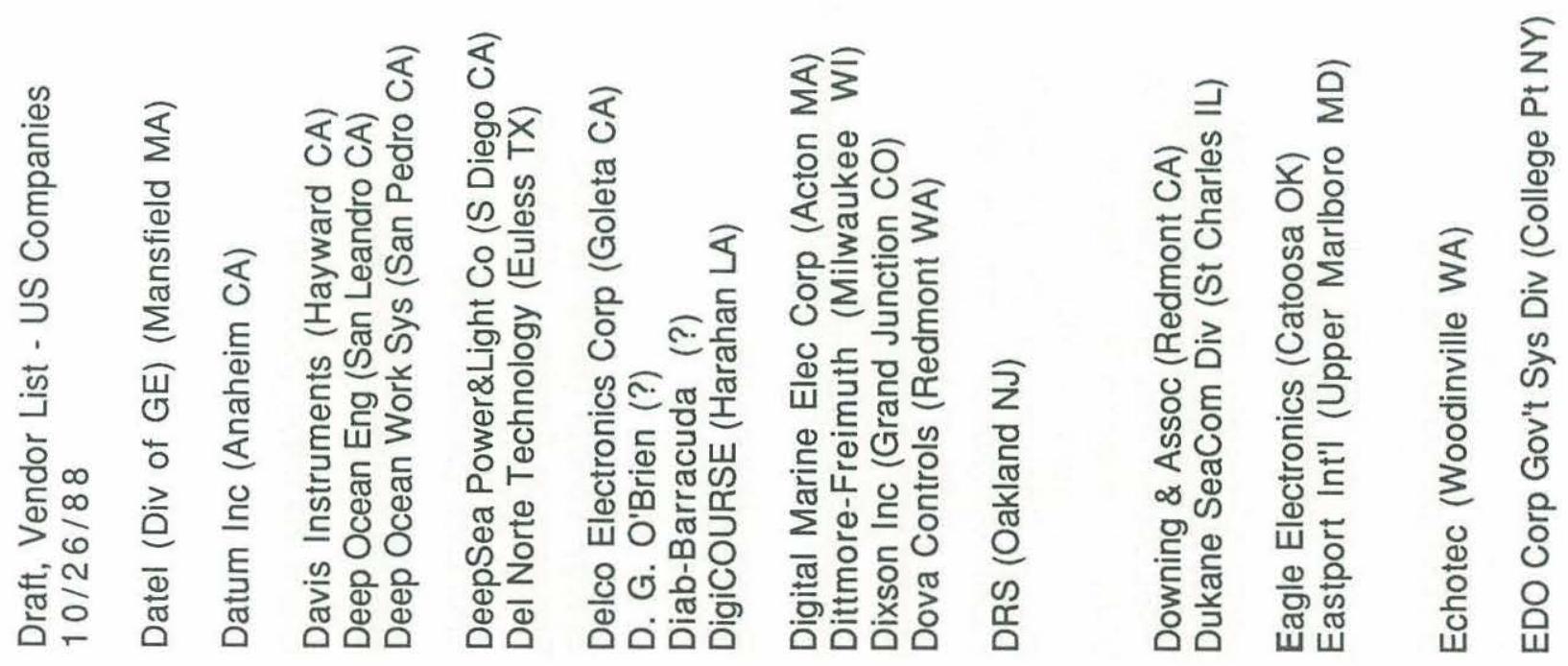




\begin{tabular}{|c|c|c|c|}
\hline $\begin{array}{l}\bar{m} \\
\sim\end{array}$ & $\nabla$ & $\checkmark$ & ○े \\
\hline${ }^{*}{ }^{*}{ }_{0}$ & & & $\underset{10}{E}$ \\
\hline$=$ & 朵 & E & $N$ \\
\hline
\end{tabular}

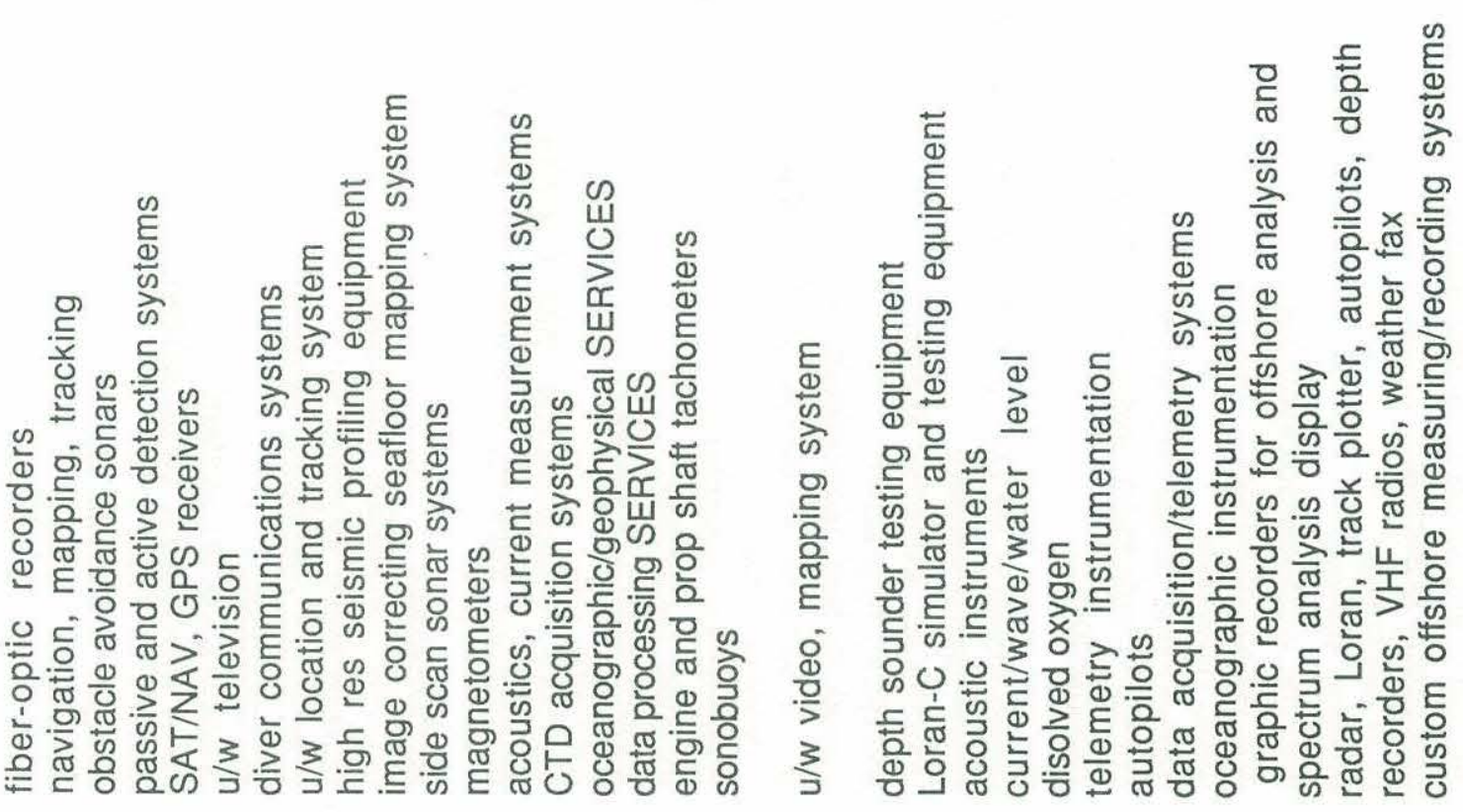

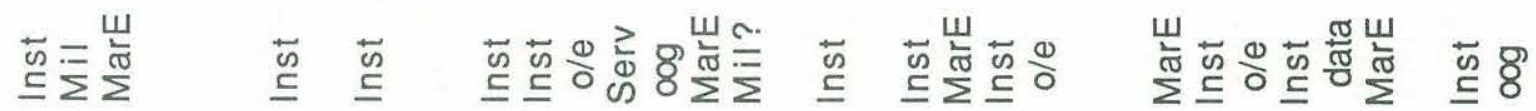

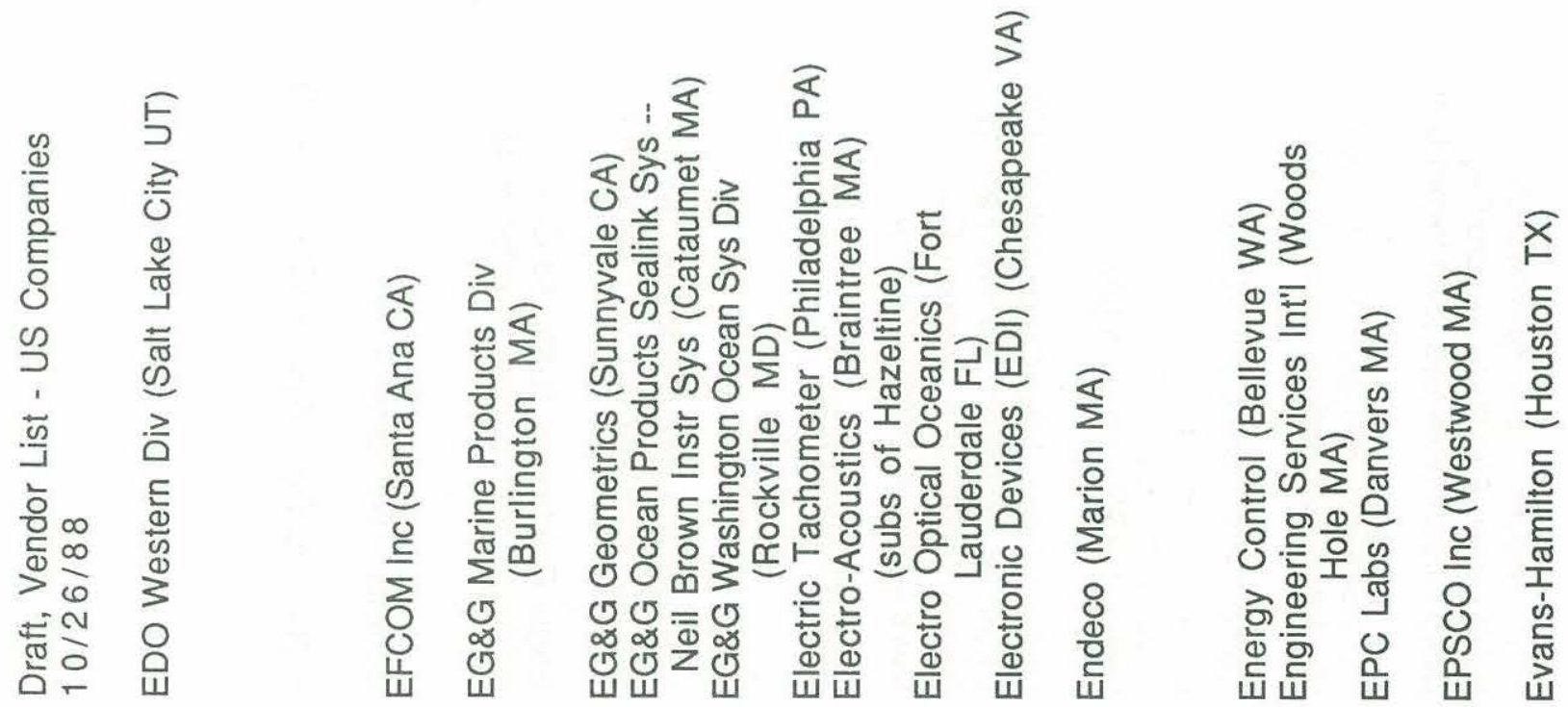




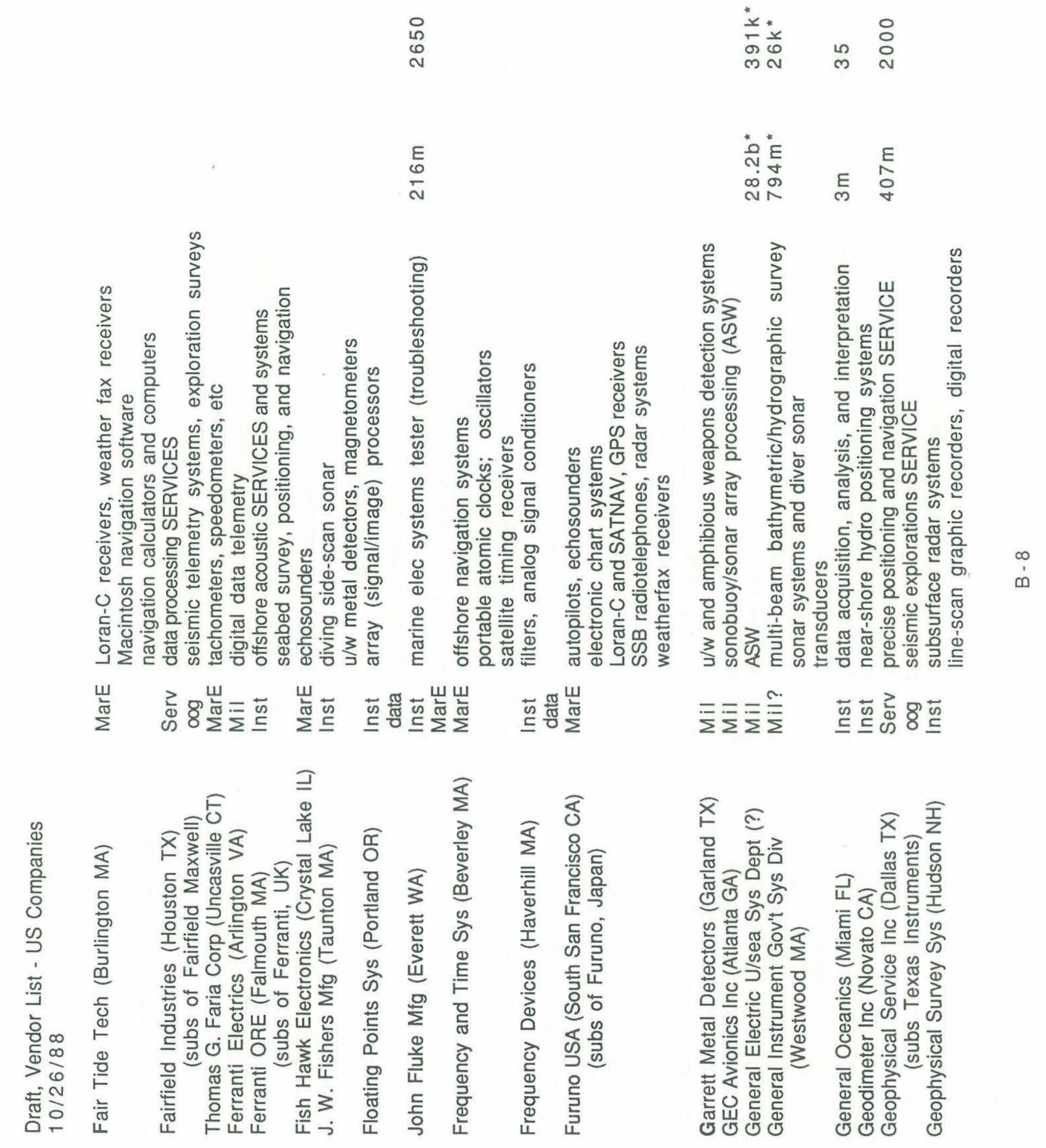




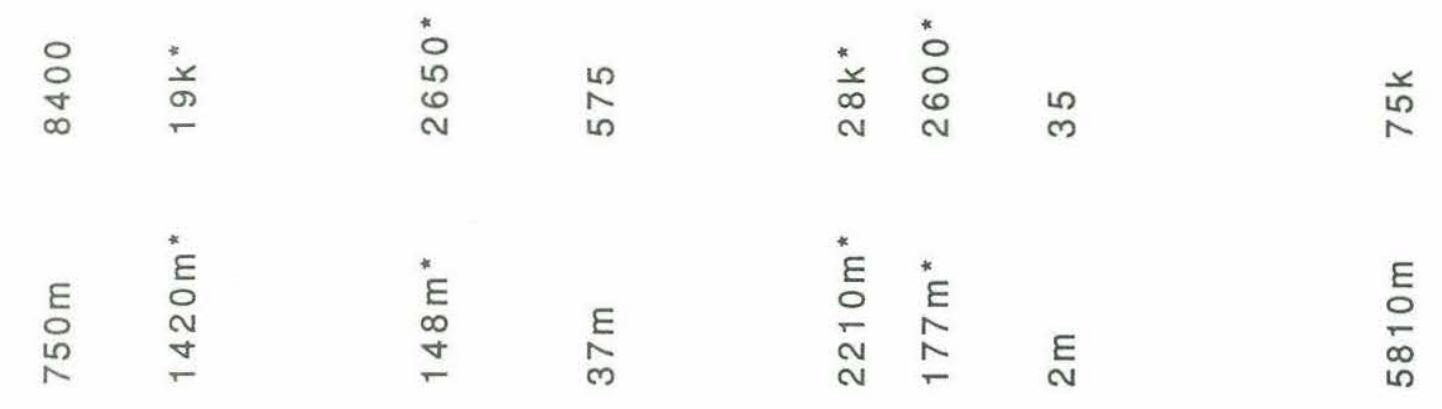

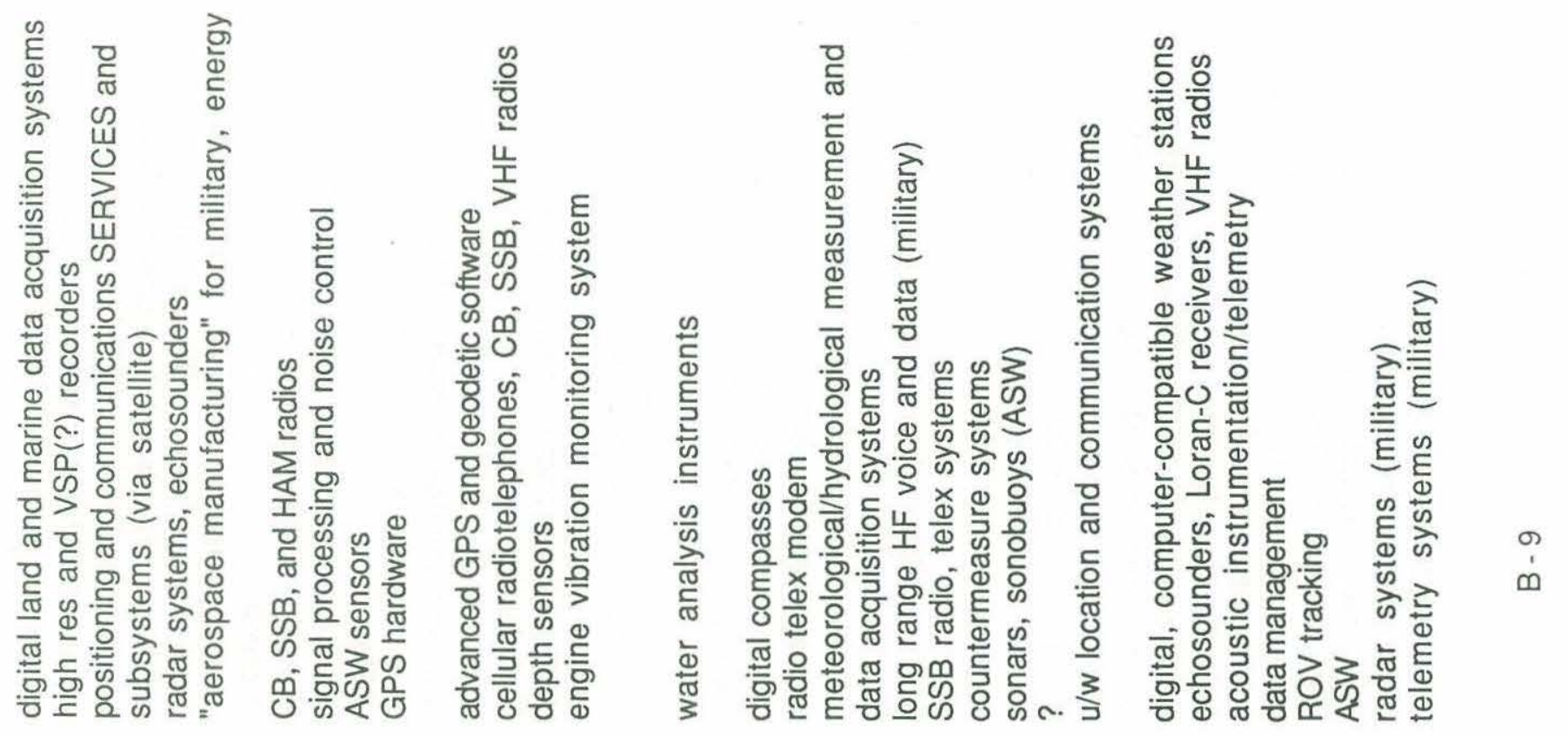

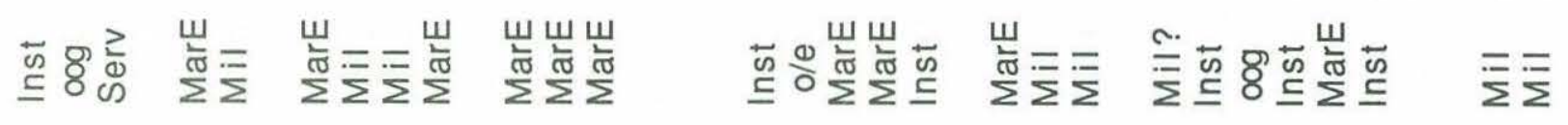

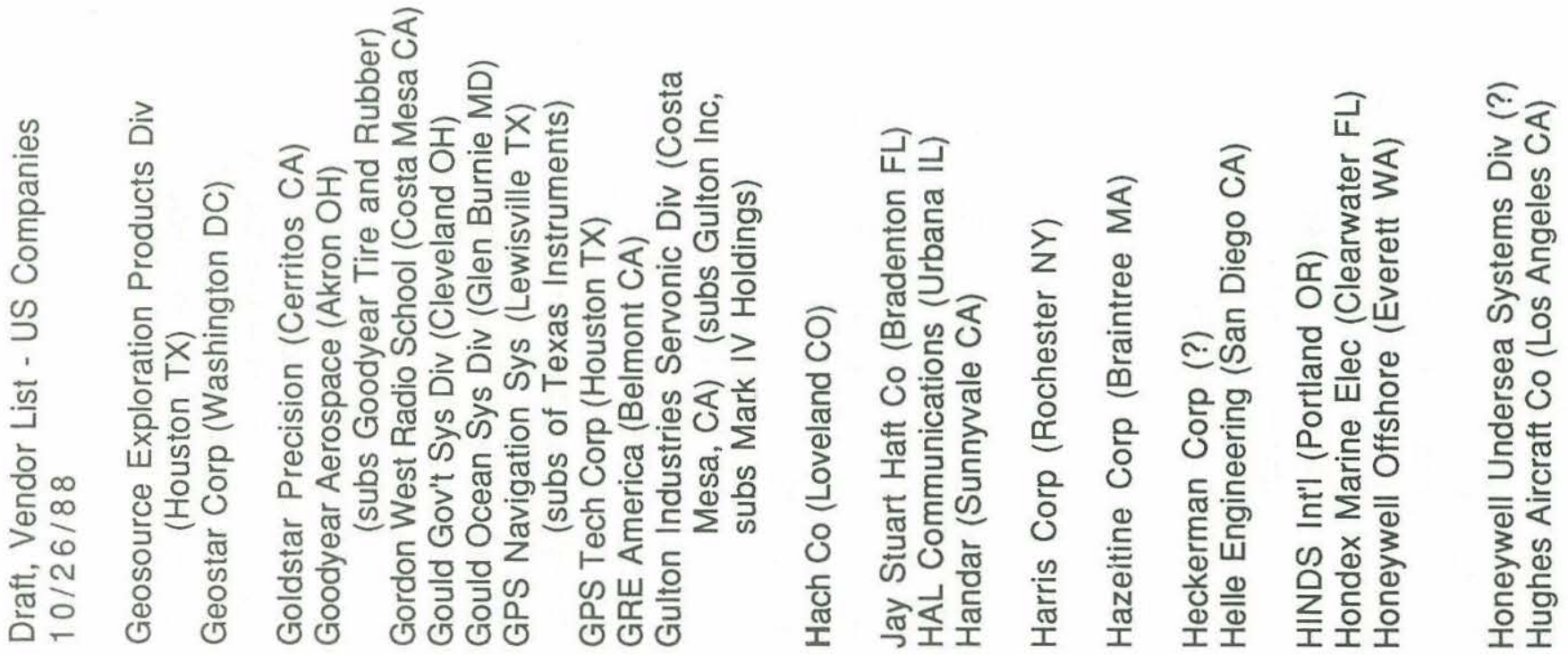




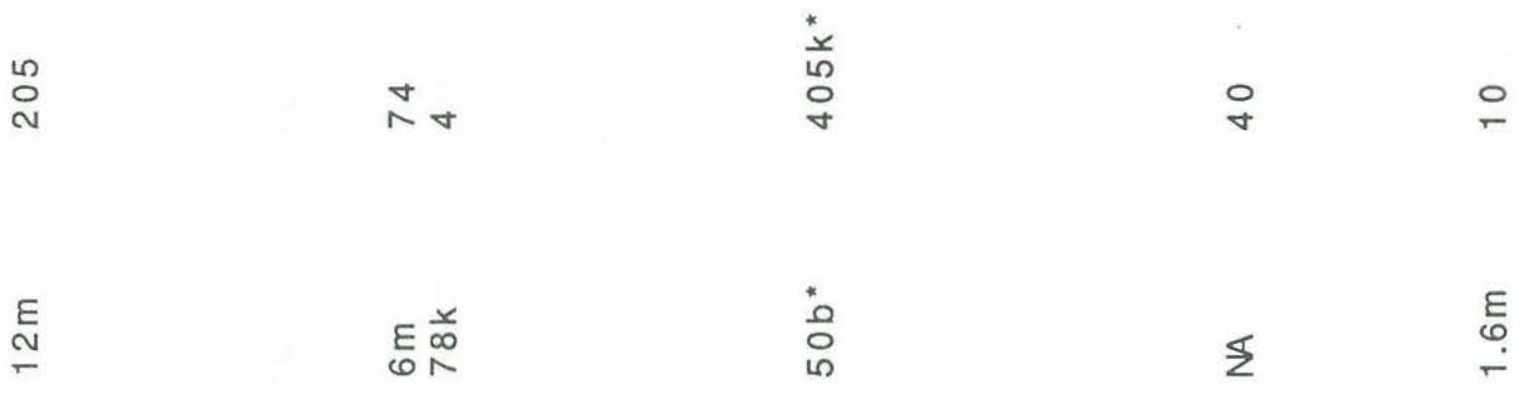

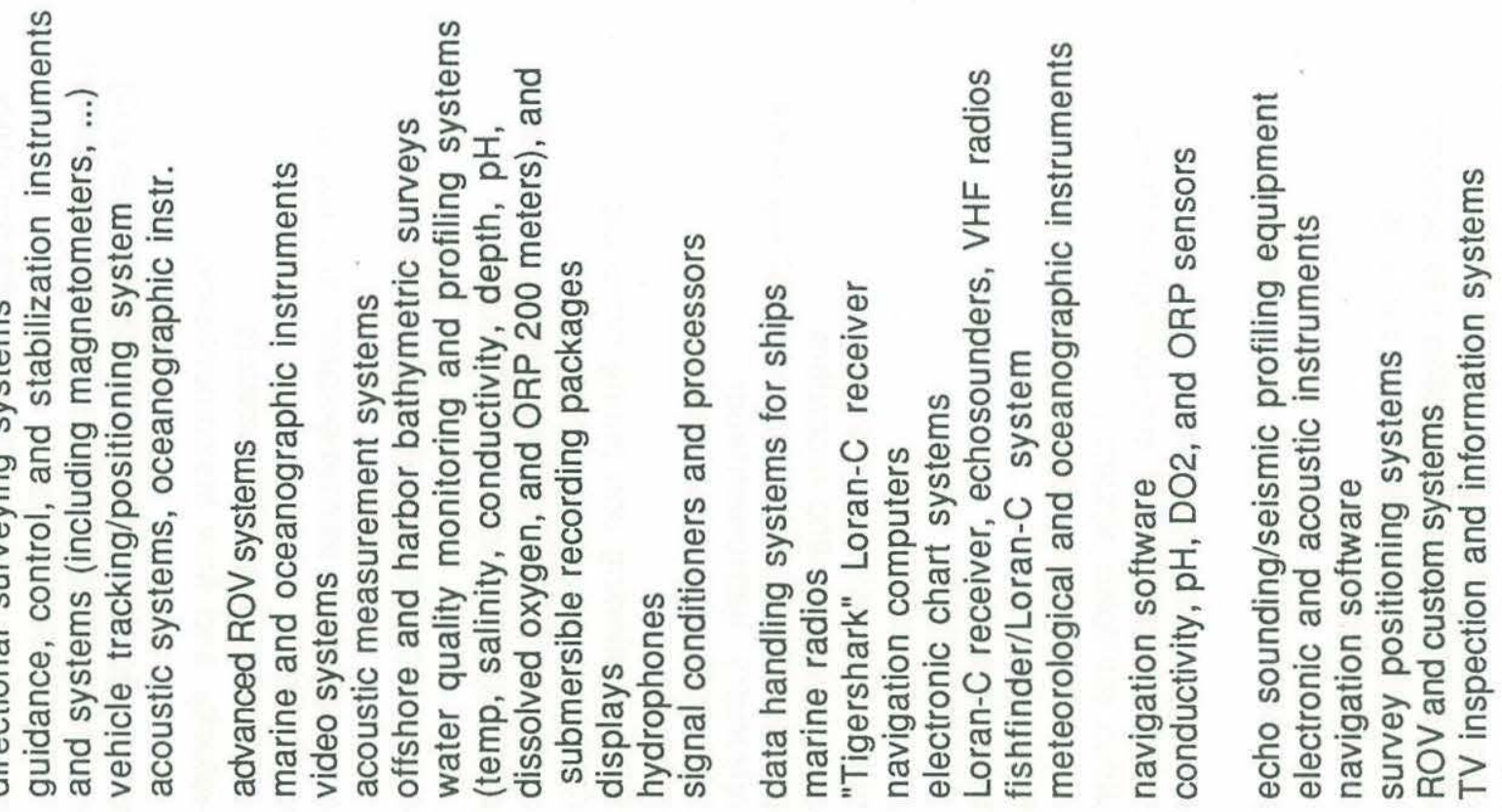

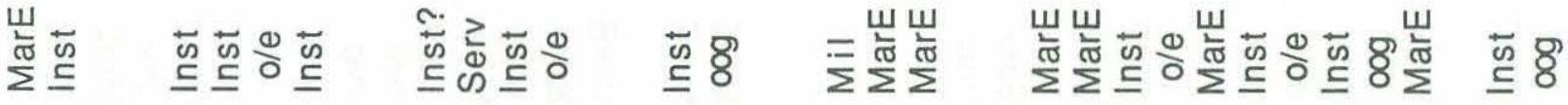

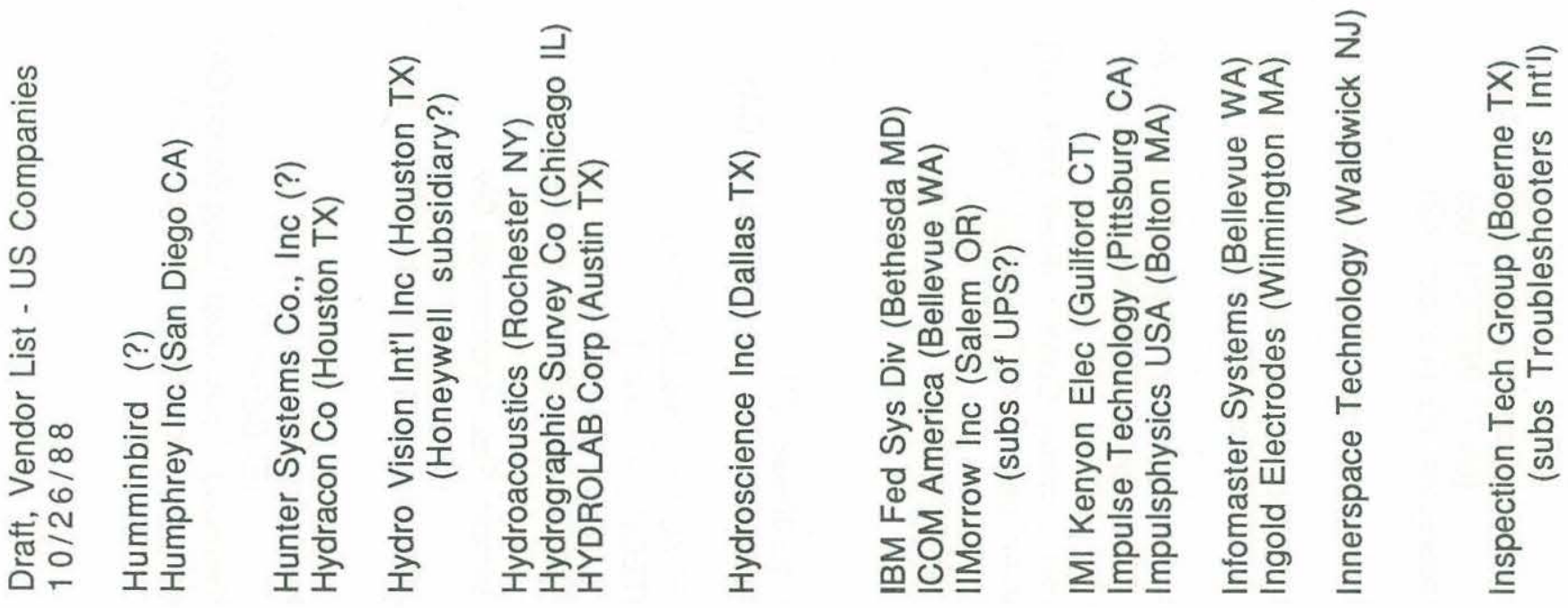




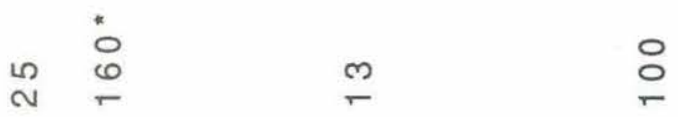

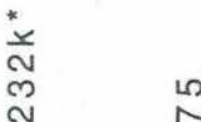

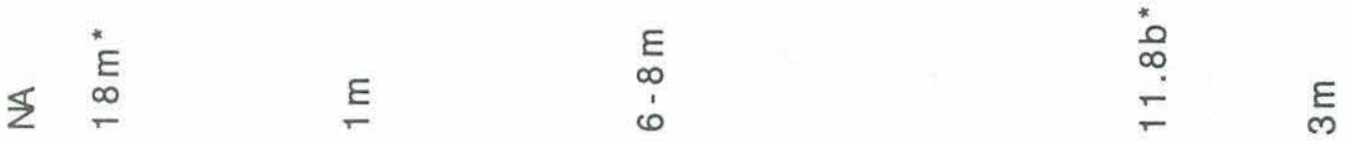
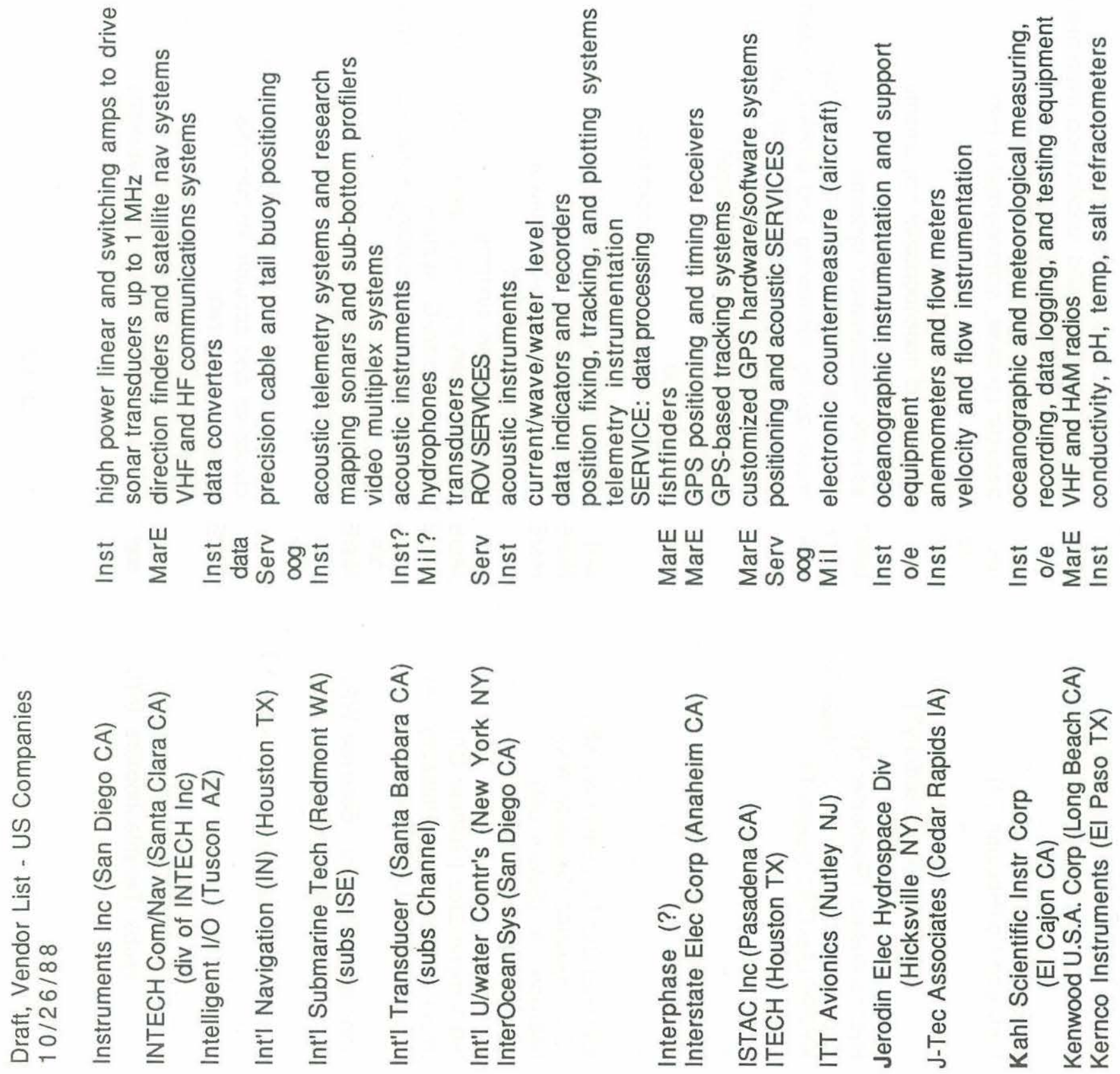


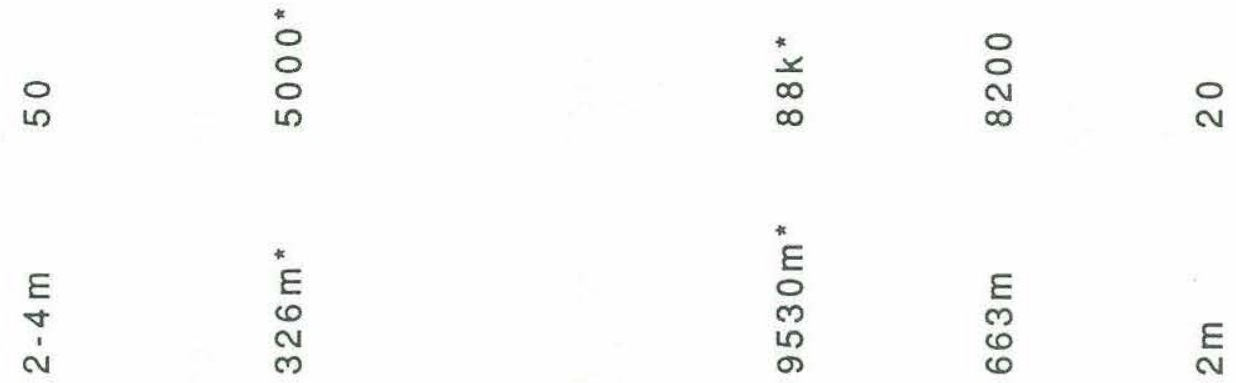

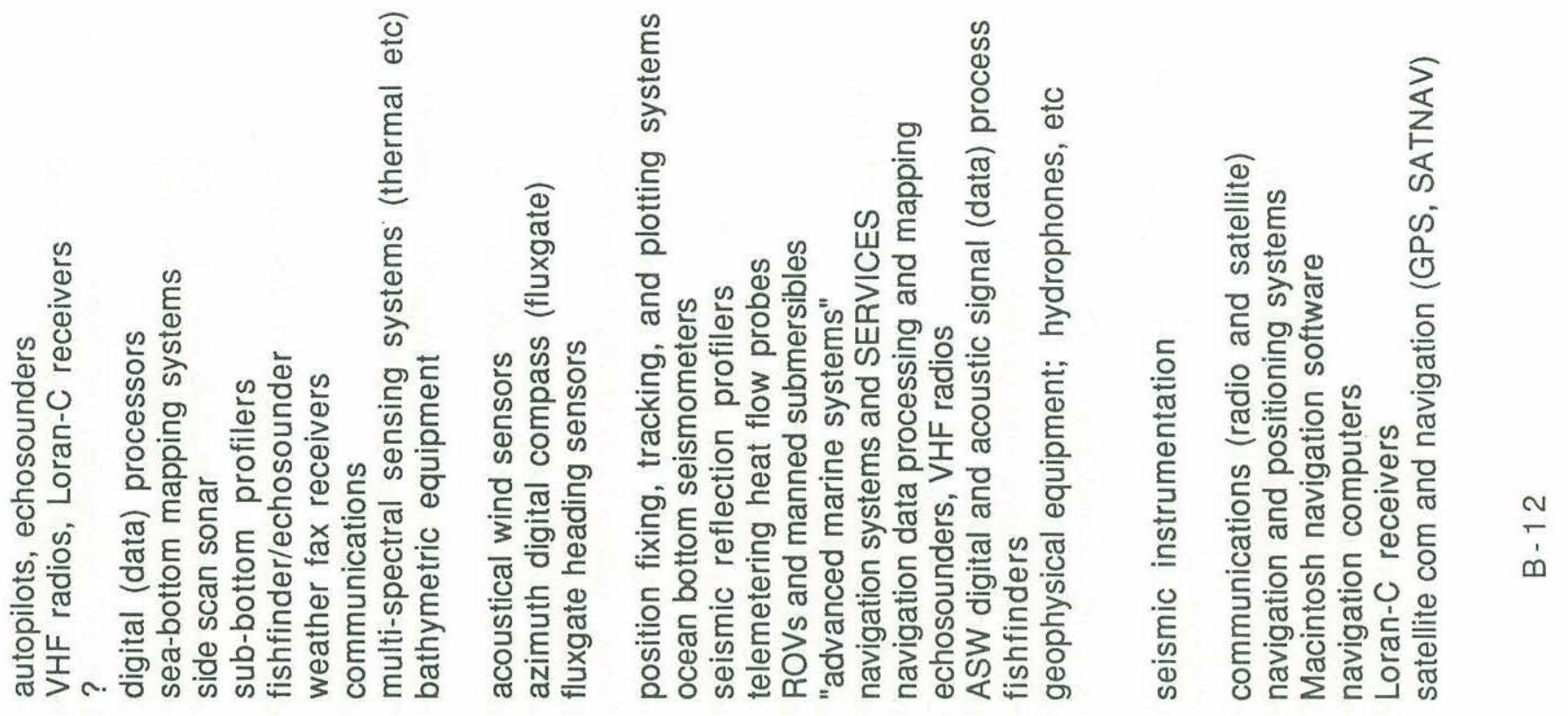
宸旁至

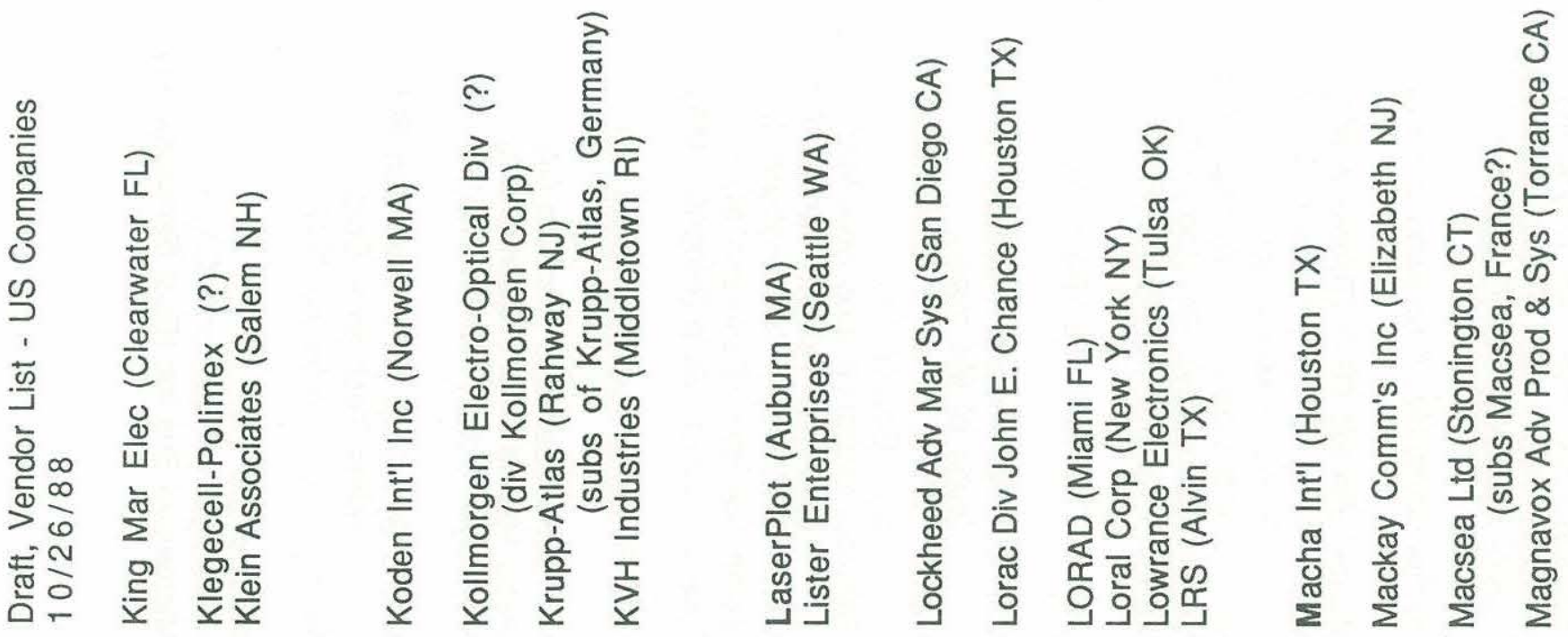



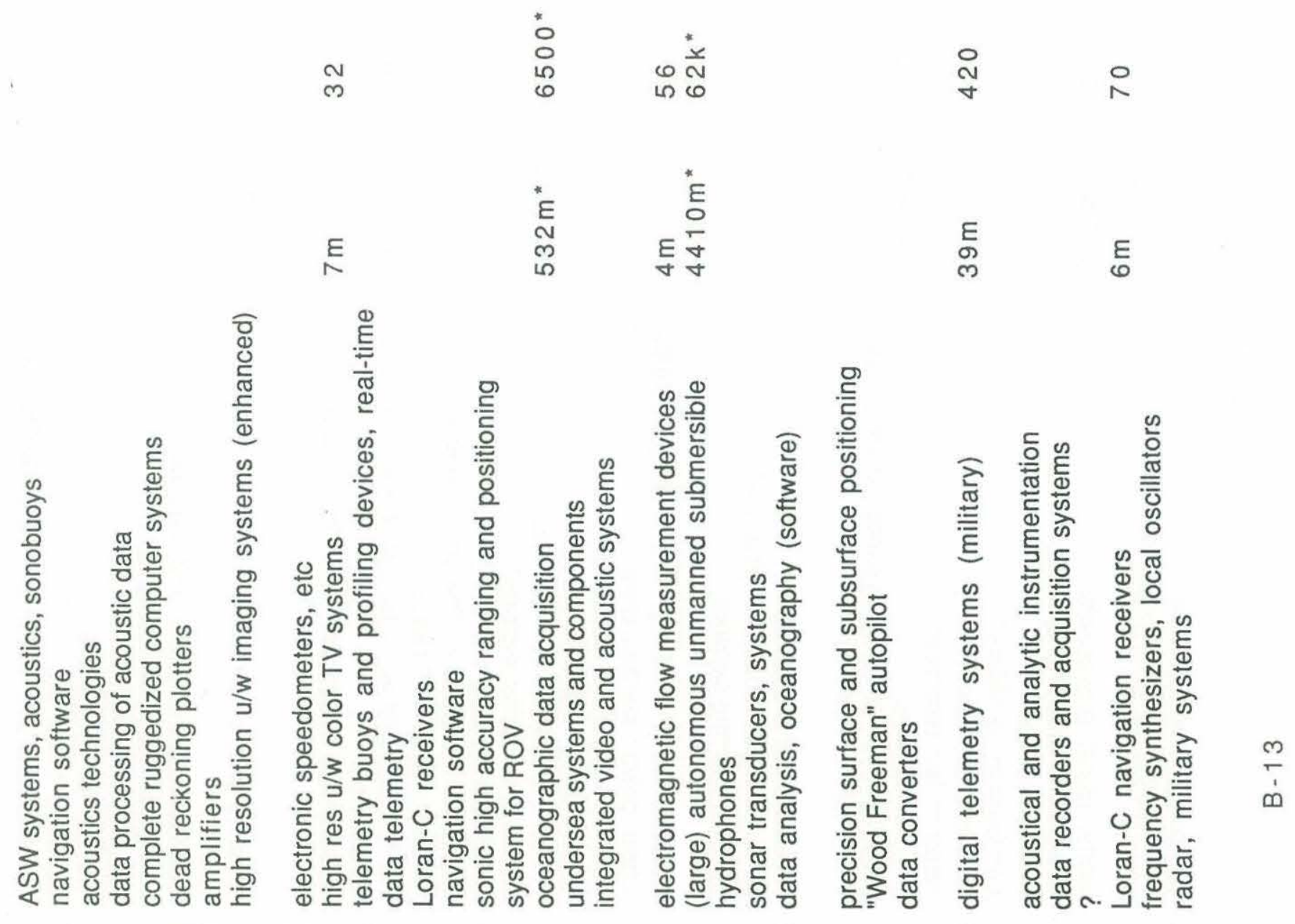

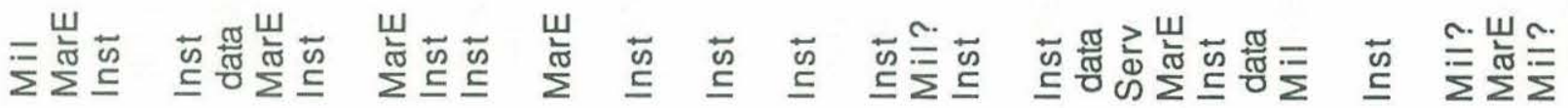

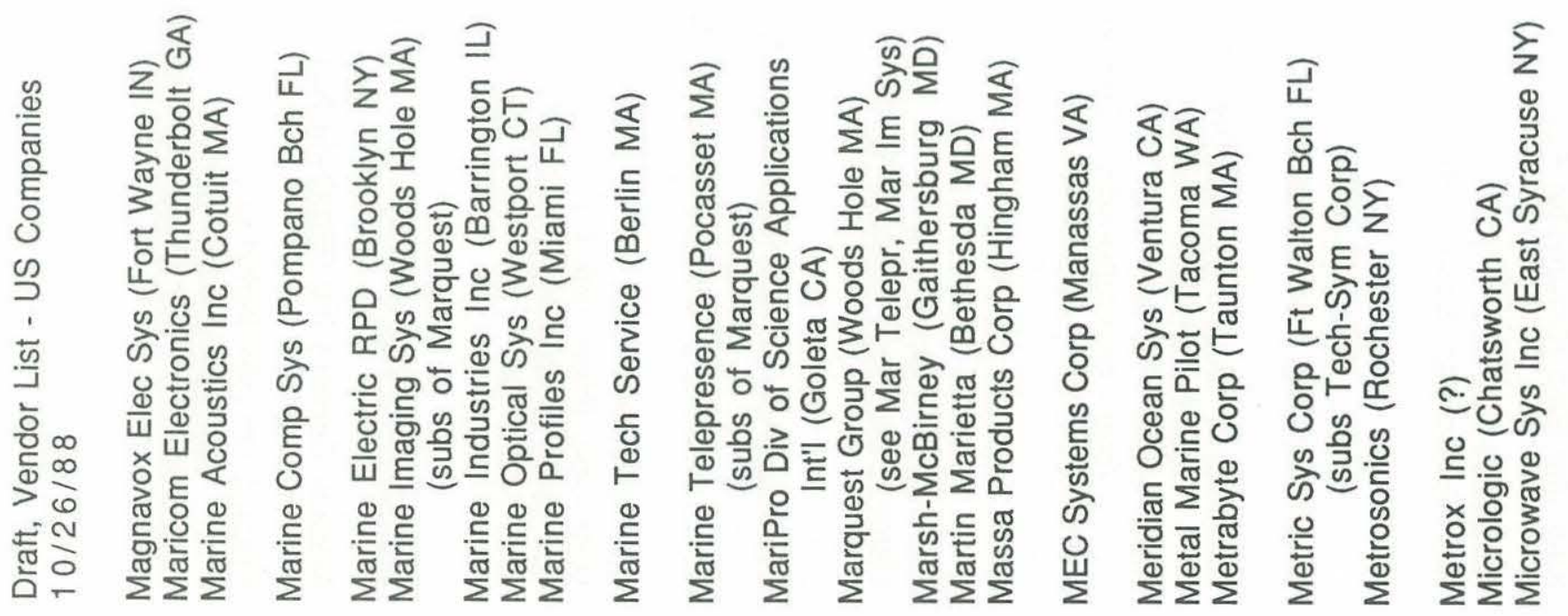


$\begin{array}{ll}* & * \\ 0 & \frac{1}{0} \\ 10 & 0\end{array}$

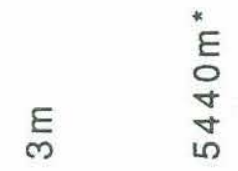

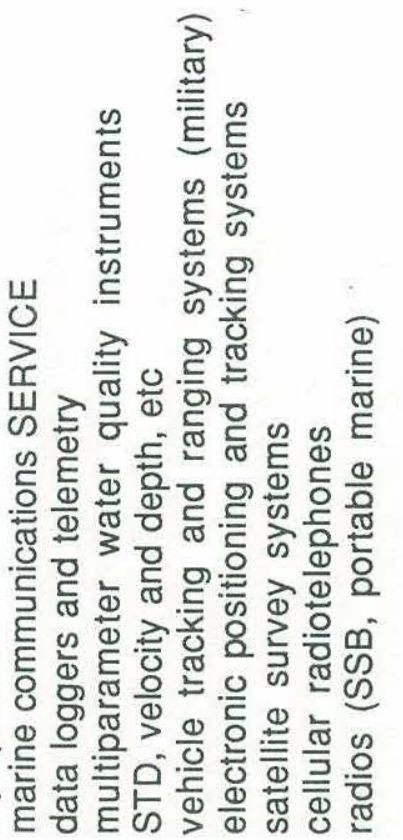

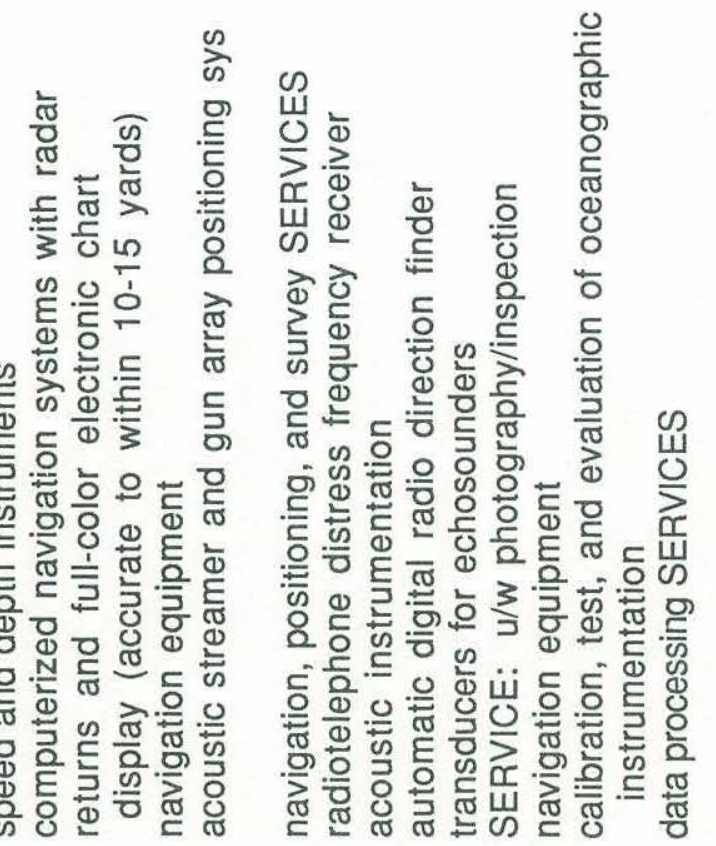

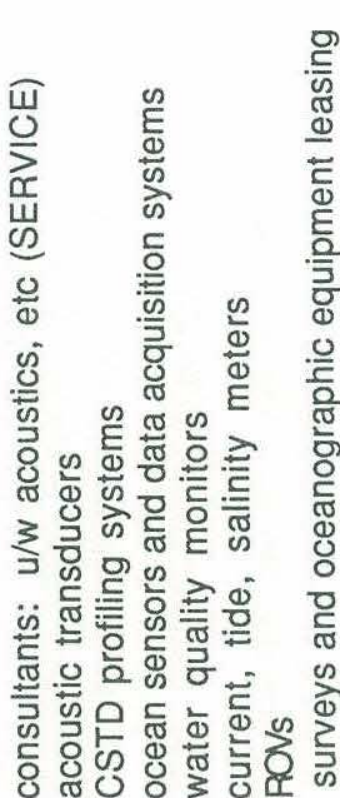

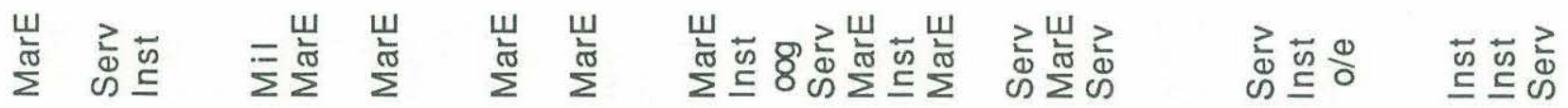

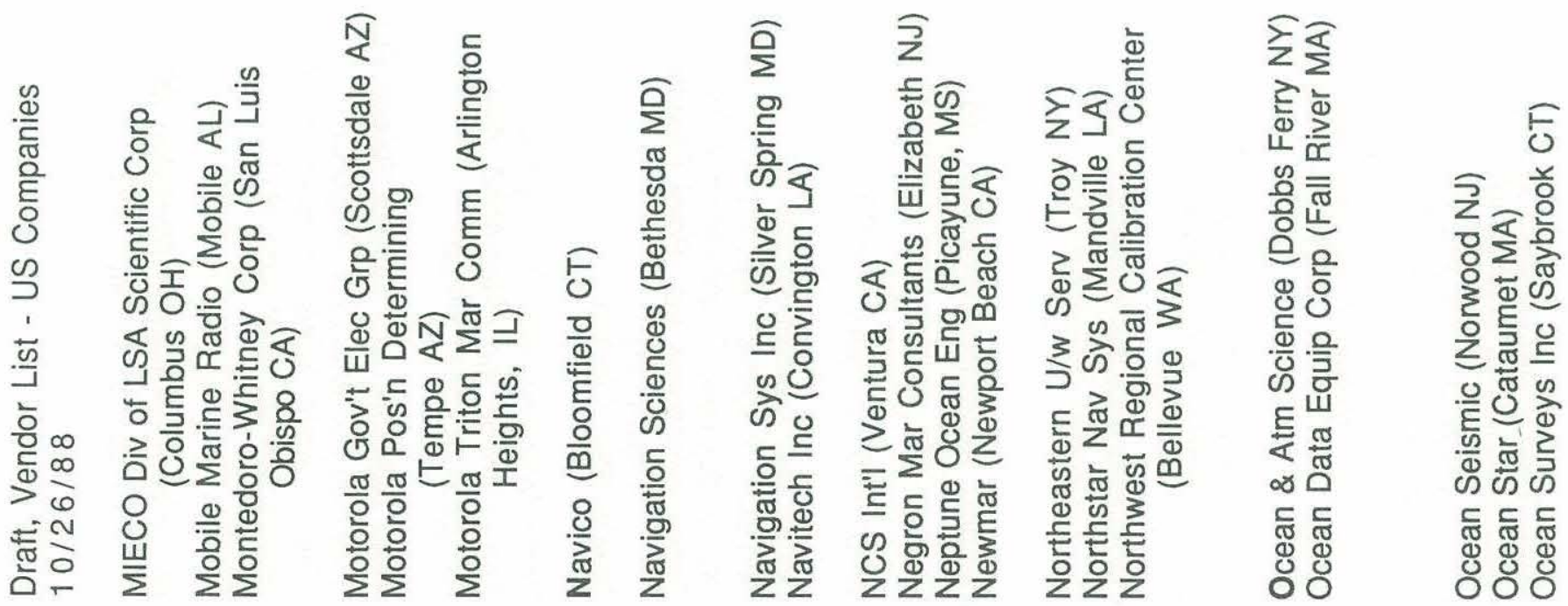




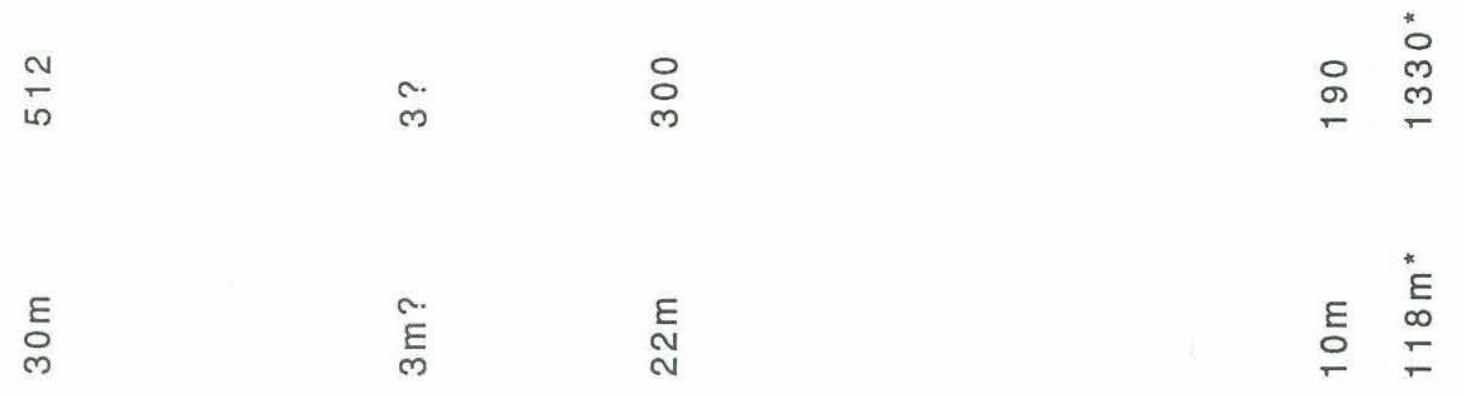

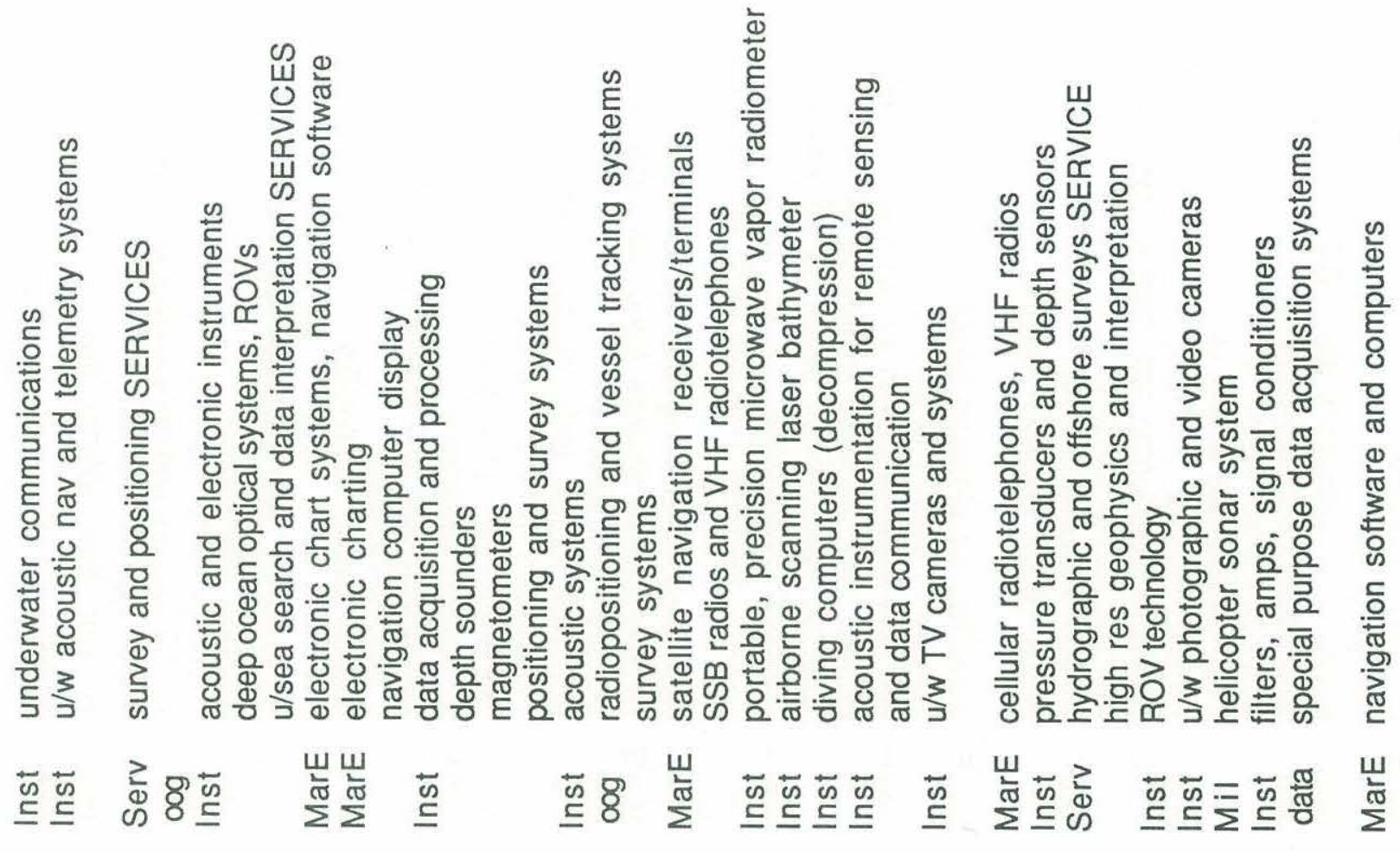

$\frac{10}{5}$

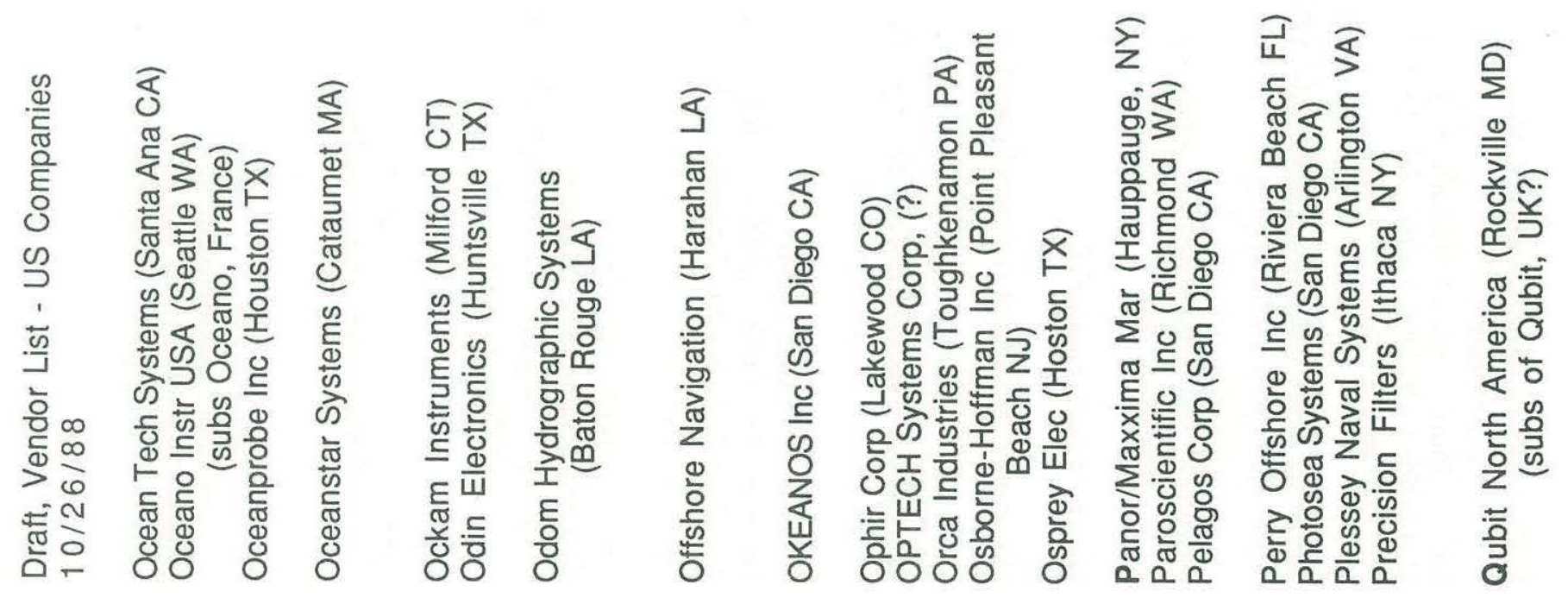




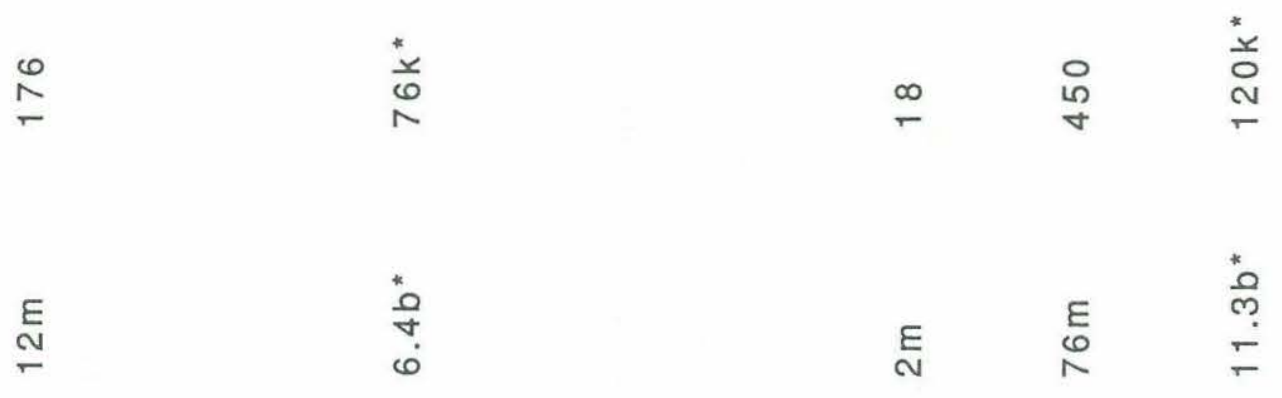

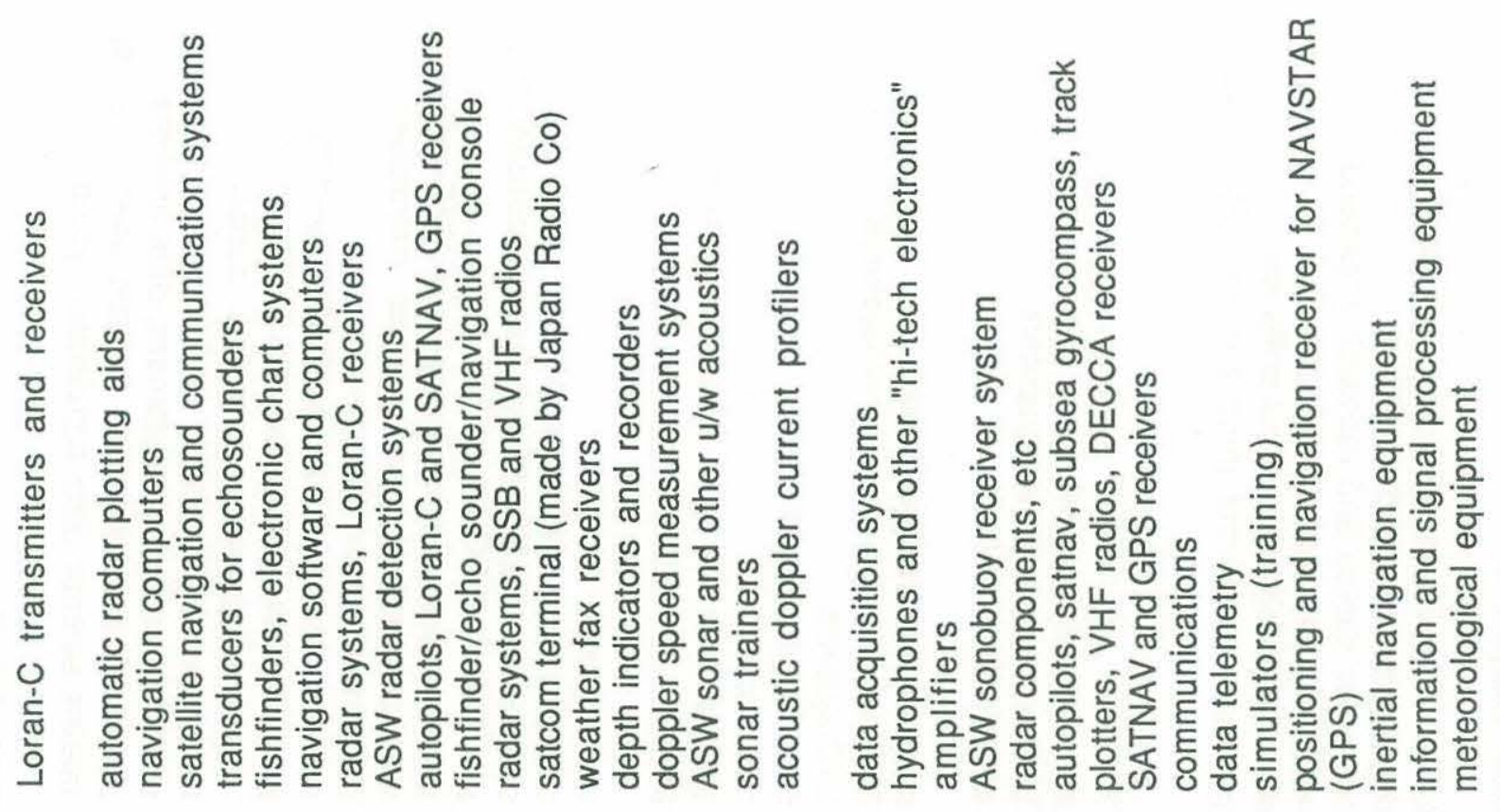

$\frac{0}{\dot{m}}$

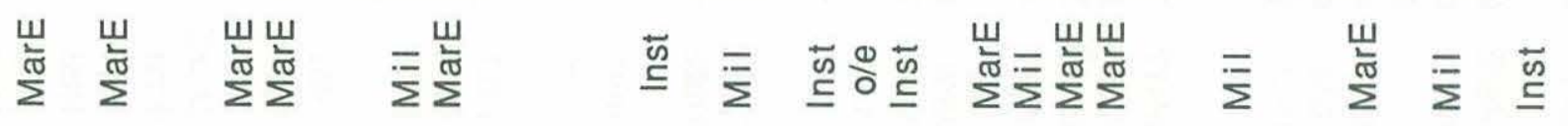

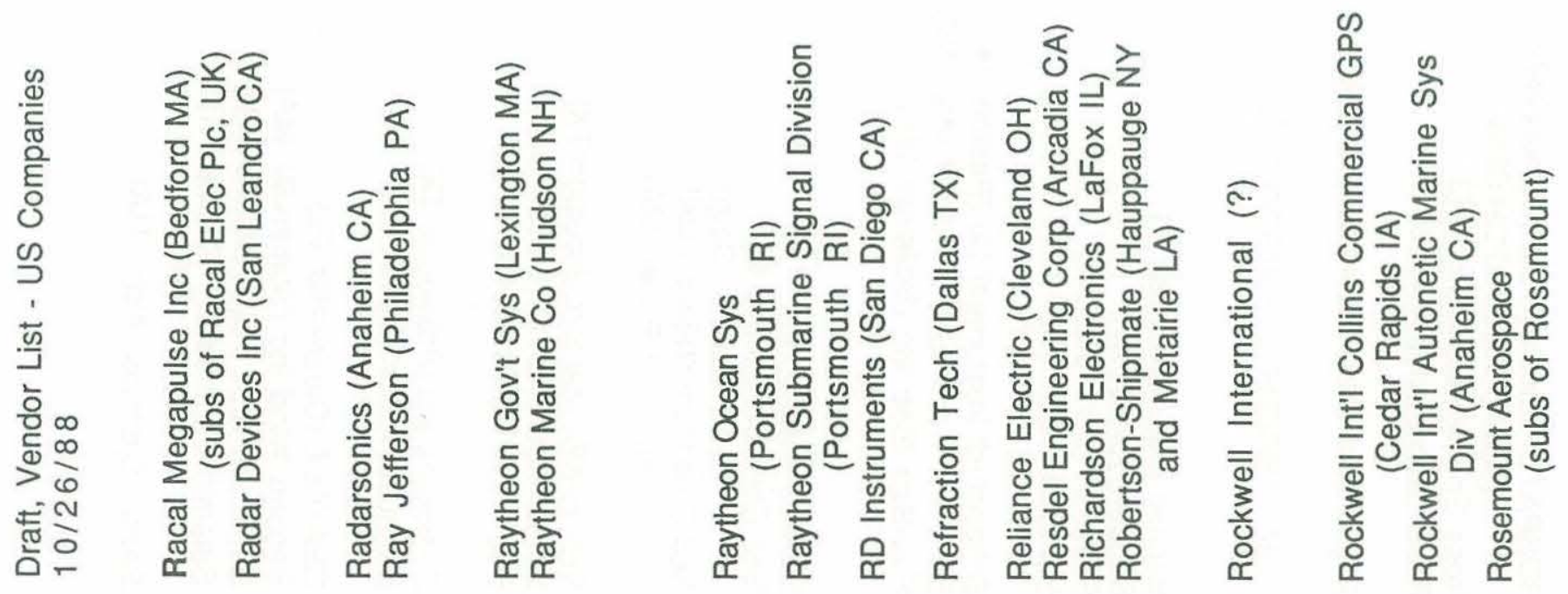


$\stackrel{\circ}{\circ}$

E

$\underset{G}{E}$
$\underset{\infty}{E}$

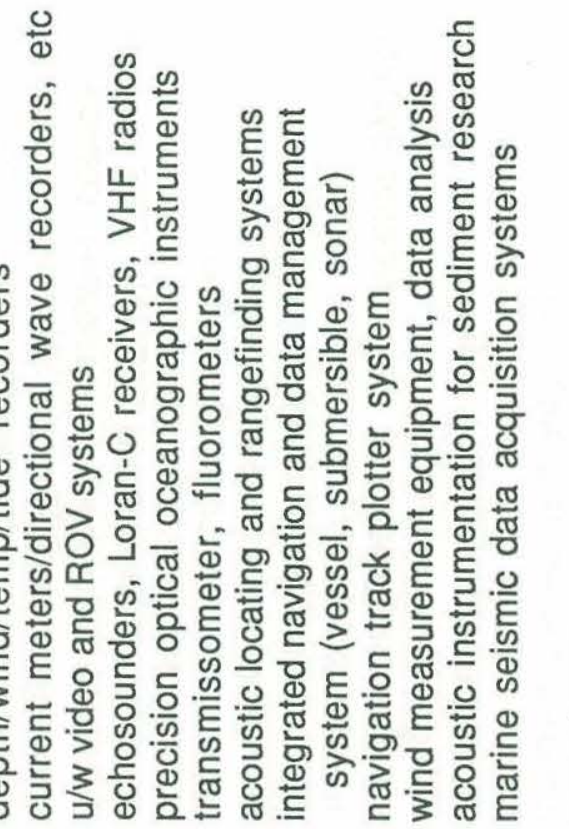

$\frac{N}{1}$

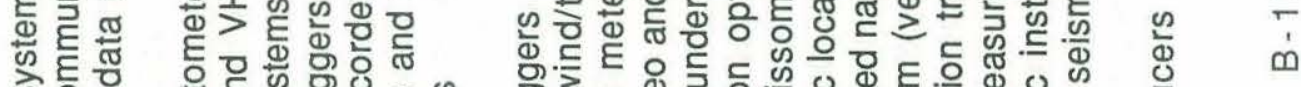

के

苋

휴

$5 m$ का

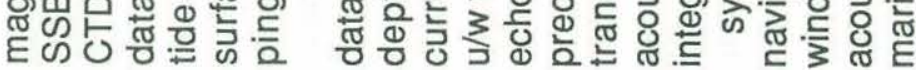

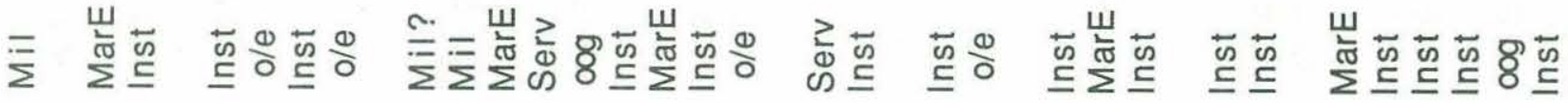

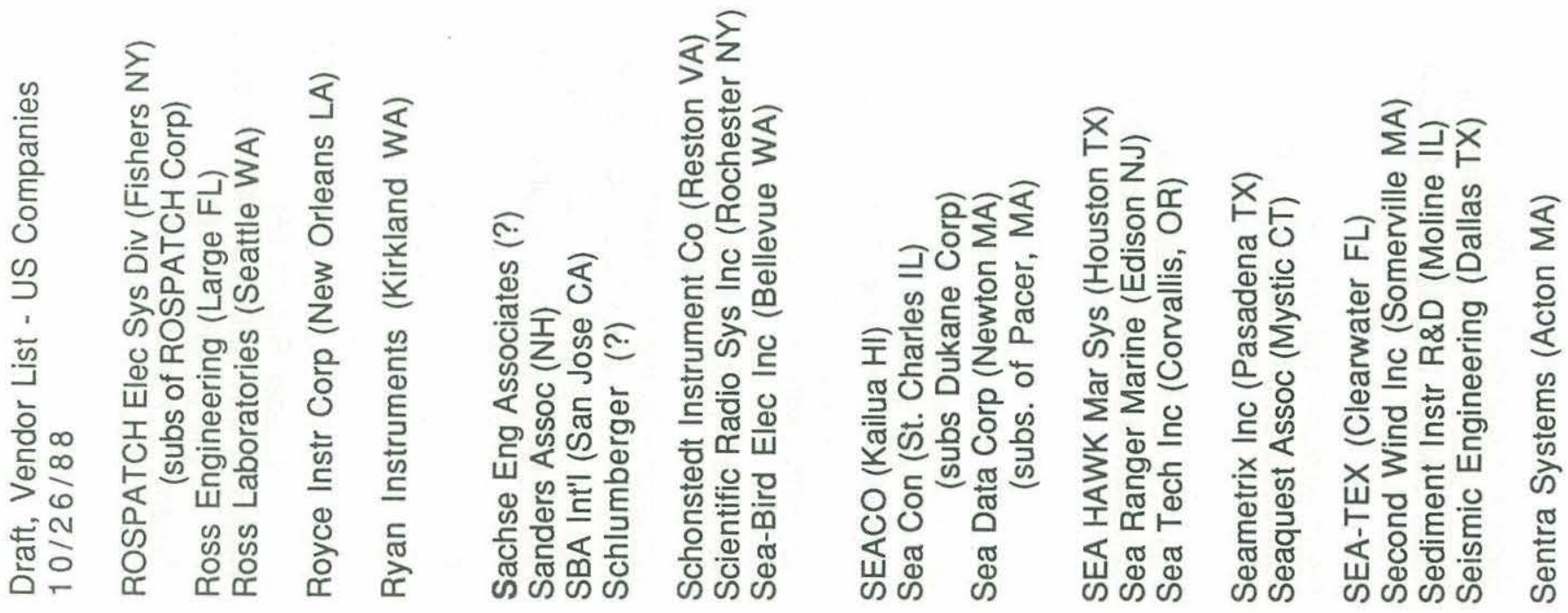




$$
\begin{aligned}
& \text { 品 } \\
& \begin{array}{ll}
* & * \\
0 & n=0 \\
0 & \square
\end{array}
\end{aligned}
$$

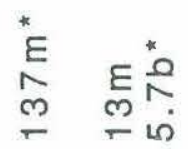

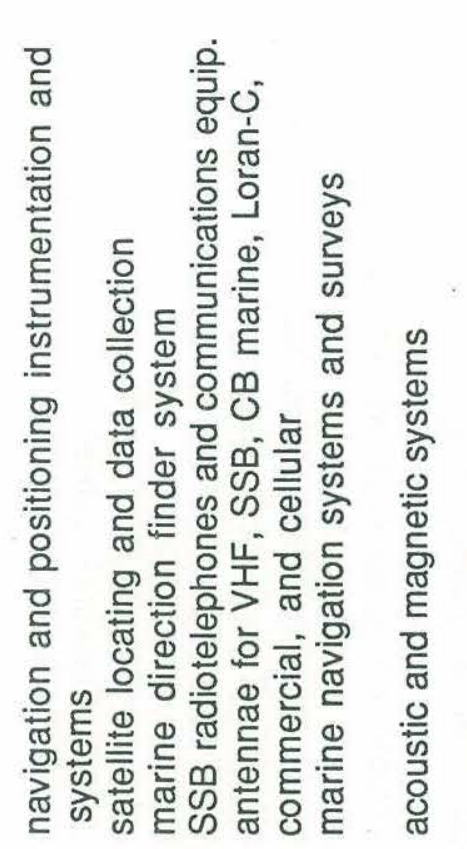

(

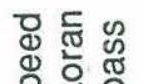

용을

兵

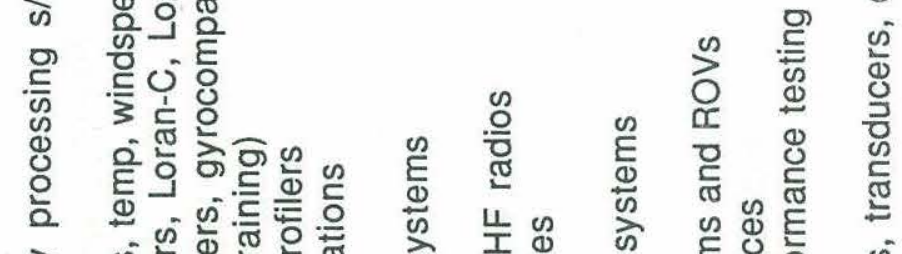

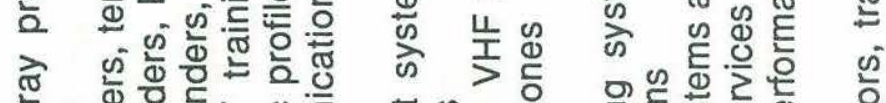

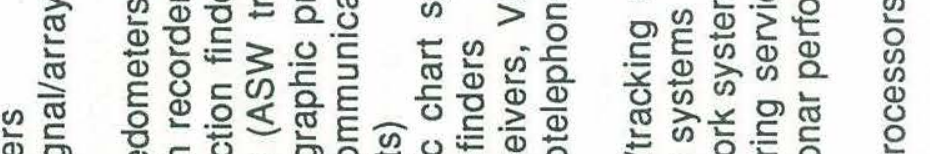

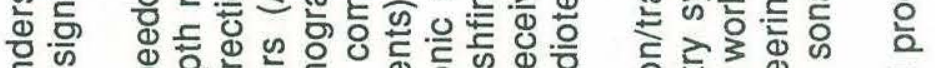

.

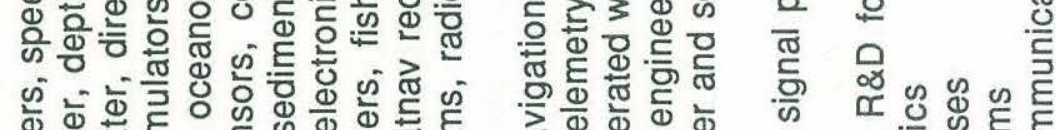

드을 을

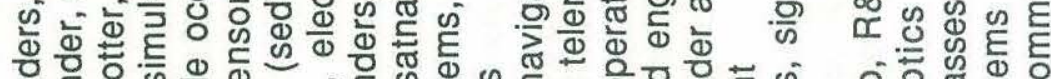

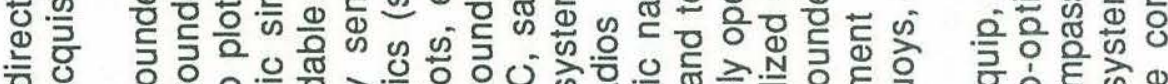
o

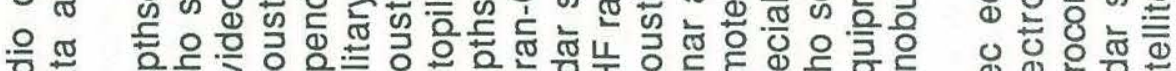

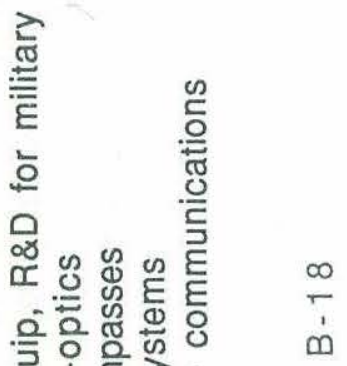

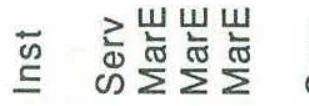
๘্ㄴ $\frac{\pi}{0}$

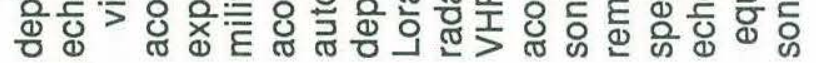

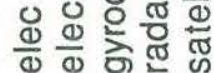

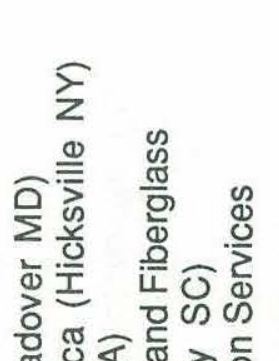

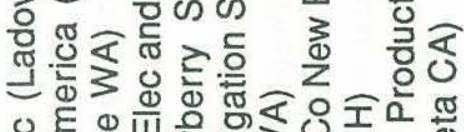

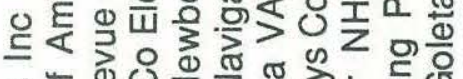
क力 ऐ 인은

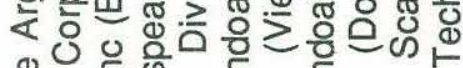
\%

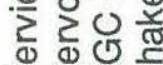
लळळक

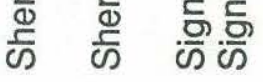

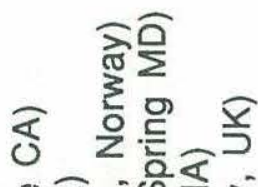

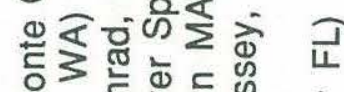

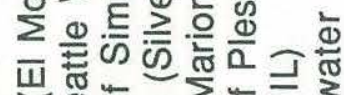
Шᄑ Ф

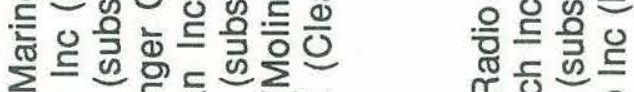

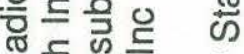
떠을

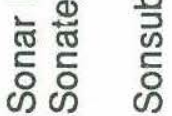

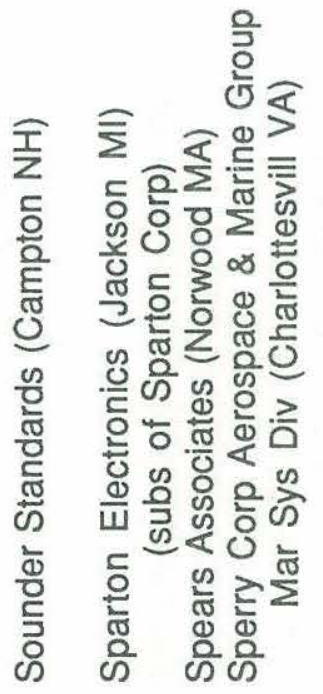




$$
\begin{aligned}
& \text { 욤요 }
\end{aligned}
$$

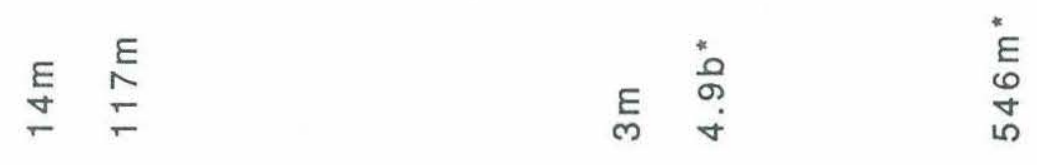
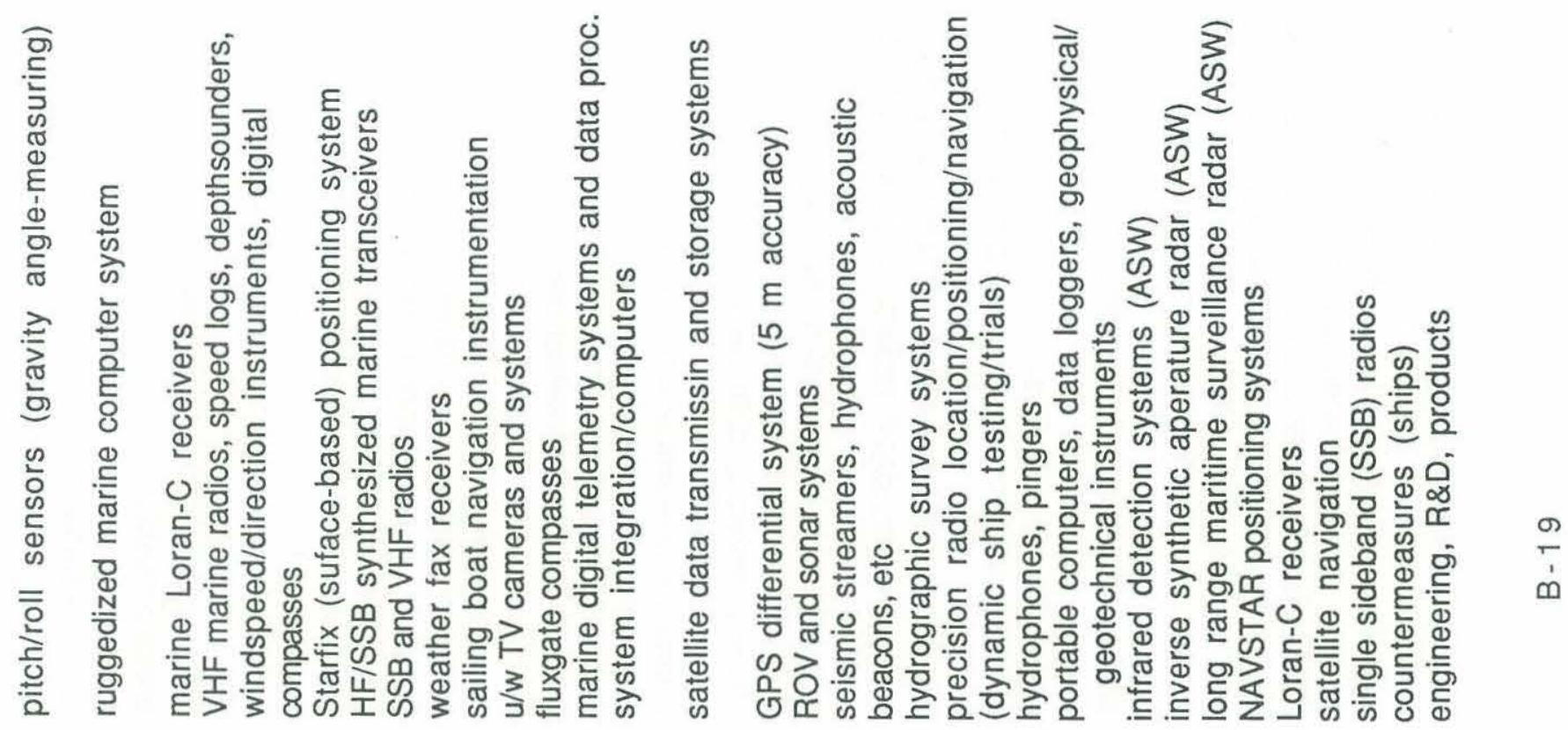

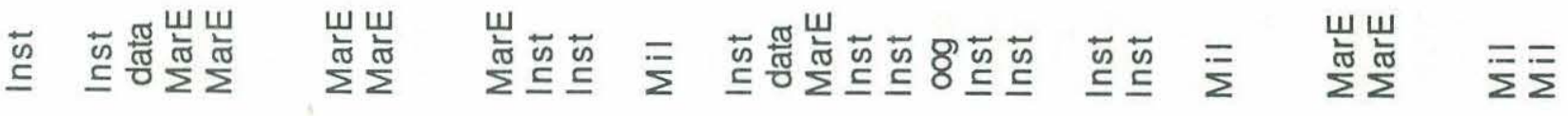

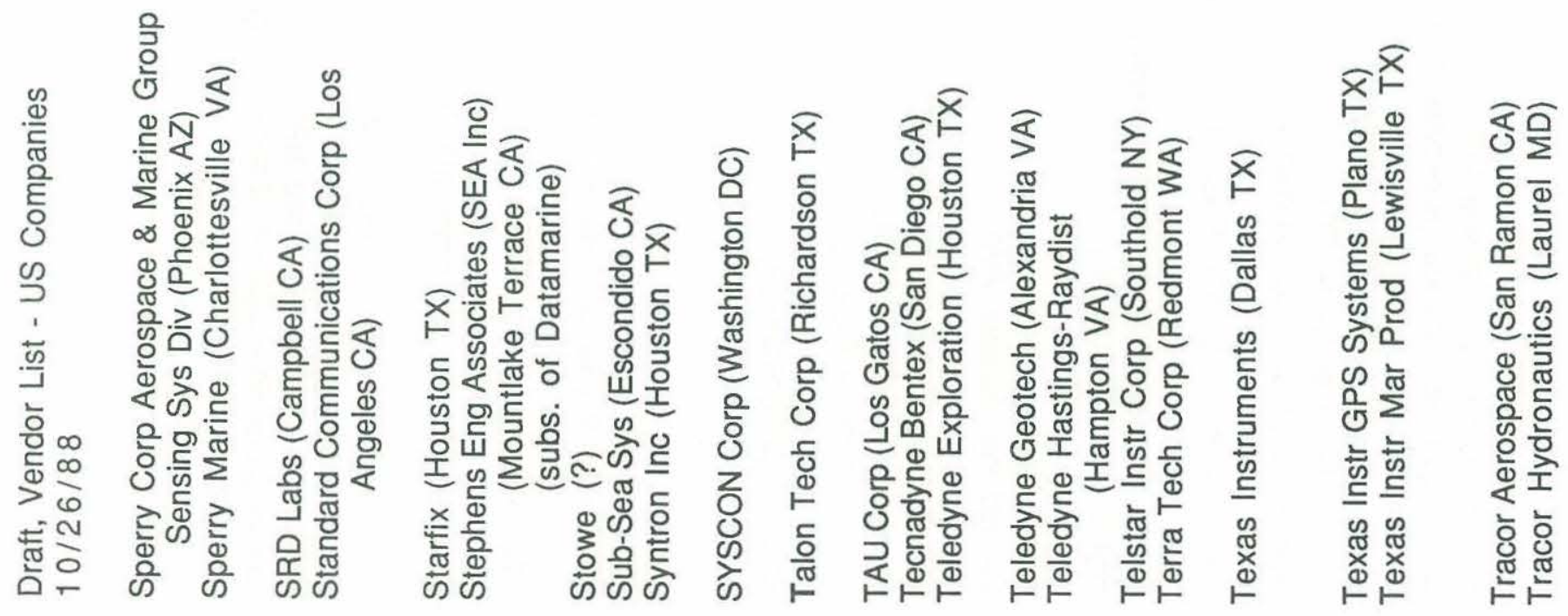




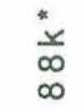

คे
ம்

$\stackrel{*}{\stackrel{0}{0}}$

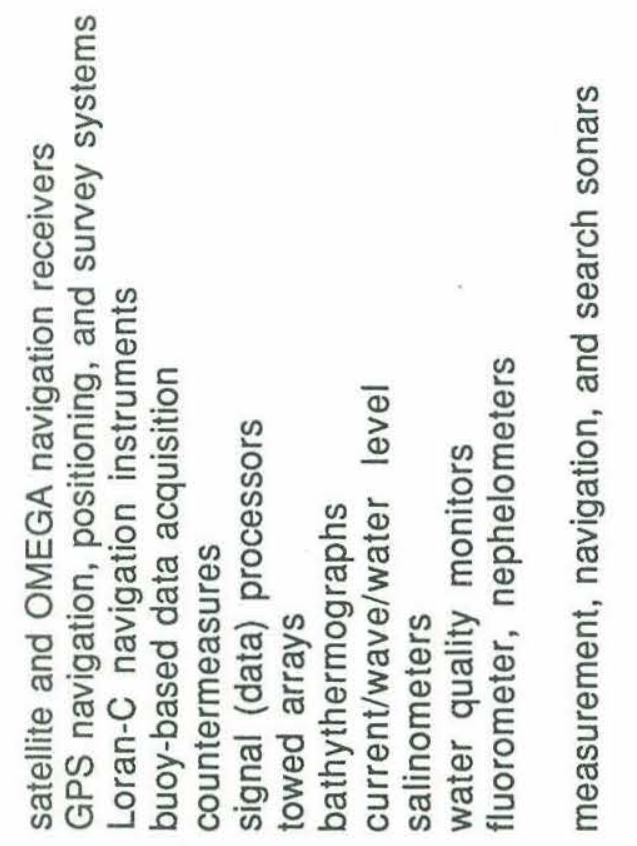

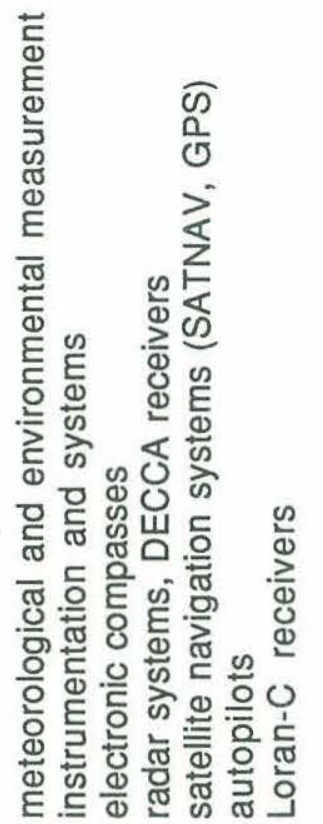

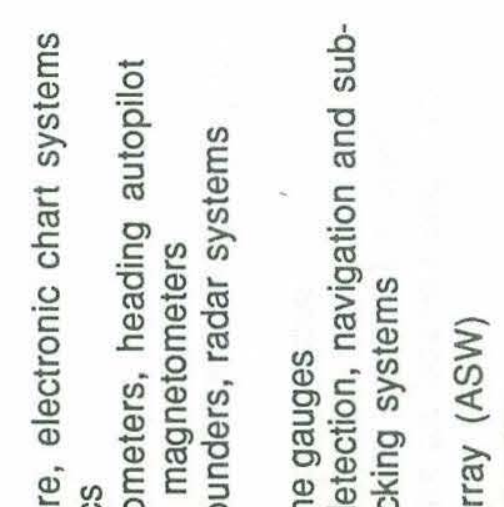

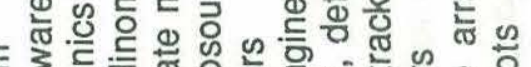

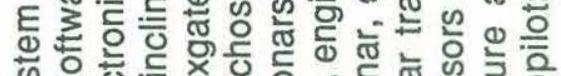

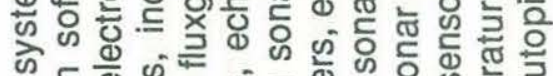

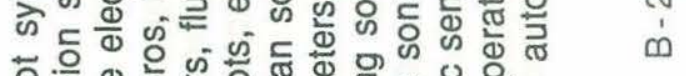

ᄂ 땅

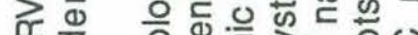

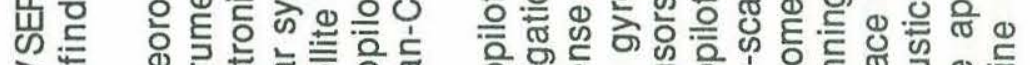
ว

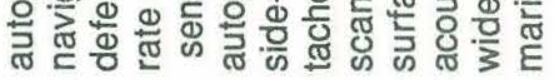
峁峁

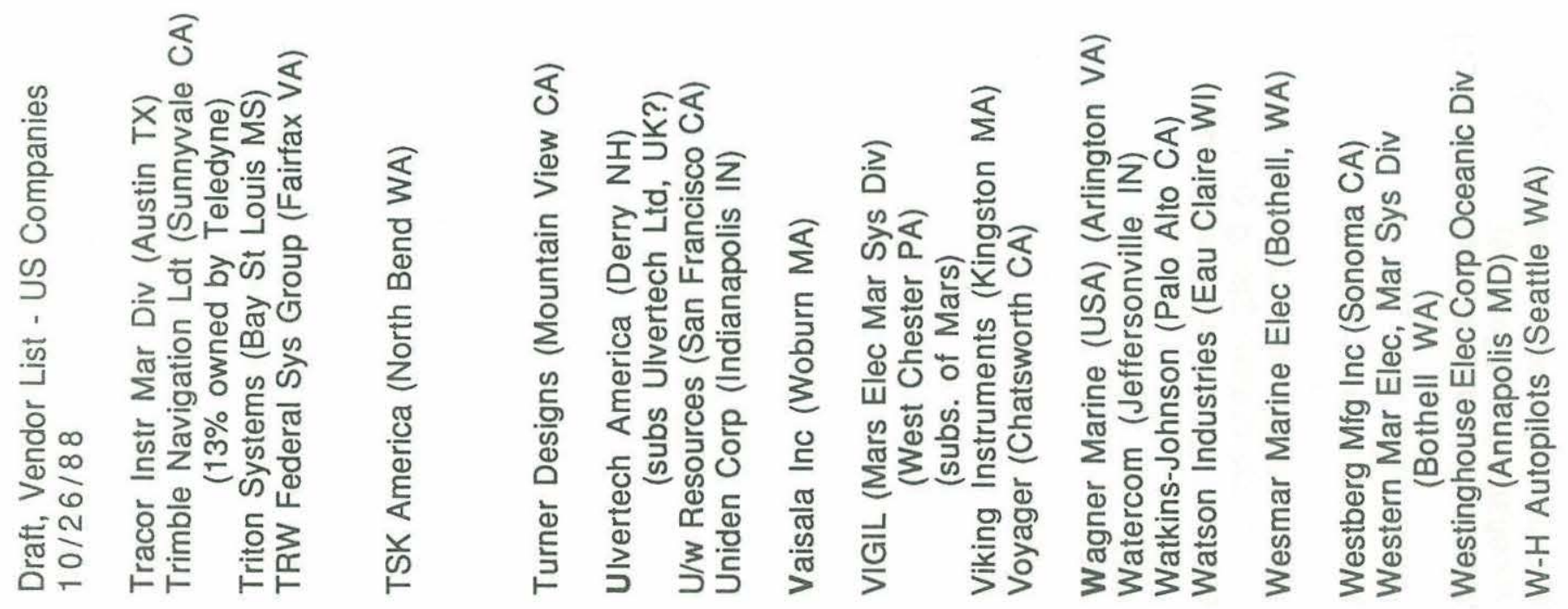



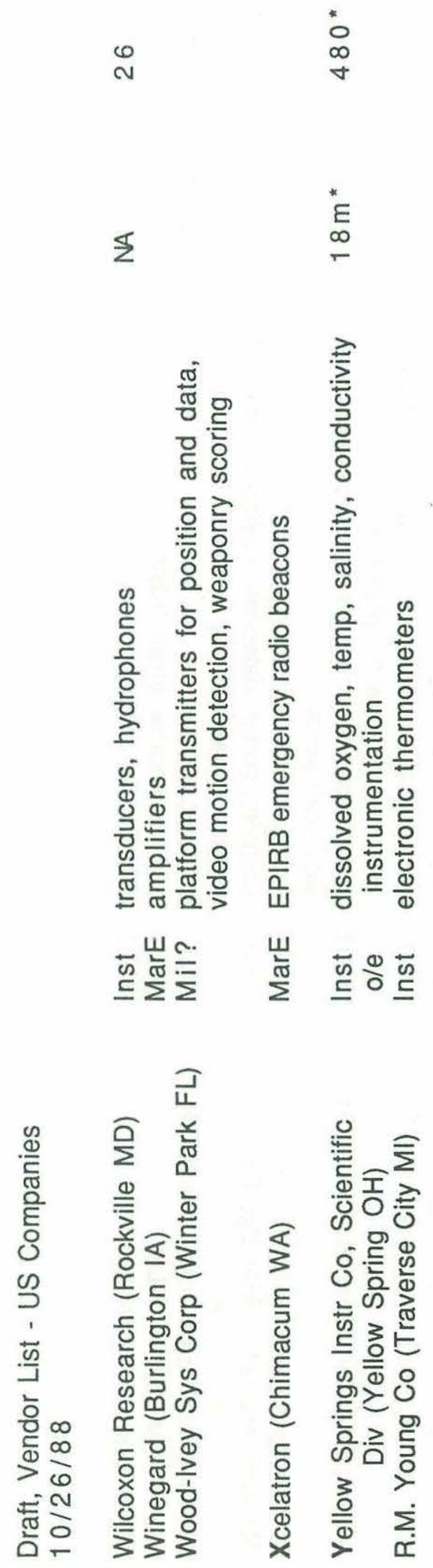
Appendix C:

Marine Electronic Instrumentation

Non-U.S. Firms 



\title{
Marine Electronic Instrumentation Non-US Firms
}

\author{
key: Inst Instrumentation Firm \\ o/e specializing in oceanographic/environmental instrumentation \\ oog specializing in offshore oil \& gas instrumentation \\ data specializing in data management instrumentation \\ MarE Marine Electronics Firm (commercial/recreational) \\ Mil Defense Contractor \\ Serv Service-Oriented Company
}

Fullerton, Sherwood Eng Ltd (?)

International Submarine Eng Ltd (?)

\author{
Australia \\ Nautronix \\ Steedman Ltd \\ Under Sea Australia Ldt \\ Cananda \\ AGE Instruments \\ Applied Microsystems Ltd \\ Barringer Research Ltd \\ CAE \\ Candian Astronautics Ltd \\ Canadian Marconi Co \\ Caulfield Engineering \\ CompuNav Systems Ltd \\ Computing Devices Co
}

Underwater Systems of Australia Ltd
Mil? ?

Mil? ?
Inst integrated long and short baseline positioning sys

Inst data collection/processing specialized instrumentation

Inst ROV technologies

Mil? ?

Inst optical particle counters

o/e portable salinometers, etc

Inst oceanographic instrumentation

(CTD, water...)

o/e aquaculture monitoring systems

Inst magnetometer systems

Mil ASW ("MAD") detection systems (aircraft)

Inst data processing SERVICES

navigation equipment sonar systems

MarE NAVSTAR GPS receivers Omega and Doppler navigation systems

Inst acoustic core stereo side scan micro (data) processors specialty sonar systems

MarE autopilots

Mil ASW acoustic processors 


$$
\begin{aligned}
& \text { C-Tech Ltd } \\
& \text { CTF Systems }
\end{aligned}
$$

Fenco Newfoundland Ltd

Guildline Instruments Ltd

Hermes Elec Offshore Data Sys

Huntec('70) Ltd

Hyco Submersibles Ltd

International Datacasting Corp

International Submarine Eng Ltd

The McElhanney Group Ldt

Mesotech Systems Ldt

(subs Simrad)

Metocean Data Systems Ltd

Nortech Control Equipment Inc

Nova Scotia Reseach Foundation

Offshore Survey and Positioning Services Ltd

Optech Inc.

Quester Tangent Corp

RSI Robotic Systems Int'I Ltd
Mil? sonar $u / w$ detection, classification, tracking

Inst geophysical/oceanographic

oog magnetometers

transducers

Inst data collection/processing data

Inst

o/e

CSTD oceanographic systems laboratory salinometers, digital thermometers

Inst bathythermographs

communications equipment

data links

sonobuoys

Serv high res marine (deep) tow seismic systems

oog seismic subbottom profiling instruments and SERVICES

Inst ROV technology

MarE satellite-based network for transmission of full-sized charts from central database

Inst ROVs and associated equipment

Serv SERVICES: navigation and

oog positioning; surveys

Inst acoustic scanning/profiling, obstacle avoidance

echo sounders

general surveillance sonars

navigation/telemetry/transponders

pingers

Inst oceanographic and meteorological

o/e data acquisition and argos transmitter systems

Inst acoustic navigation equipment $\mathrm{u} / \mathrm{w}$ photographic systems fluorometers, oxygen meters, transponders, etc

Mil ASW dipping-sonar, etc

Serv navigation and rig positioning

oog surveys and profiling

Inst airborne scanning laser system

Inst compact, field system for real-time navigation, graphics, data logging, and post-processing

Inst ROV and data telemetry systems 
Scintrex Ltd

Seaboy Marine Services Ltd

Seakem Oceanography Ltd

Seimac Ltd

Sonotek Ltd

Vemco Ltd

Western Subsea Technology Ltd

Denmark

Eiva A/S

Navitronics A.S.

Reson Systems APS

Finland

Hollming Ltd Electronics

Rauma Repola

France

Creo S. A.

Crouzet

CSI

ECA

Hytec (Hydro-Technologie) SA
Inst data acquisition systems optical pumped high sensitivity magnetometers

portable atomic absorbtion spectrometers

Inst autonomous robotic buoys autopilots (navigation) satellite/radio telemetry systems

Inst physical, chemical, and biological

o/e oceanographic instruments

Inst custom oceanographic instruments

$\mathrm{o} / \mathrm{e}$ and integrated data systems

Inst digital data acquisition systems

oog geophysical and meteorological instruments

Inst $u / w$ telemetry and instrumentation systems

Serv oceanographic and offshore engineering design SERVICES

Inst software for navigation and survey data mapping

Inst navigation data processing systems survey echo sounders, velocimeter

Inst advanced sonar, transducer, hydrophone systems

Inst acoustic navigation systems

distributed data processing networks

hyroacoustic instrumentation multi-beam echo sounders navigation equipment

Inst (shipyard associated)

Inst data collection, satellite systems data

Mil digital magnetic anomaly detection (ASW)

Mil mine countermeasures ROVs

Inst integrated bathymetric systems ROV technologies

Inst $u / w$ cameras and ROV technologies 
Nereides

Oceano Instruments SA

Sercel

Service Argos

Suber S.A.

Thomson Sintra ASM

\section{Germany (West)}

Dr. Fahrentholz - Kiel

Honeywell Elac Nautik GmbH

Hydro-Bios Apparatebau GmbH

IBAK Helmut Hunger GmbH \& Co KG

Krupp Atlas Elekronik

ME Meerestechnik-Elektronik $\mathrm{GmbH}$

CTDs, etc

Salzgitter Elektronik GmbH

SIS Meeres- und Umweltmesstechnik
Inst oil spill detection systems

satellite (Argos) transmission systems

wave spectrum etc buoy systems

Inst acoustic positioning, navigation, tracking

data transmission and telemetry oceanographic and geophysical instruments

Inst positioning systems

Serv environmental, XBT, location terminals for satellite data transmission/collection

Inst $u / w$ and meteorological instruments and data loggers

Mil sonars, u/w communications, precision positioning, data processing, echosounders, etc

Inst integrated survey echo sounders and laser positioning and recording system

Inst survey sounders and digitizers

Inst CTD probe, time-depth-temp

$\mathrm{o} / \mathrm{e}$ recorders, etc

Inst specialized (u/w) television systems

Mil advanced echosounders

Swath and other survey systems Inst acoustic current meters,

Mil sensor technologies: CTD, etc

Inst electronic digital thermometers, CTDs, etc

\author{
Japan \\ Furuno \\ ICOM \\ Kowa Corp \\ Mitsubishi Heavy Industries ? \\ Mitsui Engineering \& Shipbuilding ? \\ Nippon Electric Co Ltd, Radio \\ Applicance Div \\ Sumitomo Metal Mining Co \\ Ocean Resource Dept \\ Union Engineering Ltd
}

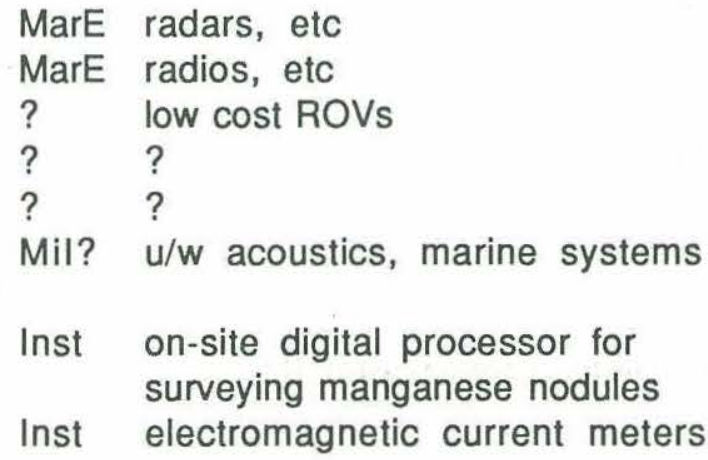


Netherlands

Van Essen B.V.

instruments

Norway

Aanderaa Instruments

instrumentation

Fjord Instruments A/S

Kongsberg Navigation A/S

MIROS A.S.

Oceanor, Oceanographic Co. of Norway

Robertson Tritech A/S

ROVTech AS

Seatex A.S.

Sensordata A/S

Simrad-Bergen Ocean Data

Simrad Subsea A.S.

\section{Sweden}

Navtex

Standard Radio \& Telefon $A B$
Inst current, depth, water level

Inst oceanographic/meteorological

o/e

Inst hydrophones/arrays

MarE differential GPS and integrated navigation sys

Inst inertial navigation systems remote sensing equipment wave radar system

Inst oceanographic data acquisition systems, data analysis, forecasting, etc

Inst ROV systems technologies

Inst ROV systems technologies

Inst buoy systems for metocean data

o/e collection and analysis, and transmission

GPS software for offshore positioning

Inst miniature current meters and

o/e salinometers with internal solid state data loggers

Inst automatic weather stations

o/e meteorological/oceanographic systems ultrasonic current meter

Inst hydroacoustic position reference system, etc

MarE telex receiver

MarE telex receiver (for navigation)

United Kingdom (England, unless otherwise indicated)

AB Precision (Poole) Ltd

Ametek Offshore Co (Scot)

Andrews Hydrographic Ltd

Inst echosounders

Inst ROV technologies

Inst survey data logging/navigation systems

Bathymetrics Ltd

Inst real time combined SWATH depth sounder and sidescan sonar system

Bennico Ltd (Scot) profic survey and curren profiling systems

ROV technologies 


\author{
British Aerospace Dynamics Div \\ British Aerospace Naval and \\ Electronic Systems Div \\ Britsurvey Div of Britdive Ltd \\ Brookes \& Gatehouse \\ Brookes \& Gatehouse Industrial Div \\ Caledonian Geotech (Scot) \\ Camera Alive Ltd \\ Cetrek Ltd (subs Marinex) \\ Chelsea Environmental Instruments
}

Chemlab Instruments Ltd

Colnbrook Instrument Development Ltd

Concept Systems Ltd (Scot)

T\&J Crump Scientific Instruments

DBE Technology Ltd

Deep Ocean Engineering (Scot)

Deep Ocean Robotics

Del Norte Technology

Dowty Marine Systems Ltd

Druck Ltd

EDO Almondbury Ltd

EEV (subs of Gen Elec Co, England)

Efcom Incorporated (Scot)

E.S. Products
Mil acoustic transducers (and other military)

Mil Versatile Exercise Mine System (VEMS) marine mine simulator/trainer

Inst positioning software, signal

data digitizing packages

Inst anemometers, echosounders, fluxgate compasses ultrasonic surface current meters

Inst meteorological instruments and recorders

Serv geophysical survey SERVICES

oog

Inst $u / w$ cameras, offshore photogrammetric system

MarE autopilots

Inst in-site fluorimeter, turbidity

o/e measurement

oil sensing

transmission/logging of data

Inst water and oceanographic analysis

o/e instruments

Inst electromagnetic water velocity meters

gyroscopes

Inst integrated navigation/tracking systems

Inst tranmissometer, turbidity meter $\mathrm{u} / \mathrm{w}$ light sensors

Mil acoustinc positioning, hydrophones

Inst ROV technologies

Serv ROV SERVICES

Inst electronic distance measurement and positioning

receivers for navigation, survey, and geodetic

Inst sidescan sonar systems, including: thermal linescan recorders

Inst pressure transducers and indicators

Inst ultra-short baseline acoustic positioning system

Inst marine magnetrons (part of radar)

Inst diver communications and navigation systems

Inst data acquisition and monitoring systems 
Ferranti ORE Ltd

Fugro-McClelland Ltd

Gardline Surveys

Geodata Systems Ltd

telemetry, and

Geofix Ltd (Scotland)

(subs Oceonics Group Plc)

Geografix Ltd

Geosite Surveys Group

Geoteam UK Ltd (Scot)

Horizon Exploration Ltd

(subs Horizon Exploration Holdings)

Hunting Surveys Ltd, Marine Div

Hydraulics Research Ltd

Hydrovision (Scot)

Kelvin Hughes Ltd

Kemo Ltd

Littlemore Scientific Eng. Co.

Magnavox Systems Ltd

The Marconi Int'I Mar Co Ltd

Marconi Space and Defence Sys Ltd Naval \& Ocean Eng Div

Marconi Underwater Systems (subs LEC ?)

MAREX

Marine Acoustics Ltd

Marine Electronics Ltd
Mil acoustic flowmeters and tracking systems

Inst long-range acoustic telemetry systems

sonar image record enhancement system sub-bottom profiling systems

Serv marine geotechnical SERVICES

Serv survey, positioning, and ROV SERVICES

Inst acoustic navigation, control systems

Inst integrated nav/pos system for

oog offshore explor.

Inst integrated

Serv offshore positioning, data

og acquisition and interpretation

Serv hydrographic and marine

oog geophysical surveys

seismic and bathymetric data processing SERV's

Serv seismic data acquisition,

oog processing, interpretation

Serv hydrographic, oceanographic,

oog marine geological and geophysical surveys

offshore position fixing

Serv data acquisition SERVICES

Inst ROV technologies

MarE radar, automatic radar plotting aid sonar navigation systems

Inst custom electronic filters and signal data processing

Inst towed and diver-held magnetometers/metal detectors

MarE satellite communications and navigation systems

MarE marine communications navigation aids, radar

Mil integrated navigation, location and positioning, sonar, sub-sea tracking systems

Mil GLORIA seafloor mapping system $\mathrm{u} / \mathrm{w}$ diver communications systems

Inst ocean data systems and weather stations

Mil acoustic systems and transducers

Inst acoustic sector scanning sonar 
Marine Microsystems Ltd (Ire)

Measurement Devices Ltd

Mertech Systems Ltd (Scot)

Micromake Electronics

Mobell Survey Ltd

NBA [Controls] Ltd

NBA Environmental Systems Ltd

Norcom Technology Ltd

Nortech Surveys

Oceano Instruments (UK) Ltd

Osel Group

Osprey Electronics Ltd (Scot)

Plessey Naval Systems Group

Qubit

Racal Marine Systems Ltd

Racal Survey Ltd

Raymar Technical Services Ltd

Robertson Autopilots UK

Schaevitz EM Ltd

Seaeye Marine

Seametrix Ltd (Scot)

Seateam (UK) Ltd acoustic navigation/telemetry systems

Inst seabed data acquisition and interpretation systems

Inst bathymetric survey packages

laser positioning systems

Serv ROV and survey SERVICES

Inst radio telemetry systems

data

Serv hydrographic survey SERVICES

Inst wave crest wave profiling, etc

Inst environmental data acquisition

o/e systems

Inst hydrographic surveying software

data

Serv navigation and positioning SERVICES for surveys

Inst satnav/acoustic integrated systems $\mathrm{u} / \mathrm{w}$ acoustic systems, long and short baseline

Inst ROVs

Inst $\mathrm{u} / \mathrm{w}$ video equipment

Mil ROV (mine countermeasures) technologies

Inst real-time integration of sonar and positioning

high res sonar logging to optical disk

digital sonar enhancement techniques

MarE radio, acoustic, and satellite

Mil positioning

survey recording and processing systems

various radar systems

Serv worldwide survey SERVICES

Inst portable surveying sounders

MarE gyrocompass autopilots for survey vessels, etc

Inst angular position/inclination transducers

pressure measurement offshore and sub-sea

Inst ROV technologies ("low-cost ROVs")

Inst acoustic locating/rangefinder systems

diver navigation systems, ROV technolgies

Serv Quod plus computer charting system 
Seaway Technology Ltd (Scot)

Simrad Albatross Ltd (Scot)

Smiths Industries

Sonar Research and Development Ltd

Sonardyne Ltd

Spiro Diving Services Ltd (Scot)

SUTec (UK) Ltd (Scandinavian Underwater Technology) (Scot)

Technical Survey Services Ltd

Technical Survey Services Ltd (Scot)

Tower Computer Systems

Transamerica Instruments Ltd

T.T. Surveys

UDI Groups Ltd (Scot) (subs John Brown plc)

Ulvertech Ltd

Valeport Marine Scientific Ltd

David J. Vyner Ltd

Waverley Electronics Ltd Wimpol Ltd $\infty$

Inst

Inst

Inst

Inst (avion, etc acoustic tidal gauges, etc data transmission, dispiay, storage, and processing

integrated vessel and ROV navigation systems

Inst high accuracy system for tracking multiple 3D seismic streamers

Inst sonar acoustic positioning systems, transponders communications systems

Inst ROVs for mine countermeasures

Inst processing instruments for high res oog seismic surveys and graphic recorder annotator system

Inst signal processing equipment

data

Inst software/hardware for data hydrographic surveys, data acquisition, and electronic charting

Inst data acquisition and recording systems

Inst high res seismic data recorder data

Inst high definition scanning sonar oog offshore survey and positioning systems

Inst dual scanning profiler obstacle avoidance sonar

Inst oceanographic instrumentation

o/e (self-recording current meters, etc)

Inst inexpensive telemetry systems $\mathrm{RF}$ rangefinder and bearing units survey sounders

Inst computer controlled modular sidescan sonars

Serv worldwide survey SERVICES 
W.S. Ocean Systems

Inst current meters, salinometers,

o/e fluorometers, transmissometers, irradiance meters, etc 
Appendix D:

Export Controls:

Commodity List Entries Pertaining to Marine Electronic Instrumentation 

Appendix D: Export Controls: Commodity List Entries Pertaining to Marine Electronic Instrumentation

1391 A "Robots", "robot" controllers and "robot" end-effectors; and specially designed components therefor (including those for underwater use)

1417A Submersible systems, even when incorporated in a submersible vehicle

2418A Manned submersible vehicles that may be discretely operated with an autonomy equal to or greater than 10 hours

4417B Underwater photographic cameras and associated equipment

1418A Deep submergence vehicles, manned or unmanned, tethered or untethered, capable of operating at depth exceeding $1000 \mathrm{~m}$, and specially designed associated systems

1501 A Navigation, direction finding, radar and airborne communication equipment

$1502 \mathrm{~A}$ Communication, detection or tracking equipment of a kind using ultraviolet radiation, infrared radiation or ultra-sonic waves, and specially designed components therefor.

1510A Marine or terrestrial acoustic or ultrasonic systems or equipment specially designed for positioning surface vessels or underwater vehicles, or for locating or detecting underwater or subterranean objects or features, and specially designed components of such systems or equipment, including but not limited to hydrophones, transducers, beacons towed hydrophone arrays, beamformers and geophones (with specific listed exceptions) .

5510C Doppler sonar navigation equipment; and parts and accessories.

1516A Radio receivers, including panoramic and digitally controlled radio receivers.

1517A Radio transmitters.

1519A Single- and multi-channel communication transmission equipment.

1520 A Radio relay communication equipment, specially designed test equipment, and specially designed components.

$1521 \mathrm{~A}$ Solid-state broadband amplifiers and related equipment having an untuned bandwidth exceeding $100 \mathrm{MHz}$ or output power exceeding $50 \mathrm{~W}$. 
1522A Lasers and laser systems including equipment containing them.

1526A Cable and optical fibers (including underwater communication cable).

1529A Electronic measuring, calibrating, counting, testing, and/or time interval measuring equipment, whether or not incorporating frequency standards.

1531A Frequency synthesizers.

1565A Electronic computers, "related equipment", equipment or systems containing electronic computers; and specially designed components and accessories (except personal computers) .

1571A Magnetometers, magnetometer systems and related equipment, and specially designed parts therefor.

1585A Photographic equipment (including high speed cameras and film).

1586A Acoustic wave devices and specially designed components therefor.

1595A Gravity meters (gravimeters), gravity gradiometers and specially designed components therefor.

$6598 \mathrm{~F}$ other electronic and precision instruments specially designed or modified for geophysical or mineral prospecting or for the examination, testing, or controlling of equipment (including equipment specially designed or modified for offshore floating or bottom-supported drilling and producing structures including all gathering equipment). 
Appendix E:

Acknowledgements 

Appendix E: Acknowledgements

We would like to acknowledge the following individuals and organizations, who, though blameless for our conclusions, have helped contribute to this project through interviews, discussions, comments, and suggestions:

Tom Aldrich, Atlantic Marine Geology, U.S. Geological Survey

Richard Arthur, Sippican Inc.

David Bartlett, Marconi Underwater Systems

Steve Beaver, Simrad Inc.

Tony Brackett, Sippican Inc.

Adrian Brierly, Geografix Ltd.

Cynthia Carlson, Marine Policy Center, WHOI

Joseph Chuchla, OTPA, Bureau of Export Administration

Lawrence Clark, Ocean Sciences Division, National Science Foundation

Jack Clotworthy, Joint oceanographic Institutions Inc.

Dan Curran, Raytheon Submarine Signal Division

Michele Elrod, Marine Technology Society

Bill Fletcher, International Trade Commission

Ronald Fortier, Canada Marine Systems Division

Greg Freitas, Datasonics Inc.

Arthur Gaines, Marine Policy Center, WHOI

Ellen Gately, Marine Policy Center, WHOI

Ron Geer, Marine Technology Society

Bill Grella, Navy Submarine Development Group

John Haffenden, British Naval Equipment Association

J. E. Hand, U.K. Department of Trade and Industry

Eric Hartwig, Office of Naval Research

Kjell Hauge, Norwegian Geotechnical Institute

Karen Holtz, Marine Policy Center, WHOI

P. E. Humphrey, Humphrey Inc.

R. M. Iverson, Engineering Service Associates

Rick Jablonski, EG\&G Marine Instruments Division

Gilles Jaquemet, Thomson Sintra Activites Sous-Marines

John Kinn, National Electronic Industries Association

Heinz Krietsch, Salzgitter Elektronik GmbH

Ken Lawson, Sea-Bird Electronics Inc.

Ethel LeFave, Marine Policy Center, WHOI

Pete Lowell, Ferranti O.R.E. Inc.

Doug Mocall, Raytheon Submarine Signal Division

Helen McCammon, Ecological Research Division, Department of Energy

Edward McCann, Elberstadt Fleming, Inc.

Kevin McCarthy, Benthos Inc.

Ed McLean, R/V Ship Manager, Envirommental Protection Agency

Frank McManus, Datamarine Inc.

Richard Mills, Ferranti O.R.E. Ltd.

Ruben Moller, Internation Trade commission

Minoru Odamaki, Japan Science and Technology Agency

Art Pederson, Sea-Bird Electronics Inc. 
Dave Porta, Datasonics Inc.

Sam Powel, Groton R\&D Center, U.S. Coast Guard

Hank Powell, Hoare Govett Investment Research

Sarah Pratt, National Ocean Industries Association

Ralph Rayner, Wimpol Itd.

Mike Riches, CO2 Program, Department of Energy

Mortimer Rogoff, The Digital Directions Co., Inc.

Jim Ross, Ross Laboratories Inc.

David Shamp, Scientific Data Systems

Gene Silva, Office of Naval Research

J. Francis Smith, Northwest Regional Calibration Center

Kim Stephenson, Marine Policy Center, WHOI

Svein Tangen, Simrad Albatross A.S.

David Thompson, The Underwater Centre Ltd.

Lim Vallianos, Dredging Research Center, Army Corps of Engineers

Ann Wagner, Marine Policy Center, WHOI

David Wardle, Society for Underwater Technology

Rick Whitney, Whitney Associates Inc.

Robert Winokur, Office of Naval Research

Steve Wolff, Pacific Marine Geology Lab, U.S. Geological Survey

and the members of the Marine Instrumentation Panel:

John Alden, Alden Products Inc.

Ken van Assenderp, Young, van Assenderp \& Benton

John F. Aylmer, Massachusetts Maritime Academy

Michael J. Balboni, Sippican Inc.

Chris Barebo, Barebo Inc.

Terry Bevels, Heron, Burchetter, Ruchert \& Rothwell

Richard Bixby, Sippican Inc.

Charles R. Booth, Biosperical Instruments Inc.

Lawson Brigham, Marine Policy Center, WHOI

Neil Brown, EG\&G Ocean Products

Alan Brunsman, Yellow Springs Instrument Co. Inc.

Steven Chansky, Vaisala Corp.

H. Lawrence Clark, National Science Foundation

Robert Comerford, University of Rhode Island

Thomas Curry, Southeastern Massachusetts University

Jim Dartez, Royce Instrument Corp.

Jan Dill, Oceanic Institute

Norman Doelling, Sea Grant Program, MIT

Jack Donohoe, Massachusetts Maritime Academy

Marshall Earle, MEC System Inc.

William S. Evans, Ryan Instruments Inc.

Ken Ferer, NORDA

Edward A. Fernald, Florida State University

Sam Francis, Raytheon Submarine Signal Division

Christine Gill, Sea Data Inc.

Gary Glenn, Massachusetts Centers of Excellence Corp.

David Graham, Compass Publications Inc. 
James Griffin, University of Rhode Island

Donald Grossman, Coastal Leasing Inc.

Dean Horn

Hartley Hoskins, Ocean Industry Program, WHOI

Megan Jones, Massachusetts Centers of Excellence corp.

Charles Kearse, NOAA

Martin Klein, Klein Associates Inc.

Frank MacPherson, Sea Data Inc.

William M. Marquet, Deep Submergence Lab, WHOI

Geoffrey K. Morrison, EG\&G Ocean Products

Shale J. Niskin, General Oceanics Inc.

Michael D. Pearlman, Interocean Systems Inc.

Henry Perry, Perry offshore Inc.

Bernard Polanin, NOAA

Chris Polloni, U.S. Geological Survey

Kenneth Prada, Ocean Engineering Department, WHOI

David Ruch, ACR Electronics Inc.

Robert Sassaman, National Marine Electronics Association

Raymond Schiff, Yellow Springs Instrument Co. Inc.

Fritz Schuler, Office of Sea Grant

Allyn C. Vine, WHOI

Malte von Matthiessen, Yellow Springs Instrument Co. Inc.

Charles R. Walsh, Naval Underwater Systems Center

A. J. Williams, Ocean Engineering Department, WHOI 

Appendix F:

References 



\section{Appendix F: References}

Air and Space Magazine.

Allison, David K. "U.S. Navy Research and Development Since World War II." In: Smith, Merritt Roe, ed., 1985. Military Enterprise and Technology Change: Perspectives on the American Experience. The MIT Press, Cambridge.

American Defense Preparedness Association (ADPA), Undersea Warfare Systems Division, 1987. Investment Implications of Current Acquisition Policies. Arlington, VA, October 1987.

Baily, Martin M. N., 1987. Statement in "Hearing on Interaction Between U.S. Tax Policy and Domestic Research and Development," on 3 April 1987, before the Subcommittee on Taxation and Debt Management of the Committee on Finance, U.S. Senate, 100th Congress, Washington.

Baldwin, Robert E. and Krueger, Anne O., eds, 1984. The Structure and Evolution of Recent U.S. Trade Policy. The University of Chicago Press, Chicago.

Baxter, W. F., 1985. "Antitrust Law and Technological Innovation." Issues in Science and Technology 1():80-91 (Winter 1985).

Bureau of the Census, Oct. 1978. Numerical List of Manufactured Products. MC77$\mathrm{R}-1$, Washington: Department of Commerce.

Bureau of the Census, 1982. Census of Manufactures: Communication Equipment, Including Radio and TV. MC82-1-36D, Washington: Department of Commerce, Mar 1985.

Bureau of the Census, December 1984. 1982 Census of Manufactures Ship and Boat Building, Railroad and Miscellaneous Transportation Equipment. MC82-1-37C, Washington: Department of Commerce.

Bureau of the Census, 1985. U.S. High Technology trade and Competitiveness. Staff Report, Washington: Department of Commerce.

Bureau of the Census. March 1985. 1982 Census of Manufactures: Engineering, Measuring and Controlling, and Optical Instruments. MC82-1-38A, Washington: Department of Commerce.

Bureau of the Census, December 1985 and March 1986. 1982 Census of Manufactures: General Summary, parts 1 and 2. MC82-S-1, Washington: Department of Commerce.

Bureau of the Census, Aug. 1986. current Industrial Reports: Communication Equipment, Including Telephone, Telegraph, and Other Electronic Systems and Equipment. MA36P(85)-1, Washington: Department of Commerce. 
Bureau of the Census, Sept. 1986. Current Industrial Reports: Switchgear, Switchboard Apparatus, Relays, and Industrial Controls. MA36A(85)-1, Washington: Department of Commerce.

Bureau of the Census, Oct. 1986. current Industrial Reports: Selected Instruments and Related Products. MA38B(85)-1, Washington: Department of commerce.

Bureau of the Census, Oct. 1987. Current Industrial Reports: Semiconductors, Printed Circuit Boards, and Other Electronic Components. MA36Q(86)-1, Washington: Department of Conmerce.

Champness, Michael and Jenkins, Gilbert, 1985. Oil Tanker Databook 1985. Elsevier Applied Science Publishers, London.

Coles, James S., 1983. "Academic Patent Management," seminar presentation, Department of Ocean Engineering, Woods Hole Oceanographic Institution, Woods Hole, MA, 21 September 1983.

Comerford, Robert, 1988. "Stimulating Small Businesses in the Marine Electronic Instrumentation Industries," unpublished working paper, Marine Instrumentation Panel, Woods Hole, 7-8 June 1988.

Commission on Marine Science, Engineering and Resources (CMSER, "Stratton Commission"), 1969. our Nation and the Sea: A Plan for National Action. United States House of Representatives Document Number 91-42, Washington.

Commission on Marine Science, Engineering and Resources (CMSER/PR), 1969. Panel Reports accompanying the Stratton Commission Report. United States House of Representatives Document Number 91-42, Washington.

Committee on Atmosphere and Oceans (CAO), 1986. Federal Marine Science Budget Summary, FY77-FY86. Federal Coordinating Council for Science, Engineering, and Technology. U.S. Department of Commerce.

Congressional Budget Office (CBO), 1987. Federal Financial Support for HighTechnology Industries. U.S. Government Printing Office, Washington, DC.

Congressional Budget Office (CBO), 1987. The GATT Negotiations and U.S. Trade Policy. DoC. Y 10.2:G 28, U.S. Government Printing Office, Washington, DC.

Cox, Albert W., 1974. Sonar and Underwater Sound. Lexington Books, Lexington.

Daddario, Emilio Q., 1985. "Patents." Science $227(4694)$.

Deardorff, A. V. and Stern, R. M., 1984. "The Effects of the Tokyo Round on the Structure of Protection." In: R. E. Baldwin and A. O. Krueger, The Structure and Evolution of Recent U.S. Trade Policy. Chicago: The University of Chicago Press, 1984, pp. 191-236.

Department of Defense (DOD). Selling to the Military. U.S. Government Printing office, Washington, DC. 
Department of Defense (DoD), Defense Small Business Innovation Research Program, 1987. Volume II: Navy Abstracts of Phase I Awards 1987. Washington.

Department of Justice (DOJ), Antitrust Division, 1980. Antitrust Guide Concerning Research Joint Ventures. U.S. Government Printing Office, Washington.

Douglas, S. J., 1985. "Technological Innovation and Organizational Change: The Navy Adoption of Radio, 1899-1919." In M. R. Smith, ed., Military Enterprise and Technological Change, MIT Press, Cambridge, MA.

Driscoll, David M. and Kransdorf, Ronald J., 1987. "Criteria and Procedures for Patenting Inventions," seminar presentation, Ocean Engineering Department, Woods Hole Oceanographic Institution, Woods Hole, MA, 28 January 1987.

Duncan, Robert C., 1987. Statement in "Hearings on Department of Defense Appropriations for 1988," 23 March 1987, before the Subcommittee on the Department of Defense, Committee on Appropriations, U.S. House of Representatives, 100th Congress, Washington.

Eisner, R., 1987. "Proposals to Increase and Extend the Research and Experimentation Tax credit." Statement in "Hearing on Interaction Between U.S. Tax Policy and Domestic Research and Development," on 3 April 1987, before the Subcommittee on Taxation and Debt Management of the Conmittee on Finance, U.S. Senate, 100th Congress, Washington.

Electronic Industries Association (EIA), 1988. (Import/export figures quoted in The Boston Globe.)

EUROMAR Secretariat, 1988. EUREKA, EU 37: EUROMAR. Bremerhaven, West Germany: Alfred Wegener Institute for Polar and Marine Research, 1988.

The Federal Ocean Program (FOP), April 1972. The annual report of the President to the Congress on the Nation's efforts to comprehend, conserve, and use the sea.

Fay, H.J.W., 1963. Submarine Signal Log: A History of Raytheon's Submarine Signal Division. Portsmouth, R.I.: Raytheon Company.

Florida, Richard L. and Kenney, Martin, 1988. "Venture Capital-Financed Innovation and Technological Change in the USA." Research Policy 17:119-137.

Freeman, Christopher, 1986. The Economics of Industrial Innovation. Second Edition, The MIT Press, Cambridge.

General Accounting Office (GAO), 1985. Foreign Industrial Targeting -- U.S. Trade Law Remedies. GAO/NSIAD-85-77, Washington.

General Accounting Office (GAO), 1986a. Export Promotion: Implementation of the Export Trading Company Act of 1982. GAO/NSIAD-86-42, Washington. 
General Accounting Office (GAO), 1986b. Export Licensing: Commerce-Defense Review of Applications to Certain Free World Nations. GAO/NSIAD-86169, Washington.

General Accounting Office (GAO), 1987a. Patent Policy: Recent Changes in Federal Law. Considered Beneficial. GAO/RCED-87-44, Washington.

General Accounting Office (GAO), 1987b. International Trade: Combating Unfair Trade Practices. GAO/NSIAD-87-100, Washington.

General Accounting Office (GAO), 1988a. DOD Acquisition Programs: Status of Selected Systems. GAO/NSIAD-88-160, Washington.

General Accounting Office (GAO), 1988b. Procurement: Multiyear contracting and Its Impact on Investment Decisions. GAO/NSIA D88-125, Washington.

General Accounting office (GAO), 1988c. Tax Policy: Preliminary Analysis of the Research and Experimentation Tax credit. GAO/GGD-88-98BR, Washington.

General Accounting Office (GAO), 1988d. Export licensing: Number of Applications Reviewed by the Defense Department. GAO/NSIAD-88176FS, Washington.

Geophysics Magazine.

Global Ocean Science Program (GOSP), 1987. Washington: JOI, Inc.

Gomory, Ralph E. and Schmitt, Roland W., 1988. "Science and Product." Science 240:1131.

Great Britain Cabinet Office (GBCO), 1984. Annual Review of Government Funded R\&D, 1984. London: Her Majesty's Stationery Office, 1984.

Guile, Bruce R. and Brooks, Harvey, eds., 1987. Technology and Global Industry: Companies and Nations in the World Economy. National Academy Press, Washington, DC.

Hatsopoulos, George N., Krugman, Paul R., and Summers, Lawrence H., 1988. "U.S. Competitiveness: Beyond the Trade Deficit." Science 241:299.

Hezlet, Arthur, 1975. Electronics and Sea Power. Stein and Day, New York.

Hoagland, Porter III and Broadus, James M., 1987. Seabed Material and Commodity and Resource Summaries. WHOI-87-43, Woods Hole Oceanographic Institution.

Holcott, Claude R. and Purser, Paul E., 1983. "Energy and the Oceans." Oceans 183 Proceedings. IFEE.

Hufbauer, Gary C. and Erb, Joannas S., 1984. Subsidies in International Trade. Institute for International Economics, Washington, DC. 
International Monetary Fund (IMF), 1988. World Economic Outlook: A Survey. Washington, April 1988.

International Trade Administration (ITA), 1983. U.S. Competitiveness in High Technology Industries. U.S. Government Printing Office, Washington, DC: Department of Commerce.

International Trade Administration (ITA), 1985. U.S. High Technology Trade and Competitiveness. U.S. Department of Commerce DIE-01-85, Washington, DC: Department of Commerce.

International Trade Commission (ITC), June 1982. Summary of Trade and Tarrif Information: Measuring, Controlling, and Similar Instruments. USITC Publication 841, Washington.

International Trade Commission (ITC), Sept. 1983. Summary of Trade and Tariff Information: Analytic and other Scientific Instruments. USITC Publication 841, Washington.

International Trade Commission (ITC), Jan. 1985. Summary of Trade and Tarrif Information: Measuring, Controlling, and Similar Instruments. USITC Publication 841, Washington.

International Trade Commission (ITC), 1986a. Tariff Schedules of the United States, Annotated 1987. USITC Publication 1910, Washington.

International Trade Commission (ITC), 1986b. Annual Report 1986. USITC Publication 1935, Washington.

Journal of the Society for Underwater Technology (JSUT). Society for Underwater Technology, London.

Kitamura, T., Deputy Chief, Department of General Affairs, Japan Ocean Industries Association, 1988. Personal communication, Woods Hole, MA, 28 April 1988.

Kite-Powell, Hauke L., 1988. A Broad-Scale Profile of the Marine Advanced Technology Industry. WHOI-88-6, Woods Hole Oceanographic Institution.

Landau, Ralph and Rosenberg, Nathan, eds., 1986. The Positive Sum Strategy: Harnessing Technology for Economic Growth. National Academy Press, Washington, DC.

Langley, Monica, and Mossberg, Walter S., 1988. "Senate Approves Trade Measure by Wide Margin." Wall Street Journal 4 August 1988.

Leading Edge Magazine. 
Lehman, John F., 1987. "Posture and Fiscal Year 1988-1989 Budget of the United States Navy and Marine Corps." Statements in "Hearings of Department of Defense Appropriations for 1988," on 24 February 1987, before the Subcommittee on the Department of Defense, Committee on Appropriations, U.S. House of Representatives, 100th Congress, Washington.

Lindstrom, Talbot S., 1985. "Devising Fair and Effective Technology-Export Controls." Defense Management Journal 21(1):2-7.

Lou, Jack Y. K., 1988. "Ocean Engineering Good, Getting Better, Still Not Quite There." Sea Technology $29(1): 44$.

Marine Science Affairs - A Year in Transition (MSA), February 1967. The First Report of the President to the Congress on Marine Resources and Engineering Development.

Marine Technology Society Journal (MISJ). Marine Technology Society, Washington, DC.

Marine Technology Society, New England Section Newsletter. Marine Technology Society, Falmouth, MA.

McCarthy, Paul F. Jr., 1987. Statements in "Hearings on National Defense Authorization Act for Fiscal Years 1988/1989 -- H.R. 1748, and Oversight of Previously Authorized Programs," 25 February 1987, before the committee on Armed Services, U.S. House of Representatives, 100th Congress. U.S. Government Printing Office 76-012, Washington DC.

McConnell, Anita, 1982. No Sea Too Deep: The History of Oceanographic Instruments. Adam Hilger Ltd., Bristol.

MoGuckin, Robert H. and Pascoe, George A. Jr., 1988. The Longitudinal Research Database (IRD): Status and Research Possibilities. U.S. Department of Commerce, Bureau of the Census, Center for Economic Studies Discussion Paper CES 88-2.

McMahon, Kevin, 1986. "Patents Better Protected, But Look Who's Getting Them." Wall Street Journal, 4 March 1986.

Mentz, J. Roger, 1987. Statement in "Hearing on Interaction Between U.S. Tax Policy and Domestic Research and Development," on 3 April 1987, before the Subcommittee on Taxation and Debt Management of the Committee on Finance, U.S. Senate, 100th Congress, Washington.

National Academy of Engineering (NAE), Marine Board, 1972. Toward Fulfillment of a National Ocean Commitment. National Academy of Sciences Printing and Publishing Office, Washington, DC.

National Academy of Engineering (NAE), 1984. The competitive Status of the U.S. Electronics Industry. Washington: National Academy Press, 1984. 
National Academy of Engineering (NAE), 1988. The Technological Dimensions of International competitiveness. Washington: Office of Administration, Finance, and Public Awareness, NAE, 1988, p. 35.

National Marine Manufacturers Association (NMMA), 1987. Pamphlet: "A Statistical Report on America's Top Family Sport." NMMA, Chicago.

National Research Council (NRC), Commission on Engineering and Technical Systems, 1984. The competitive Status of the U.S. Electronics Industry. National Academy Press, Washington, DC.

National Science Board (NSB), 1987. Science and Engineering Indicators -- 1987. U.S. Govermment Printing Office, Washington, DC.

National Science Foundation (NSF), 1986. National Patterns of Science and Technology Resources. NSF 86-309, Washington, DC.

National Science Foundation (NSF), 1988. Science Resources Studies Highlights NSF 88-303. Washington, DC.

Naval Ocean Research and Development Activity (NORDA), 1986. The NORDA Review, March 31, 1976 -- March 31, 1986. NSTL, Mississippi.

Navy News \& Undersea Technology (NNUT). Pasha Publications, Arlington, VA.

NIEA NewS: The Journal of Marine Electronics. National Marine Electronics Association, Tinton Falls, NJ.

Ocean Science NewS (OSN), 1988. "\$613 Million Would be Spent to Modernize the NOAA Oceanographic Fleet." June 6, 1988.

Office of Management and Budget (OMB), 1961-1986. Budget of the United States Govermment. Washington, DC.

Office of Technology Assessment (OTA), 1981. Technology and Oceanography: An Assessment of Federal Technologies for Oceanographic Research and Monitoring. OTA-0-141.

Office of Technology Assessment (OTA), 1983. International Competitiveness in Electronics. OTA-ISC-200.

Office of Technology Assessment (OTA), 1987. Marine Minerals: Exploring Our New Ocean Frontier. OTA-0-342.

Offshore Magazine. The Petroleum Publishing Company, Tulsa, OK.

Offshore Engineer Magazine. Thomas Telford Ltd., London.

Organization for Economic Co-operation and Development (OECD), 1986. OECD Science and Technology Indicators, No. 2: R\&D, Invention and competitiveness. OECD, Paris. 
Paine, Ward F., 1968. "Capital Requirements of New Ocean Companies." The Ocean and the Investor. Dean Witter and Co., Los Angeles, 1969.

Paisley, Melvyn R., 1987. Statements in "Hearings on the Department of Defense Appropriations for 1988," Subcommittee on the Department of Defense, Committee on Appropriations, U.S. House of Representatives, 100th Congress. U.S. Govermment Printing Office 76-056 0, Washington, DC.

Patent and Trademark office (PIO), 1982. General Information Concerning Patents. Washington: Department of Commerce.

Pechman, Joseph A., 1987. Federal Tax Policy. Fifth Edition, The Brookings Institution, Washington, DC.

Penrose, Edith, 1988. Defending the Price of Oil. The Energy Journal, Volume 9, Number 1.

Platt, Stuart, 1984. "Advocating Competition in Navy Procurements." Defense Management Journal 20(3):13-15.

President's Science Advisory Committee (PSAC), 1966. Report of the Panel on Oceanography: Effective Use of the Sea. U.S. Government Printing Office, Washington.

President's Commission on International Industrial competitiveness (PCIIC), 1985. Global Competition: The New Reality. A. Young, Chairman. U.S. Govermment Printing Office, Washington DC.

Roman, Daniel D. and Puett, Joseph F. Jr., 1983. International Business and Technological Innovation, North-Holland, New York.

Rowden, William H., 1987. Statements in a Hearing before the Seapower Subcommittee of the House Armed Services Committee on Shipbuilding and Conversion, U.S. House of Representatives, 100th Congress, 5 March 1987. Washington, DC.

Rumpf, 1987. Statement in "Hearings on Department of Defense Appropriations for 1988," before the Subcommittee on the Department of Defense, Committee on Appropriations, U.S. House of Representatives, 100th Congress, Washington.

Saeki, M., 1984. "Current Research and Development at JAMSTEC (Japan Marine Science and Technology Center)." Proceedings Oceans '84.

Washington: MTS and IEEE, 1984, pp. 917-920.

Sapir, A. and Lundberg, L., 1984. "The U.S. Generalized System of Preferences and Its Impacts." In: R. E. Baldwin and A. O. Krueger, The Structure and Evolution of Recent U.S. Trade Policy. Chicago: The University of Chicago Press, 1984, pp. 191-236.

Schrage, Michael, 1988. "Venture Capital's New Look." Wall Street Journal, 20 May 1988. 
Sea Technology Buyers Guide and Directory, 1986-87 and 1987-88. Compass Publications, Arlington, VA.

Sea Technology Magazine (ST), Compass Publications, Arlington, VA.

Senior, G., 1987. "Resources from the Sea Programme: Preamble." Journal of the Society for Underwater Technology $13(3): 1-3$.

Sinha, Evelyn, ed., 1966. Oceanic Abstracts, Vol. 1: State of the Art Instrumentation: An Annotated Bibliography. Oceanic Library and Information Center, La Jolla.

Small Business Administration (SBA), 1987. Your Business and the SBA. Pamphlet, OPC-2, February 1987, Washington.

Small Business Administration (SBA), Office of Innovation, Research, and Technology, 1984-87. Listing of SBIR Awardees for FY83-FY86. Washington.

Smith, Merritt Roe, ed., 1985. Military Enterprise and Technology Change: Perspectives on the American Experience. The MIT Press, Cambridge.

Smith, William D., 1987. Statements in "Hearings on Department of Defense Appropriations for 1988," 11 March 1987, before the Subcommittee on the Department of Defense, Committee on Appropriations, U.S. House of Representatives, 100th Congress. U.S. Government Printing Office 75-440 O, Washington, DC.

Spagni, Daniel; Georghiou, Luke; and Gibbons, Michael, 1985. "French Marine Technology Policy: Industrializing Ocean Depths." Marine Policy.

Spence, A. Michael and Hazard, Heather A., eds. 1988. International Competitiveness. Ballinger Publishing Company, Cambridge.

Spilhaus, Athelstan, 1987. "On Reaching 50: An Early History of the Bathythermograph." Sea Technology 28(11): 19-28 (November).

Starrels, John, 1988. "The Slow March Toward More Trade." New York Times 8 May 1988.

Stern, Robert M., ed., 1987. US Trade Policies in a Changing World Economy. MIT Press, Cambridge.

Stiglitz, Joseph E. and Mathewson, G. Frank, eds., 1986. New Developments in the Analysis of Market Structure. The MIT Press, Cambridge.

Teece, David J., ed., 1987. The Competitive Challenge: Strategies for Industrial Innovation and Renewal. Ballinger Publishing Company, Cambridge MA.

Undersea Vehicles Directory, 1987. Busby Associates Inc., Arlington, VA. 
United Kingdom House of Lords, Select committee on Science and Technology (SCST), 1985. Marine Science and Technology. London: Her Majesty's Stationery Office, 1985.

United Kingdom Natural Envirommental Research Council (NERC), 1988. NERC NewS, April 1988, p. 156.

United States, House, Committee on Appropriations, Surveys and Investigations Staff, 1982. Independent Research and Development Program of the Department of Defense. Unpublished monograph, March 1982, Washington.

United States Naval Institute, 1987/88. proceedings Magazine. Annapolis, MD.

United States Navy, January 1985. RDT\&E Management Guide. NAVSO P-2457 (Rev. 1-85).

United States Navy, August 1988. "Domestic Technology Transfer Factsheet" 13(8).

United States Senate Banking Committee, 1987. "Hearing on the Toshiba Kongsberg Technology Diversion Case," on 17 June 1987, before the Subcommittee on International Finance and Monetary Policy of the Committee on Banking, Housing, and Urban Affairs, U.S. Senate, 100th Congress, Washington.

Urick, R.J., 1983. Principles of Underwater Sound. New York: MoGraw-Hill.

Vine, Allyn, 1988. Personal communications, Woods Hole, May 1988.

Wells, Donald R., 1988. "Navy Ocean Engineering: Working Against a Potential Decline." Sea Technology 29(1):31.

Williams, A. J., 1988. "Research and Development," unpublished working paper, Marine Instrumentation Panel, Woods Hole, 7-8 June 1988.

Wilson, J. R., 1988. "The U.S. Navy: Oceanography's Critical Role." Sea Technology $29(1): 12$.

Woodsum, Glenn, 1988. Oceanographic Instrumentation in Marine Pollution Studies. Center for Aquatic Research and Resource Management, Florida State University, Tallahassee, FL.

Young, John A., 1986. "Global Competition -- The New Reality: Results of the President's Commission on Industrial competitiveness." In: R. Iandau and N. Rosenberg, eds., The Positive Sum Strategy, National Academy Press, Washington, DC.

Young, John A., 1988. "Technology and Competitiveness: A Key to the Economic Future of the United States." Science 241:313. 
DOCUMENT LIBRARY

August 9, 1988

Distribution List for Technical Report Exchange

Attn: Stella Sanchez-Wade

Documents Section

Scripps Institution of Oceanography

Library, Mail Code C-075C

La Jolla, CA 92093

Hancock Library of Biology \& Oceanography

Alan Hancock Laboratory

University of Southern California

University Park

Los Angeles, CA 90089-0371

Gifts \& Exchanges

Library

Bedford Institute of Oceanography

P.O. Box 1006

Dartmouth, NS, B2Y 4A2, CANADA

Office of the International

Ice Patrol

c/o Coast Guard R \& D Center

Avery Point

Groton, CT 06340

Library

Physical Oceanographic Laboratory

Nova University

8000 N. Ocean Drive

Dania, FL 33304

NOAA/EDIS Miami Library Center

4301 Rickenbacker Causeway

Miami, FL 33149

Library

Skidaway Institute of Oceanography

P.O. Box 13687

Savannah, GA 31416

Institute of Geophysics

University of Hawaii

Library Room 252

2525 Correa Road

Honolulu, HI 96822

Library

Chesapeake Bay Institute

4800 Atwell Road

Shady Side, MD 20876

MIT Libraries.

Serial Journal Room 14E-210

Cambridge, MA 02139
Director, Ralph M. Parsons Laboratory

Room 48-311

MIT

Cambridge, MA 02139

Marine Resources Information Center

Building E38-320

MIT

Cambridge, MA 02139

Library

Lamont-Doherty Geological Observatory

Colombia University

Palisades, NY 10964

Library

Serials Department

Oregon State University

Corvallis, OR 97331

Pell Marine Science Library

University of Rhode Island

Narragansett Bay Campus

Narragansett, RI 02882

Working Collection

Texas A\&M University

Dept. of Oceanography

College Station, TX 77843

Library

Virginia Institute of Marine Science

Gloucester Point, VA 23062

Fisheries-Oceanography Library

151 Oceanography Teaching Bldg.

University of Washington

Seattle, WA 98195

Library

R.S.M.A.S.

University of Miami

4600 Rickenbacker Causeway

Miami, FL 33149

Maury Oceanographic Library

Naval Oceanographic Office

Bay St. Louis

NSTL, MS 39522-5001

Marine Sciences Collection

Mayaguez Campus Library

University of Puerto Rico

Mayagues, Puerto Rico 00708 



\begin{tabular}{|c|c|c|c|}
\hline $\begin{array}{l}\text { REPORT DOCUMENTATION } \\
\text { PAGE }\end{array}$ & $\begin{array}{l}\text { 1. REPORT NO. } \\
\text { WHOI-88-55 }\end{array}$ & 2. & 3. Recipient's Accession No. \\
\hline \multirow{2}{*}{\multicolumn{3}{|c|}{$\begin{array}{l}\text { 4. Title and Subtitle } \\
\text { Determining the Structure of the United States Marine Instrumentation Industry and Its } \\
\text { Position in the World Industry }\end{array}$}} & $\begin{array}{l}\text { 5. Report Date } \\
\text { November } 1988\end{array}$ \\
\hline & & & 6. \\
\hline \multicolumn{3}{|c|}{$\begin{array}{l}\text { 7. Author(s) } \\
\text { James M. Broadus, Porter Hoagland III, Hauke L. Kite-Powell }\end{array}$} & $\begin{array}{l}\text { 8. Performing Organization Rept. No. } \\
\text { WHOI-88-55 }\end{array}$ \\
\hline \multicolumn{3}{|c|}{ 9. Performing Organization Name and Address } & 10. Project/Task/Work Unit No. \\
\hline \multicolumn{3}{|c|}{$\begin{array}{l}\text { The Woods Hole Oceanographic Institution } \\
\text { Woods Hole, Massachusetts } 02543\end{array}$} & $\begin{array}{l}\text { 11. Contract(C) or Grant(G) No. } \\
\text { (C) NA87 AA-D-M0037 } \\
\text { (G) }\end{array}$ \\
\hline \multicolumn{3}{|c|}{ 12. Sponsoring Organization Name and Address } & 13. Type of Report \& Period Covered \\
\hline \multirow{2}{*}{\multicolumn{3}{|c|}{$\begin{array}{l}\text { Department of Commerce, NOAA, National Ocean Service, Office of Marine } \\
\text { Operations through the Massachusetts Centers of Excellence Corporation }\end{array}$}} & Technical Report \\
\hline & & & 14. \\
\hline
\end{tabular}

15. Supplementary Notes

This report should be cited as: Woods Hole Oceanog. Inst. Tech. Rept., WHOI-88-55.

16. Abstract (Limit: 200 words)

This report is a general, but comprehensive, description and analysis of industrial organization in the field of marine electronic instrumentation (MEI), a broadly defined "industry," which until now has received little systematic, scholarly attention. The report reviews the current literature on international trade and competitiveness, as well as trade and scientific journals relevant to the industry. The results of a series of interviews with representatives of the industry and responsible government agencies are presented and industry and government data on R\&D and output have been collected and analyzed together with other indicators of industrial performance. On the basis of these sources, the structure of the industry and its markets is characterized and the importance of marine electronic instrumenation in international high technology trade is established. Over 350 firms in the U.S. industry are identified, which annually earn total estimated gross revenues of approximately $\$ 5$ billion. These firms fall into three largely distinct industry groups: (1) defense systems contractors; (2) commercial marine electronics; and (3) scientific instrumentation. The first group is by far the largest in sales volume and is oligopolistic in structure, consisting of a few large rivals for infrequent and complex defense systems contracts. The other groups are more purely competitive. Four major customer groups are distinguished: (1) military; (2) commercial and recreational shipping and boating; (3) offshore oil and gas; and (4) oceanographic/environmental. Most of the firms in the industry face international competititon. The importance of marine electronic instrumentation to technological advance and economic activity in the world's oceans is strongly apparent. Parameters affecting the international competitiveness of firms in this industry, including those relating to industry structure and behavior and governmental practices and institutions such as sponsored research, procurement, intellectual property rights, tax allowances, antitrust enforcement, small business encouragements, export controls, import restrictions, exchange rates, and technology transfer are summarized. A number of issues relating to international competititon, economic analysis, and government policy that are fruitful areas for further research also are identified.

17. Document Analysis a. Descriptors
1. Marine
4. Industry
2. Electronic
5. Competitiveness
3. Instrument
6. Economics

b. Identifiers/Open-Ended Terms

c. COSATI Field/Group

18. Availability Statement

Approved for publication; distribution unlimited.

\begin{tabular}{|c|c|}
\hline $\begin{array}{c}\text { 19. Security Class (This Report) } \\
\text { UNCLASSIFIED }\end{array}$ & $\begin{array}{c}\text { 21. No. of Pages } \\
99\end{array}$ \\
\hline 20. Security Class (This Page) & 22. Price \\
\hline
\end{tabular}

(See ANSI-Z39.18)

Se日 Instructions on Reverse

OPTIONAL FORM 272 (4-77)

(Formerly NTIS-35)

Department of Commerce 
